\title{
ANÁLISE DA INFLUÊNCIA DE CARACTERÍSTICAS GEOMÉTRICAS DE RODOVIAS NOS CUSTOS DOS USUÁRIOS UTILIZANDO O PROGRAMA HDM-4
}

Dissertação apresentada à Escola de Engenharia de São Carlos da Universidade de São Paulo, como parte dos requisitos para obtenção do Título de Mestre em Engenharia Civil - Área de Concentração: Transportes.

ORIENTADOR: Prof. Associado José Leomar Fernandes Júnior

São Carlos

2005 
Dedico este trabalho às pessoas mais importantes da minha vida: meus pais, Sandra e Fernando, e à minha irmã Bárbara, por todo amor, carinho, incentivo e por estarem sempre ao meu lado. 


\section{Agradecimentos}

Primeiramente, ao meu orientador Prof. José Leomar Fernandes Júnior, pela orientação, pelos ensinamentos e pela amizade;

Aos professores Alexandre Benetti Parreira e Sandra Oda, pela participação na banca do Exame de Qualificação e pelas contribuições para a conclusão do trabalho;

À Coordenadoria de Aperfeiçoamento de Pessoal de Nível Superior - CAPES, pela bolsa de estudo concedida durante o Mestrado;

Ao Sr. Mario Yamada e demais diretores da Concessionária Centrovias, pelo auxílio na aquisição de dados;

A todos os professores do Departamento de Transportes da EESC-USP;

Aos funcionários do STT;

Aos meus amigos do Departamento de Transportes, especialmente aos demais orientandos do Prof. Leomar, meus “irmãos acadêmicos”;

Ao companheiro de república, Marcos Bottene Cunha, pela amizade e pelo auxílio na revisão da dissertação;

Aos meus familiares, avós, tios, primos e amigos, pelo incentivo e pelo carinho;

E, sobretudo, a Deus. 
"Longe do estéril turbilhão da rua, Beneditino, escreve! No aconchego Do claustro, na paciência e no sossego, Trabalha, e teima, e lima, e sofre, e sua!

Mas que na forma se disfarce o emprego Do esforço; e a trama viva se construa De tal modo, que a imagem fique nua, Rica mas sóbria, como um templo grego.

$\mathcal{N}$ ão se mostre na fábrica o suplício Do mestre. E, natural, o efeito agrade, Sem lembrar os andaimes do edifício:

Porque a Beleza, gêmea da Verdade, Arte pura, inimiga do artifício, É a força e a graça na simplicidade." 


\section{Sumário}

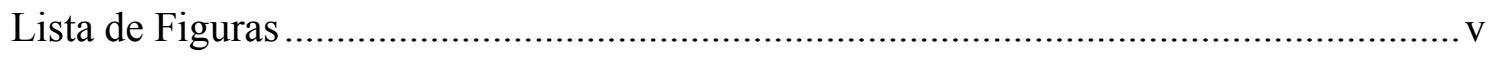

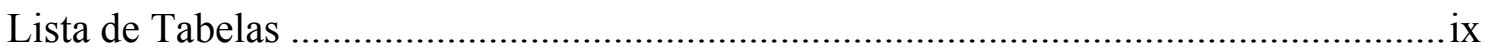

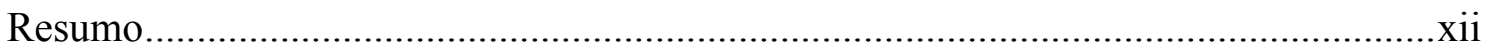

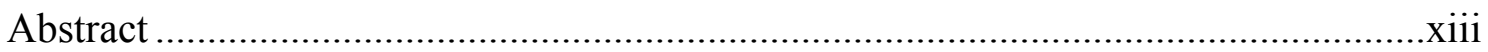

\section{Capítulo 1}

Introdução.

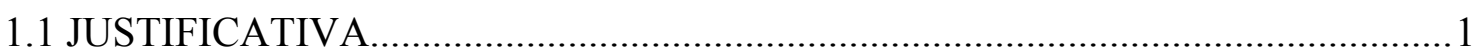

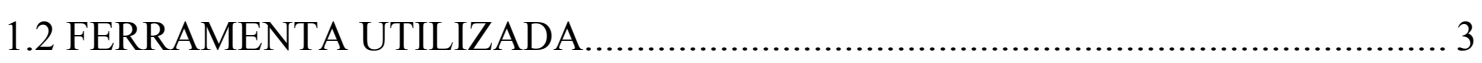

1.3 OBJETIVO DA PESQUISA........................................................................... 4

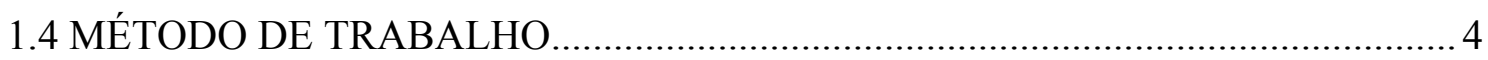

1.4 ESCOPO DO TRABALHO ...................................................................... 4

\section{Capítulo 2}

As condições das rodovias no Brasil

\section{Capítulo 3}

O programa HDM-4

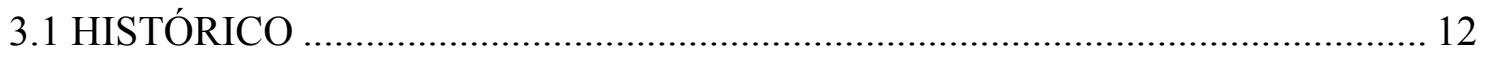

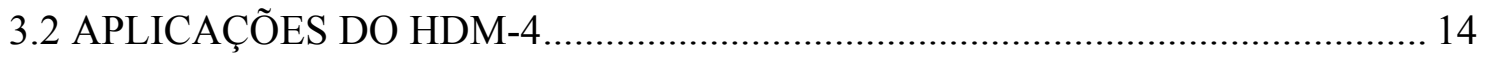

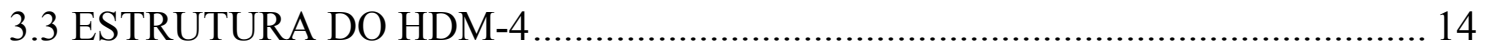

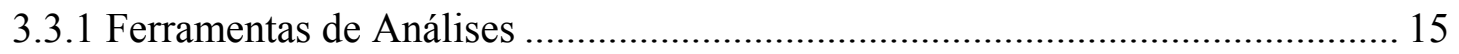

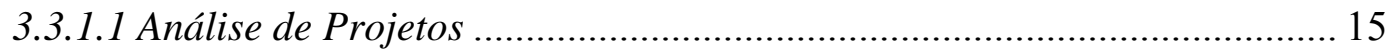

3.3.1.2 Análise de Programas ........................................................................... 15

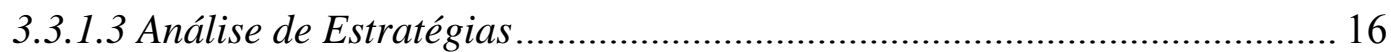

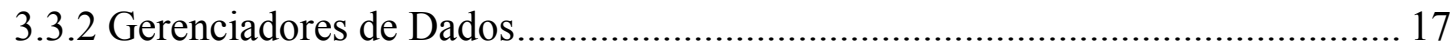

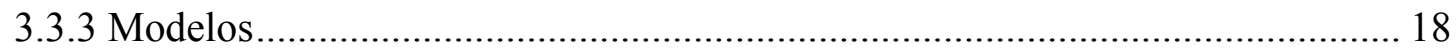


3.3.3.1 Deterioração da via 18

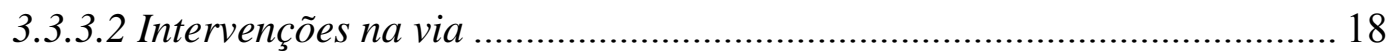

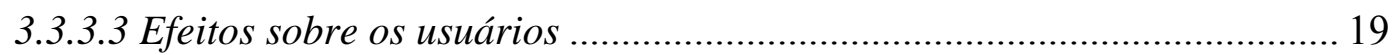

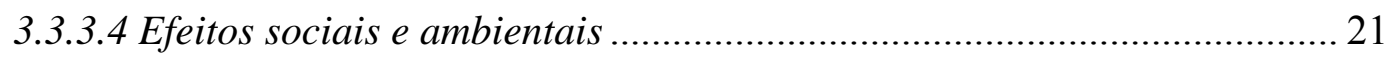

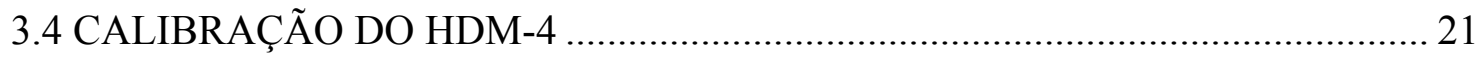

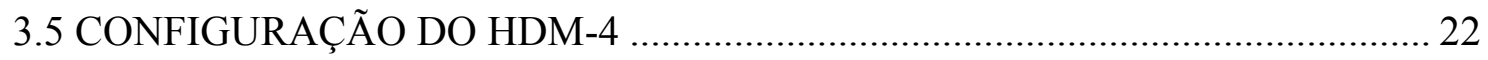

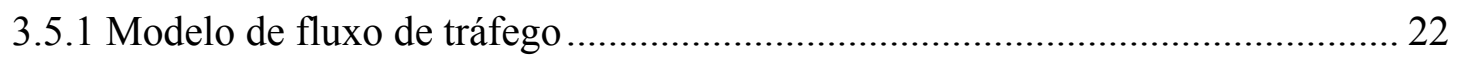

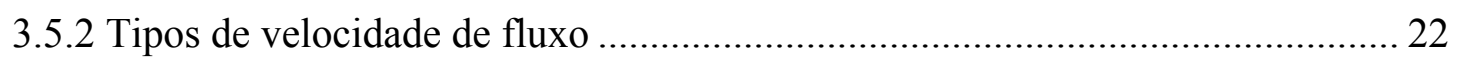

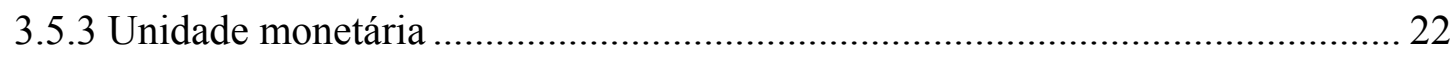

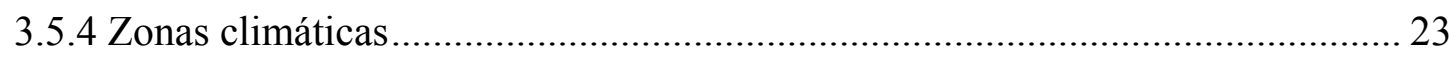

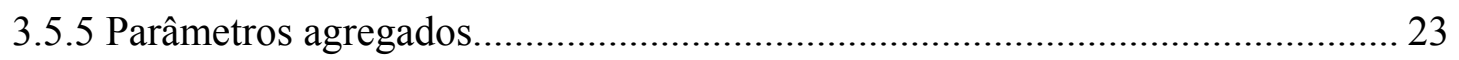

3.5.6 Características geométricas das rodovias.................................................... 24

3.5.6.1 Média das Subidas e Descidas ................................................................. 24

3.5.6.2 Média da Curvatura Horizontal........................................................... 25

3.5.6.3 Classes de geometria padronizadas pelo HDM-4 ............................... 25

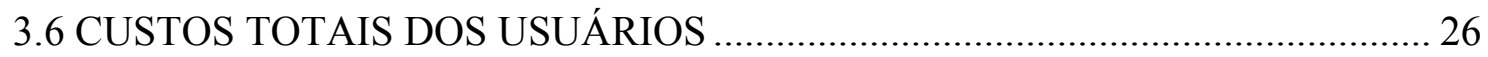

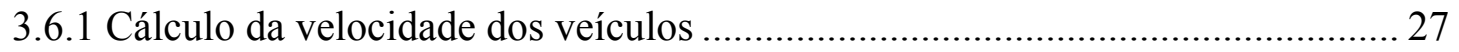

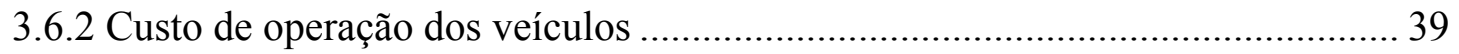

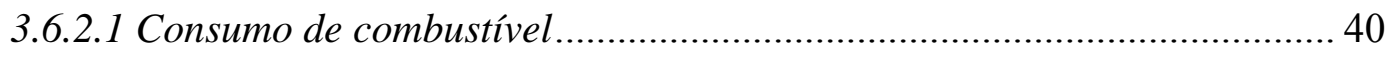

3.6.2.2 Consumo de óleo lubrificante ............................................................. 46

3.6.2.3 Consumo de pneus ....................................................................... 46

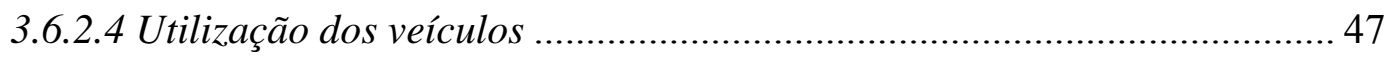

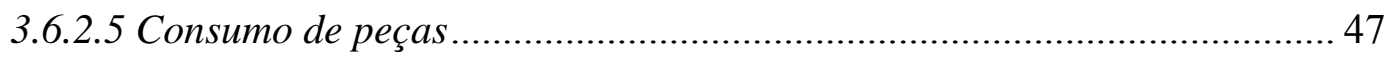

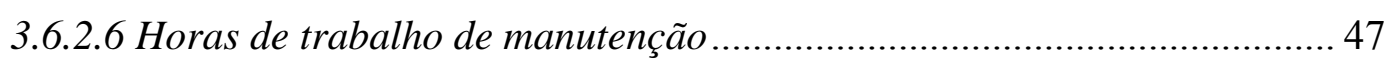

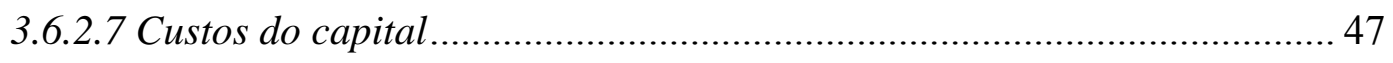

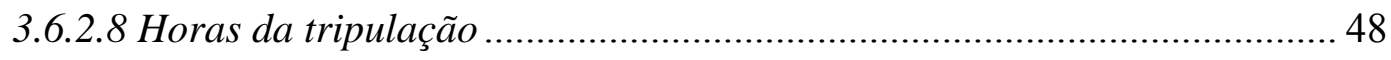


3.6.2.9 Custos gerais 48

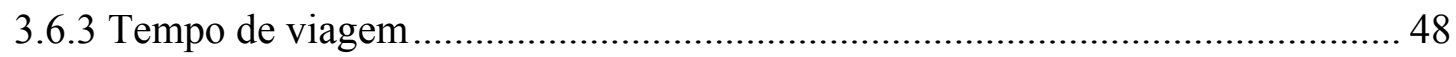

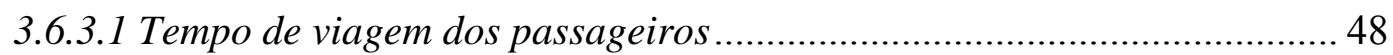

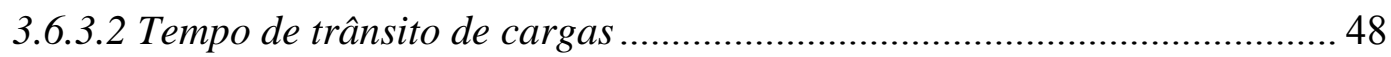

3.7 ESCOLHA DAS ALTERNATIVAS DE INVESTIMENTOS ............................. 49

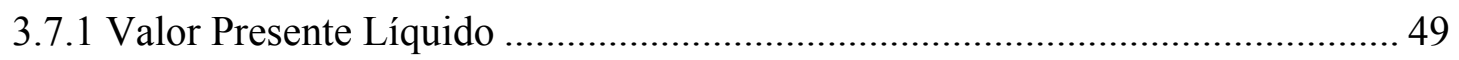

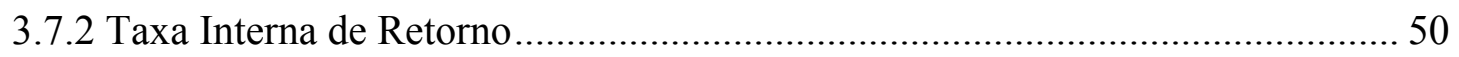

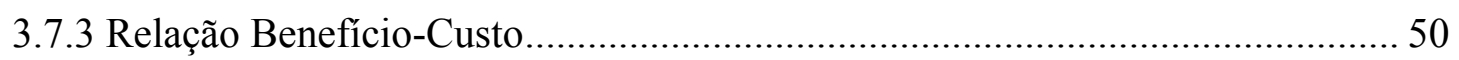

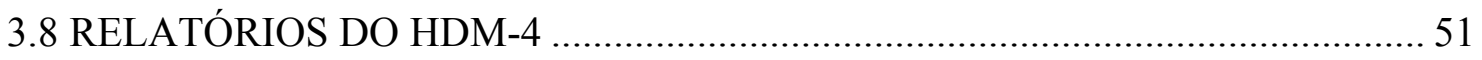

\section{Capítulo 4}

Estudo de caso 52

4.1 SELEÇÃO E DEFINIÇÃO DE TRECHOS RODOVIÁRIOS................................ 52

4.1.1 Definição de trechos para a análise de sensibilidade (trechos fictícios) ............ 52

4.1.2 Trechos representativos das classes do HDM-4 …........................................... 53

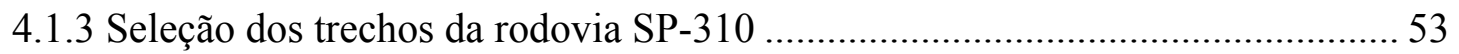

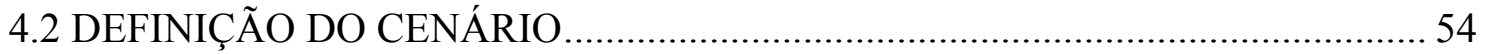

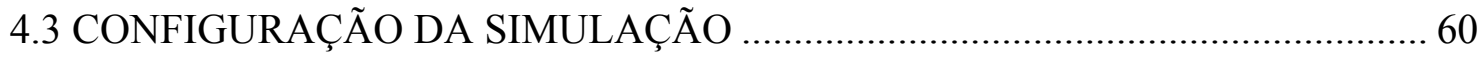

4.4 CUSTOS DE TERRAPLENAGEM E DE PAVIMENTAÇÃO PARA ALTERAÇÃO DO TRAÇADO DE TRECHOS DE RODOVIAS .......................... 63

\section{Capítulo 5}

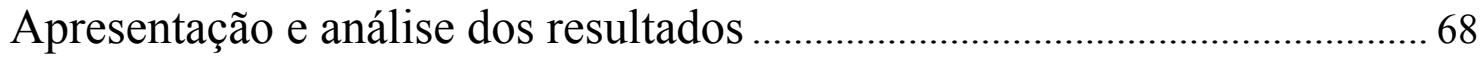

5.1 RESULTADOS DA INFLUÊNCIA DA GEOMETRIA VERTICAL (RF) ........... 68

5.2 RESULTADOS DA INFLUÊNCIA DA GEOMETRIA HORIZONTAL (ADC) 
5.3 RESULTADOS DOS TRECHOS DAS CLASSES DE GEOMETRIA

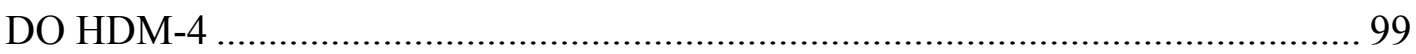

5.4 RESULTADOS DOS TRECHOS DA RODOVIA SP-310 ….............................. 110

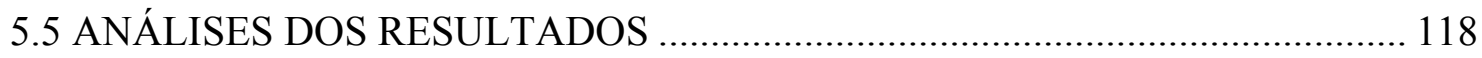

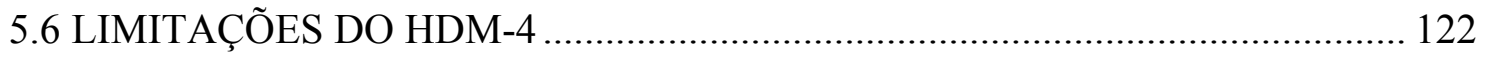

\section{Capítulo 6}

Conclusões e sugestões para trabalho futuros ................................................. 124

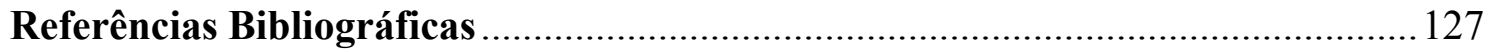

Bibliografia Consultada ................................................ 129

Apêndice

Tabelas utilizadas nos cálculos da velocidade e do consumo de combustível dos veículos. 


\section{Lista de Figuras}

FIGURA 01 - Classificação quanto às condições gerais das rodovias...........................07

FIGURA 02 - Classificação quanto à condição da geometria das rodovias...................09

FIGURA 03 - Estrutura analítica do HDM-4 (KERALI et al., 2000)............................14

FIGURA 04 - Representação de subidas e descidas ao longo de um trecho...................24

FIGURA 05 - Representação dos ângulos centrais ao longo de um trecho.....................25

FIGURA 06 - Esquema de inter-relação entre os componentes dos custos totais relacionados aos custos dos usuários.......................................... 28

FIGURA 07 - Fatores que têm influência na velocidade dos veículos..........................29

FIGURA 08 - Inserção dos dados referentes ao cenário considerado

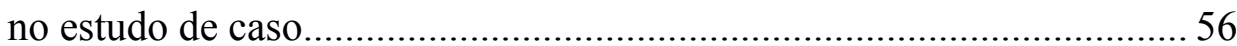

FIGURA 09 - Inserção dos dados referentes ao pavimento.......................................... 57

FIGURA 10 - Inserção dos dados referentes à condição do pavimento.........................58

FIGURA 11 - Inserção dos dados referentes à geometria............................................58

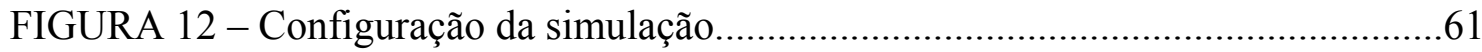

FIGURA 13 - Inserção da composição do tráfego.......................................................... 62

FIGURA 14 - Configuração da análise econômica, de custos de acidentes e de modelos a serem incluídos na simulação..........................62

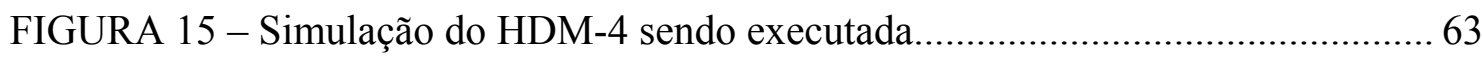

FIGURA 16 - Perfis longitudinais dos trechos de $R F=40 \mathrm{~m} / \mathrm{km}, \mathrm{RF}=35 \mathrm{~m} / \mathrm{km}$,

$\mathrm{RF}=30 \mathrm{~m} / \mathrm{km}$ e $\mathrm{RF}=25 \mathrm{~m} / \mathrm{km}$.

FIGURA 17 - Perfis longitudinais dos trechos de $\mathrm{RF}=20 \mathrm{~m} / \mathrm{km}, \mathrm{RF}=15 \mathrm{~m} / \mathrm{km}$, $\mathrm{RF}=10 \mathrm{~m} / \mathrm{km}, \mathrm{RF}=5 \mathrm{~m} / \mathrm{km}$ e $\mathrm{RF}=0 \mathrm{~m} / \mathrm{km}$...... 65

FIGURA 18 - Seções transversais de cortes e de aterros dos trechos. 66

FIGURA 19 - Representação das camadas do pavimento a ser executado.................... 67

FIGURA 20 - Custo de consumo de combustível em função de RF.............................. 74

FIGURA 21 - Custo de consumo de óleo lubrificante em função de RF........................ 74

FIGURA 22 - Custo de consumo de pneus em função de RF....................................... 75

FIGURA 23 - Custo de consumo de peças em função de RF........................................75

FIGURA 24 - Custo de manutenção dos veículos em função de RF..............................76

FIGURA 25 - Custo do capital em função de RF...........................................................76

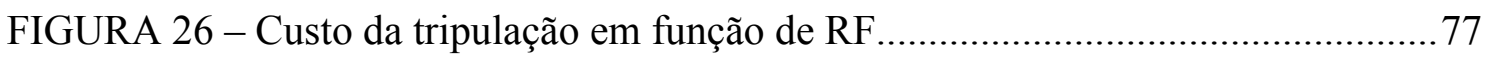


FIGURA 27 - Custos gerais em função de RF. 77

FIGURA 28 - Custo de operação dos veículos em função de RF................................. 78

FIGURA 29 - Custo do tempo de viagem em função de RF.......................................... 78

FIGURA 30 - Custo total dos usuários em função de RF.............................................79

FIGURA 31 - Influência da curvatura vertical (RF) na velocidade de operação de cada tipo de veículo............................................................ 79

FIGURA 32 - Influência da curvatura vertical (RF) no consumo de combustível de cada tipo de veículo.

FIGURA 33 - Custos estimados de escavação, transporte, compactação e pavimentação para redução do RF dos trechos.

FIGURA 34 - Variação do tempo de retorno de cada investimento para as diferentes taxas de desconto. 85

FIGURA 35 - Custo de consumo de combustível em função de ADC.......................... 86

FIGURA 36 - Custo de consumo de óleo lubrificante em função de ADC.....................86

FIGURA 37 - Custo de consumo de pneus em função de ADC.....................................92

FIGURA 38 - Custo de consumo de peças em função de ADC.....................................92

FIGURA 39 - Custo de manutenção dos veículos em função de ADC...........................93

FIGURA 40 - Custo do capital em função de ADC ......................................................... 93

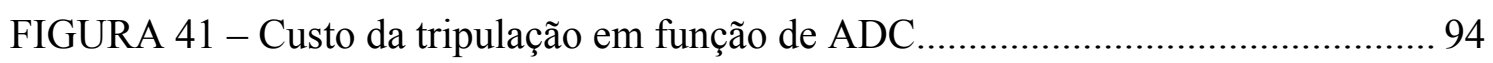

FIGURA 42 - Custos gerais em função de ADC.............................................................94

FIGURA 43 - Custo de operação dos veículos em função de ADC................................95

FIGURA 44 - Custo do tempo de viagem em função de ADC....................................... 95

FIGURA 45 - Custo total dos usuários em função de ADC...........................................96

FIGURA 46 - Influência da curvatura horizontal (ADC) na velocidade de operação de cada tipo de veículo....................................................... 96

FIGURA 47 - Influência da curvatura horizontal (ADC) no consumo de combustível de cada tipo de veículo................................................... 98

FIGURA 48 - Custo de consumo de combustível para os trechos do HDM-4...............99

FIGURA 49 - Custo de consumo de óleo lubrificante para os trechos do HDM-4........ 99

FIGURA 50 - Custo de consumo de pneus para os trechos do HDM-4......................... 104

FIGURA 51 - Custo de consumo de peças para os trechos do HDM-4 ........................ 104

FIGURA 52 - Custo de manutenção para os trechos do HDM-4 .................................. 104

FIGURA 53 - Custo do capital para os trechos do HDM-4 ......................................... 105

FIGURA 54 - Custo da tripulação para os trechos do HDM-4 .......................................105 
FIGURA 55 - Custos gerais para os trechos do HDM-4.

FIGURA 56 - Custo de operação dos veículos e do tempo de viagem na composição do custo total dos trechos do HDM-4.

FIGURA 57 - Detalhe do custo do tempo de viagem para os trechos

do HDM-4

FIGURA 58 - Velocidade de operação do Caminhão Leve - Trechos do HDM-4 107

FIGURA 59 - Velocidade de operação do Caminhão Pesado - Trechos do HDM-4

FIGURA 60 - Velocidade de operação do Automóvel Médio - Trechos do HDM-4

FIGURA 61 - Velocidade de operação do Ônibus Pesado - Trechos do HDM-4 108

FIGURA 62 - Consumo de combustível do Caminhão Leve - Trechos do HDM-4.

FIGURA 63 - Consumo de combustível do Caminhão Pesado - Trechos do HDM-4

FIGURA 64 - Consumo de combustível do Automóvel Médio - Trechos do HDM-4

FIGURA 65 - Consumo de combustível do Ônibus Pesado - Trechos do HDM-4

FIGURA 66 - Custo de consumo de combustível para os trechos da SP-310

FIGURA 67 - Custo de consumo de óleo lubrificante para os trechos da SP-310.

FIGURA 68 - Custo de consumo de pneus para os trechos da SP-310.

FIGURA 69 - Custo de consumo de peças para os trechos da SP-310. .114

FIGURA 70 - Custo de manutenção para os trechos da SP-310. 114

FIGURA 71 - Custo do capital para os trechos da SP-310. 114

FIGURA 72 - Custo da tripulação para os trechos da SP-310. 115

FIGURA 73 - Custos gerais para os trechos da SP-310.

FIGURA 74 - Custo de operação dos veículos e do tempo de viagem na composição do custo total dos trechos da SP-310.

FIGURA 75 - Detalhe do custo do tempo de viagem para os trechos da SP-310. 
FIGURA 76 - Velocidade de operação de cada tipo de veículo nos trechos da SP-310.

FIGURA 77 - Consumo de combustível de cada tipo de veículo nos trechos da SP-310. 


\section{Lista de Tabelas}

TABELA 01 - Estado geral das rodovias brasileiras......................................................... 07

TABELA 02 - Classificação das rodovias brasileiras.........................................................

TABELA 03 - Estado da geometria das rodovias brasileiras.......................................... 08

TABELA 04 - Histórico da classificação das rodovias quanto à condição da geometria

TABELA 05 - Redução da velocidade das rodovias em função do traçado......................10

TABELA 06 - Tipos de rodovias no Brasil............................................................. 10

TABELA 07 - Classificação da umidade na configuração das zonas climáticas............23

TABELA 08 - Classificação da temperatura na configuração das zonas climáticas......23

TABELA 09 - Classes de geometria padronizadas pelo HDM-4....................................26

TABELA 10 - Regras para a escolha de investimentos...................................................51

TABELA 11 - Trechos "fictícios" para a análise de sensibilidade....................................53

TABELA 12 - Trechos representativos das classes de geometria do HDM-4................54

TABELA 13 - Dados dos trechos da rodovia SP-310 selecionados................................55

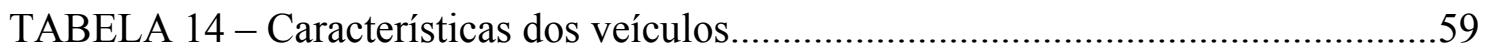

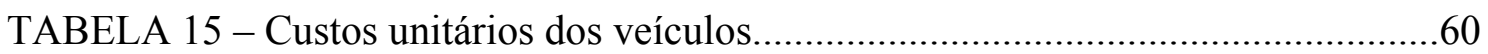

TABELA 16 - Custos unitários de serviços de terraplenagem e pavimentação..............67

TABELA 17 - Custos totais dos usuários para o Trecho Base.........................................69

TABELA 18 - Custos totais dos usuários para o Trecho a...............................................69

TABELA 19 - Custos totais dos usuários para o Trecho b.............................................70

TABELA 20 - Custos totais dos usuários para o Trecho c.............................................70

TABELA 21 - Custos totais dos usuários para o Trecho $d$..................................................71

TABELA 22 - Custos totais dos usuários para o Trecho e e...............................................71

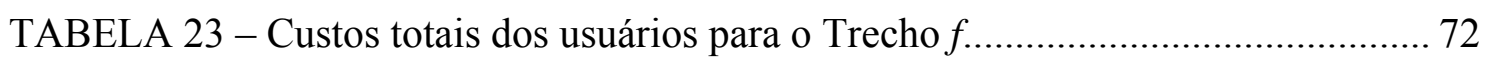

TABELA 24 - Custos totais dos usuários para o Trecho g............................................72

TABELA 25 - Custos totais dos usuários para o Trecho h................................................73

TABELA 26 - Velocidade de operação e consumo de combustível (em litros) de cada tipo de veículo em função de RF. . .80

TABELA 27 - Componentes com maiores porcentagens no COV - Trechos Base e Trechos $a$ a $h$. 
TABELA 28 - Custos totais de terraplenagem para redução do RF..............................82

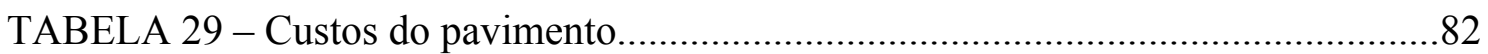

TABELA 30 - Custo total para cada intervenção de redução do RF dos trechos............83

TABELA 31 - Avaliação econômica das intervenções de redução do RF

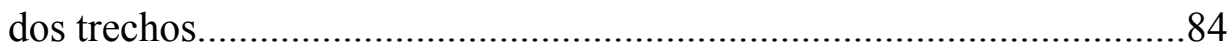

TABELA 32 - Custos totais dos usuários para o Trecho i.............................................87

TABELA 33 - Custos totais dos usuários para o Trecho j............................................87

TABELA 34 - Custos totais dos usuários para o Trecho k............................................8

TABELA 35 - Custos totais dos usuários para o Trecho $l$.............................................8

TABELA 36 - Custos totais dos usuários para o Trecho m.........................................89

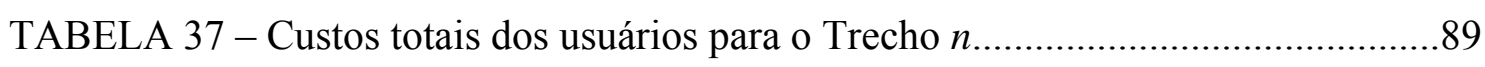

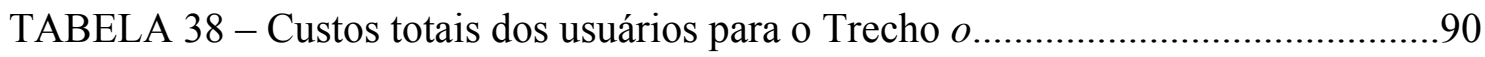

TABELA 39 - Custos totais dos usuários para o Trecho p.............................................90

TABELA 40 - Custos totais dos usuários para o Trecho q...........................................91

TABELA 41 - Custos totais dos usuários para o Trecho $r$.............................................91

TABELA 42 - Velocidade de operação e consumo de combustível (em litros) de cada tipo de veículo em função de ADC

TABELA 43 - Componentes com maiores porcentagens no COV - Trechos Base

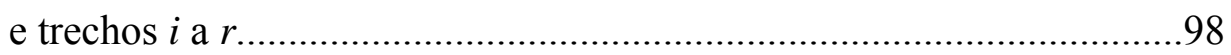

TABELA 44 - Custos totais dos usuários para o Trecho A...........................................100

TABELA 45 - Custos totais dos usuários para o Trecho B...........................................100

TABELA 46 - Custos totais dos usuários para o Trecho C............................................ 101

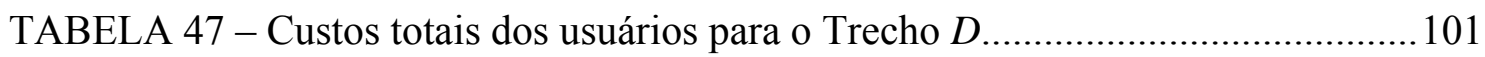

TABELA 48 - Custos totais dos usuários para o Trecho E........................................... 102

TABELA 49 - Custos totais dos usuários para o Trecho F......................................... 102

TABELA 50 - Custos totais dos usuários para o Trecho G.........................................103

TABELA 51 - Consumo de combustível e velocidade de operação dos veículos nos trechos do HDM-4

TABELA 52 - Componentes com maiores porcentagens no COV - Trechos do HDM-4...

TABELA 53 - Custos totais dos usuários para o Trecho 1

TABELA 54 - Custos totais dos usuários para o Trecho 2.........................................111

TABELA 55 - Custos totais dos usuários para o Trecho 3...........................................112

TABELA 56 - Custos totais dos usuários para o Trecho 4. 
TABELA 57 - Consumo de combustível e velocidade de operação dos veículos nos trechos da SP-310.

TABELA 58 - Componentes com maiores porcentagens no COV - Trechos

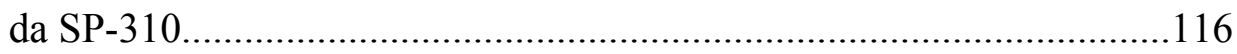


KLEIN, F. C. (2005) Análise da Influência de Características Geométricas de Rodovias nos Custos dos Usuários Utilizando o Programa HDM-4. São Carlos. Dissertação (Mestrado) - Escola de Engenharia de São Carlos, Universidade de São Paulo, São Carlos, 2005.

\section{Resumo}

A dissertação tem como objetivo verificar e analisar a influência das características geométricas de trechos de rodovia no custo total dos usuários, em termos de custo de operação dos veículos e custo do tempo de viagem, com a utilização do programa computacional HDM-4 (Highway Development \& Management). Para esta análise, foi realizado um estudo de caso para o qual foram criados sete trechos representativos das classes de geometria consideradas pelo HDM-4 e dezenove trechos com características geométricas que permitissem uma análise de sensibilidade dos parâmetros relacionados às curvaturas vertical e horizontal das vias. Foram selecionados, ainda, quatro trechos da Rodovia Washington Luiz (SP-310), representativos de rodovias com distintas características geométricas. A simulação foi realizada fixando-se um cenário de fatores que compõem o modelo HDM-4: tipo de fluxo de tráfego, classe da rodovia, composição e volume de tráfego, tipo e condição do pavimento, dentre outros. O estudo de caso permitiu a quantificação dos efeitos da geometria sobre todas as parcelas que compõem os custos dos usuários. Foram calculados os custos de terraplenagem e pavimentação para diferentes curvaturas verticais com a finalidade de comparação dos custos de melhorias no projeto de rodovias existentes com os benefícios decorrentes dessas intervenções. Os resultados obtidos mostraram que a geometria pode ter grande influência nos custos totais dos usuários e, portanto, seus efeitos devem ser considerados em projetos de construção e de manutenção de rodovias, possibilitando maiores benefícios à sociedade.

Palavras-chave: projeto geométrico de rodovias, HDM-4, custos dos usuários, custos de operação dos veículos. 
KLEIN, F. C. (2005) Analysis of the Influence of Highway Geometric Characteristics in Users' Costs Using HDM-4. São Carlos. M.Sc. Dissertation Escola de Engenharia de São Carlos, Universidade de São Paulo, São Carlos, 2005.

\begin{abstract}
The main goal of the master dissertation is to verify and to analyze the influence of geometric characteristics of road sections on highway users' costs, in terms of vehicle operation costs and costs associated to travel time, using the software HDM-4 (Highway Development \& Management). The study was initiated with the creation of seven sections representing the HDM-4 highway geometric classes, and nineteen sections with geometric characteristics defined to allow a sensitivity analysis of parameters associated to vertical and horizontal alignments. Four sections were selected from Washington Luiz Highway (SP-310), representing highways with distinct geometric characteristics. The computer simulations were performed considering a scenario that includes: traffic flow pattern, road class, average daily traffic and traffic composition, pavement type and condition, among others. The study calculated the effects of highway geometry on each component of users' costs. The costs of earth work and paving were calculated aiming at the comparison between costs of geometric improvements and benefits associated to that. The results showed that highway geometry may have a great influence on users' costs and, therefore, its effects must be considered in highway construction and maintenance projects assuring more benefits to the society.
\end{abstract}

Keywords: highway geometric design, HDM-4, users' costs, vehicle operation costs. 


\section{Capítulo 1}

\section{Introdução}

A infra-estrutura rodoviária brasileira encontra-se em condições desfavoráveis aos usuários em termos de desempenho, segurança e economia, quando são avaliados os seguintes aspectos fundamentais das vias: o pavimento, a sinalização e a geometria. Para que este quadro seja revertido, será necessário um planejamento bem estruturado de investimentos (CNT, 2004).

As atividades de construção, manutenção e reabilitação da malha viária necessitam de recursos, que estão cada vez mais limitados. Assim, torna-se importante a análise de propostas de investimentos que tragam os maiores benefícios à sociedade. Para que se possam avaliar as implicações econômicas, é importante considerar tanto os custos quanto os benefícios de qualquer projeto rodoviário, sendo um componente importante das análises econômicas a determinação dos custos de operação dos veículos.

Conforme destacado pelo GEIPOT (1982), a relação entre os custos e as características das rodovias ainda não está muito bem esclarecida. Por isso, são necessários estudos para a determinação das relações entre os custos de operação dos veículos tanto com as condições de rolamento como com os padrões geométricos das rodovias.

\subsection{JUSTIFICATIVA}

Na década de 80, foi realizada pela Empresa Brasileira de Planejamento de Transportes (GEIPOT, 1982) a Pesquisa sobre o Inter-relacionamento de Custos de Rodovias (PICR) para determinar o inter-relacionamento dos três principais componentes do custo dos transportes: custos de construção, custos de conservação das vias e os custos de 
operação dos veículos que por elas trafegam. Pressupôs-se que variáveis que caracterizam uma estrada, como a qualidade da superfície de rolamento e a geometria vertical e horizontal, influenciariam significativamente os custos de operação dos veículos. Diante disso, com a elaboração de funções matemáticas que descrevessem o impacto de cada variável sobre o custo de operação, seria possível avaliar o efeito de diferentes padrões de construção e conservação sobre o custo total. Além disso, poderiam ser calculados os benefícios de uma melhoria no traçado de uma rodovia e determinada a velocidade de menor consumo de combustível para diferentes tipos de veículos.

A PICR, porém, já afirmava que "a questão da geometria e seus efeitos sobre os custos de operação dos veículos não está completamente resolvida... Isso deveria ser um assunto prioritário para os programas futuros de trabalho" (GEIPOT, 1982). O estudo da PICR considerava a dificuldade de se obter os efeitos da geometria por causa da pequena amplitude da geometria das rotas pesquisadas e da debilidade da forma hipotética da relação entre a geometria e o consumo de combustível ou de pneus.

A necessidade do estudo dos efeitos da geometria da rodovia no desempenho dos veículos cresceu devido ao aumento drástico dos preços dos combustíveis na metade da década de 70. Anteriormente a essa data, as vias eram projetadas principalmente com a preocupação na segurança, na durabilidade e nos custos de construção. Posteriormente, os projetistas começaram a estimar o impacto das características dos projetos das vias no consumo de combustível dos veículos, comparando os custos de diversas alternativas de projeto com os benefícios em termos de redução dos custos de operação dos veículos.

Para estimar com precisão o consumo de combustível há a necessidade de informações sobre características específicas dos veículos e, por isso, de obtenção de um maior conhecimento de engenharia automotiva. Estudos de KLAUBERT (2001) para o FHWA (Federal Highway Administration) procuraram demonstrar que os efeitos das principais características geométricas (rampas e curvas) no sistema de propulsão de um veículo podem ser medidos e são independentes dos parâmetros dos veículos, exceto das características físicas conhecidas (peso, área frontal, coeficiente de arrasto etc.). 
Ainda segundo os estudos da PICR, os fatores que afetam o consumo de combustível incluem a geometria e estrutura da via e a operação dos veículos (influenciada pela geometria, pelo controle de tráfego e pelas adjacências da via). Para o veículo, as acelerações podem impor uma maior taxa de consumo de combustível, enquanto a segunda maior influência na taxa de consumo instantânea é o conjunto de rampas da via. Depois das rampas, a característica geométrica que mais afeta o consumo de combustível é o alinhamento horizontal (curvatura). As variações de velocidade de projeto ao longo de um trecho da via também tendem a aumentar a taxa de consumo de combustível e podem causar problemas de segurança.

O projeto de uma via pode influenciar a velocidade de operação do tráfego com mudanças na geometria (alinhamentos horizontal e vertical, número e largura de faixas, superelevação), nos controles de tráfego (limites de velocidade, semáforos e sinalizações) nas adjacências (interseções, rampas de acesso e saída, acostamentos etc.). Além desses, outros dois fatores podem afetar o consumo de combustível: a irregularidade longitudinal do pavimento e a forma de operação do veículo.

Cabe aos pesquisadores de transportes o estudo detalhado de cada um dos componentes dos custos de operação dos veículos. Quanto mais se souber sobre a influência de cada componente, melhor será a estimativa do custo final aos usuários. Dessa forma, os projetos rodoviários poderão proporcionar maior economia de recursos econômicos e naturais, além de maior segurança e conforto.

\subsection{FERRAMENTA UTILIZADA}

Uma ferramenta que vem sendo utilizada para auxiliar na escolha da melhor alternativa de investimento para um sistema de gerência de projetos rodoviários é o HDM-4 (Highway Development \& Management), ou Sistema de Desenvolvimento e Gerenciamento de Rodovias, que é a versão atual do modelo HDM, desenvolvido com o financiamento do Banco Mundial, do governo brasileiro e de outros organismos internacionais. O HDM-4 permite que os gerentes das redes rodoviárias analisem possibilidades de projetos de construção e manutenção em termos da eficiência econômica, trazendo benefícios à sociedade. 
O HDM-4 utiliza modelos para a previsão de custos de construção e de manutenção das vias, bem como de custos aos usuários, em termos de custos de operação dos veículos e de tempo de viagem. Ele é composto por modelos formados por equações nas quais estão presentes, dentre outras, variáveis relacionadas a características geométricas das rodovias, objetos de estudo deste trabalho.

\subsection{OBJETIVO DA PESQUISA}

Esta pesquisa tem por objetivo verificar e analisar a influência dos parâmetros geométricos, presentes nas equações dos modelos do HDM-4, nos custos dos usuários de rodovias, em termos dos custos de operação dos veículos e do tempo de viagem, através da análise da velocidade e dos insumos consumidos pelos veículos (tais como, consumos de combustível, de óleo lubrificante, de pneus, de peças etc.).

\subsection{MÉTODO DE TRABALHO}

Para atingir este objetivo, a pesquisa segue as seguintes etapas:

1. Revisão bibliográfica sobre as condições das rodovias no Brasil e sobre os conceitos e aplicações do HDM-4, com destaque para aspectos relacionados à mecânica da locomoção dos veículos, aos parâmetros geométricos de vias e ao cálculo do consumo de insumos dos veículos;

2. Elaboração de um estudo de caso, com a seleção de trechos rodoviários reais e com base na classificação do HDM-4 para a geometria das vias, além da criação de trechos que possuem características geométricas previamente definidas, visando à verificação da influência destas nos resultados finais;

3. Definição de um cenário com as características dos trechos selecionados (tráfego, frota de veículos, pavimento etc.) e simulação utilizando o HDM-4;

4. Análise da influência das características geométricas nos resultados de cada trecho.

\subsection{ESCOPO DO TRABALHO}

O Capítulo 2 deste trabalho apresenta as condições das rodovias no Brasil, reveladas pela Pesquisa Rodoviária 2004 da Confederação Nacional dos Transportes. Além dos 
dados da condição geral das rodovias, é dada atenção especial aos resultados relacionados à geometria.

O Capítulo 3 trata do programa HDM-4: suas funções, aplicações, estrutura, configuração e modelos. Este capítulo apresenta e descreve cada um dos componentes dos custos dos usuários, com enfoque nos custos de operação dos veículos e relacionados ao tempo de viagem.

No Capítulo 4 é apresentado o estudo de caso. Foram selecionados quatro trechos da Rodovia Washington Luiz (SP-310) e também foram criados trechos representativos das sete classificações do HDM-4 quanto à geometria e dezenove trechos com características geométricas previamente estabelecidas, que permitissem uma análise de sensibilidade. $\mathrm{O}$ estudo de caso permitiu a quantificação dos efeitos das características geométricas sobre todas as parcelas que compõem os custos dos usuários. Foram calculados os custos de terraplenagem para diferentes geometrias verticais com a finalidade de comparação dos custos de melhorias no projeto de rodovias existentes com os benefícios decorrentes das intervenções.

O Capítulo 5 é destinado à análise dos resultados do estudo de caso e, no Capítulo 6, estão presentes as conclusões do trabalho e sugestões para trabalhos futuros. Em seguida, são apresentadas as referências bibliográficas e a bibliografia consultada. O Apêndice A traz tabelas com os valores dos parâmetros presentes nas equações dos cálculos das velocidades e do consumo de combustível dos veículos. 


\section{Capítulo 2}

\section{As condições das rodovias no Brasil}

Em sua nona edição, a Pesquisa Rodoviária CNT 2004 avaliou 100\% da malha rodoviária federal pavimentada e também os principais trechos sob gestão estadual e sob administração terceirizada.

A Pesquisa Rodoviária CNT foi concebida para ser o referencial bibliográfico mais completo sobre as condições das rodovias brasileiras, atuando como um importante instrumento para planejar, investir, gerar estudos e análises orientadoras de políticas e de execução de obras de infra-estrutura viária, tornando-se fonte de conhecimento para as pessoas que procuram se orientar sobre o estado de conservação de rodovias e auxiliando na definição de prioridades em relação a investimentos e manutenção de rodovias (CNT, 2004).

Durante vários dias, equipes de pesquisadores da CNT rodaram $74.681 \mathrm{~km}$ de rodovias em todo país para avaliar o seu estado geral de conservação, levando em conta a qualidade do pavimento, a sinalização e a geometria das vias. Foram pesquisados $8.638 \mathrm{~km}$ na região Norte, $21.582 \mathrm{~km}$ no Nordeste, $11.052 \mathrm{~km}$ no Centro-Oeste, $20.612 \mathrm{~km}$ na região Sudeste e $12.797 \mathrm{~km}$ no Sul.

Ao analisar as condições das rodovias sob aspectos que refletem, sobretudo, os níveis de conservação, segurança e conforto ao rolamento oferecidos aos usuários do sistema rodoviário, a pesquisa se propõe, dentre outros objetivos, a subsidiar estudos relacionados à avaliação dos impactos produzidos pelo estado das rodovias sobre a 
atividade de transporte de passageiros e cargas; identificar necessidades para efeito da gerência de pavimentos em nível de rede e produzir séries históricas sobre as condições das rodovias nacionais.

As condições gerais das rodovias no país estão ilustradas na Figura 1:
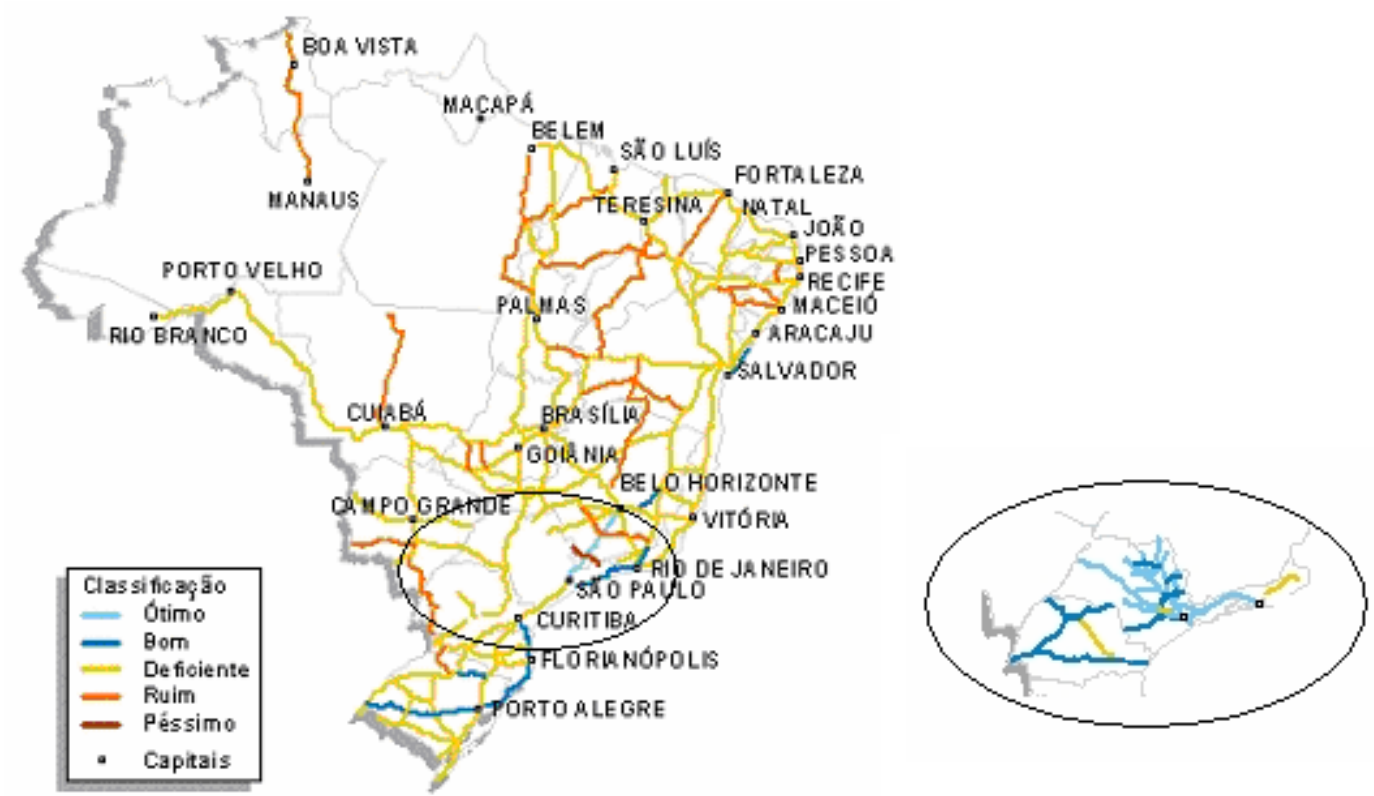

FIGURA 01 - Classificação quanto às condições gerais das rodovias (CNT, 2004).

A Pesquisa Rodoviária CNT 2004 mostrou que, mesmo considerando as melhores condições das malhas sudeste e sul, a malha rodoviária nacional está em situação desfavorável, em que $74,7 \%$ da extensão pesquisada apresentaram algum grau de imperfeição (36,4\% Deficientes, 23,7\% Ruins, 14,6\% Péssimos), conforme a Tabela 1.

TABELA 01 - Estado geral das rodovias brasileiras.

\begin{tabular}{lcccccc}
\hline \multirow{2}{*}{$\begin{array}{c}\text { Estado } \\
\text { Geral }\end{array}$} & \multicolumn{2}{c}{ Extensão Total } & \multicolumn{2}{c}{ Gestão Estatal } & \multicolumn{2}{c}{ Gestão Terceirizada } \\
\cline { 2 - 7 } & $\mathbf{K m}$ & $\mathbf{\%}$ & $\mathbf{K m}$ & $\mathbf{\%}$ & $\mathbf{K m}$ & $\mathbf{\%}$ \\
\hline Ótimo & 8692 & 11,6 & 3474 & 5,4 & 5218 & 51,5 \\
Bom & 10227 & 13,7 & 7506 & 11,6 & 2721 & 26,9 \\
Deficiente & 27148 & 36,4 & 25371 & 39,3 & 1777 & 17,5 \\
Ruim & 17686 & 23,7 & 17319 & 26,8 & 367 & 3,6 \\
Péssimo & 10928 & 14,6 & 10878 & 16,9 & 50 & 0,5 \\
\hline \hline Total & 74681 & 100,0 & 64548 & 100,0 & 10133 & 100,0 \\
\hline
\end{tabular}

Fonte: CNT (2004). 
A Pesquisa Rodoviária 2004 aponta os melhores e piores corredores rodoviários brasileiros. A Tabela 2 apresenta os dez melhores trechos segundo esta pesquisa, cabendo ressaltar que todos eles são administrados por concessionárias.

TABELA 02 - Classificação das rodovias brasileiras.

\begin{tabular}{cccc}
\hline Ranking & Ligação & Rodovias & Notas \\
\hline $1^{\circ}$ & São Paulo SP - Limeira SP & 100,0 \\
$2^{\text {o }}$ & Limeira SP - São José do Rio Preto SP & SP-310/BR-364, SP-310/BR-456 & 99,5 \\
$3^{\circ}$ & São Paulo SP - Taubaté SP & SP-070 & 99,4 \\
$4^{\text {o }}$ & São Paulo SP - Uberaba MG & BR-050, SP-330/BR-050 & 98,8 \\
& Engenheiro Miller SP - Jupiá SP & SP-209, SP-300, SP-300/BR-154, & 98,1 \\
$5^{\circ}$ & SP-300/BR-262, SP-300/BR-267 & 97,2 \\
$6^{\circ}$ & São Paulo SP - Itaí SP - Espírito Santo do Turvo SP & SP-255, SP-280/BR-374 & 96,5 \\
$7^{\circ}$ & Barretos SP - Bueno de Andrade SP & SP-326/BR-364 & 96,3 \\
$8^{\circ}$ & Araraquara SP - São Carlos - Franca SP - Itirapuã SP & SP-255, SP-318, SP-334, SP-345 & 96,2 \\
$9^{\circ}$ & Campinas SP - Jacareí SP & SP-065 & 95,5 \\
$10^{\circ}$ & Rio de Janeiro RJ - São Paulo SP & BR-116 & \\
\hline
\end{tabular}

Fonte: Modificada de CNT (2004).

No que diz respeito às condições de geometria, cada trecho foi analisado em função dos elementos do alinhamento horizontal, alinhamento vertical e seção transversal. Esses são os fatores que, direta e indiretamente, têm impacto na segurança e na fluidez oferecida pela via aos seus usuários. Pode-se verificar, conforme a Tabela 3, que mais de $80 \%$ da extensão total estão em situação desfavorável, com classificação Deficiente, Ruim ou Péssima, e que os trechos sob gestão estatal possuem condições piores que aqueles sob gestão terceirizada. A Figura 2 apresenta um panorama geral dessa situação.

TABELA 03 - Estado da geometria das rodovias brasileiras.

\begin{tabular}{lcccccc}
\hline & \multicolumn{2}{c}{ Extensão Total } & \multicolumn{2}{c}{ Gestão Estatal } & \multicolumn{2}{c}{ Gestão Terceirizada } \\
\cline { 2 - 7 } & Km & $\mathbf{\%}$ & $\mathbf{K m}$ & $\mathbf{\%}$ & $\mathbf{K m}$ & $\mathbf{\%}$ \\
\hline Ótimo & 5128 & 6,9 & 1744 & 2,6 & 3384 & 33,5 \\
Bom & 9286 & 12,4 & 7595 & 11,8 & 1691 & 16,7 \\
Deficiente & 17811 & 23,8 & 14880 & 23,1 & 2931 & 28,9 \\
Ruim & 18558 & 24,9 & 17368 & 26,9 & 1190 & 11,7 \\
Péssimo & 23898 & 32,0 & 22961 & 35,6 & 937 & 9,2 \\
\hline Total & 74681 & 100,0 & 64548 & 100,0 & 10133 & 100,0 \\
\hline Fonte: CNT
\end{tabular}

Fonte: CNT (2004). 


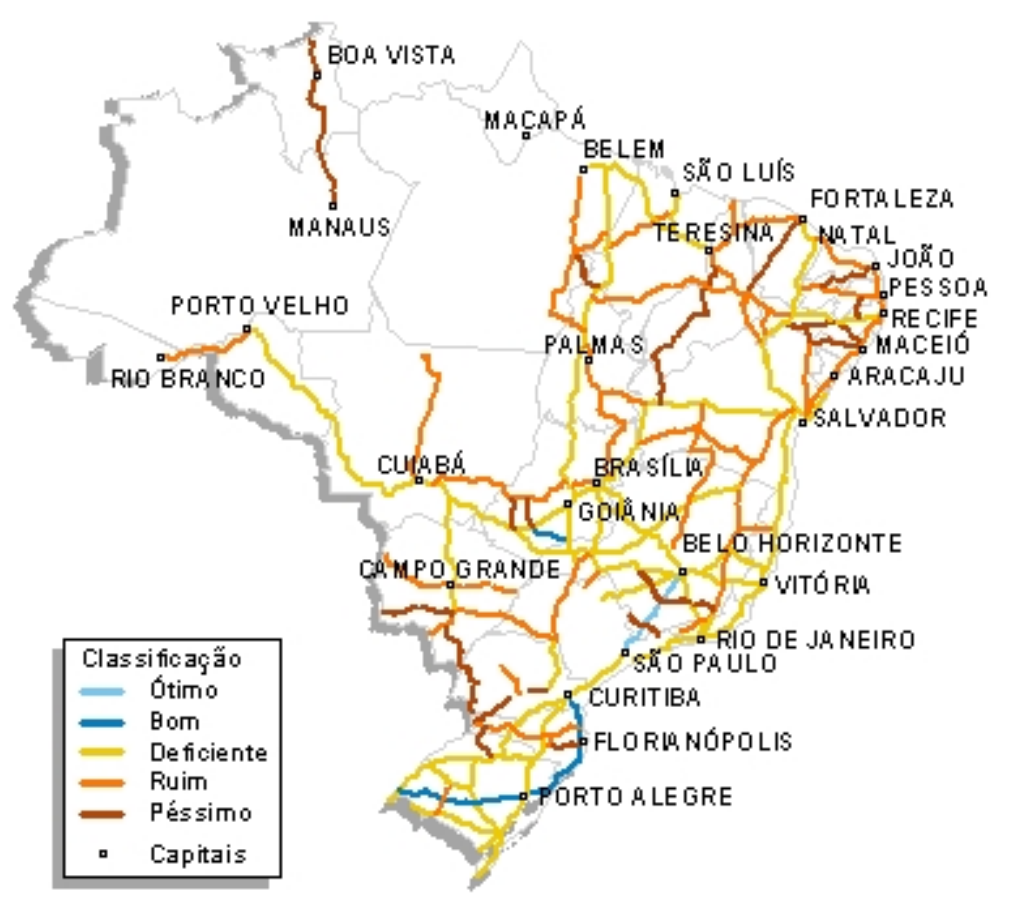

FIGURA 02 - Classificação quanto à condição da geometria das rodovias (CNT, 2004).

O histórico das condições da geometria das rodovias brasileiras, de 1995 a 2003, mostra que houve um aumento significativo na porcentagem de rodovias com classificação Ruim e Péssima, no que diz respeito à geometria, passando de 10,7\% em 1995 para $52,7 \%$ em 2003, como mostra a Tabela 4 . Na realidade, não significa que tenha havido alteração no traçado ao longo dos anos, o que piorou foi a sensação dos usuários em relação às condições geométricas, devido ao aumento do número de veículos, por exemplo, além do que mais trechos foram sendo incluídos nas pesquisas durante o período considerado.

TABELA 04 - Histórico da classificação das rodovias quanto à condição da geometria.

\begin{tabular}{lcccccccc}
\hline & \multicolumn{2}{c}{$\mathbf{1 9 9 5}$} & \multicolumn{2}{c}{$\mathbf{1 9 9 6}$} & \multicolumn{2}{c}{$\mathbf{1 9 9 7}$} & \multicolumn{2}{c}{$\mathbf{1 9 9 9}$} \\
\cline { 2 - 9 } & $\mathbf{K m}$ & $\mathbf{~ \%}$ & $\mathbf{K m}$ & $\mathbf{\%}$ & $\mathbf{K m}$ & $\mathbf{\%}$ & $\mathbf{K m}$ & $\%$ \\
\hline Ótimo & 864 & 5,5 & 1554 & 4,0 & 1717 & 4,1 & 2284 & 5,3 \\
Bom & 7729 & 49,2 & 427 & 1,1 & 461 & 1,1 & 679 & 1,6 \\
Deficiente & 5436 & 34,6 & 3474 & 89,4 & 39062 & 93,3 & 39070 & 91,3 \\
Ruim & 1084 & 6,9 & 2486 & 6,4 & 628 & 1,5 & 782 & 1,8 \\
Péssimo & 597 & 3,8 & 39 & 0,1 & - & - & - & - \\
\hline Total & 15710 & 100,0 & 38838 & 100,0 & 41867 & 100,0 & 42815 & 100,0 \\
\hline
\end{tabular}




\begin{tabular}{lcccccccc}
\hline & \multicolumn{2}{c}{$\mathbf{2 0 0 0}$} & \multicolumn{2}{c}{$\mathbf{2 0 0 1}$} & \multicolumn{2}{c}{$\mathbf{2 0 0 2}$} & \multicolumn{2}{c}{$\mathbf{2 0 0 3}$} \\
\cline { 2 - 9 } & $\mathbf{K m}$ & $\mathbf{\%}$ & $\mathbf{K m}$ & $\mathbf{\%}$ & $\mathbf{K m}$ & $\mathbf{\%}$ & $\mathbf{K m}$ & $\mathbf{\%}$ \\
\hline Ótimo & 2591 & 6,0 & 2814 & 6,2 & 3657 & 7,8 & 3635 & 6,4 \\
Bom & 733 & 1,7 & 940 & 2,1 & 983 & 2,1 & 6570 & 11,6 \\
Deficiente & 38605 & 89,2 & 40181 & 88,7 & 41959 & 89,1 & 16683 & 29,4 \\
Ruim & 1354 & 3,1 & 1359 & 3,0 & 504 & 1,0 & 13785 & 24,3 \\
Péssimo & - & - & - & - & - & - & 16125 & 28,4 \\
\hline Total & 43283 & 100,0 & 45294 & 100,0 & 47103 & 100,0 & 56798 & 100,0 \\
\hline
\end{tabular}

Obs: Não houve pesquisa em 1998.

Fonte: CNT (2004).

Um dado importante é que, segundo a pesquisa, o traçado das rodovias obriga a redução de velocidade em mais de $30 \%$ da extensão total da malha (Tabela 5), reforçando a necessidade de estudos de melhorias na geometria das vias para contribuir com a segurança dos usuários e com o desempenho dos veículos.

TABELA 05 - Redução da velocidade das rodovias em função do traçado.

\begin{tabular}{lcccccc}
\hline & \multicolumn{2}{c}{ Extensão Total } & \multicolumn{2}{c}{ Gestão Estatal } & \multicolumn{2}{c}{ Gestão Terceirizada } \\
\cline { 2 - 7 } & $\mathbf{K m}$ & $\mathbf{\%}$ & $\mathbf{K m}$ & $\mathbf{\%}$ & $\mathbf{K m}$ & $\%$ \\
\hline Não obriga a reduções de velocidade & 50419 & 67,5 & 43718 & 67,7 & 6701 & 66,1 \\
Obriga a reduções de velocidade & 19934 & 26,7 & 17535 & 27,2 & 2399 & 23,7 \\
Velocidade reduzida & 4328 & 5,8 & 3295 & 5,1 & 1033 & 10,2 \\
\hline Total & 74681 & 100,0 & 64548 & 100,0 & 10133 & 100,0 \\
\hline
\end{tabular}

Fonte: CNT (2004).

O tipo de rodovia mais comum na malha nacional é a rodovia de pista simples de mão dupla, conforme apresentado na Tabela 6 , que representa $90,1 \%$ da extensão total, seguida da rodovia de pista dupla com canteiro central, representando 7,4\%.

TABELA 06 - Tipos de rodovias no Brasil.

\begin{tabular}{lcccccc}
\hline & \multicolumn{2}{c}{ Extensão Total } & \multicolumn{2}{c}{ Gestão Estatal } & \multicolumn{2}{c}{ Gestão Terceirizada } \\
\cline { 2 - 8 } & $\mathbf{K m}$ & $\mathbf{\%}$ & $\mathbf{K m}$ & $\mathbf{\%}$ & $\mathbf{K m}$ & $\mathbf{\%}$ \\
\hline Pista simples de mão dupla & 67239 & 90,1 & 61529 & 95,2 & 5710 & 56,4 \\
Pista dupla com canteiro central & 5559 & 7,4 & 2254 & 3,5 & 3305 & 32,6 \\
Pista dupla com barreira central & 1234 & 1,7 & 449 & 0,7 & 785 & 7,7 \\
Pista dupla com faixa central & 539 & 0,7 & 296 & 0,5 & 243 & 2,4 \\
Pista simples de mão única & 110 & 0,1 & 20 & 0,1 & 90 & 0,9 \\
\hline \hline Total & 74681 & 100,0 & 64548 & 100,0 & 10133 & 100,0 \\
\hline
\end{tabular}

Fonte: CNT (2004). 
A análise dos resultados da pesquisa apontou para uma situação de elevado grau de deficiência nas condições das rodovias brasileiras, o que, em termos práticos, se traduz em comprometimento dos níveis de desempenho e de segurança do setor de transportes. É importante ressaltar que o transporte rodoviário é o responsável pelo maior percentual de movimentação de passageiros e de cargas no país. Com esta característica, as deficiências na infra-estrutura rodoviária comprometem muito a integração com as demais modalidades, gerando restrições operacionais e dificultando o crescimento da intermodalidade.

Verifica-se o nítido desequilíbrio entre as regiões brasileiras. Ainda segundo a pesquisa CNT, o Nordeste apresenta cerca de $25 \%$ de sua extensão em péssimo estado de conservação, contra $11 \%$ no Sudeste. Estes valores, que representam as condições do pavimento, da sinalização e da geometria, fazem do Nordeste a região detentora da malha rodoviária em piores condições de todo o país, fato que compromete seu próprio desenvolvimento e também as possibilidades de maior integração econômica com as demais regiões. Esses percentuais traduzem-se em um obstáculo para o desenvolvimento do país. A retomada do crescimento econômico passa pela necessidade de retomada de investimentos rodoviários, ação que deve ser implementada com urgência, para que se evite o desmantelamento da atividade de transporte no Brasil. 


\section{Capítulo 3}

\section{O programa HDM-4}

\subsection{HISTÓRICO}

O primeiro passo para a produção de um modelo de avaliação de projetos rodoviários foi dado pelo Banco Mundial em 1968, por meio de estudos em conjunto com o TRRL (Transport and Road Research Laboratory) e o LCPC (Laboratoire Centrale des Ponts et Chausseés). Em seguida, o MIT (Massachusetts Institute of Technology) realizou uma pesquisa e elaborou um modelo baseado nas informações disponíveis, o Highway Cost Model (MOAVENZADEH et al., 1971; 1975), que foi um avanço na análise das interações entre custos de construção, de manutenção e de operação dos veículos. Porém, faltava uma base empírica, além da necessidade de adequação a diversas regiões, estendendo a sua utilização a países em desenvolvimento.

O TRRL e o Banco Mundial realizaram estudos no Quênia para investigar a deterioração de vias pavimentadas e não-pavimentadas e os fatores que afetavam os custos de operação dos veículos. Os resultados desse estudo foram usados pelo TRRL para elaborar a primeira versão do modelo RTIM (Road Transport Investment Model) para países em desenvolvimento (ABAYNAYAKA et al., 1977). Em 1976, o Banco Mundial incrementou o modelo criado pelo MIT e produziu a primeira versão do HDM (Highway Design and Maintenance Standards Model) (HARRAL, 1979).

Outros trabalhos foram realizados em diversos países para estender o alcance geográfico do RTIM e do HDM: nas ilhas do Caribe (MOROSIUK e ABAYNAYAKA, 1982), em que foram investigados os efeitos da geometria da via nos custos de operação dos veículos, na Índia (CRRI, 1982) e também no Brasil, por meio de um convênio entre o governo brasileiro, através do GEIPOT, e o Programa das Nações Unidas para o Desenvolvimento (PNUD). 
Com os resultados desses estudos, o TRRL criou o modelo RTIM2 (PARSLEY e ROBINSON, 1982), enquanto que o Banco Mundial desenvolveu um modelo que incorporou os resultados de todos os estudos anteriores, o HDM-III (WATANATADA et al., 1987). Com o avanço da informática, a Universidade de Birmingham criou a versão para micro-computador do RTIM2 (KERALY et al., 1985) enquanto o Banco Mundial desenvolvia a versão HDM-PC (ARCHONDO-CALLAO e PUROHIT, 1989). Em 1993, o TRRL desenvolveu o RTIM3 (CUNDILL e WITHNALL, 1995) e, em 1994, o Banco Mundial produziu duas novas versões do HDM, o HDM-Q, que incorporou efeitos de congestionamento do tráfego no modelo do HDM-III, e o HDM Manager (ARCHONDO-CALLAO, 1994).

Com o passar dos anos, as relações técnicas presentes nos modelos RTIM3 e HDM-III ficaram ultrapassadas e, embora os modelos de deterioração ainda fossem relevantes, havia a necessidade de se incorporar os resultados de estudos que haviam sido conduzidos em diversas partes do mundo nos anos anteriores. No caso dos custos de operação dos veículos, por exemplo, reconhecia-se que a tecnologia dos veículos havia sido muito modificada desde 1980 e que os resultados dos custos de operação podiam ser significativamente menores que os previstos pelo RTIM3 e pelo HDM-III.

Era necessário, portanto, que os modelos até então utilizados fossem reformulados para a incorporação de uma maior variedade de tipos e estruturas de pavimentos e de condições de utilização, como também aplicar as tecnologias computacionais mais recentes. Além disso, o novo sistema deveria incluir capacidades adicionais como a de considerar efeitos de congestionamentos, climas frios, aspectos relacionados a acidentes e efeitos ambientais.

Diante disso, o ISOHDM (International Study of Highway Development and Management), projeto internacional coordenado pelo PIARC (World Road Association) e com a participação de centros de pesquisa de diversos países, foi conduzido para estender o alcance do modelo HDM-III, tendo obtido como resultado um novo programa computacional de análise técnico-econômica, o HDM-4 - Highway Development \& Management (KERALI et al., 2000). 


\subsection{APLICAÇÕES DO HDM-4}

O HDM-4 compara estimativas de custos e faz avaliações de alternativas de construção, de manutenção e de estratégias de intervenções, fornecendo um sistema para a gerência de rodovias, para a programação de serviços de pavimentação e alocação de recursos, previsão de desempenho da rede viária e de avaliação de projetos. Ele permite a análise de sensibilidade dos resultados de mudanças em seus parâmetros mais importantes (custos unitários, composição do tráfego, características da rede viária, taxa de desconto, dentre outros).

\subsection{ESTRUTURA DO HDM-4}

A estrutura do HDM-4, mostrada na Figura 3, é composta por:

- Ferramentas de Análises;

- Gerenciadores de Dados;

- Modelos.

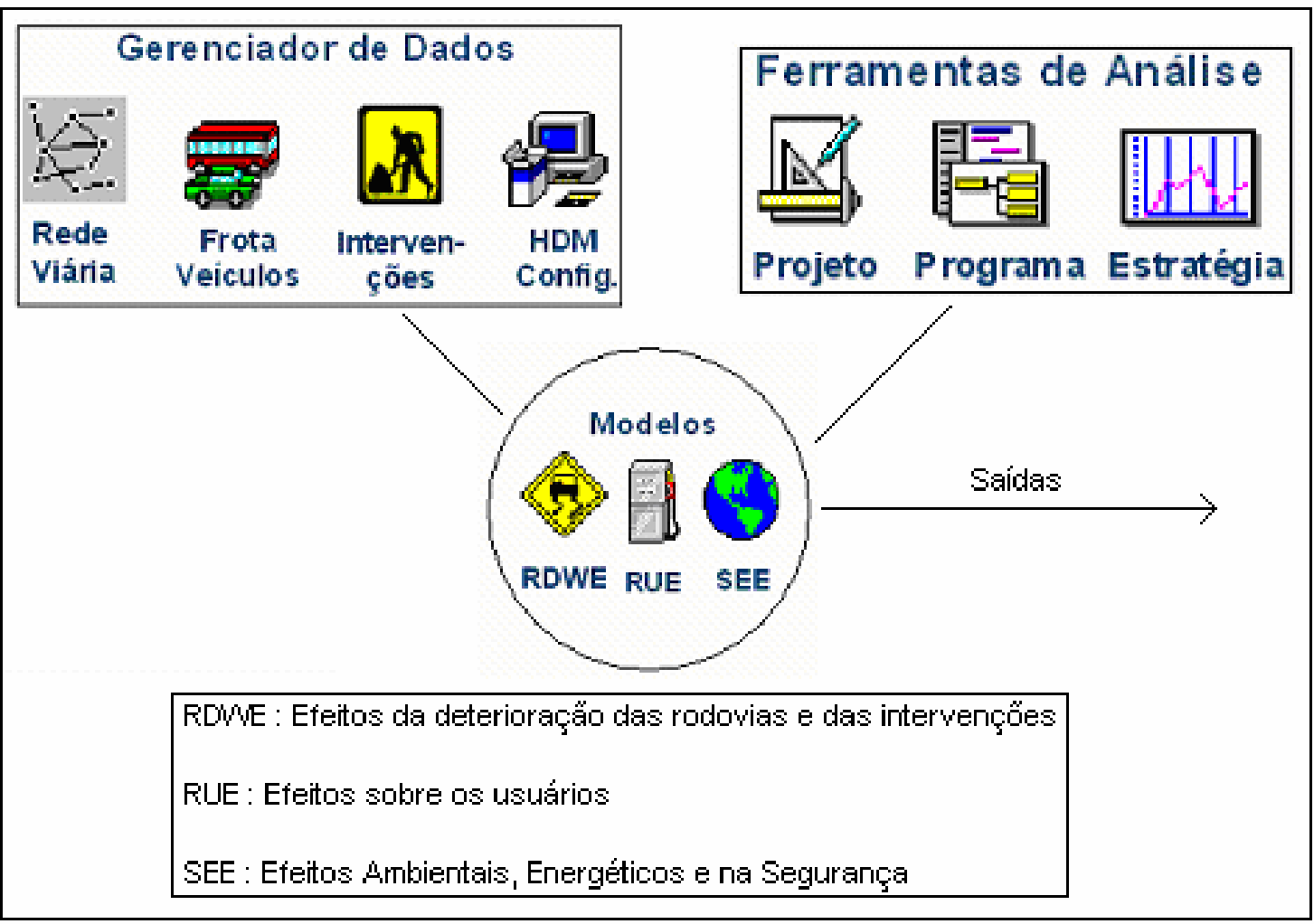

FIGURA 03 - Estrutura analítica do HDM-4 (adaptada de KERALI et al., 2000). 


\subsubsection{Ferramentas de Análises}

Segundo KERALI et al.(2000), as ferramentas de análises do HDM-4 são:

- Análise de Projetos;

- Análise de Programas;

- Análise de Estratégias.

\subsubsection{Análise de Projetos}

A análise de projetos está interessada na avaliação de um ou mais projetos ou opções de investimentos. O aplicativo analisa os custos e benefícios dessas opções a serem aplicadas numa seção da via, programadas anualmente ao longo do período de análise. Indicadores econômicos são determinados para diferentes opções de investimentos. Esta ferramenta pode ser usada para estimar a viabilidade econômica e técnica dos projetos de investimentos, considerando os seguintes temas:

- desempenho estrutural e deterioração dos pavimentos;

- efeitos de intervenções nas vias sobre os custos;

- custos e benefícios dos usuários;

- comparações econômicas entre alternativas de projetos.

Projetos típicos aos quais esta ferramenta é aplicada incluem a manutenção e reabilitação de vias existentes, alargamentos ou melhorias geométricas, melhorias no pavimento e construções de novos trechos. Este aplicativo do HDM-4 é praticamente igual ao do HDM-III, porém foram elaboradas melhores relações da deterioração de vias para cobrirem um número maior de pavimentos e o desempenho de materiais em climas frios.

\subsubsection{Análise de Programas}

As modificações mais significativas do HDM-4 em relação ao HDM-III ocorreram na análise de programas, assim como na análise de estratégias. A análise de programas lida, primeiramente, com a priorização de uma lista definida de possíveis projetos, para 
um programa de serviços anual ou plurianual, sob um orçamento definido. Neste aplicativo do HDM-4, normalmente uma longa lista de alternativas de projetos é selecionada em segmentos discretos da rede viária. A análise de programas é usada para comparar os custos previstos sob o regime de gerência de pavimentos existente (por exemplo, "não fazer nada") com os custos previstos por um outro regime de gerência, com diferentes alternativas de manutenção ou melhorias. Pode-se, dessa forma, estimar os benefícios econômicos que seriam gerados pela inclusão de outros projetos alternativos dentro do esquema orçamentário em uso pelo administrador da rodovia.

Índices tais como o Valor Presente Líquido (VPL), a Taxa Interna de Retorno (TIR) ou os atributos de previsão da condição do pavimento (ex. irregularidade longitudinal da via) não são recomendados como critérios de classificação. A taxa VPL/custo satisfaz o objetivo de maximizar os benefícios econômicos para cada unidade adicional de gastos, pois quantifica os benefícios líquidos para cada unidade monetária do orçamento disponível investido.

\subsubsection{Análise de Estratégias}

O conceito de planejamento estratégico de médio e longo prazo dos gastos com a rede rodoviária requer que a agência considere as necessidades de todos os componentes da rede. Dessa forma, a análise estratégica lida com toda a rede gerenciada pela agência rodoviária. Exemplos de redes rodoviárias incluem as vias principais, as secundárias e as locais.

Para prever as necessidades em médio e longo prazo de toda uma rede, o HDM-4 aplica o conceito de uma matriz da rede que engloba categorias da rede definidas de acordo com atributos que têm maior influência no desempenho dos pavimentos e nos custos dos usuários. Uma matriz típica da rede poderia ser classificada de acordo com:

- volume de tráfego e de cargas;

- tipos e condições dos pavimentos;

- zonas climáticas e ambientais;

- classificação funcional. 
Por exemplo, uma matriz de rede poderia ser modelada usando três categorias de tráfego (alto, médio e baixo), dois tipos de pavimentos (concreto asfáltico e tratamentos superficiais) e três níveis de condição do pavimento (bom, regular e ruim). A matriz resultante constaria de 18 seções representativas de pavimentos $(3 \times 2 \times 3=18)$.

A principal diferença entre a análise estratégica e a de programa é a forma com que as seções são identificadas. A análise de programa lida com seções que são unidades físicas individuais da rede rodoviária ao longo da análise. $\mathrm{Na}$ análise estratégica, o sistema viário perde as características individuais de suas seções devido ao agrupamento, na matriz de categorias da rede, de todos os segmentos com características similares.

Para ambas as análises, o problema pode ser colocado como sendo o de procurar a combinação de alternativas de projetos em um número de seções na rede que otimize uma função objetivo sob restrição de orçamento. Se, por exemplo, a função objetivo é maximizar o Valor Presente Liquido (VPL), o problema pode ser definido como: "selecione a combinação de intervenções para as seções que maximize o VPL para toda a rede, sujeito a uma somatória dos custos de intervenções inferiores ao orçamento disponível".

\subsubsection{Gerenciadores de Dados}

As três ferramentas de análise operam com os dados definidos em um dos quatro Gerenciadores de Dados do HDM-4:

- Rede Viária: contém dados que definem as características físicas das seções das vias de uma rede ou sub-rede a ser analisada;

- Frota de Veículos: define as características da frota de veículos que opera na rede a ser analisada;

- Intervenções na Via: define os padrões de manutenção e de melhorias, juntamente com os custos unitários, que serão aplicados às diferentes seções a serem analisadas; 
- Configuração do HDM: define os dados padrões a serem utilizados nos aplicativos. Os dados padrões devem ser modificados para refletirem as condições locais.

\subsubsection{Modelos}

As análises técnicas são conduzidas usando-se quatro modelos:

- Deterioração da via: prevê a deterioração de pavimentos betuminosos, de concreto de cimento Portland e de vias não-pavimentadas;

- Efeitos das intervenções: simula os efeitos das intervenções na condição do pavimento e determina os custos correspondentes;

- Efeitos sobre os usuários da via: determina os custos de operação dos veículos, acidentes e tempo de viagem;

- Efeitos sociais e ambientais: determina os efeitos das emissões dos veículos e o consumo de energia.

\subsubsection{Deterioração da via}

A deterioração é modelada no HDM-4 para três classes de pavimentos:

- betuminoso;

- concreto de cimento Portland;

- não-pavimentado.

\subsubsection{Intervenções na via}

Ao se fazer uma análise de custos da via, geralmente é necessário simular, na modelagem, os efeitos de vários tipos de intervenções durante o período de análise. $\mathrm{O}$ termo "intervenção" é usado para qualquer mudança nas características físicas de uma via e pode incluir operações desde uma simples manutenção, como a limpeza da superfície, até a construção de uma nova seção. Um dos objetivos da análise econômica é encontrar a combinação de intervenções que, ao longo de um determinado período de análise, irá proporcionar a solução ótima para os fundos disponíveis. 
Para cada real gasto em uma intervenção na via deve haver um benefício correspondente de um real ou mais, caso contrário a intervenção não deve ser realizada. Os benefícios das intervenções podem ocorrer imediatamente ou em longo prazo e surgem da redução dos custos à sociedade (operação dos veículos, efeitos ambientais) e/ou da redução dos custos da agência rodoviária na manutenção futura da via. O HDM4 considera as seguintes classes de intervenções:

- Manutenção de rotina: serviços que devem ser realizados a cada ano ou em intervalos ao longo de um ano. Exemplos incluem selagem de trincas, execução de remendos de panelas e limpeza da drenagem lateral;

- Manutenção periódica: serviços que são agendados para serem realizados em intervalos de alguns anos e são geralmente classificados como preventivos, recapeamentos e reconstruções;

- Especial: serviços cuja freqüência não pode ser estimada com certeza prévia. Exemplos incluem limpeza de destroços devidos a deslizamentos de terra ou acidentes, remoção de neve etc.;

- Serviços de melhorias: por exemplo, o alargamento e o realinhamento de vias;

- Construção: por exemplo, a pavimentação da via ou a construção de um novo trecho.

Para determinar o tempo e os limites dos serviços a serem realizados são utilizados critérios de intervenção. As intervenções podem ser programadas ou em resposta à evolução de um defeito. A programação pode ser em intervalos fixos de tempo (por exemplo, recapeamento em intervalos de sete anos) para serviços de manutenção, ou em datas fixas para serviços de melhorias ou construção (por exemplo, alargamento da via em 2010). Por outro lado, as intervenções podem ser realizadas em resposta a níveis limites especificados pelo usuário. Por exemplo, um determinado tipo de intervenção deverá ser realizado quando a irregularidade longitudinal da via atingir um valor de IRI igual a cinco, ou a área de trincamento exceder dez por cento.

\subsubsection{Efeitos sobre os usuários}

A modelagem dos efeitos sobre os usuários no HDM-4 compreende análises da: 
- velocidade de veículos motorizados, seus custos de operação e tempo de viagem;

- velocidade de veículos não-motorizados e seus custos de operação;

- $\quad$ segurança da via (custos de acidentes).

As principais classes de veículos motorizados são:

- motocicletas;

- automóveis;

- utilitários;

- caminhões;

- ônibus.

Há 16 tipos de veículos motorizados no HDM-4. Por exemplo, para automóveis são definidos os tipos pequeno, médio e grande. As velocidades dos veículos e o consumo dos componentes dos custos de operação são determinados como funções das características de cada tipo de veículo e da geometria, do tipo de superfície e da condição atual da via, sob condições de fluxo livre ou de tráfego congestionado.

Os custos dos usuários compreendem os custos de operação dos veículos, os custos de tempo de viagem (de passageiros e cargas) e os custos relacionados a acidentes na via. Os custos operacionais são obtidos pela multiplicação de várias quantidades de insumos consumidos por seus preços unitários, que são especificados pelo usuário em termos econômicos ou financeiros. Os custos financeiros representam os custos reais dos operadores por possuírem e operarem os veículos pela via. Os custos econômicos representam os custos reais de posse e operação dos veículos, com ajustes feitos para permitir as distorções dos preços de mercado decorrentes de taxas, subsídios, leis salariais etc.

O tempo de viagem é considerado em termos da hora do passageiro a trabalho ou a passeio e do tempo de espera de cargas. Os custos do tempo de viagem são expressos em termos econômicos. A presença de veículos não-motorizados pode ter influência na velocidade dos veículos motorizados, afetando os custos de operação destes. 
O HDM-4 permite a definição de tabelas de taxas de acidentes. Existem descrições de taxas de acidentes esperadas, definidas de acordo com conjuntos de atributos da via e do tráfego (por exemplo, tipo de via, nível de tráfego e modelo de fluxo, presença de veículos não-motorizados e geometria). Para cada tipo de via, os usuários do programa podem especificar a taxa de acidentes de cada severidade (fatais, ferimentos ou danos) em termos do número de acidentes por milhão de veículos-quilômetro. É possível analisar, por exemplo, a variação no número de acidentes e nos custos resultantes de uma melhoria em um trecho de rodovia decorrente de uma diferente alternativa de projeto.

\subsubsection{Efeitos sociais e ambientais}

Os modelos de efeitos sociais e ambientais do HDM-4 analisam o balanço de energia e a emissão de poluentes. Esses efeitos precisam ser considerados nas políticas de investimentos e projetos, para a redução dos custos de operação dos veículos, redução da poluição e do consumo de recursos energéticos.

\subsection{CALIBRAÇÃO DO HDM-4}

O HDM-4 simula as alterações futuras no sistema viário com base nas condições atuais. A confiabilidade dos resultados depende de duas considerações:

- de quanto os dados fornecidos ao modelo representam a realidade das condições atuais e os fatores mais influentes;

- de quanto as previsões do modelo representam o comportamento real e as interações entre vários fatores para a variedade de condições às quais o modelo é aplicado.

Portanto, a aplicação do modelo HDM-4 envolve dois passos importantes:

- a correta interpretação de quais dados de entrada são importantes e a qualidade desses dados, de modo a obter a confiabilidade desejada dos resultados da aplicação do modelo; 
- o ajuste dos parâmetros do modelo para que os resultados representem as mudanças ao longo do tempo e sob as diversas intervenções.

Os usuários do programa podem ajustar os fatores para que as previsões dadas pelo modelo reflitam as observações feitas nas condições locais sob estudo.

\subsection{CONFIGURAÇÃO DO HDM-4}

Uma vez que o HDM-4 pode ser utilizado em diversas situações de projetos, ele permite que o usuário defina alguns parâmetros da configuração do programa, de acordo com as características do projeto analisado, no que diz respeito ao modelo de fluxo de tráfego, à velocidade de fluxo, às zonas climáticas e à unidade monetária utilizada.

\subsubsection{Modelo de fluxo de tráfego}

O modelo de fluxo de tráfego é usado para representar a variação da intensidade de tráfego que ocorre na via ao longo do dia. Ele é definido como um conjunto de períodos que representam as horas do dia com um mesmo fluxo de tráfego.

\subsubsection{Tipos de velocidade de fluxo}

Este modelo representa a capacidade de diferentes tipos de vias (pista simples, pista dupla etc.) e define as características da velocidade de fluxo, em termos de:

- capacidade máxima;

- mudanças de velocidade;

- capacidade de fluxo livre e capacidade nominal;

- porcentagem de acidentes.

\subsubsection{Unidade monetária}

O usuário pode configurar a unidade monetária que será utilizada pelo programa para apresentar os dados de entrada e de saída relacionados a custos. 


\subsubsection{Zonas climáticas}

As zonas climáticas representam as condições do clima com base na classificação da umidade e do regime da temperatura. Elas são importantes, pois o clima tem um grande impacto na deterioração dos pavimentos e afeta a operação dos veículos. A classificação da umidade é dada em função da precipitação média anual, do índice de umidade de Thorntwaithe e da duração do período de seca anual, conforme a Tabela 7. A classificação da temperatura (Tabela 8) é dada pela temperatura média anual, pelo número de dias com temperaturas superiores a $32^{\circ} \mathrm{C}$, pelo índice de congelamento etc.

TABELA 07 - Classificação da umidade na configuração das zonas climáticas.

\begin{tabular}{lccccc} 
& \multicolumn{5}{c}{ Classificação da Umidade } \\
\cline { 2 - 6 } & Árido & Semi-árido & Sub-úmido & Úmido & Super-úmido \\
\hline $\begin{array}{l}\text { Precipitação média } \\
\text { mensal (mm) }\end{array}$ & 15 & 50 & 100 & 175 & 210 \\
$\begin{array}{l}\text { Índice de Umidade de } \\
\begin{array}{l}\text { Thornthwaite } \\
\text { Duração do período seco } \\
\text { (em \% do ano) }\end{array}\end{array}$ & -80 & -40 & 0 & +60 & +100 \\
\hline
\end{tabular}

Fonte: Modificada de KERALI et al., 2000.

TABELA 08 - Classificação da temperatura na configuração das zonas climáticas.

\begin{tabular}{|c|c|c|c|c|c|}
\hline & \multicolumn{5}{|c|}{ Classificação da Temperatura } \\
\hline & Tropical & $\begin{array}{c}\text { Sub- } \\
\text { tropical }\end{array}$ & $\begin{array}{c}\text { Sub- } \\
\text { tropical frio }\end{array}$ & $\begin{array}{c}\text { Temperado } \\
\text { frio } \\
\end{array}$ & $\begin{array}{c}\text { Temperado } \\
\text { congelado }\end{array}$ \\
\hline $\begin{array}{l}\text { Temperatura média anual } \\
\left({ }^{\circ} \mathrm{C}\right)\end{array}$ & 27 & 22 & 18 & 12 & 8 \\
\hline Intervalo de temperatura $\left({ }^{\circ} \mathrm{C}\right)$ & 15 & 50 & 40 & 45 & 60 \\
\hline $\begin{array}{l}\text { Número de dias por ano com } \\
\text { temperatura }>32^{\circ} \mathrm{C}\end{array}$ & 90 & 60 & 30 & 15 & 10 \\
\hline $\begin{array}{l}\text { Índice de congelamento }\left({ }^{\circ} \mathrm{C} \text { - }\right. \\
\text { dias) }\end{array}$ & 0 & 0 & 0 & 55 & 220 \\
\hline $\begin{array}{l}\text { Porcentagem do tempo com } \\
\text { vias cobertas por neve }\end{array}$ & 0 & 0 & 0 & 10 & 20 \\
\hline $\begin{array}{l}\text { Porcentagem do tempo com } \\
\text { vias cobertas por água }\end{array}$ & 20 & 10 & 15 & 5 & 10 \\
\hline Densidade do ar $\left(\mathrm{kg} / \mathrm{m}^{3}\right)$ & 1,2 & 1,2 & 1,2 & 1,2 & 1,2 \\
\hline
\end{tabular}

Fonte: Modificada de KERALI et al., 2000.

\subsubsection{Parâmetros agregados}

Os parâmetros agregados utilizados pelo HDM-4 são relacionados com: 
- volume de tráfego;

- classe da via;

- geometria da via;

- qualidade da construção;

- resistência estrutural (cargas sobre o pavimento);

- qualidade de rolamento (indicativo de irregularidade), que é um parâmetro importante para indicar a condição da via e a necessidade de manutenção e para prever o custo de operação dos veículos;

- condição superficial (defeitos superficiais);

- textura superficial (indicação da profundidade da textura e da resistência ao atrito superficial).

\subsubsection{Características geométricas das rodovias}

As variáveis relacionadas aos aspectos geométricos das rodovias consideradas no modelo do HDM-4 e que influenciam os custos totais dos usuários são:

- Média de subidas e descidas (“Rise plus Fall”) do trecho estudado;

- Média da curvatura horizontal do trecho;

- Limite de velocidade estabelecido para o trecho.

Para esta pesquisa, serão realizadas análises variando-se a média das subidas e descidas e a média da curvatura horizontal dos trechos.

\subsubsection{Média das Subidas e Descidas}

A média das subidas e descidas é a somatória das distâncias entre os pontos de máxima cota e de mínima cota de curvas verticais adjacentes, dividida pelo comprimento total do trecho (Figura 4):

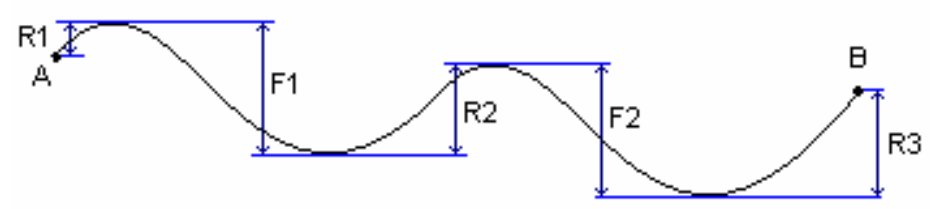

FIGURA 04 - Representação de subidas e descidas ao longo de um trecho. 


$$
R F=\frac{R_{1}+F_{1}+R_{2}+F_{2}+R_{3}}{L_{\text {total }}}
$$

\section{Em que:}

RF: média das subidas e descidas $[\mathrm{m} / \mathrm{km}]$;

$\mathrm{R}_{\mathrm{i}}$ : distância vertical entre os pontos de mínima e de máxima cotas de duas curvas verticais adjacentes $[\mathrm{m}]$;

$\mathrm{F}_{\mathrm{i}}$ : distância vertical entre os pontos de máxima e de mínima cotas de duas curvas verticais adjacentes $[\mathrm{m}]$;

$\mathrm{L}_{\text {total }}$ : comprimento total do trecho $[\mathrm{km}]$

\subsubsection{Média da Curvatura Horizontal}

A média da curvatura horizontal (ADC) é a somatória dos ângulos centrais das curvas dividida pelo comprimento total do trecho (Figura 5):

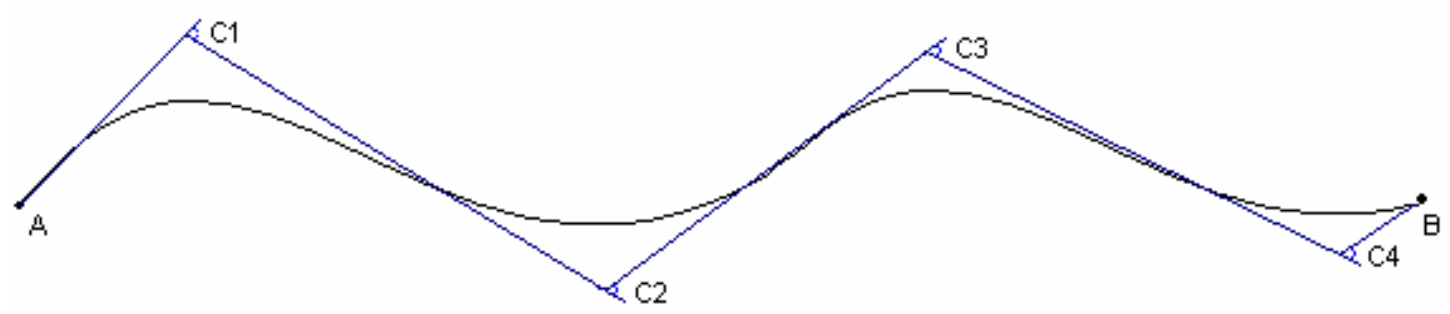

FIGURA 05 - Representação dos ângulos centrais ao longo de um trecho.

$$
A D C=\frac{C_{1}+C_{2}+C_{3}+C_{4}}{L_{\text {total }}}
$$

Em que:

ADC: curvatura horizontal média [graus / km];

$\mathrm{C}_{\mathrm{i}}$ : ângulos centrais das curvas ao longo do trecho [graus]

$\mathrm{L}_{\text {total }}$ : comprimento total do trecho $[\mathrm{km}]$.

\subsubsection{Classes de geometria padronizadas pelo HDM-4}

O HDM-4 considera em seus modelos sete diferentes classes de geometria (classes A a G da Tabela 9), classificadas de acordo com parâmetros que representam as condições 
de geometria vertical e horizontal dos trechos. Essas classes são definidas de acordo com a combinação dos alinhamentos vertical e horizontal e variam desde trechos com características geométricas mais suaves até trechos em que essas características são mais acentuadas.

TABELA 09 - Classes de geometria padronizadas pelo HDM-4.

\begin{tabular}{|c|c|c|c|c|c|}
\hline Classes da Geometria & $\begin{array}{c}\text { Subidas }+ \\
\text { Descidas } \\
(\mathrm{m} / \mathrm{km}) \\
\end{array}$ & $\begin{array}{c}\text { N. }{ }^{\circ} \text { Subidas } \\
\text { e Descidas } \\
\text { (por km) }\end{array}$ & $\begin{array}{l}\text { Curvatura } \\
\text { Horizontal } \\
\text { (graus/km) } \\
\end{array}$ & $\begin{array}{c}\text { Supere- } \\
\text { levação } \\
(\%)\end{array}$ & $\begin{array}{c}\text { Limite } \\
\text { Velocidade } \\
(\mathrm{km} / \mathrm{h}) \\
\end{array}$ \\
\hline A Reta e Plana & 1 & 1 & 3 & 2 & 110 \\
\hline $\begin{array}{l}\text { Praticamente Reta } \\
\text { e Pouco Ondulada }\end{array}$ & 10 & 2 & 15 & 2,5 & 100 \\
\hline $\begin{array}{l}\text { Pouco Sinuosa e } \\
\text { Praticamente Plana }\end{array}$ & 3 & 2 & 50 & 2 & 100 \\
\hline $\begin{array}{l}\text { Pouco Sinuosa e } \\
\text { Pouco Ondulada }\end{array}$ & 15 & 2 & 75 & 3 & 80 \\
\hline $\begin{array}{l}\text { Pouco Sinuosa e } \\
\text { Muito Ondulada }\end{array}$ & 25 & 3 & 150 & 5 & 70 \\
\hline $\begin{array}{l}\text { F Sinuosa e } \\
\text { Pouco Ondulada }\end{array}$ & 20 & 3 & 300 & 5 & 60 \\
\hline $\begin{array}{l}\text { Sinuosa e } \\
\text { Muito Ondulada }\end{array}$ & 40 & 4 & 500 & 7 & 50 \\
\hline
\end{tabular}

Fonte: Modificada de ODOKI e KERALI (2000).

\subsection{CUSTOS TOTAIS DOS USUÁRIOS}

Os custos totais dos usuários compreendem os custos de operação dos veículos e os custos em função do tempo das viagens. Além desses, podem ser incluídos nos custos dos usuários os custos relacionados a acidentes e a emissões de poluentes provocadas pelos veículos.

No HDM-4 é feita a implementação do modelo de efeitos sobre usuários (RUE) para o cálculo:

- das velocidades dos veículos motorizados;

- dos custos de operação dos veículos;

- do tempo de viagem;

- dos custos dos acidentes e das emissões de poluentes. 
Para modelar o custo de operação, assim como o tempo de viagem, são utilizados procedimentos computacionais para:

- calcular a velocidade para cada tipo de veículo (velocidade livre, velocidade de congestionamento, velocidade de operação média anual, velocidade de tráfego média anual);

- calcular a quantidade de insumos consumidos (combustível, óleo lubrificante, pneus, peças, custo do trabalho de manutenção, custo do capital, custo da tripulação e custos gerais);

- calcular o tempo de viagem (passageiros por hora e carga por hora);

- calcular o custo dos insumos consumidos pelos veículos e o tempo de viagem, aplicando os custos unitários;

- calcular o aumento nos custos operacionais (devido a possíveis reduções de velocidade provocadas por estrangulamentos do tráfego ou pela deterioração da via). Para um trecho de rodovia e um período de projeto, o consumo de insumos dos veículos é modelado considerando-se a operação de cada tipo de veículo sob as condições do fluxo de tráfego.

A Figura 6 mostra um esquema do inter-relacionamento entre os componentes dos custos totais relacionados com os custos dos usuários, no que diz respeito aos fatores que influenciam o consumo de insumos. Verifica-se que fatores como a geometria da via e a condição do pavimento influenciam direta e indiretamente (através do efeito na velocidade dos veículos) o consumo.

\subsubsection{Cálculo da velocidade dos veículos}

Segundo ODOKI e KERALI (2000), o cálculo da velocidade dos veículos é necessário para determinar os custos de operação, o tempo de viagem, a quantidade de emissões de poluentes e o consumo de energia. Existem diversos fatores que têm influência na velocidade, desde as condições da via até o comportamento do motorista, passando pelas características dos veículos, dentre outros. 
A Figura 7 resume os grupos a que estes fatores pertencem, dando destaque aos relacionados às condições da via que, segundo BENNETT e GREENWOOD (2001), são os mais significativos para o HDM-4. Ainda segundo estes autores, de acordo com estudos sobre o impacto de alguns fatores na velocidade, existem alguns - como as rampas e as curvas - que invariavelmente têm influência, e outros que podem ou não ter influência dependendo das condições locais do estudo.

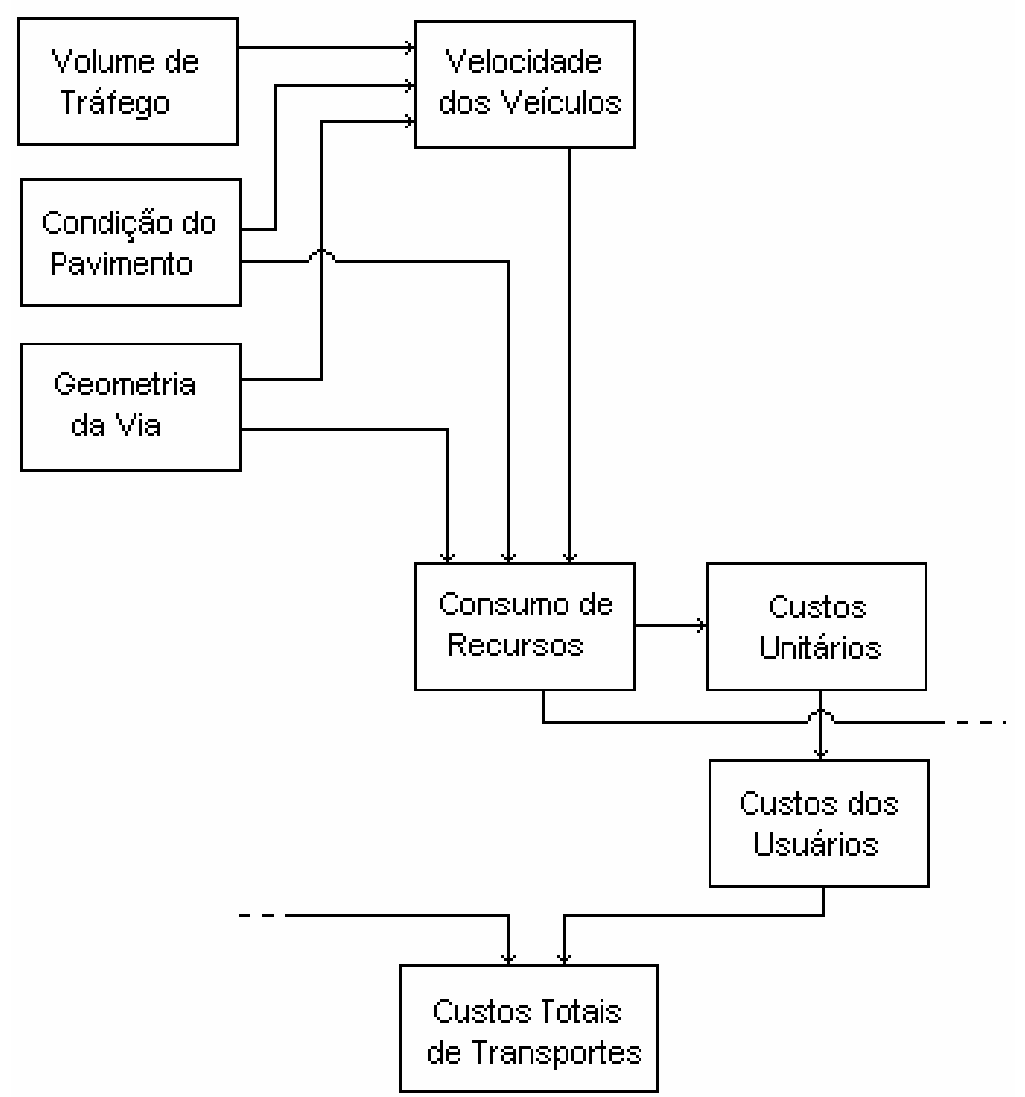

FIGURA 06 - Esquema da inter-relação entre os componentes dos custos totais relacionados aos custos dos usuários (Adaptada de BENNETT e GREENWOOD, 2001).

De acordo com as condições do tráfego, os veículos podem apresentar uma velocidade livre ou uma velocidade média de operação para diferentes níveis de fluxo de tráfego. A velocidade livre é definida como aquela na qual cada veículo trafega em seções não congestionadas do trecho estudado. Para calculá-la, são empregados modelos mecanísticos / comportamentais baseados na potência e capacidade de frenagem de cada tipo de veículo, na curvatura da via, na irregularidade longitudinal da superfície e na velocidade desejada. 


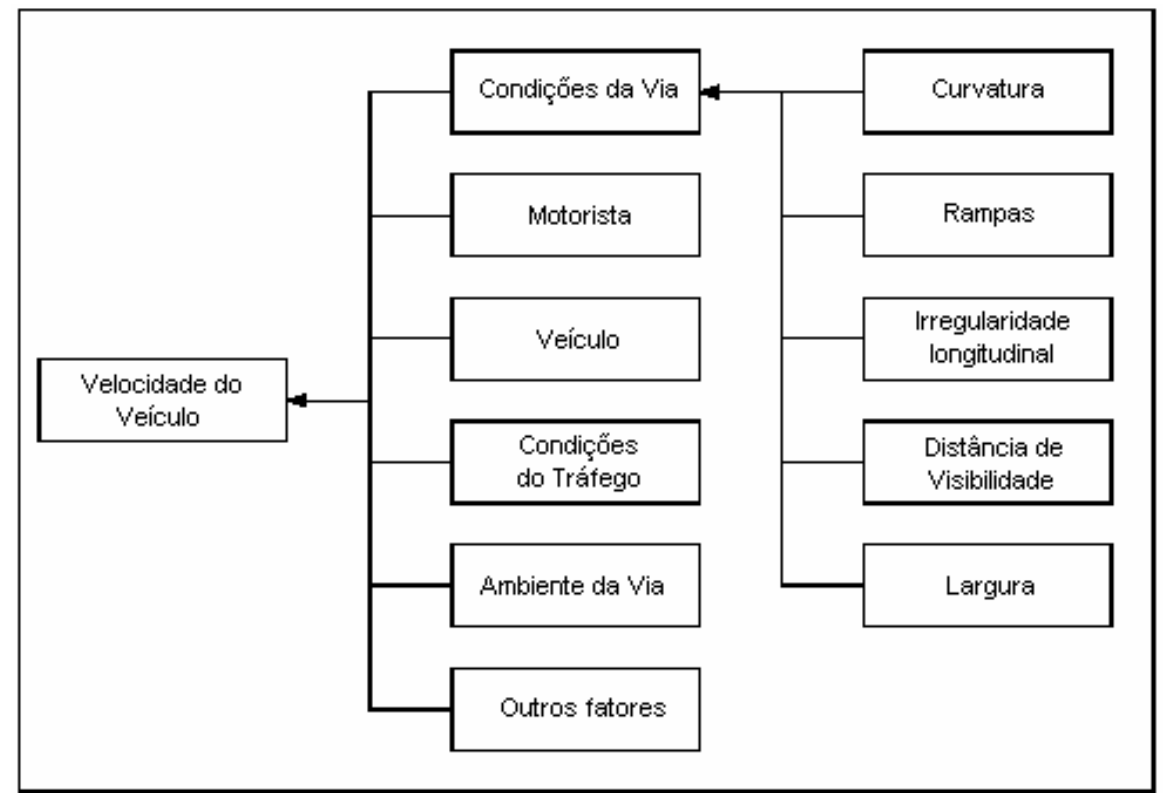

FIGURA 07 - Fatores que têm influência na velocidade dos veículos (BENNETT e GREENWOOD, 2001).

- Cálculo da velocidade livre:

A velocidade livre na subida ou na descida (m/s) é dada por (ODOKI et al., 2000):

$$
V S_{k u, d}=\frac{\exp \left[\frac{\sigma^{2}}{2}\right]}{\left[\left(\frac{1}{V D R_{u, d}}\right)^{\frac{1}{\beta}}+\left(\frac{1}{V B R_{u, d}}\right)^{\frac{1}{\beta}}+\left(\frac{1}{V C U_{u, d}}\right)^{\frac{1}{\beta}}+\left(\frac{1}{V R O_{u, d}}\right)^{\frac{1}{\beta}}+\left(\frac{1}{V D E_{u, d}}\right)^{\frac{1}{\beta}}\right]^{\beta}}
$$

$\mathrm{VS}_{\mathrm{ku}, \mathrm{d}}$ : velocidade livre na subida/descida $[\mathrm{m} / \mathrm{s}]$;

$\mathrm{VDR}_{\mathrm{u}, \mathrm{d}}$ : velocidade limitada pelas rampas e pela potência na subida/descida $[\mathrm{m} / \mathrm{s}]$;

$\mathrm{VBR}_{\mathrm{u}, \mathrm{d}}$ : velocidade limitada pelas rampas e pela potência de frenagem usada na subida/descida $[\mathrm{m} / \mathrm{s}]$;

$\mathrm{VCU}_{\mathrm{u}, \mathrm{d}}$ : velocidade limitada pela curvatura $[\mathrm{m} / \mathrm{s}]$;

$\mathrm{VRO}_{\mathrm{u}, \mathrm{d}}$ : velocidade limitada pela irregularidade longitudinal $[\mathrm{m} / \mathrm{s}]$;

$\mathrm{VDE}_{\mathrm{u}, \mathrm{d}}$ : velocidade desejada sob condições ideais $[\mathrm{m} / \mathrm{s}]$;

$\sigma$ e $\beta$ : parâmetros do modelo Weibull. 
O parâmetro $\beta$ determina a forma assumida pela distribuição dos limitantes de velocidade: quando $\beta$ se aproxima de zero, a velocidade média é igual a velocidade mínima entre as velocidade dos cinco limitantes; quanto maior for $\beta$, mais longe da velocidade limitante será a velocidade média prevista.

A velocidade nos dois sentidos (subida e descida, ou "round trip") é dada por:

$$
S_{k}=\frac{7,2}{\left[\left(\frac{1}{V S_{k u}}\right)+\left(\frac{1}{V S_{k d}}\right)\right]}
$$

$\mathrm{S}_{\mathrm{k}}$ : velocidade livre de equilíbrio média $(\mathrm{km} / \mathrm{h})$ para o tipo de veículo $\mathrm{k}$.

As limitações da velocidade são dadas por:

\section{a) Limitações baseadas nas rampas e na potência do motor (VDR)}

A limitação da velocidade é baseada na potência utilizada e no conjunto de rampas da via através do balanço de forças na ausência de aceleração. É dada por uma equação cúbica, com hipótese de veículo em velocidade de equilíbrio numa via suave e reta, em que PDR é a potência usada, em kW, e z0 e z1 são coeficientes dados em função das forças que se opõem ao movimento (resistências aerodinâmica, de rampa e ao rolamento):

$$
1000 * P D R=z 0 * V D R^{3}+z 1 * V D R
$$

Esses coeficientes z0 e z1 são dados por:

$$
\begin{gathered}
z 0=0,5 * R H O * C D_{\text {mult }} * C D * A F+b 13 * C R 1 * C R 2 * F C L \\
z 1=b 11 * C R 2 * F C L * N W+b 12 * C R 1 * C R 2 * F C L * W_{\text {op }}+W_{\text {op }} * g * G R
\end{gathered}
$$


Nas quais:

RHO: densidade do $\operatorname{ar}\left[\mathrm{kg} / \mathrm{m}^{3}\right]=1,20$ (valor padrão)

ou:

$$
R H O=1,225 *\left(1-2,26 * A * 10^{-5}\right)^{4,255}
$$

A: altitude [m];

CD: coeficiente de arrasto aerodinâmico;

$\mathrm{CD}_{\text {mult: }}$ fator de ajuste para variação da direção do vento;

$\mathrm{AF}$ : área frontal projetada $\left[\mathrm{m}^{2}\right]$;

CR1: coeficiente de resistência ao rolamento, dependente do tipo de pneu:

$\mathrm{CR} 1=1,0$ para pneu radial;

$\mathrm{CR} 1=1,3$ para pneu diagonal;

CR2: coeficiente de resistência ao rolamento, que depende do pavimento.

$$
C R 2=\operatorname{Kcr} 2 *\left(a 0+a 1 * T D_{a v}+a 2 * R I_{a v}\right)
$$

Em que:

Kcr2: fator de resistência ao rolamento;

$\mathrm{TD}_{\mathrm{av}}$ : profundidade média da textura $[\mathrm{mm}]$;

$\mathrm{RI}_{\mathrm{av}}$ : irregularidade longitudinal média [IRI: $\mathrm{m} / \mathrm{km}$ ];

a0, a1 e a2: coeficientes tabelados.

FCL: fator de ajuste climático;

NW: número de rodas por veículo;

$\mathrm{W}_{\mathrm{op}}$ : peso de operação dos veículos [kg];

g: aceleração da gravidade $\left[9,81 \mathrm{~m} / \mathrm{s}^{2}\right]$;

GR: alinhamento vertical (rampas) médio da seção [fração];

b11, b12 e b13: parâmetros de resistência ao rolamento.

O diâmetro e o número de rodas influenciam a resistência ao rolamento:

$$
\begin{aligned}
& b 11=C R B a 0 * W D \\
& b 12=C R B a 1 \div W D \\
& b 13=C R B a 2 * N W \div W D^{2}
\end{aligned}
$$


Em que:

WD: diâmetro da roda [m];

CRBa0, CRBa1, CRBa2: coeficientes tabelados do modelo.

A resistência ao rolamento depende da porcentagem do tempo viajado com neve (PTS) ou água na pista (PTW):

$$
F C L=1+0,003 * P T S+0,002 * P T W
$$

O alinhamento vertical médio (rampas) da seção é dado por:

$$
G R= \pm R F \div 1000
$$

Em que:

RF: média de subidas e descidas $[\mathrm{m} / \mathrm{km}]$;

Para

$$
\begin{aligned}
& G R=+R F \div 1000 \text { temos o } \mathrm{VDR}_{\mathrm{u}} \\
& G R=-R F \div 1000 \text { temos o } \mathrm{VDR}_{\mathrm{d}}
\end{aligned}
$$

A solução da equação cúbica é dada através da regra de sinais de Descartes:

$$
\begin{gathered}
z 2=\frac{z 1}{(3 * z 0)} \\
z 3=\frac{1000 * P D R}{(2 * z 0)} \\
D T=z 2^{3}+z 3^{2}
\end{gathered}
$$

Se DT $>0$ :

$$
V D R=\sqrt[3]{\sqrt{D T}+z 3}-\sqrt[3]{\sqrt{D T}-z 3}
$$




$$
\text { Se } \quad \begin{aligned}
& (\sqrt{D T}-z 3)<0 \rightarrow(\sqrt{D T}-z 3)=0 \\
& (\sqrt{D T}+z 3)<0 \rightarrow(\sqrt{D T}+z 3)=0
\end{aligned}
$$

Se DT $\leq 0$ :

$$
V D R=\max \left[r * \cos (z), r * \cos \left(z+\frac{2 \pi}{3}\right), r * \cos \left(z+\frac{4 \pi}{3}\right)\right]
$$

Em que:

$$
\begin{gathered}
z=\frac{1}{3} \arccos \left(\frac{-2 * z 3}{z 2 * r}\right) \\
r=2 * \sqrt{-z 2}
\end{gathered}
$$

\section{b) Limitações baseadas nas rampas e na capacidade de frenagem (VBR)}

Nas subidas, o valor de VBR tende ao infinito, pois a velocidade na subida não é limitada pela potência do freio. Nas descidas, a velocidade depende do comprimento da rampa (GL); se passar do valor crítico, os freios são usados para reduzir a velocidade; abaixo desse comprimento crítico, a descida não influencia a velocidade.

$$
C G L=C G R a 0 * \exp (C G R a 1 * G R)+C G R a 2
$$

Em que:

CGL: comprimento de rampa crítico;

CGRa0, CGRa1, CGRa2: coeficientes de regressão;

GR: rampa média do trecho [valor absoluto em fração].

$\mathrm{Se} \mathrm{GL}<\mathrm{CGL} \rightarrow \mathrm{VBR}_{\mathrm{d}}=\infty$

Se GL > CGL: resolver a equação cúbica:

$$
-1000 * P B R=z 0 * V B R_{d}{ }^{3}+z 1 * V B R_{d}
$$


Sendo:

PBR: potência de frenagem usada $[\mathrm{kW}]$;

$$
\begin{gathered}
z 0=0,5 * R H O * C D_{\text {mult }} * C D * A F+b 13 * C R 1 * C R 2 * F C L \\
z 1=b 11 * C R 2 * F C L * N W+b 12 * C R 1 * C R 2 * F C L * W_{\text {op }}+W_{\text {op }} * g * G R \\
G L=\frac{1}{N R F} \quad[\mathrm{~km}]
\end{gathered}
$$

Em que:

NRF: número de subidas e descidas médio por $\mathrm{km}[$ mínimo $=0,1]$;

A solução da equação cúbica é dada pela regra de sinais de Descartes:

$$
\begin{gathered}
z 2=\frac{z 1}{(3 * z 0)} \\
z 3=\frac{-1000 * P B R}{(2 * z 0)} \\
D T=z 2^{3}+z 3^{2}
\end{gathered}
$$

Se $\quad \mathrm{DT} \geq 0 \quad \rightarrow \quad \mathrm{VBR}_{\mathrm{d}}=\infty$

Se $\quad \mathrm{DT}<0$ :

$$
\begin{gathered}
z=\frac{1}{3} \arccos \left(\frac{-2 * z 3}{z 2 * r}\right) \\
r=2 * \sqrt{-z 2} \\
V B R_{d}=r * \cos \left(z+\frac{4 \pi}{3}\right)
\end{gathered}
$$




\section{c) Limitações determinadas pela curvatura da via (VCU)}

A limitação é dada em função do raio de curvatura. Os motoristas escolhem a velocidade de curva tal que o atrito lateral não cause deslizamento das rodas.

$$
V C U=V C U a 0 * R^{V C U a 1}
$$

Em que:

$\mathrm{R}$ : raio médio de curvatura da via $[\mathrm{m}]$;

VCUa0, VCUa1: parâmetros de regressão.

$$
R=\frac{18000}{\pi * \max \left(\frac{18}{\pi}, C\right)}
$$

Em que:

C: curvatura horizontal média [graus $/ \mathrm{km}$ ]

\section{d) Limitações baseadas na irregularidade longitudinal (VRO)}

A limitação é dada pela velocidade que corresponde ao movimento máximo permitido da suspensão do veículo, que é medido pela taxa de deslocamento absoluto do eixo traseiro do veículo em relação ao chassi deste (chamado ARS, em m/ $\mathrm{km}$ ou mm/m).

$$
A R V=V * A R S
$$

Em que:

ARV: velocidade de suspensão padrão $[\mathrm{mm} / \mathrm{s}]$;

$$
V R O=\frac{A R V_{\max }}{\left(V R O a 0 * R I_{a v}\right)}
$$

$\mathrm{ARV}_{\max }$ : velocidade de suspensão máxima permitida $[\mathrm{mm} / \mathrm{s}]$;

VROa0: parâmetro de regressão;

$\mathrm{RI}_{\mathrm{av}}$ : irregularidade longitudinal média $[\mathrm{m} / \mathrm{km}]$. 


\section{e) Velocidade desejada (VDE)}

É a velocidade nas condições ideais, ou seja, na ausência de limitações devido a alinhamento vertical, curvatura, congestionamento do tráfego etc. É influenciada pelo comportamento do motorista em resposta a considerações psicológicas de segurança, culturais e econômicas, em adição a fatores como a largura da via, o atrito externo (laterais), a presença de veículos não-motorizados e aos limites de velocidade e outras regulamentações.

Na ausência de limite de velocidade, temos:

$$
V D E 0=V D E S * X F R I * X N M T * V D E_{m u l}
$$

Em que:

VDES: velocidade desejada ajustada para o efeito da largura;

XFRI: fator de redução devido ao atrito externo (varia de 0,6 a 1,0);

XNMT: fator de redução devido aos veículos não-motorizados (varia de 0,6 a 1,0);

$\mathrm{VDE}_{\mathrm{mul}}$ : fator de multiplicação (varia de 0,85 a 1,3 - padrão $=1,0$, para vias de 2 faixas).

Se

$$
\begin{aligned}
& \mathrm{CW} \leq \mathrm{CW} 1 \rightarrow \mathrm{VDES}=\mathrm{VDES}_{\min } \\
& \mathrm{CW} 1<\mathrm{CW} \leq \mathrm{CW} 2 \rightarrow \mathrm{VDES}=\mathrm{VDES}_{\min }+\mathrm{VDESa} 3^{*}(\mathrm{CW}-\mathrm{CW} 1) \\
& \mathrm{CW}>\mathrm{CW} 2 \rightarrow \mathrm{VDES}=\mathrm{VDES} 2+\mathrm{VDESa} 1^{*}(\mathrm{CW}-\mathrm{CW} 2)
\end{aligned}
$$

Em que:

CW: largura do leito da via [m];

CW1: largura mínima para faixas simples;

VDES $_{\text {min: }}$ velocidade desejada mínima em via muito estreita (faixa simples);

CW2: largura mínima para vias de 2 faixas;

VDES2: velocidade desejada em vias de 2 faixas;

VDESa3: parâmetro relativo ao aumento da velocidade desejada em pista dupla com relação à pista simples $[\mathrm{m} / \mathrm{s}$ por metro de largura];

VDESa1: parâmetro relativo ao aumento da velocidade desejada em pistas com 2 ou mais faixas. 


$$
\begin{gathered}
V D E S a 3=\frac{\left(V D E S 2-V D E S_{\text {min }}\right)}{(C W 2-C W 1)} \\
V D E S_{\text {min }}=V D E S a 2 * V D E S 2
\end{gathered}
$$

VDESa2: taxa da velocidade desejada em faixa simples pela velocidade desejada em vias de 2 faixas.

Para cada tipo de superfície existe uma velocidade desejada. A velocidade desejada real é a mínima entre as velocidades desejadas e a velocidade limite regulamentada.

$$
V D E=\min \left[V D E 0, \frac{\text { PLIMIT } * \text { ENFAC }}{3,6}\right]
$$

Em que:

PLIMIT: velocidade limite regulamentada $[\mathrm{km} / \mathrm{h}]$

ENFAC: fator de regulamentação da velocidade [padrão $=1,10$ ]

- Cálculo da velocidade de operação dos veículos:

Para o cálculo da velocidade de operação dos veículos, é necessário calcular primeiramente a velocidade de congestionamento, que é a velocidade praticada pelos veículos devido ao aumento do fluxo de tráfego. Esta velocidade é modelada para cada período de fluxo de tráfego e é usada para o cálculo do consumo de combustível e do consumo de pneus.

- Velocidade de congestionamento:

A velocidade na capacidade nominal da via é igual a $85 \%$ da velocidade livre do tipo de veículo mais lento:

$$
V S_{\text {nотu }, d}=0,85 * M I N\left(V S_{k u, d}\right)
$$


Em que:

$\mathrm{VS}_{\text {nomu,d }}$ : velocidade na capacidade nominal na subida/descida $[\mathrm{m} / \mathrm{s}]$;

$\mathrm{VS}_{\mathrm{ku}, \mathrm{d}}$ : velocidade livre para o tipo de veículo $k$ na subida/descida $[\mathrm{m} / \mathrm{s}]$

A velocidade para a subida/descida, $\mathrm{V}_{\mathrm{u}, \mathrm{d}}$, para cada período de fluxo de tráfego $p$ e fluxo $Q_{p}$ é calculada por:

- para $\mathrm{Q}_{\mathrm{p}}<\mathrm{Q}_{\mathrm{o}} \quad \rightarrow \quad \mathrm{V}_{\mathrm{kpu}, \mathrm{d}}=\mathrm{VS}_{\mathrm{ku}, \mathrm{d}}$

- para $\mathrm{Q}_{\mathrm{o}} \leq \mathrm{Q}_{\mathrm{p}} \leq \mathrm{Q}_{\mathrm{nom}} \rightarrow \quad V_{k p u, d}=V S_{k u, d}-\left[\frac{\left(V S_{k u, d}-V S_{\text {поти }, d}\right) *\left(Q_{p}-Q_{o}\right)}{\left(Q_{\text {nот }}-Q_{o}\right)}\right]$

- para $\mathrm{Q}_{\mathrm{nom}} \leq \mathrm{Q}_{\mathrm{p}} \leq \mathrm{Q}_{\mathrm{ult}} \rightarrow \quad V_{\text {kpu,d }}=V S_{\text {nоти }, d}-\left[\frac{\left(V S_{\text {поти }, d}-V S_{\text {ult }}\right) *\left(Q_{p}-Q_{\text {nom }}\right)}{\left(Q_{\text {ult }}-Q_{\text {nom }}\right)}\right]$

Em que:

Q: nível de fluxo em que as interações do tráfego são insignificantes [PCSE/h];

$\mathrm{Q}_{\text {nom: }}$ capacidade nominal da via $[\mathrm{PCSE} / \mathrm{h}]$;

Qult: capacidade última da via para fluxo estável [PCSE/h];

PSCE: fator de equivalência ao espaço do veículo de passageiro.

A velocidade de congestionamento em cada período de fluxo de tráfego é ajustada por um fator de calibração da velocidade, CALBFAC, dependente do modelo de velocidade-fluxo:

$$
V_{k p u, d}=\operatorname{MAX}\left(V_{k p u, d} * C A L B F A C, V S_{u l t}\right)
$$

Em que:

CALBFAC: varia de 0,1 a 10 [padrão=1];

$\mathrm{VS}_{\text {ult }}$ : velocidade na capacidade última da via $[\mathrm{m} / \mathrm{s}]$.

A velocidade de congestionamento de equilíbrio média $\left(S_{\mathrm{kp}}\right)$ nos dois sentidos, isto é, considerando-se a média dos valores para a subida e a descida ("round trip"), em $\mathrm{km} / \mathrm{h}$, é dada por: 


$$
S_{k p}=\frac{7,2}{\left[\left(\frac{1}{V_{k p u}}\right)+\left(\frac{1}{V_{k p d}}\right)\right]}
$$

A velocidade de congestionamento é ajustada por um fator que considera a velocidade média no tempo (média aritmética da velocidade de todos os veículos passando num ponto da via por um período de tempo) ao invés da velocidade média no espaço (velocidade média de todos os veículos que ocupam uma seção da via por um período de tempo). Essa velocidade ajustada, chamada de velocidade de equilíbrio de operação dos veículos, é usada para o cálculo da utilização dos veículos, tempo de trabalho da tripulação, tempo de viagem dos passageiros e tempo de trânsito de cargas. É dada por:

$$
S S_{k p}=S_{k p} * S P E E D B I A S
$$

Em que:

$\mathrm{SS}_{\mathrm{kp}}$ : velocidade de operação dos veículos $[\mathrm{km} / \mathrm{h}]$ num período de fluxo de tráfego $p$; $\mathrm{S}_{\mathrm{kp}}$ : velocidade de congestionamento para o período de fluxo de tráfego $p$; SPEEDBIAS: fator de ajuste [padrão $=0,982174]$.

\subsubsection{Custo de operação dos veículos}

Os custos de operação dos veículos dependem dos tipos de veículos, do volume de tráfego, da geometria da via, da condição da superfície do pavimento e do comportamento do motorista. Portanto, alterações de projeto em qualquer destes parâmetros irão resultar em alterações nos custos de operação.

As características dos veículos consideradas são: atributos físicos (número de eixos, número de rodas etc.), características do desempenho (potência), da utilização do veículo e da vida útil. O HDM-III apresentava 10 veículos representativos para a análise, enquanto o HDM-4 é mais flexível, permitindo que possam ser realizadas análises com até 16 diferentes tipos de veículos. 
Os dados necessários sobre a geometria da via incluem os dados do alinhamento, velocidade limite, fator de atrito lateral, dimensões e número de faixas. Além disso, são necessários dados sobre a relação velocidade/fluxo (capacidade da via, parâmetros que determinam a velocidade de operação dos veículos e as características do fluxo), sobre o modelo de fluxo de tráfego, sobre a condição da via (irregularidade longitudinal do pavimento), sobre o tráfego (volume diário, composição e taxa de crescimento) e sobre os custos unitários (combustível, preço de veículos novos e de pneus etc.). Os componentes do custo de operação dos veículos são derivados do:

- consumo de combustível;

- consumo de óleo lubrificante;

- desgaste do pneu;

- consumo de peças;

- tempo para a realização de serviços de manutenção;

- custos do capital (depreciação e juros);

- hora do motorista e dos ajudantes (tripulação);

- custos gerais.

\subsubsection{Consumo de combustível}

O modelo do HDM-4 para o consumo de combustível é baseado no modelo mecanístico ARFCOM, desenvolvido por BIGGS (1988), que prevê que o consumo de combustível é dado em função da potência total requerida do motor, composta de três componentes:

- potência tratora: potência necessária para superar forças opostas ao movimento (i.e., forças que atuam no sentido contrário ao movimento dos veículos);

- arrasto do motor: potência necessária para superar o arrasto interno do motor (atrito);

- potência dos acessórios: potência necessária para fazer funcionar os acessórios do veículo (ar condicionado, alternador etc.).

Para cada tipo de veículo, $k$, o consumo de combustível é calculado para cada fluxo de tráfego, $p$, separadamente para subidas e descidas, e é feita a média dos resultados para a viagem nos dois sentidos (subida e descida, ou “round trip"). 
O procedimento computacional do modelo segue as seguintes etapas:

- Para cada tipo de veículo e cada período de fluxo de tráfego calculam-se:

- a potência total requerida pelo motor para subida e para descida;

- o fator de eficiência combustível por potência para subida e para descida;

- o consumo de combustível instantâneo para subida e para descida;

- o consumo de combustível específico para a viagem toda.

- Para cada tipo de veículo calcula-se o consumo de combustível médio anual.

Cálculo do consumo de combustível instantâneo na subida e na descida:

$$
I F C_{k p u, d}=\max \left[I F_{k}, Z_{k p u, d} * P T O T_{k p u, d} *\left(1+d F_{k p u, d}\right)\right]
$$

Em que:

IFC $_{\mathrm{kpu}, \mathrm{d}}$ : consumo de combustível instantâneo [ml/s];

$\mathrm{IF}_{\mathrm{k}}$ : taxa de consumo inerente (fixo) de combustível para o tipo de veículo $\mathrm{k}[\mathrm{ml} / \mathrm{s}]$;

$Z_{\mathrm{kpu}, \mathrm{d}}$ : fator de eficiência combustível pela potência na subida e descida do tipo de veículo $\mathrm{k}[\mathrm{ml} / \mathrm{kW} / \mathrm{s}]$;

PTOT $_{\mathrm{kpu}, \mathrm{d}}$ : potência total requerida para o movimento em equilíbrio [kW];

$\mathrm{dF}_{\mathrm{kpu}, \mathrm{d}}$ : fator de consumo de combustível adicional devido a ciclos de variação da velocidade (aceleração e desaceleração). No cálculo do consumo instantâneo para a velocidade de equilíbrio, $\mathrm{dF}$ é igual a zero.

Cálculo da potência necessária:

A potência necessária deve ser calculada separadamente para subidas e descidas.

- Potência tratora:

$$
P T R_{k p}=\left(\frac{F T R_{k p} * V_{k p}}{1000}\right)
$$


$\mathrm{PTR}_{\mathrm{kp}}$ : potência tratora para veículo do tipo $\mathrm{k}$ durante período de fluxo de tráfego $\mathrm{p}$ $[\mathrm{kW}]$;

$\mathrm{FTR}_{\mathrm{kp}}$ : resistência total ao movimento em equilíbrio do veículo do tipo $\mathrm{k}$ durante período de fluxo de tráfego $\mathrm{p}[\mathrm{kW}]$;

$\mathrm{V}_{\mathrm{kp}}$ : velocidade do veículo do tipo $\mathrm{k}$ durante período de fluxo de tráfego $\mathrm{p}[\mathrm{m} / \mathrm{s}]$;

O valor da resistência total ao movimento é dado por:

$$
F T R_{k p u, d}=F A_{u, d}+F G_{u, d}+F R_{u, d}+F C V_{u, d}
$$

Sendo:

FA: resistência aerodinâmica [N];

FG: resistência de rampa $[\mathrm{N}]$;

FR: resistência ao rolamento [N];

FCV: resistência de curvatura $[\mathrm{N}]$.

As equações das resistências são:

o Resistência aerodinâmica:

$$
F A=0,5 * R H O * C D_{\text {mult }} * C D * A F * V_{k p}^{2}
$$

o Resistência de rampa:

$$
F G=W_{o p} * g * G R
$$

Na subida, o valor de GR é positivo; na descida, negativo.

o Resistência ao rolamento:

$$
F R=F C L * C R 2 *\left(b 11 * N W+C R 1 * b 12 * W_{o p}+C R 1 * b 13 * V_{k p}{ }^{2}\right)
$$

o Resistência de curvatura: 


$$
F C V=\left\{\frac{\left(\max \left[0,\left(\frac{W_{o p} * V_{k p}^{2}}{R}-W_{o p} * g * e\right)\right]^{2}\right)}{\frac{(N W * C S)}{1000}}\right\}
$$

Em que:

e: superelevação (fração);

CS: rigidez lateral dos pneus ("cornering stiffness”).

Sendo:

$$
C S=K_{c s} *\left[C S a 0+\frac{C S a 1 * W_{o p}}{N W}+C S a 2 *\left(\frac{W_{o p}}{N W}\right)^{2}\right]
$$

Em que:

$\mathrm{K}_{\mathrm{cs}}$ : fator de rigidez do pneu;

CSa0, CSa1 e CSa2: parâmetros do modelo.

o Resistência à inércia:

$$
F I=W_{o p} * E M R A T * A C C
$$

Sendo:

$$
E M R A T=E M R A T a 0+E M R A T a 1 * \operatorname{arctg}\left(\frac{E M R A T a 2}{V_{k p}{ }^{3}}\right)
$$

Em que:

EMRATa0, EMRATa1 e EMRATa2: parâmetros de resistência à inércia; ACC: aceleração do veículo $\left[\mathrm{m} / \mathrm{s}^{2}\right]$

- Potência consumida pelo motor e pelos acessórios:

$$
P E A_{k p}=K_{p e a} * P R A T_{k} *\left[P A_{c s} a 1+\frac{\left(P A_{c s} a 0-P A_{c s} a 1\right) *\left(R P M_{k p}-R P M_{i d}\right)}{R P M 100-R P M_{i d}}\right]
$$


Em que:

$\mathrm{PEA}_{\mathrm{kp}}$ : potência total consumida pelo motor e pelos acessórios [kW];

$\mathrm{K}_{\text {pea }}$ : fator de calibração para PEA;

PRAT: máxima potência do motor $[\mathrm{kW}]$;

RPM: velocidade do motor [revoluções/min];

$\mathrm{RPM}_{\mathrm{id}}$ : velocidade inerente (fixa) do motor [revoluções/min];

RPM100: velocidade do motor a $100 \mathrm{~km} / \mathrm{h}$ [revoluções/min];

$\mathrm{PA}_{\mathrm{cs}} \mathrm{a} 0$ e $\mathrm{PA}_{\mathrm{cs}} \mathrm{a}$ 1: parâmetros do modelo.

Sendo:

$$
P A_{c s} a 1=\frac{\left(-b+\sqrt{b^{2}-4 a c}\right)}{2 a}
$$

Em que:

$$
\begin{aligned}
& a=Z_{b} * E H P * K_{p e a}^{2} * P R A T *\left(\frac{100-P T P e}{100}\right) \\
& b=Z_{b} * K_{p e a} * P R A T \\
& c=-I F
\end{aligned}
$$

$\mathrm{Z}_{\mathrm{b}}$ : fator de eficiência combustível-potência $[\mathrm{ml} / \mathrm{kW} / \mathrm{s}]$;

EHP: diminuição na eficiência do motor quando produz potência maior;

$\mathrm{PTP}_{\mathrm{e}}$ : porcentagem da potência total produzida pelo motor [padrão=80].

O RPM depende da velocidade do veículo:

$\mathrm{Se}$

$$
\begin{aligned}
& \mathrm{V}_{\mathrm{kp}} \leq 5,6 \mathrm{~m} / \mathrm{s}(20 \mathrm{~km} / \mathrm{h}) \rightarrow R P M_{k p}=R P M a 0+5,6 * R P M a 1+31,36 * R P M a 2 \\
& \mathrm{~V}_{\mathrm{kp}} \leq \mathrm{RPMa} 3 \rightarrow R P M_{k p}=R P M a 0+R P M a 1 * V_{k p}+R P M a 2 * V_{k p}{ }^{2} \\
& \mathrm{~V}_{\mathrm{kp}}>\mathrm{RPMa} 3 \rightarrow \\
& \qquad R M_{k p}=\frac{\left(R P M a 0+R P M a 1 * R P M a 3+R P M a 2 * R P M a 3^{2}\right) * V_{k p}}{R P M a 3}
\end{aligned}
$$

O valor de RPM100 é dado por:

Se $27,8 \leq \mathrm{RPMa} 3 \rightarrow R P M 100=R P M a 0+27,8 * R P M a 1+27,8^{2} * R P M a 2$ 


$$
\text { Senão } \rightarrow R P M 100=\frac{\left(R P M a 0+R P M a 1 * R P M a 3+R P M a 2 * R P M a 3^{2}\right) * 27,8}{R P M a 3}
$$

Potência total requerida:

$$
\begin{aligned}
& \text { Se } \quad \mathrm{PTR}_{\mathrm{kp}} \geq 0 \rightarrow \mathrm{PTOT}_{k p}=\left(\frac{P T R_{k p}}{E D T}+P E A_{k p}\right) \\
& \mathrm{PTR}_{\mathrm{kp}}<0 \rightarrow \mathrm{PTOT}_{k p}=\left(P T R_{k p} * E D T+P E A_{k p}\right)
\end{aligned}
$$

- Fator de eficiência:

O fator de eficiência relaciona o consumo de combustível instantâneo com a potência total requerida. É calculado separadamente para subidas e descidas:

$$
Z_{k p u, d}=Z_{b} *\left\{1+E H P *\left[\frac{P T O T_{k p u, d}-P T P_{e} * P E A_{k p u, d} / 100}{P R A T_{k}}\right]\right\}
$$

- Consumo adicional de combustível:

O consumo adicional de combustível é estimado utilizando o modelo de simulação ACCFUEL, apresentado em BENNETT (1996). É dado em função do ruído da aceleração e da velocidade média do veículo:

$$
S_{k p u, d}=3,6 * V_{k p u, d}
$$

O consumo de combustível por 1000 veículo-km é:

$$
\begin{gathered}
S F C_{k p}=500 *\left[\frac{I F C_{k p u}}{V_{k p u}}+\frac{I F C_{k p d}}{V_{k p d}}\right] \\
F C_{k p}=S F C_{k p} * \text { FUELBIAS }
\end{gathered}
$$

Em que:

$\mathrm{FC}_{\mathrm{kp}}$ : consumo de combustível [1/1000 veíc-km];

FUELBIAS: fator de ajuste. 
A corrente de tráfego é formada por veículos a diferentes velocidades e, portanto, a diferentes taxas de consumo. Uma vez que o consumo de combustível não varia linearmente com a velocidade, usa-se o fator de ajuste:

$$
\text { FUELBIAS }=\max \left(\mathrm{dF}, 1-0,0182 * \mathrm{COV}+0,7319 * \mathrm{COV}^{2}\right)
$$

- Consumo de combustível médio anual:

$$
F C_{k a v}=\frac{\sum_{p=1}^{n} H R Y R_{p} * H V_{p} * F C_{k p}}{\sum_{p=1}^{n} H R Y R_{p} * H V_{p}}
$$

Em que:

$\mathrm{FC}_{\text {kav }}$ : consumo de combustível médio anual [litros/1000 veíc-km];

$H_{R Y R}$ : número de horas no período $p$ de fluxo de tráfego;

$\mathrm{HV}_{\mathrm{p}}$ : fluxo de tráfego horário (proporção do VDM);

$\mathrm{FC}_{\mathrm{kp}}$ : consumo de combustível do veículo $k$ durante o período de fluxo de tráfego $p$.

\subsubsection{Consumo de óleo lubrificante}

O modelo usado para prever o consumo de óleo lubrificante é baseado num modelo desenvolvido por Pienaar (1984), que divide o consumo em dois componentes: perda de óleo devido à contaminação, em função da distância entre trocas de óleo (em quilômetros), e devido à operação dos veículos, em função do consumo de combustível (consumo médio anual).

\subsubsection{Consumo de pneus}

O modelo de consumo de pneus é baseado no modelo usado no HDM-III, que prevê que o consumo é proporcional à energia utilizada, em função das forças que atuam em cada roda do veículo (forças radial, lateral e normal). A taxa de consumo é expressa em termos no número equivalente de pneus novos consumidos por 1000 veículos-km para cada roda. 
O consumo de pneus sofre influência da irregularidade longitudinal do pavimento, do tipo de pneu e do tráfego. A geometria da via também tem influência indireta no consumo uma vez que, no cálculo das forças que atuam nas rodas, estão presentes os parâmetros relacionados à resistência de rampa e à resistência de curvatura, já descritas no item 3.6.2.1 deste trabalho.

\subsubsection{Utilização dos veículos}

Os cálculos da utilização e da vida útil dos veículos são necessários para o cálculo do consumo de peças, dos custos do capital e dos custos gerais. A utilização do veículo é expressa em termos da quilometragem anual percorrida durante o tempo de utilização dos veículos em serviço e depende do número de horas de serviço e da idade dos veículos. A vida útil, dada pelo método de vida útil ótima, depende da distância anual percorrida pelos veículos e também da irregularidade longitudinal do pavimento.

\subsubsection{Consumo de peças}

O consumo de peças constitui um componente importante dos custos de operação dos veículos. O modelo considera os efeitos da idade dos veículos, da irregularidade longitudinal do pavimento e dos ciclos de variação da velocidade (acelerações e desacelerações, devido ao congestionamento do tráfego, do traçado da via, da presença de veículos não-motorizados, de atritos laterais e do comportamento dos motoristas). Este fator adicional devido à variação da velocidade é semelhante ao fator utilizado no cálculo do consumo de combustível e é indexado a ele (isto é, para consumo adicional de combustível há um consumo adicional proporcional de peças).

\subsubsection{Horas de trabalho de manutenção}

As horas de trabalho de manutenção de cada tipo de veículo, calculadas em função do consumo de peças, permitem o cálculo dos custos de manutenção dos veículos.

\subsubsection{Custos do capital}

Os custos do capital compreendem os custos de depreciação e dos juros (remuneração do capital), representando um importante componente do custo de operação dos veículos. O método de cálculo da depreciação de vida útil constante leva em conta o número de horas em serviço, a velocidade de operação e o valor residual dos veículos (valor dos veículos ao final de sua vida útil que, por sua vez, sofre influência da 
irregularidade longitudinal da via). A remuneração do capital consiste na receita que teria sido recebida se o capital investido no veículo tivesse sido aplicado em outro investimento. É aplicado um fator de juros que leva em conta o número de horas em serviço e a velocidade de operação dos veículos.

\subsubsection{Horas da tripulação}

Os custos da tripulação (motorista e ajudantes) são obtidos pelo produto do número de horas de trabalho da tripulação pela taxa a ser paga para ela. O número de horas necessárias por 1000 veículos-quilômetro para cada tipo de veículo, durante cada período de fluxo de tráfego, é calculado em função da velocidade de operação dos veículos.

\subsubsection{Custos gerais}

Os custos gerais correspondem aos custos de administração, seguros, estacionamento e demais custos relacionados à posse de veículos. Eles são calculados em função da utilização anual dos veículos e da velocidade de operação média.

\subsubsection{Tempo de viagem}

$\mathrm{Na}$ composição do custo total dos usuários está presente, além do custo de operação dos veículos, o custo relacionado ao tempo de viagem, que é o tempo gasto por passageiros e cargas durante as viagens.

\subsubsection{Tempo de viagem dos passageiros}

O número de horas de viagem de passageiros é calculado como uma função da velocidade de operação para cada tipo de veículo, durante cada período de fluxo de tráfego, e é calculada separadamente para viagens de passageiros durante horas em serviço e fora de horas em serviço.

\subsubsection{Tempo de trânsito de cargas}

O tempo de trânsito de cargas refere-se ao número de horas gastas pelo veículo para o transporte das cargas. É calculado como uma função da velocidade de operação de cada veículo, durante cada período de fluxo de tráfego. 


\subsection{ESCOLHA DAS ALTERNATIVAS DE INVESTIMENTOS}

O HDM-4 permite que seja feita a escolha da alternativa de investimento mais vantajosa entre as opções competitivas, com a avaliação do desempenho de cada investimento através de indicadores econômicos como o Valor Presente Líquido, a Taxa Interna de Retorno e da Relação Benefício-Custo.

\subsubsection{Valor Presente Líquido}

O Valor Presente Líquido (VPL) de um projeto de investimento é igual ao valor presente de suas entradas de caixa menos o valor presente de suas saídas de caixa. Para cálculo do valor presente das entradas e saídas de caixa é utilizada a Taxa Mínima de Atratividade (TMA) como taxa de desconto. O valor presente líquido calculado para um projeto significa o somatório do valor presente das parcelas periódicas de lucro econômico gerado ao longo da vida útil desse projeto, ou seja, agrega-se em um único índice as correntes de benefícios e custos e determina, para cada alternativa, os recursos necessários na data presente que cubram todos os custos do investimento proposto para o período de projeto analisado. O lucro econômico pode ser definido como a diferença entre a receita e o custo operacional acrescido do custo de oportunidade do investimento. O VPL tem sido o critério de investimento mais importante em decisões de investimentos públicos.

$$
V P L=\sum_{t=0}^{T}\left(B_{t}-C_{t}\right) *(1+r)^{-t}
$$

Em que:

$\mathrm{T}$ : período de projeto (anos);

$\mathrm{B}_{\mathrm{t}}$ : quantidade de benefícios no ano $\mathrm{t}$;

$\mathrm{C}_{\mathrm{t}}$ : quantidade de custos no ano $\mathrm{t}$;

r: taxa de desconto.

Um projeto de investimento pode ter um Valor Presente Líquido que seja maior do que zero, o que significa que o investimento é economicamente atrativo pois o valor presente das entradas de caixa é maior do que o valor presente das saídas de caixa; igual a zero, no qual o investimento é indiferente pois o valor presente das entradas de caixa é 
igual ao das saídas; menor do que zero, que indica que o investimento não é economicamente atrativo porque o valor presente das entradas de caixa é menor do que o das saídas. Entre vários projetos de investimento, o mais atrativo é aquele que tem maior Valor Presente Líquido.

\subsubsection{Taxa Interna de Retorno}

A Taxa Interna de Retorno (TIR) é o percentual de retorno obtido sobre o saldo investido e ainda não recuperado em um projeto de investimento. Matematicamente, a TIR é a taxa de juros que torna o valor presente das entradas de caixa igual ao valor das saídas de caixa do projeto de investimento, ou seja, determina a taxa que equilibra os custos e benefícios em um problema econômico. É freqüentemente usada pelo Banco Mundial em análises de financiamentos de projetos de infra-estrutura em países em desenvolvimento. É dada por:

$$
\sum_{t=0}^{T}\left(B_{t}-C_{t}\right) *(1+i)^{-t}=0
$$

Em que i: taxa interna (TIR)

A Taxa Interna de Retorno de um investimento pode ser maior do que a Taxa Mínima de Atratividade, o que significa que o investimento é economicamente atrativo; igual a TMA, que indica que o investimento está economicamente numa situação de indiferença; ou menor do que a TMA, quando o investimento não é economicamente atrativo, pois seu retorno é superado pelo retorno de um investimento sem risco. Entre vários investimentos, o melhor será aquele que tiver a maior Taxa Interna de Retorno.

\subsubsection{Relação Benefício-Custo}

A relação expressa o valor comparativo de projetos pela relação entre benefícios e custos anuais. 


$$
B / C=\frac{\sum_{t=0}^{T} B_{t}(1+r)^{-t}}{\sum_{t=0}^{T} C_{t}(1+r)^{-t}}
$$

Para a escolha dos melhores investimentos, seguem-se algumas regras simples apresentadas por LELEUR (1995):

TABELA 10 - Regras para a escolha de investimentos.

\begin{tabular}{lcc}
\hline \multicolumn{1}{c}{ Tipo de decisão } & Restrição orçamentária & Critério \\
\hline Aceitação do projeto & - & VPL $>0$ \\
\hline Escolha de 1 entre vários projetos aceitos & - & Máximo VPL \\
\hline Escolha de alguns entre vários projetos & Sim & Hierarquização usando B/C >1 \\
& Não & Hierarquização usando VPL $>0$ \\
\hline
\end{tabular}

Fonte: Modificada de Leleur (1995).

\subsection{RELATÓRIOS DO HDM-4}

O HDM-4 gera relatórios com os resultados da simulação sobre:

- Tráfego: fornece o volume diário médio, o número de solicitações do eixo padrão etc.;

- Condição das rodovias: fornece a evolução dos diferentes tipos de deterioração, em função da estratégia de manutenção considerada;

- Manutenção das rodovias: fornece os custos de cada atividade de manutenção realizada;

- Custos dos usuários: fornece a velocidade dos veículos e os custos dos componentes operacionais dos veículos;

- Efeitos ambientes: fornece a emissão de poluentes;

- Resumo da análise econômica: fornece comparações entre alternativas de projetos em função dos indicadores econômicos (VPL, TIR, B/C). 


\section{Capítulo 4}

\section{Estudo de caso}

Este capítulo apresenta um estudo de caso que foi realizado durante a pesquisa, com o objetivo de fornecer resultados que permitissem a análise da influência das características geométricas de rodovias no custo total dos usuários, em termos do custo de operação dos veículos e do tempo de viagem, através de simulação com o HDM-4.

O estudo de caso permitiu a quantificação dos efeitos das características geométricas sobre todas as parcelas que compõem os custos dos usuários. Além disso, o estudo de caso permitiu que fossem calculados os custos de terraplenagem para diferentes geometrias verticais com a finalidade de comparação dos custos de possíveis melhorias no projeto de rodovias existentes com os benefícios decorrentes das intervenções.

\subsection{SELEÇÃO E DEFINIÇÃO DE TRECHOS RODOVIÁRIOS}

Para que pudesse ser analisada a influência da geometria nos custos totais dos usuários, foram criados ou selecionados trechos de rodovias, agrupados de acordo com suas características de projeto de curvas verticais e horizontais.

\subsubsection{Definição de trechos para a análise de sensibilidade (trechos "fictícios")}

Foram criados trechos (chamados neste trabalho de trechos "fictícios", apenas para identificação) para a análise da sensibilidade dos parâmetros geométricos, mantendo-se o valor de um componente igual a zero e variando-se o outro. Nos trechos $a$ a $h$ da Tabela 11 há variação do parâmetro RF, enquanto nos trechos $i$ a $r$ ocorre variação do parâmetro ADC. Além disso, foi considerado um trecho que possui os dois 
componentes iguais a zero (Trecho Base), representando um trecho totalmente reto $(\mathrm{ADC}=0)$ e plano $(\mathrm{RF}=0)$.

Deve-se destacar que os intervalos de variação dos parâmetros RF e ADC englobam os valores considerados pelo HDM-4 para classificação dos trechos quanto à geometria (Tabelas 9 e 12).

TABELA 11 - Trechos "fictícios" para a análise de sensibilidade.

\begin{tabular}{ccc|ccc}
\hline Trechos & $\begin{array}{c}\text { Subidas e } \\
\text { Descidas - RF } \\
(\mathbf{m} / \mathbf{k m})\end{array}$ & $\begin{array}{c}\text { Curvatura } \\
\text { horizontal - ADC } \\
(\mathbf{g r a u s} / \mathbf{k m})\end{array}$ & Trechos & $\begin{array}{c}\text { Subidas e } \\
\text { Descidas - RF } \\
(\mathbf{m} / \mathbf{k m})\end{array}$ & $\begin{array}{c}\text { Curvatura } \\
\text { horizontal - ADC } \\
\text { (graus/km) }\end{array}$ \\
\hline Base & 0 & 0 & $\mathbf{i}$ & 0 & 50 \\
$\mathbf{a}$ & 5 & 0 & $\mathbf{j}$ & 0 & 100 \\
$\mathbf{b}$ & 10 & 0 & $\mathbf{k}$ & 0 & 150 \\
$\mathbf{c}$ & 15 & 0 & $\mathbf{1}$ & 0 & 200 \\
$\mathbf{d}$ & 20 & 0 & $\mathbf{m}$ & 0 & 250 \\
$\mathbf{e}$ & 25 & 0 & $\mathbf{n}$ & 0 & 300 \\
$\mathbf{f}$ & 30 & 0 & $\mathbf{0}$ & 0 & 350 \\
$\mathbf{g}$ & 35 & 0 & $\mathbf{p}$ & 0 & 400 \\
$\mathbf{h}$ & 40 & 0 & $\mathbf{q}$ & 0 & 450 \\
& & & $\mathbf{r}$ & 0 & 500 \\
\hline
\end{tabular}

\subsubsection{Trechos representativos das classes do HDM-4}

Para este estudo, foram criados sete trechos (trechos $A$ a $G$, Tabela 12), que representam as sete classes de geometria padronizadas pelo HDM-4 (Tabela 9) e levam em conta a combinação dos efeitos da curvatura vertical e horizontal.

\subsubsection{Seleção de trechos da rodovia SP-310}

Foram selecionados quatro trechos ao longo da Rodovia Washington Luiz (SP-310), que foi considerada a segunda melhor do país, de acordo com a Pesquisa Rodoviária CNT 2004, sendo que na edição de 2003 ela havia sido considerada a melhor. Procurou-se escolher trechos em que eram evidentes as diferenças quanto a declividade e a sinuosidade, visando-se analisar as influências dessas características nos resultados do estudo. 
TABELA 12 - Trechos representativos das classes de geometria do HDM-4.

\begin{tabular}{clcc}
\hline \multicolumn{2}{c}{ Classes da Geometria } & $\begin{array}{c}\text { Subidas e } \\
\text { Descidas - RF (m/km) }\end{array}$ & $\begin{array}{c}\text { Curvatura Horizontal - } \\
\text { ADC (graus/km) }\end{array}$ \\
\hline A & Reta e Plana & 1 & 3 \\
\hline B & $\begin{array}{l}\text { Praticamente Reta e } \\
\text { Pouco Ondulada }\end{array}$ & 10 & 15 \\
\hline C & $\begin{array}{l}\text { Pouco Sinuosa e } \\
\text { Praticamente Plana }\end{array}$ & 3 & 50 \\
\hline D & $\begin{array}{l}\text { Pouco Sinuosa e } \\
\text { Pouco Ondulada }\end{array}$ & 15 & 75 \\
\hline E & $\begin{array}{l}\text { Pouco Sinuosa e } \\
\text { Muito Ondulada }\end{array}$ & 25 & 150 \\
\hline F & $\begin{array}{l}\text { Sinuosa e } \\
\text { Pouco Ondulada }\end{array}$ & 20 & 300 \\
\hline G & $\begin{array}{l}\text { Sinuosa e } \\
\text { Muito Ondulada }\end{array}$ & 40 & 500 \\
\hline
\end{tabular}

Os dados da geometria horizontal foram obtidos através da planta da rodovia e os dados da geometria vertical através do seu perfil longitudinal. Com o auxílio de diretores da empresa concessionária da rodovia, foram obtidos também os dados relativos ao número e largura de faixas, largura do acostamento, limites de velocidade etc. A Tabela 13 apresenta os dados obtidos para cada trecho da rodovia.

O trecho 1 é um trecho praticamente reto e com poucas curvas verticais. Os trechos 2 e 3 são trechos sinuosos e montanhosos, que correspondem às duas pistas de uma mesma seção da rodovia - um trecho em aclive (pista norte) e outro em declive (pista sul) e que foram selecionados para que pudessem ser analisadas possíveis diferenças de resultados entre trechos com características geométricas semelhantes, porém com diferentes sentidos de tráfego (subida e descida). O trecho 4 é um trecho com pouca sinuosidade e pouca ondulação, considerado intermediário entre o trecho 1 e os trechos 2 e 3.

\subsection{DEFINIÇÃO DO CENÁRIO}

Definiu-se o cenário específico dos trechos estudados, composto pelas características da rede viária, pelas características do pavimento e condições de sua superfície, pelos dados da geometria dos trechos (exceto RF e ADC) e pela composição da frota de veículos. As Figuras 8 a 11 apresentam as telas do HDM-4 nas quais são inseridos os 
dados de entrada do programa, que serão mantidos constantes em todas as avaliações dos efeitos dos parâmetros geométricos RF e ADC.

TABELA 13 - Dados dos trechos da rodovia SP-310 selecionados.

\begin{tabular}{|c|c|c|c|c|}
\hline TRECHO & 1 & 2 & 3 & 4 \\
\hline \multicolumn{5}{|c|}{ Dados da Via } \\
\hline Início (Km) & 217 & 194 & 194 & 187 \\
\hline Fim (Km) & 227 & 197 & 197 & 194 \\
\hline Pista & Sul & Norte (Subida) & Sul (Descida) & Norte \\
\hline Sentido & Interior-Capital & Capital-Interior & Interior-Capital & Capital-Interiol \\
\hline Comprim. total (Km) & 10 & 3 & 3 & 7 \\
\hline \multicolumn{5}{|c|}{ Geometria Horizontal } \\
\hline$\Sigma$ AC & 4,1694 & 359,5597 & 337,6158 & 253,7486 \\
\hline ADC (graus / Km) & 0०25'1" & 119051'12" & $112^{\circ} 32^{\prime} 19^{\prime \prime}$ & $36^{\circ} 14^{\prime} 59^{\prime \prime}$ \\
\hline \multicolumn{5}{|c|}{ Geometria Vertical } \\
\hline $\begin{array}{l}\text { Média das subidas e } \\
\text { descidas }(\mathrm{m} / \mathrm{Km})\end{array}$ & 4,5 & 30 & 30 & 13 \\
\hline $\begin{array}{l}\text { N. }{ }^{\circ} \text { médio de subidas } \\
\text { e descidas } / \mathrm{Km}\end{array}$ & 1 & 3 & 3 & 1 \\
\hline \multicolumn{5}{|c|}{ Composição do Tráfego } \\
\hline Automóvel Médio (\%) & 64,2 & 59,2 & 65,1 & 60,2 \\
\hline Caminhão Leve (\%) & 22,4 & 25,5 & 21,8 & 24,9 \\
\hline Caminhão Pesado (\%) & 9,0 & 10,2 & 8,7 & 9,9 \\
\hline Ônibus Pesado (\%) & 4,5 & 5,1 & 4,4 & 5,0 \\
\hline Total & 100,0 & 100,0 & 100,0 & 100,0 \\
\hline \multicolumn{5}{|c|}{ Volume Diário Médio Anual } \\
\hline Automóvel Médio & 2128 & 2423 & 2071 & 2366 \\
\hline Caminhão Leve & 855 & 969 & 827 & 941 \\
\hline Caminhão Pesado & 6089 & 5623 & 6184 & 5718 \\
\hline Ônibus Pesado & 428 & 485 & 418 & 475 \\
\hline Total & 9500 & 9500 & 9500 & 9500 \\
\hline \multicolumn{5}{|c|}{ Dados Geométricos } \\
\hline N..$^{\circ}$ de faixas & 2 & 3 & 3 & 2 \\
\hline Largura da faixa $(m)$ & 3,50 & 3,50 & 3,50 & 3,50 \\
\hline $\begin{array}{l}\text { Largura do } \\
\text { acostamento (m) }\end{array}$ & 2,80 & 2,80 & 2,80 & 2,80 \\
\hline \multicolumn{5}{|c|}{ Velocidade Máxima $(\mathrm{Km} / \mathrm{h})$} \\
\hline Automóvel médio & 110 & 90 & 80 & 110 \\
\hline Caminhão Leve & 90 & 90 & 60 & 90 \\
\hline Caminhão Pesado & 90 & 90 & 60 & 90 \\
\hline Ônibus & 90 & 90 & 60 & 90 \\
\hline
\end{tabular}

a) Rede viária:

- Classe da rodovia: Especial;

- Tipo de fluxo: 2 faixas padrão;

- Modelo de fluxo de tráfego: Velocidade livre; 
- Classe da superfície do pavimento: Betuminosa;

- Tipo de pavimento: Mistura asfáltica sobre base granular;

- Largura do leito da via: 7 metros;

- Largura dos acostamentos: 2,8 metros;

- Volume diário médio: 9500 veículos;

- Direção do fluxo: nos dois sentidos (média de subida e descida).

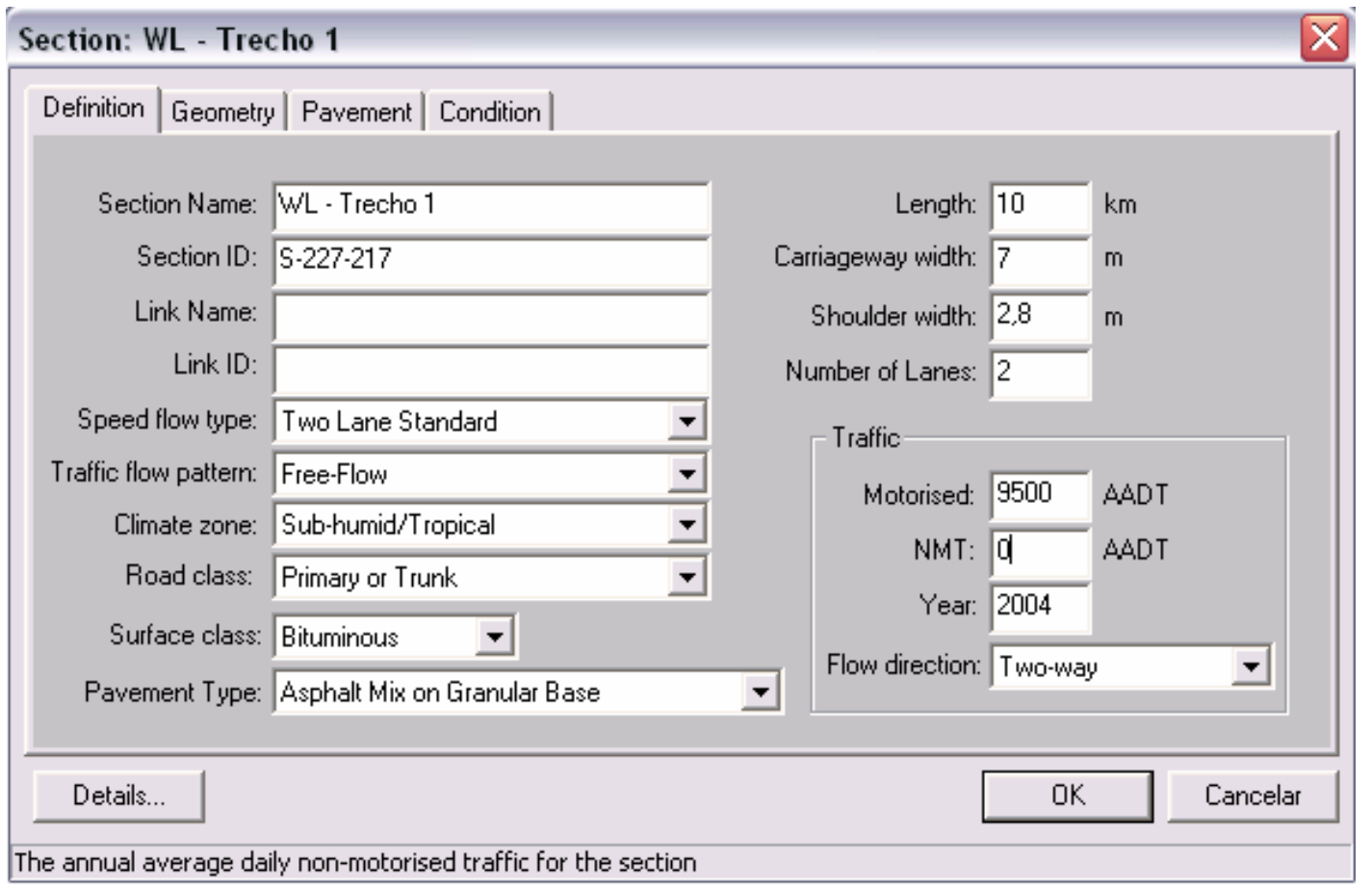

FIGURA 08 - Inserção dos dados referentes ao cenário considerado no estudo de caso.

b) Características do pavimento:

- Superfície:

- Tipo de material: concreto asfáltico;

- Espessura da camada atual: $50 \mathrm{~mm}$;

- Espessura da camada anterior: $50 \mathrm{~mm}$;

- Intervenções no pavimento: foi considerado que a data da última atividade de manutenção e/ou reabilitação realizada nos trechos foi em 2003.

- Resistência estrutural: foi definido um valor para o número estrutural, SNP, igual a 5,0, que é um valor padrão do HDM-4 para uma boa condição estrutural, e um valor de CBR (Índice de Suporte Califórnia) igual a 20\% para o subleito. 


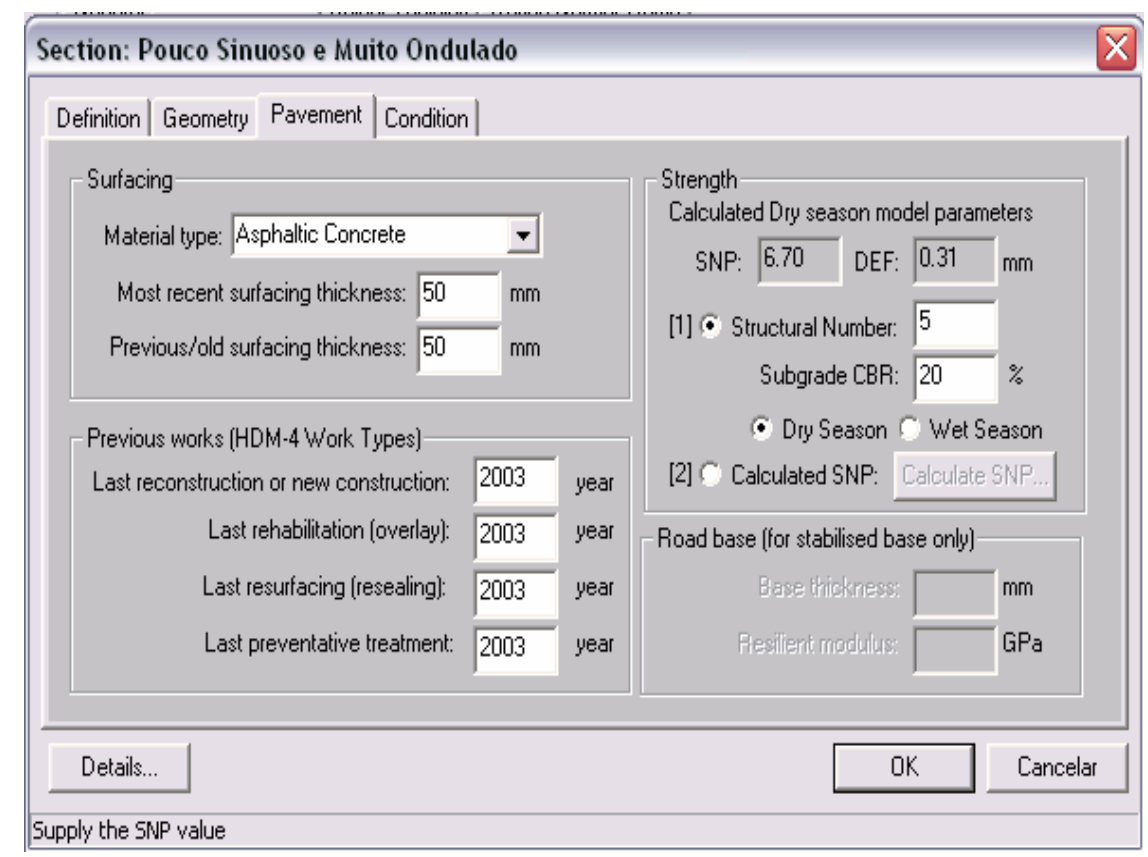

FIGURA 09 - Inserção dos dados referentes ao pavimento.

- Condição da superfície do pavimento: os valores admitidos correspondem aos valores considerados pelo HDM-4 para um pavimento recém-construído, em ótimas condições:

- IRI inicial (em 2004): $2 \mathrm{~m} / \mathrm{km}$;

- Área total de trincas: $0 \%$;

- Área de desgaste: $0 \%$;

- Número de panelas: 0 n. $\% / \mathrm{km}$;

- Área de trinca nos bordos: $0 \mathrm{~m}^{2} / \mathrm{km}$;

- Profundidade da trilha de roda: $0 \mathrm{~mm}$;

- Profundidade da textura: 0,70 mm;

- Resistência ao deslizamento: 0,50.

Apesar de especificado um valor de irregularidade inicial - IRI - igual a 2, o HDM-4 realiza sua simulação com um valor de IRI igual a 4,69, provavelmente porque o programa considera que ocorre uma deterioração no pavimento entre o ano cuja condição do pavimento foi fornecida (2004) e o ano em que se inicia a simulação (2005). De qualquer forma, um valor de IRI igual a 4,69 é considerado bom para as condições das rodovias brasileiras. 


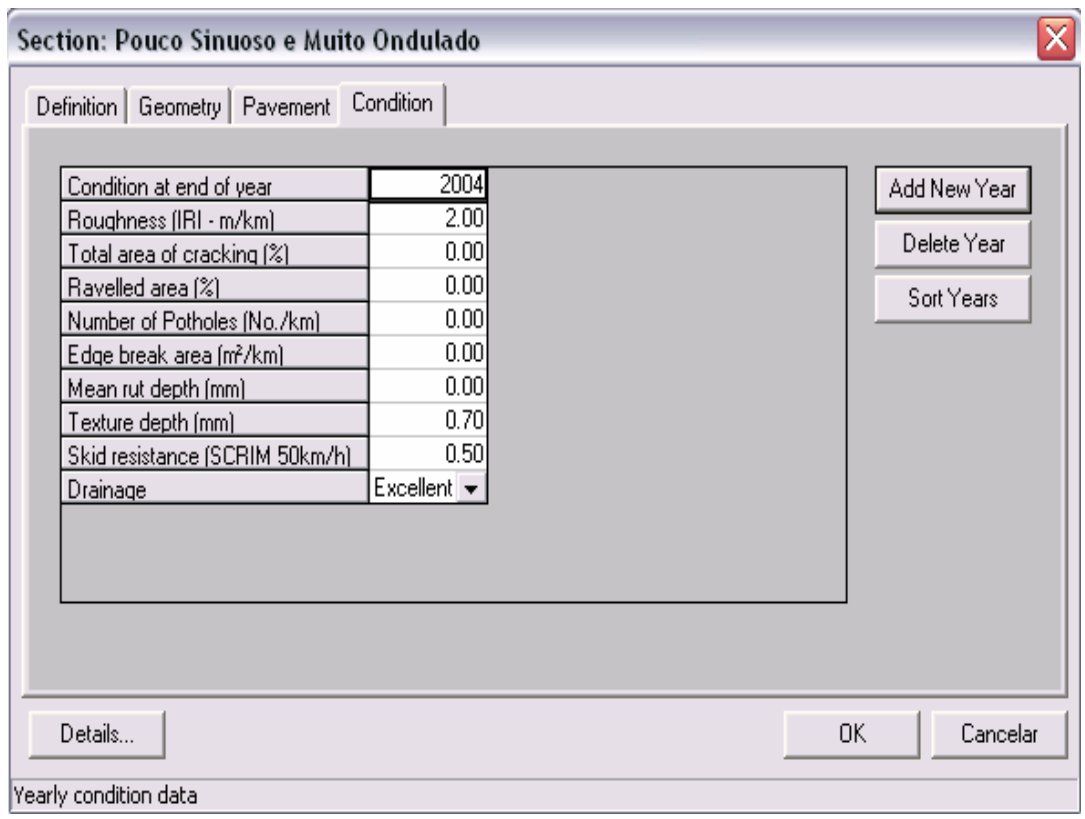

FIGURA 10 - Inserção dos dados referentes à condição do pavimento.

c) Dados da geometria:

Nesta tela do programa são inseridos os dados referentes à geometria de cada trecho rodoviário: a quantidade de subidas e descidas $(\mathrm{RF})$ e a curvatura horizontal média (ADC), além da altitude do trecho - que foi adotada comum a todos os trechos e igual a 790 metros (é um valor médio aproximado da altitude dos trechos selecionados na SP310) - e dos efeitos da drenagem, que não foram considerados na simulação.

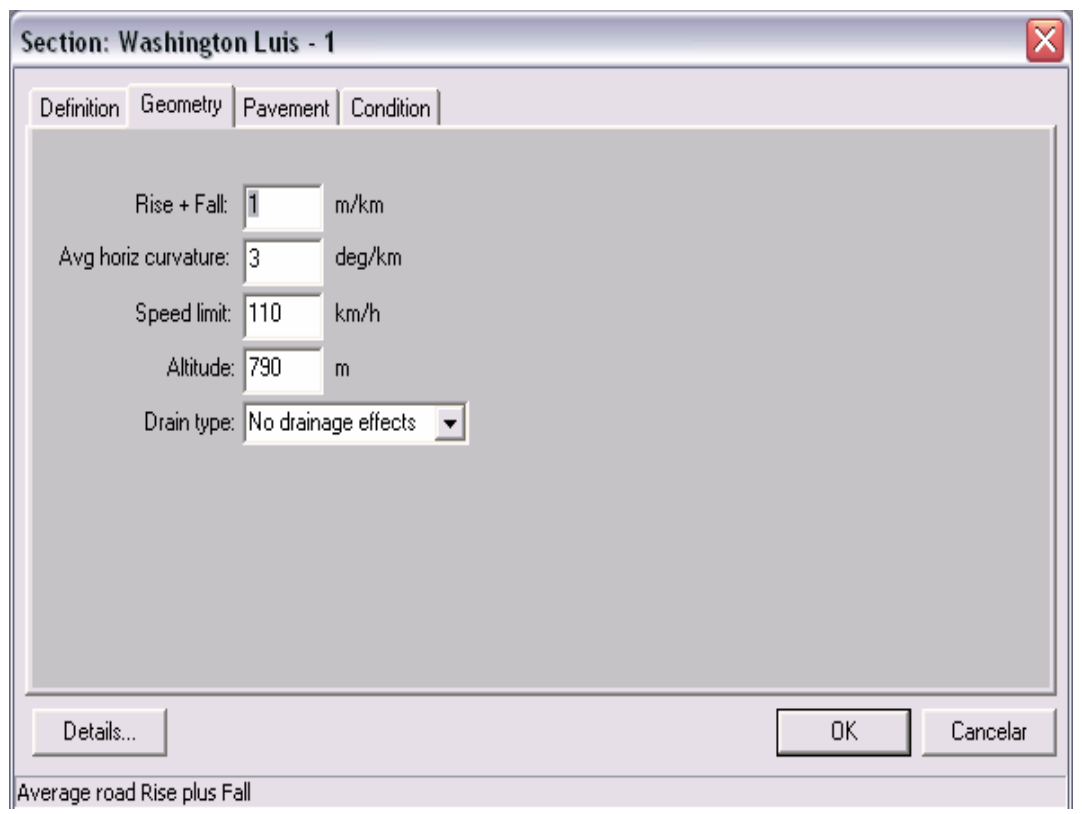

FIGURA 11 - Inserção dos dados referentes à geometria. 
d) Frota de veículos:

Dentre as dezesseis opções fornecidas pelo HDM-4, foram escolhidos quatro tipos de veículos que podem representam uma hipotética composição de tráfego para os trechos: automóvel médio, caminhão leve, caminhão pesado e ônibus pesado. Com relação às porcentagens da composição, foram feitas estimativas baseadas em números reais obtidos para cada trecho da SP-310 durante o período entre janeiro e outubro de 2004.

As composições dos tráfegos dos trechos representativos das classes do HDM-4 e dos trechos fictícios foram adotadas como sendo iguais à composição do trecho 1 da SP310, tendo-se verificado, também, pequena diferença nos percentuais das composições dos trechos 1 a 4 . A Tabela 14 apresenta as características dos veículos escolhidos para comporem a frota de veículos.

TABELA 14 - Características dos veículos.

\begin{tabular}{|c|c|c|c|c|}
\hline & $\begin{array}{l}\text { Automóvel } \\
\text { médio (CM) }\end{array}$ & $\begin{array}{l}\text { Caminhão } \\
\text { Leve (CL) }\end{array}$ & $\begin{array}{c}\text { Caminhão } \\
\text { Pesado (CP) }\end{array}$ & $\begin{array}{c}\text { Ônibus } \\
\text { Pesado (OP) }\end{array}$ \\
\hline Tipo padrão do HDM & Medium car & Truck - light & Truck - heavy & Bus - heavy \\
\hline Classe & Carro passageiro & Caminhões & Caminhões & Ônibus \\
\hline Categoria & Motorizado & Motorizado & Motorizado & Motorizado \\
\hline Número de eixos & 2 & 2 & 3 & 3 \\
\hline Número de rodas & 4 & 4 & 10 & 10 \\
\hline Tipo de pneu & radial & diagonal & diagonal & diagonal \\
\hline Peso de operação (t) & 1,2 & 2 & 13 & 10 \\
\hline ESALF $^{(1)}$ & 0 & 0,1 & 2,28 & 0,8 \\
\hline PCSE ${ }^{(2)}$ & 1 & 1,3 & 1,6 & 1,6 \\
\hline
\end{tabular}

(1) Equivalent Standard Axles Load Factor = fator de equivalência de cargas.

(2) Passenger Car Space Equivalent = fator de equivalência ao espaço do veículo de passageiro.

Fonte: Modificada de KERALI et al. (2000).

Para as simulações, foram considerados tipos de veículos e valores de seus respectivos custos unitários (custos de veículos novos, trocas de pneus, custos de combustível e óleo lubrificante, gastos gerais e custos de horas de manutenção, de viagem de passageiros e de cargas) de um dos exemplos apresentados pelo HDM-4. Tais valores, mostrados nas Tabelas 14 e 15, são utilizados neste trabalho apenas com a finalidade de estudar situações hipotéticas com as quais podem ser feitas comparações entre diferentes tipos de veículos, para determinadas condições de rodovias. 
TABELA 15 - Custos unitários dos veículos.

\begin{tabular}{|c|c|c|c|}
\hline \multicolumn{4}{|c|}{ Caminhão Leve } \\
\hline Veículo novo: & US\$ 30000 & Manutenção: & US\$ 5,60 p/ hora \\
\hline Troca de pneu: & US\$ 300 & Tripulação: & US\$ $8,90 \mathrm{p} /$ hora \\
\hline Combustível: & US\$ $0,50 \mathrm{p} /$ litro & Gastos gerais: & US\$ $800 \mathrm{p} /$ ano \\
\hline Óleo lubrificante: & US\$ $2 \mathrm{p} /$ litro & & \\
\hline Passageiro em serviço: & US\$ $0 \mathrm{p} /$ hora & Carga: & US\$ $0,40 \mathrm{p} /$ hora \\
\hline Passageiro: & US\$ $0 \mathrm{p} /$ hora & & \\
\hline \multicolumn{4}{|c|}{ Caminhão Pesado } \\
\hline Veículo novo: & US\$ 75000 & Manutenção: & US\$ 5,60 p/ hora \\
\hline Troca de pneu: & US\$ 300 & Tripulação: & US\$ $8,90 \mathrm{p} /$ hora \\
\hline Combustível: & US\$ $0,50 \mathrm{p} /$ litro & Gastos gerais: & US\$ $800 \mathrm{p} /$ ano \\
\hline Óleo lubrificante: & US\$ $2 \mathrm{p} /$ litro & & \\
\hline Passageiro em serviço: & US\$ $0 \mathrm{p} /$ hora & Carga: & US\$ $0,10 \mathrm{p} /$ hora \\
\hline Passageiro: & US\$ $0 \mathrm{p} /$ hora & & \\
\hline \multicolumn{4}{|c|}{ Automóvel Médio } \\
\hline Veículo novo: & US\$ 9000 & Manutenção: & US\$ $4,20 \mathrm{p} /$ hora \\
\hline Troca de pneu: & US\$ 60 & Tripulação: & US\$ $0 \mathrm{p} /$ hora \\
\hline Combustível: & US\$ $0,50 \mathrm{p} /$ litro & Gastos gerais: & US\$ $400 \mathrm{p} /$ ano \\
\hline Óleo lubrificante: & US\$ $2 \mathrm{p} /$ litro & & \\
\hline Passageiro em serviço: & US\$ $0,40 \mathrm{p} /$ hora & Carga: & US\$ $0 \mathrm{p} /$ hora \\
\hline Passageiro: & US\$ $0,10 \mathrm{p} /$ hora & & \\
\hline \multicolumn{4}{|c|}{ Ônibus Pesado } \\
\hline Veículo novo: & US\$ 70000 & Manutenção: & US\$ 5,60 p/ hora \\
\hline Troca de pneu: & US\$ 350 & Tripulação: & US\$ $8,90 \mathrm{p} /$ hora \\
\hline Combustível: & US\$ $0,50 \mathrm{p} /$ litro & Gastos gerais: & US\$ $800 \mathrm{p} /$ ano \\
\hline Óleo lubrificante: & US\$ $2 \mathrm{p} /$ litro & & \\
\hline Passageiro em serviço: & US\$ $0,25 \mathrm{p} /$ hora & Carga: & US\$ $0,10 \mathrm{p} /$ hora \\
\hline Passageiro: & US\$ $0,10 \mathrm{p} /$ hora & & \\
\hline
\end{tabular}

\subsection{CONFIGURAÇÃO DA SIMULAÇÃO}

Alguns parâmetros precisam ser definidos para que o programa possa realizar as simulações, dentre eles o ano de início, o período de projeto, a unidade monetária e as alternativas de intervenções do projeto. Diante disso, tem-se:

- Ano de início da simulação: 2005; 
- Período de projeto: foi considerado um período de projeto de 1 ano, uma vez que a análise realizada não necessita considerar a evolução das condições do tráfego e do pavimento ao longo do tempo;

- Unidade monetária: dólar;

- Alternativas de intervenções: foram criadas apenas duas alternativas de manutenção e, em ambas, a única atividade a ser executada foi a limpeza da superfície da rodovia que, para não interferir nos custos, teve custo zero.

Ainda durante a configuração, foram desativados os modelos de acidentes e de emissão de poluentes, uma vez que os seus respectivos custos não foram considerados na composição do custo total dos usuários porque haveria a necessidade da obtenção e da calibração dos dados referentes ao número e à gravidade dos acidentes e aos tipos e quantidades de poluentes emitidos pelos veículos, bem como seus respectivos custos. Ressalta-se que, quando houver a disponibilidade desses dados, estes fatores devem ser incluídos na simulação, pois podem sofrer influência da geometria.

As Figuras 12 a 14 mostram as telas do HDM-4 nas quais são inseridos os dados referentes à configuração geral necessária para a simulação.

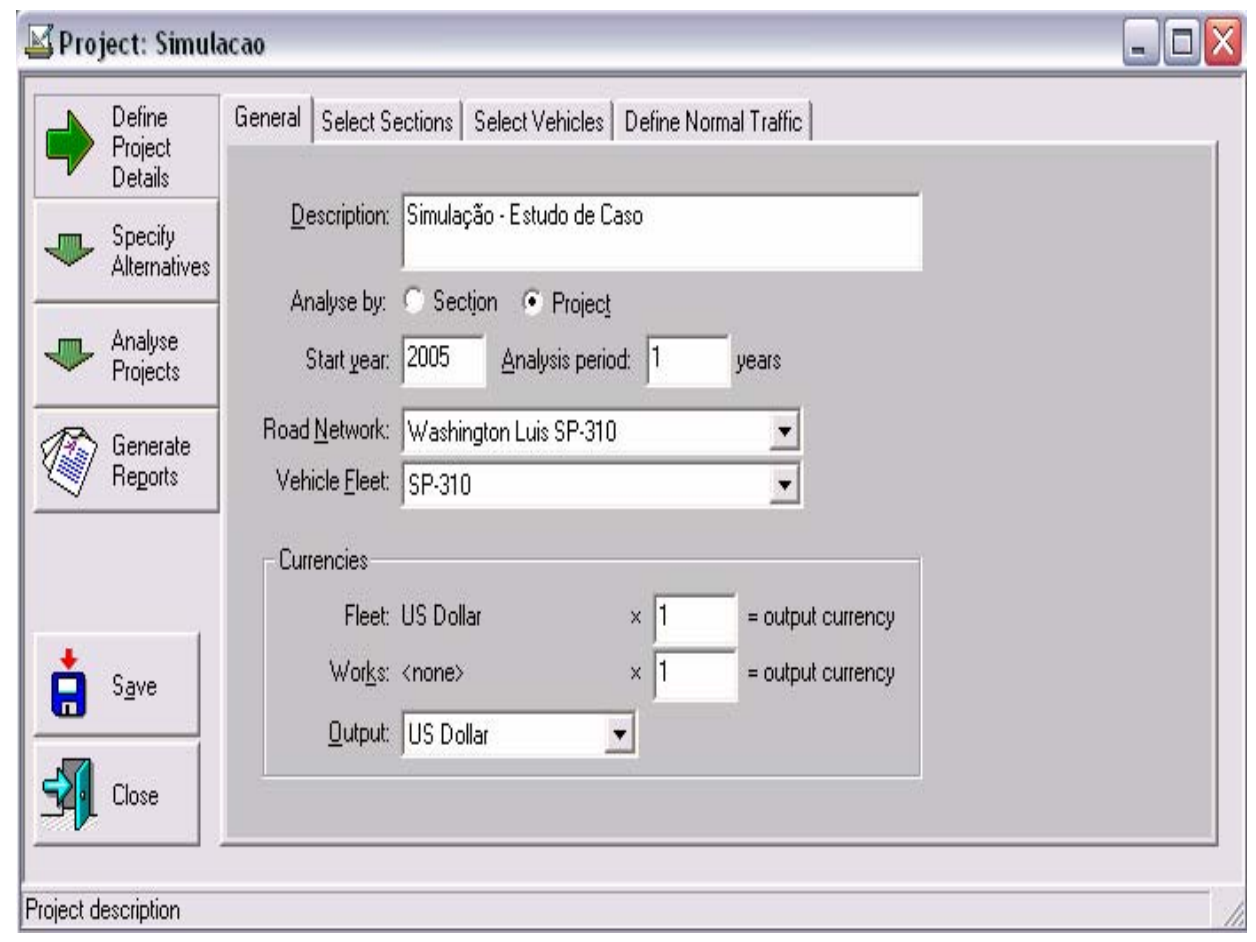

FIGURA 12 - Configuração da simulação. 


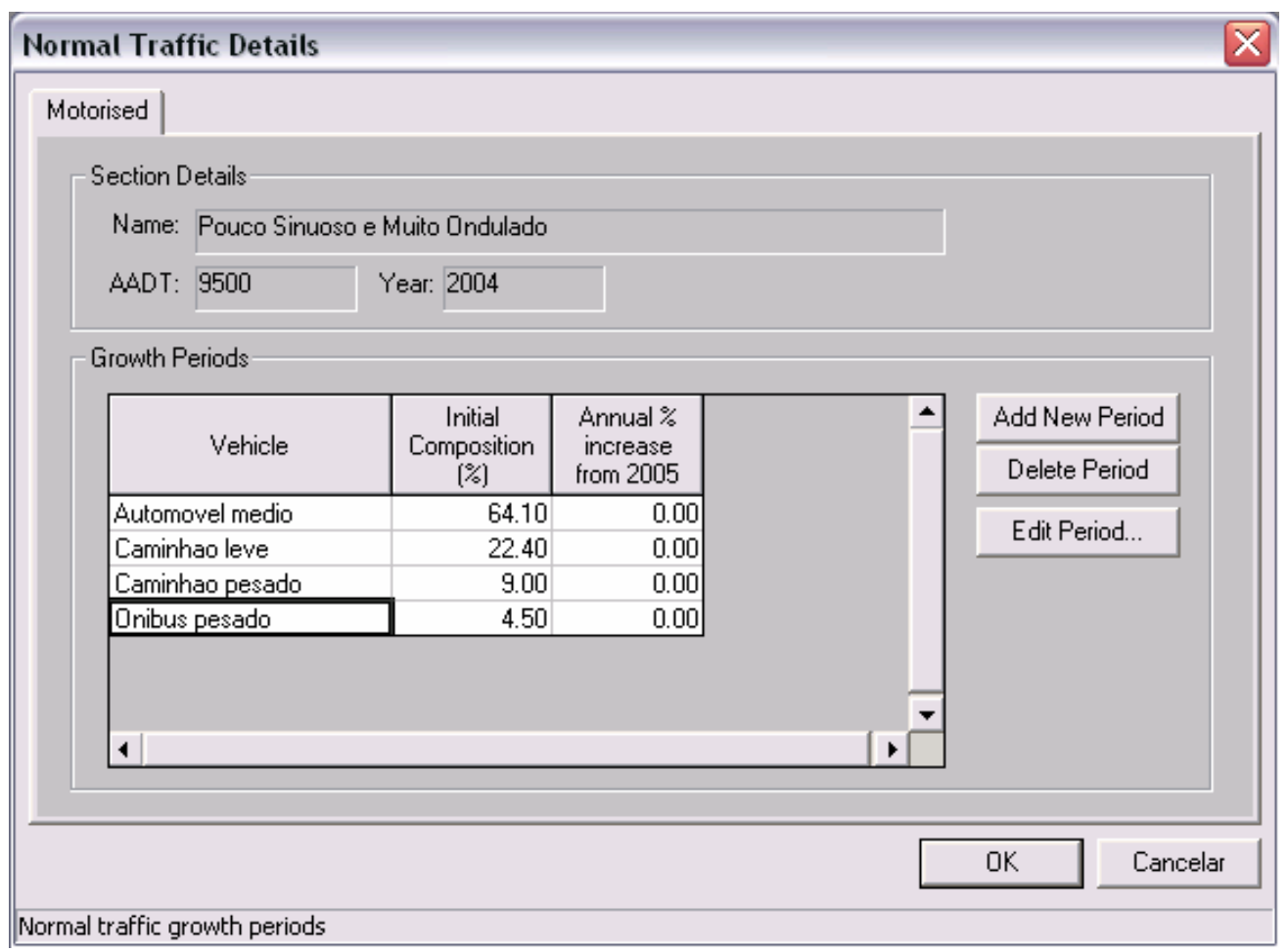

FIGURA 13 - Inserção da composição do tráfego.

Observa-se, na Figura 13, que não foi especificada a taxa de crescimento anual do tráfego dos veículos (Annual \% increase from 2005) pois, como o período de projeto estipulado é de apenas um ano, este dado não é necessário.

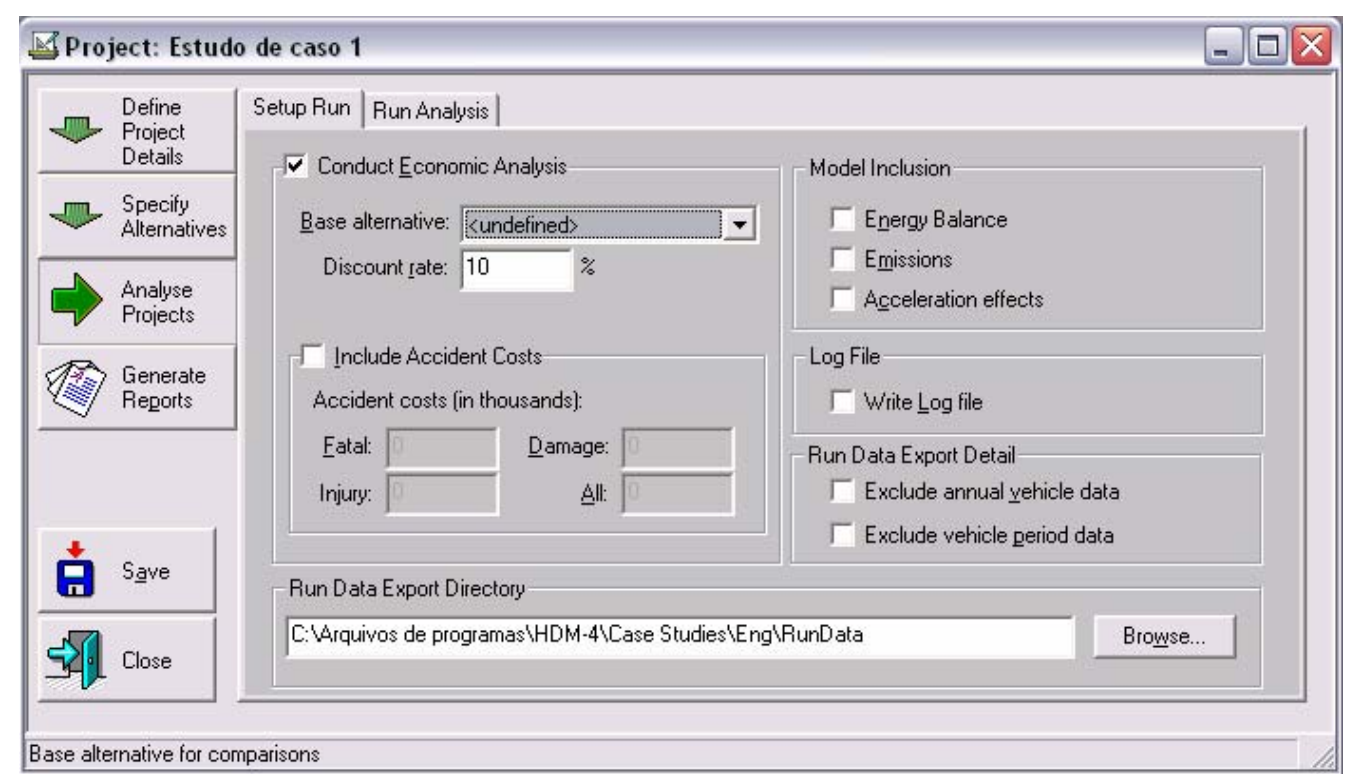

FIGURA 14 - Configuração da análise econômica, de custos de acidentes e de modelos a serem incluídos na simulação. 
Após a inserção de todos os dados de entrada do programa é realizada a simulação (Figura 15), que demora alguns segundos e fornece os relatórios com os resultados.

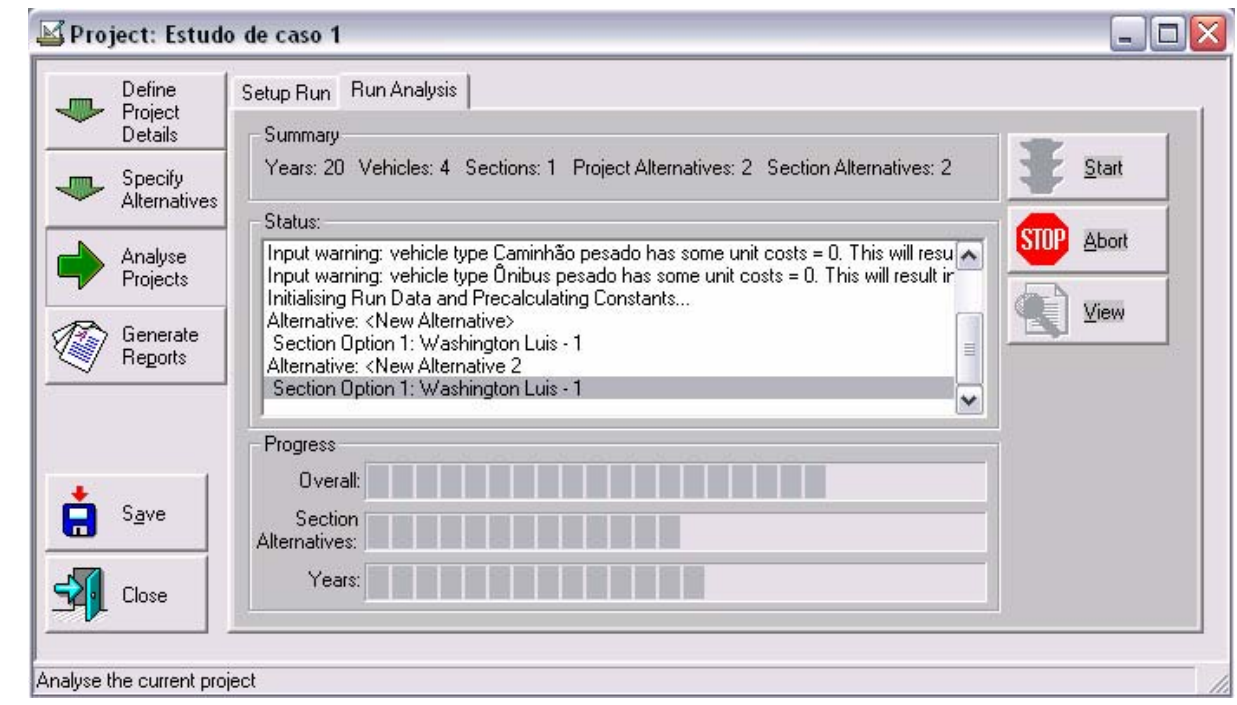

FIGURA 15 - Simulação do HDM-4 sendo executada.

\subsection{CUSTOS DE TERRAPLENAGEM E PAVIMENTAÇÃO PARA ALTERAÇÃO DO TRAÇADO DE TRECHOS DE RODOVIAS}

Para fins de comparação dos custos de alterações no projeto de curvas verticais com os benefícios que cada novo traçado poderia trazer aos usuários, foram calculados os custos de terraplenagem e de um novo pavimento para geometrias verticais hipotéticas, representativas de traçados de rodovias com valores de RF variando de 0 a $40 \mathrm{~m} / \mathrm{km}$.

Para o cálculo dos volumes de terraplenagem tomou-se como referência o trecho $h$, que possui a maior média de subidas e descidas $(\mathrm{RF}=40 \mathrm{~m} / \mathrm{km})$. Foi considerado um mesmo projeto de curvas horizontais para todos os trechos. Estes trechos têm uma extensão de $10 \mathrm{~km}$ e admitiu-se que todos eles apresentam duas rampas ascendentes e duas descendentes, com distância de $2,5 \mathrm{~km}$ entre os pontos de intersecção das rampas (PIV). Portanto, a distância vertical entre PIVs adjacentes (altura a ser vencida pela rampa) varia de $100 \mathrm{~m}$, para o trecho com $\mathrm{RF}$ igual a $40 \mathrm{~m} / \mathrm{km}$, até $0 \mathrm{~m}$ para o trecho com RF igual a zero (Figuras 16 e 17). As seções transversais de cortes e de aterros, utilizadas para o cálculo dos volumes, são mostradas na Figura 18. 

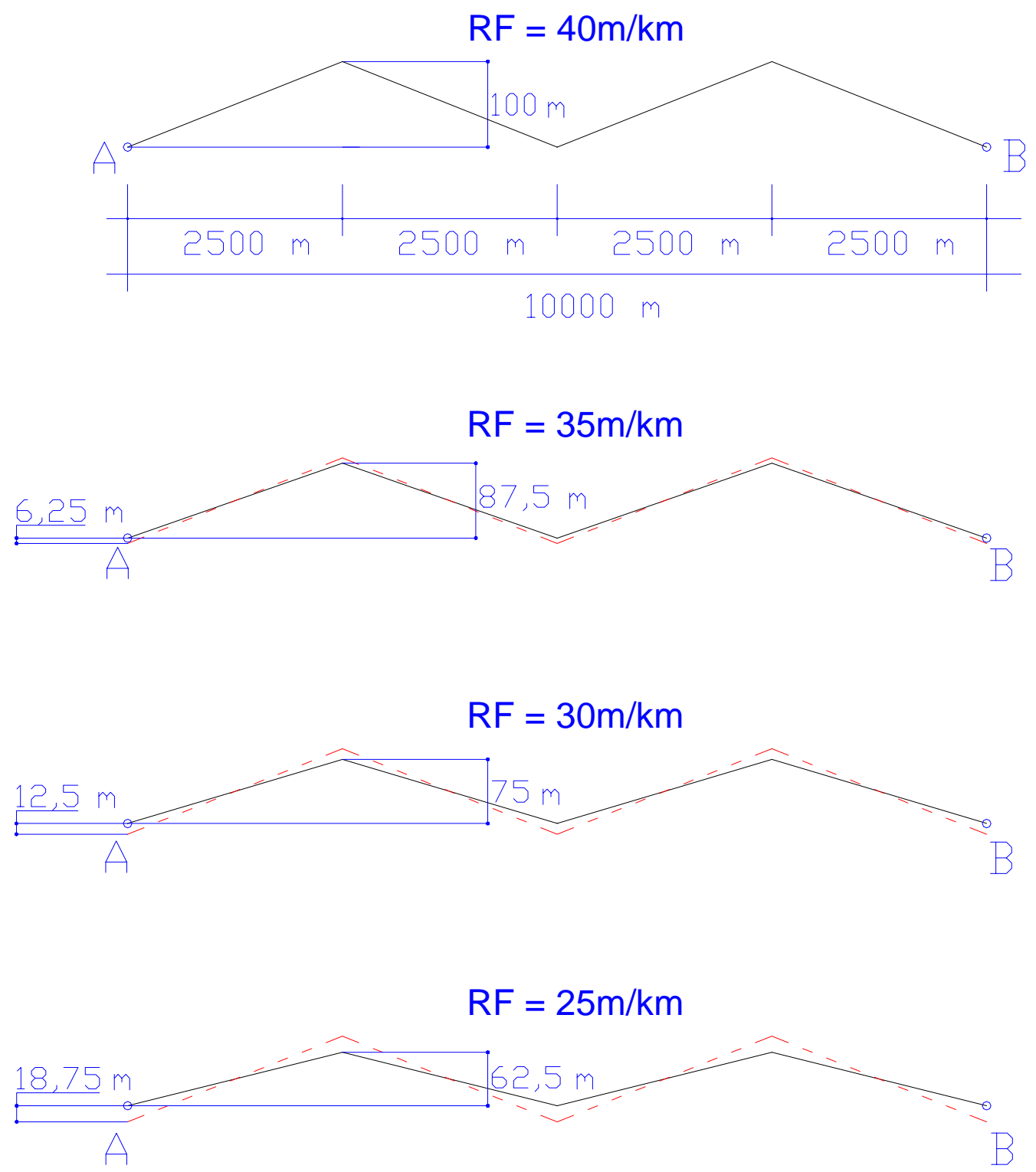

FIGURA 16 - Perfis longitudinais dos trechos de RF=40 m/km , RF=35 m/km, $R F=30 \mathrm{~m} / \mathrm{km}$ e $R F=25 \mathrm{~m} / \mathrm{km}$. 


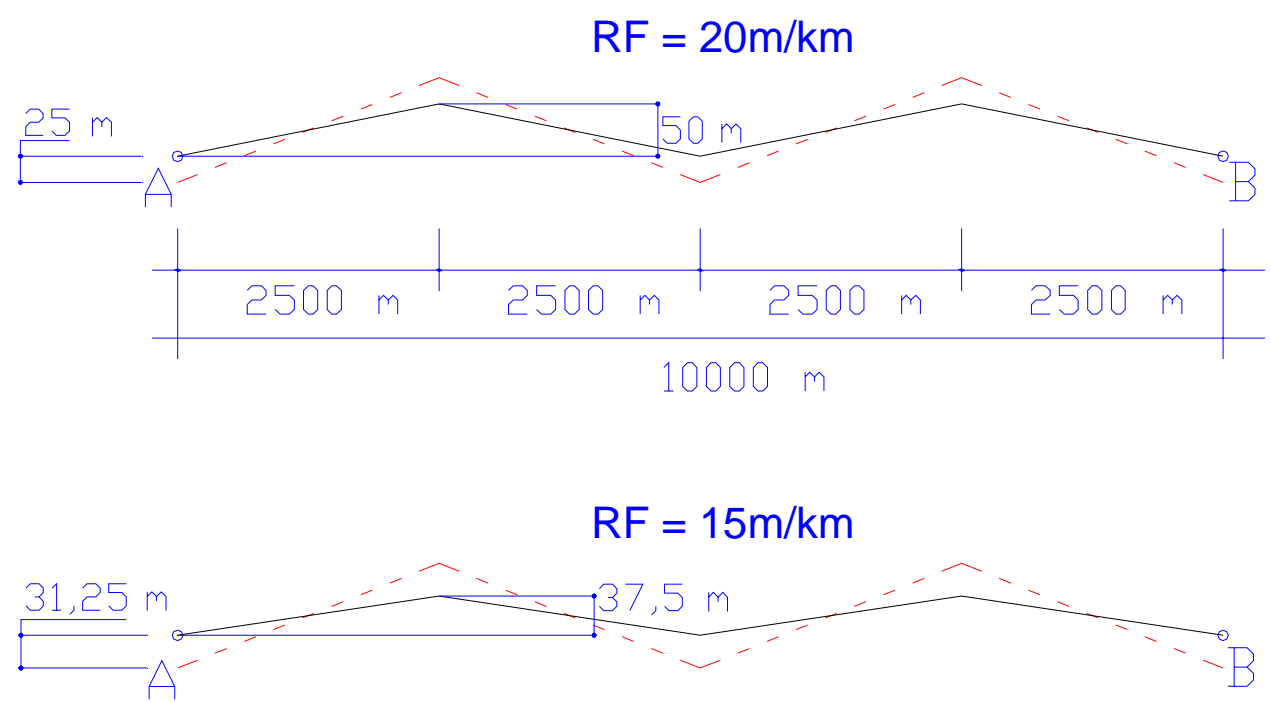

$\mathrm{RF}=10 \mathrm{~m} / \mathrm{km}$

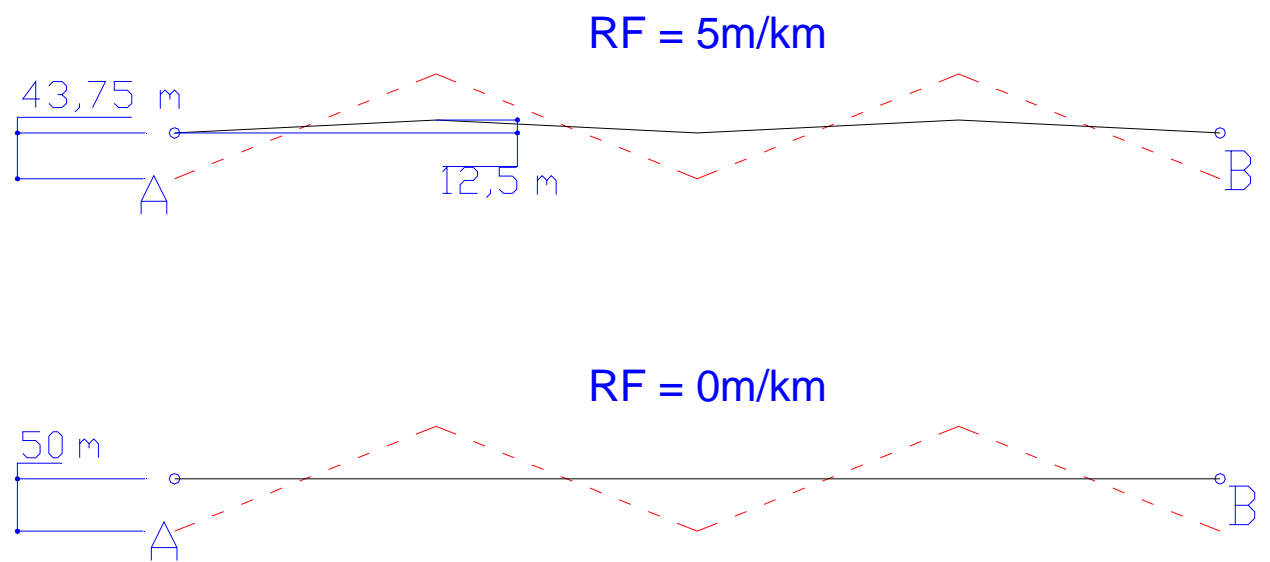

FIGURA 17 - Perfis longitudinais dos trechos de $R F=20$ m/km , RF=15 m/km, $\mathrm{RF}=10 \mathrm{~m} / \mathrm{km}, \mathrm{RF}=5 \mathrm{~m} / \mathrm{km}$ e $\mathrm{RF}=0 \mathrm{~m} / \mathrm{km}$. 


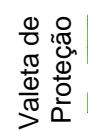

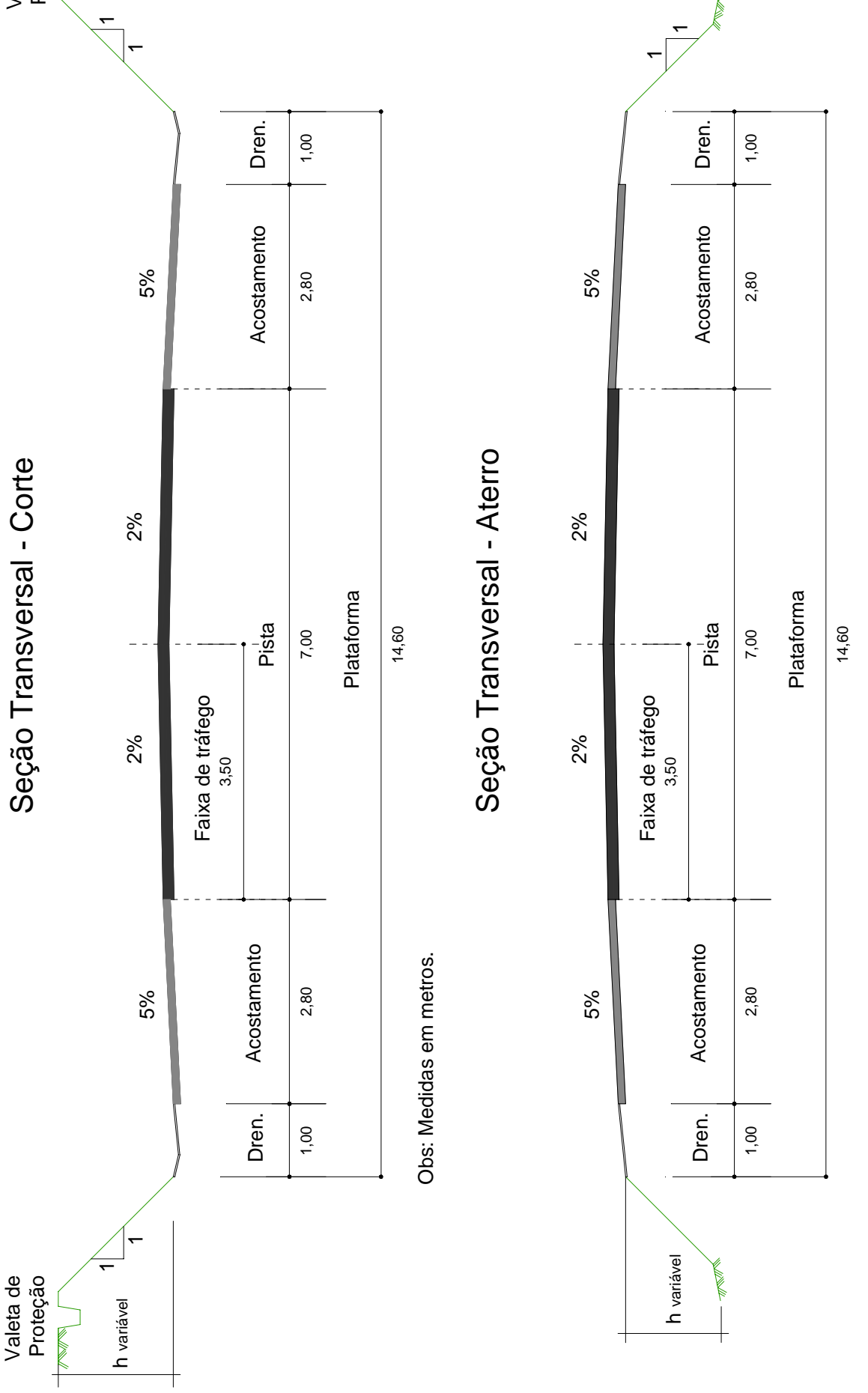


Os custos de movimentação de terra e de pavimentação fornecem uma estimativa dos custos da reconstrução do traçado de cada trecho, em relação ao trecho com RF igual a $40 \mathrm{~m} / \mathrm{km}$. Conforme a Figura 19, o projeto do novo pavimento considerou uma camada de concreto asfáltico usinado a quente (CAUQ) de $10 \mathrm{~cm}$, uma base de brita graduada simples (BGS) de $25 \mathrm{~cm}$, uma sub-base de solo arenoso fino laterítico (SAFL) de $30 \mathrm{~cm}$ e um reforço do subleito (Rf) de $20 \mathrm{~cm}$. A Tabela 16 mostra os custos unitários dos serviços de terraplenagem (de escavação, transporte e compactação do solo) e de pavimentação, de acordo com a Tabela de Preços Unitário de Serviços e Obras do Departamento de Estradas de Rodagem do Estado de São Paulo, de 31 de dezembro de 2004 (DER-SP, 2004). A distância média de transporte do solo escavado nos cortes para ser compactado nos aterros é de $1,25 \mathrm{~km}$.

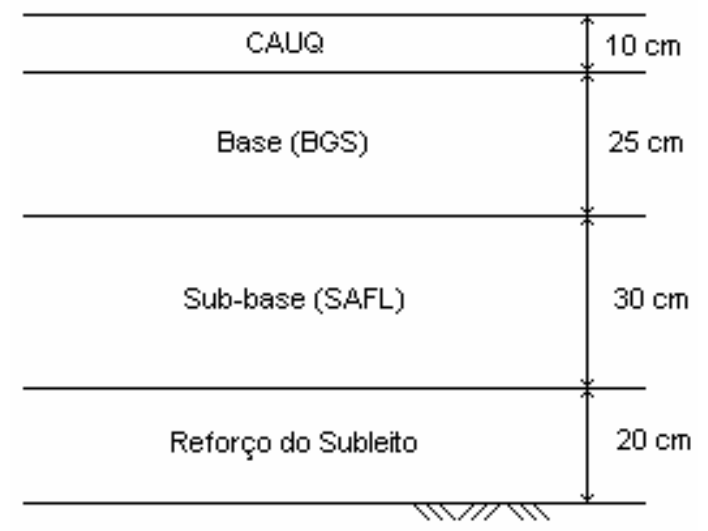

FIGURA 19 - Representação das camadas do pavimento a ser executado.

TABELA 16 - Custos unitários de serviços de terraplenagem e pavimentação.

\begin{tabular}{lcl}
\hline \multicolumn{3}{c}{ Custos unitários (US\$) } \\
\hline Escavação & 1,24 & $\mathrm{p} / \mathrm{m}^{3}$ \\
Transporte & 0,46 & $\mathrm{p} / \mathrm{m}^{3} * \mathrm{~km}$ \\
Compactação & 0,65 & $\mathrm{p} / \mathrm{m}^{3}$ \\
Concreto Asfáltico Usinado a Quente (CAUQ) & 138,56 & $\mathrm{p} / \mathrm{m}^{3}$ \\
Base de Brita Graduada Simples (BGS) & 25,13 & $\mathrm{p} / \mathrm{m}^{3}$ \\
Sub-base de Solo Arenoso Fino Laterítico (SAFL) & 4,81 & $\mathrm{p} / \mathrm{m}^{3}$ \\
Reforço do Subleito & 0,80 & $\mathrm{p} / \mathrm{m}^{3}$ \\
\hline
\end{tabular}

Fonte: Modificada de DER-SP (2004) 


\section{Capítulo 5}

\section{Apresentação e análise dos resultados}

Neste capítulo, são apresentados e a analisados os resultados da influência das características geométricas obtidos através do estudo de caso apresentado no Capítulo 4. Foram utilizados os seguintes relatórios do HDM-4: Custo Médio Anual (por 1000 veíckm), Consumo de Combustível (por 1000 veíc-km), Velocidade de Operação dos Veículos e Custos dos Usuários. Os resultados permitem a identificação da influência da geometria vertical (RF) e da geometria horizontal (ADC) sobre os custos de todos os trechos analisados. Apresentam-se, também, os resultados das análises dos trechos das classes de geometria do HDM-4 e da Rodovia SP-310.

\subsection{RESULTADOS DA INFLUÊNCIA DA GEOMETRIA VERTICAL (RF)}

As Tabelas 17 a 25 apresentam as parcelas dos custos totais dos usuários para o trecho Base e para os trechos fictícios $a$ a $h$ (que permitem a análise da influência da geometria vertical - RF - nos custos), bem como as porcentagens de cada componente dos custos de operação dos veículos e os custos do tempo de viagem.

Os gráficos das Figuras 20 a 27 mostram os custos da soma de cada componente do custo de operação dos veículos em função de RF. As Figuras 28 a 30 apresentam as somas dos custos de operação, do tempo de viagem e dos custos totais, de todos os veículos considerados (caminhão leve, caminhão pesado, automóvel médio e ônibus pesado) em função de RF. 


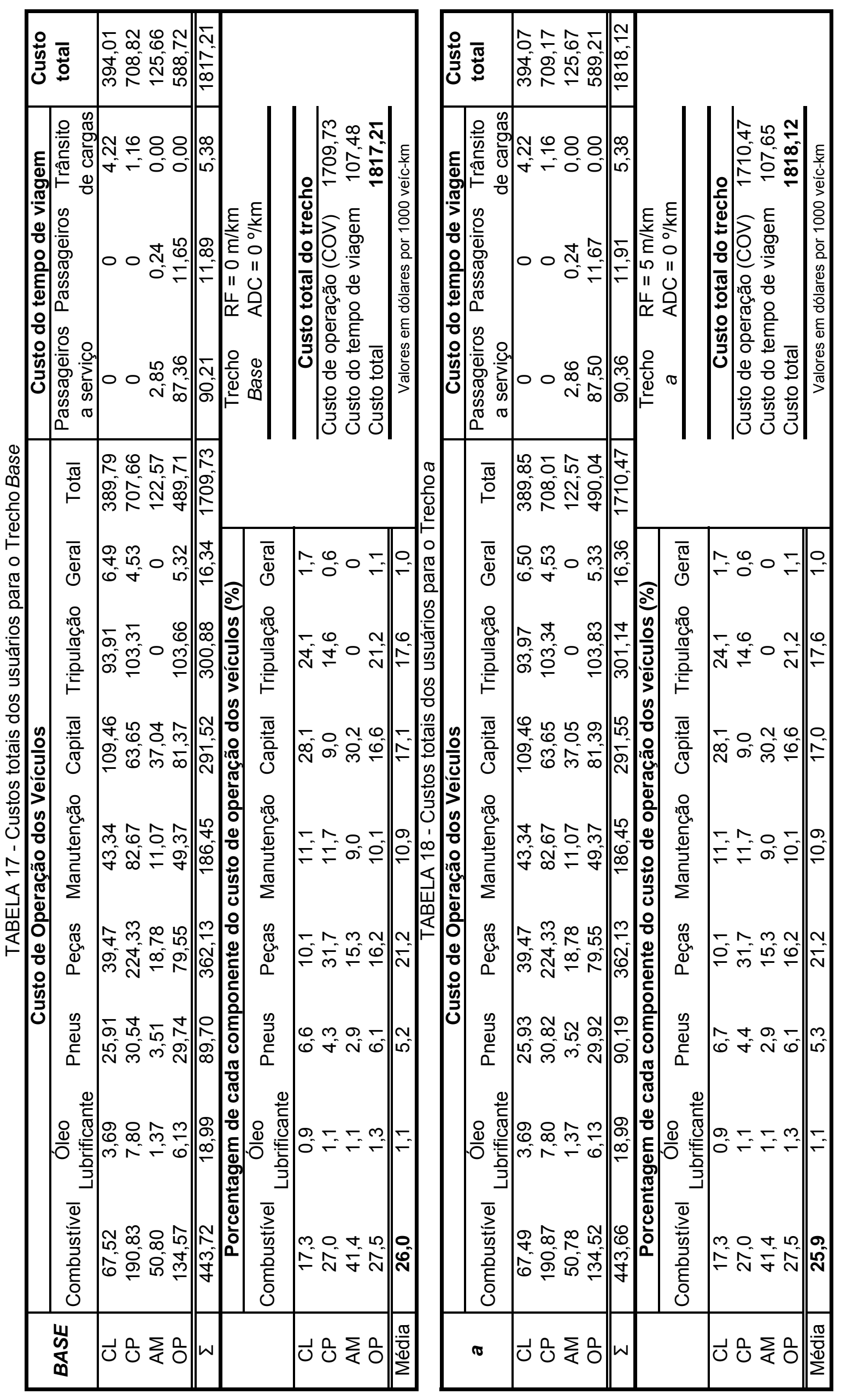




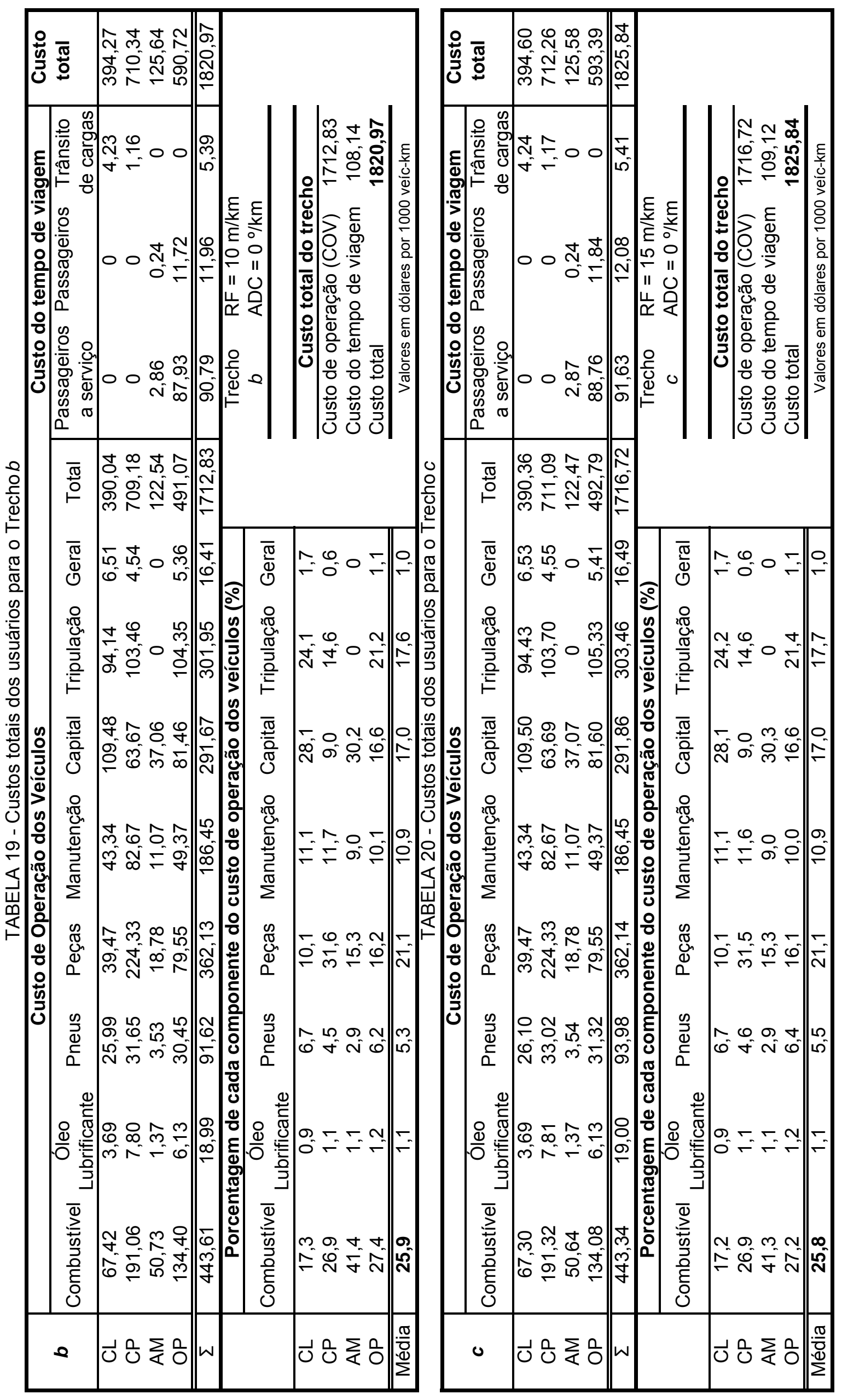




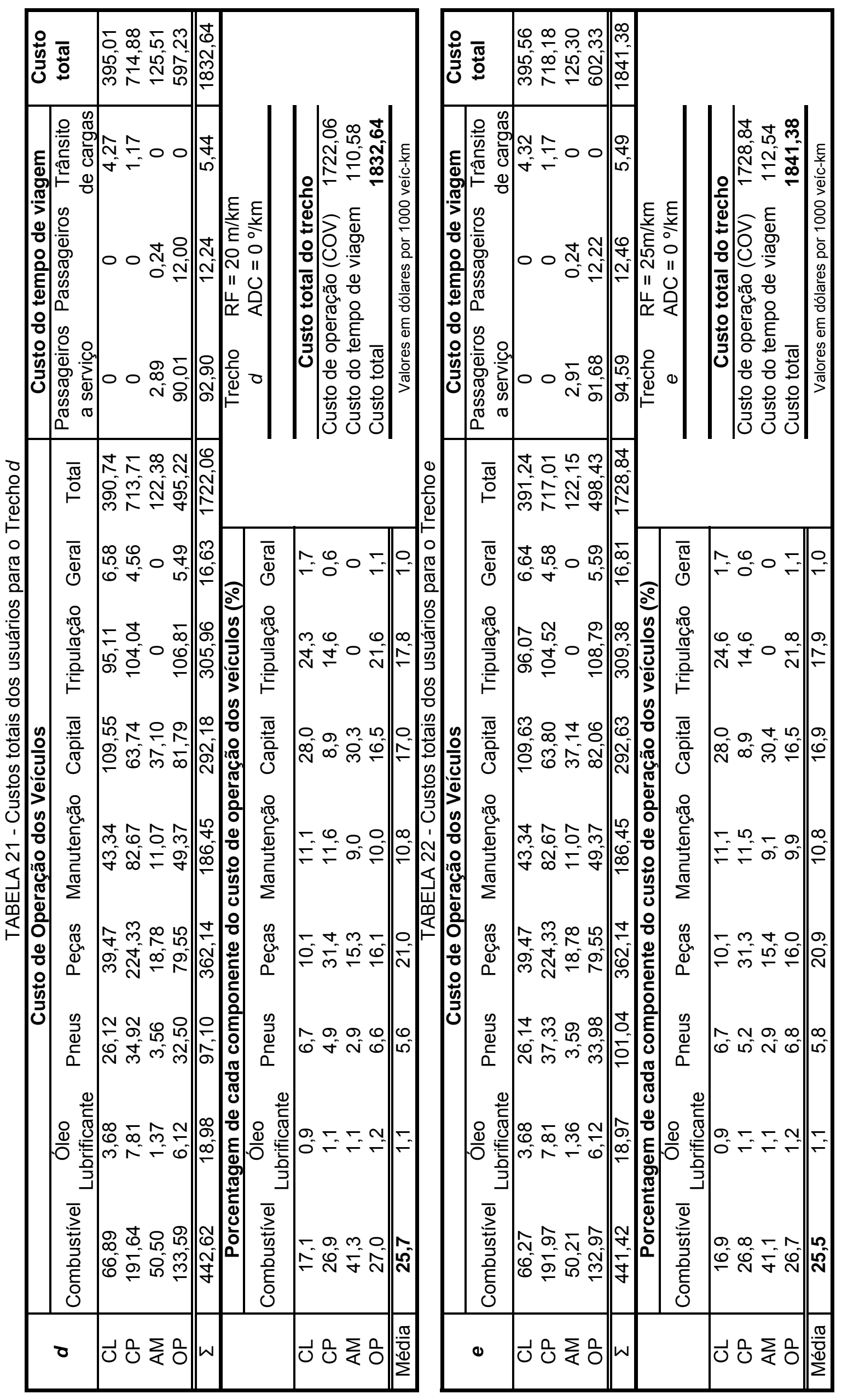




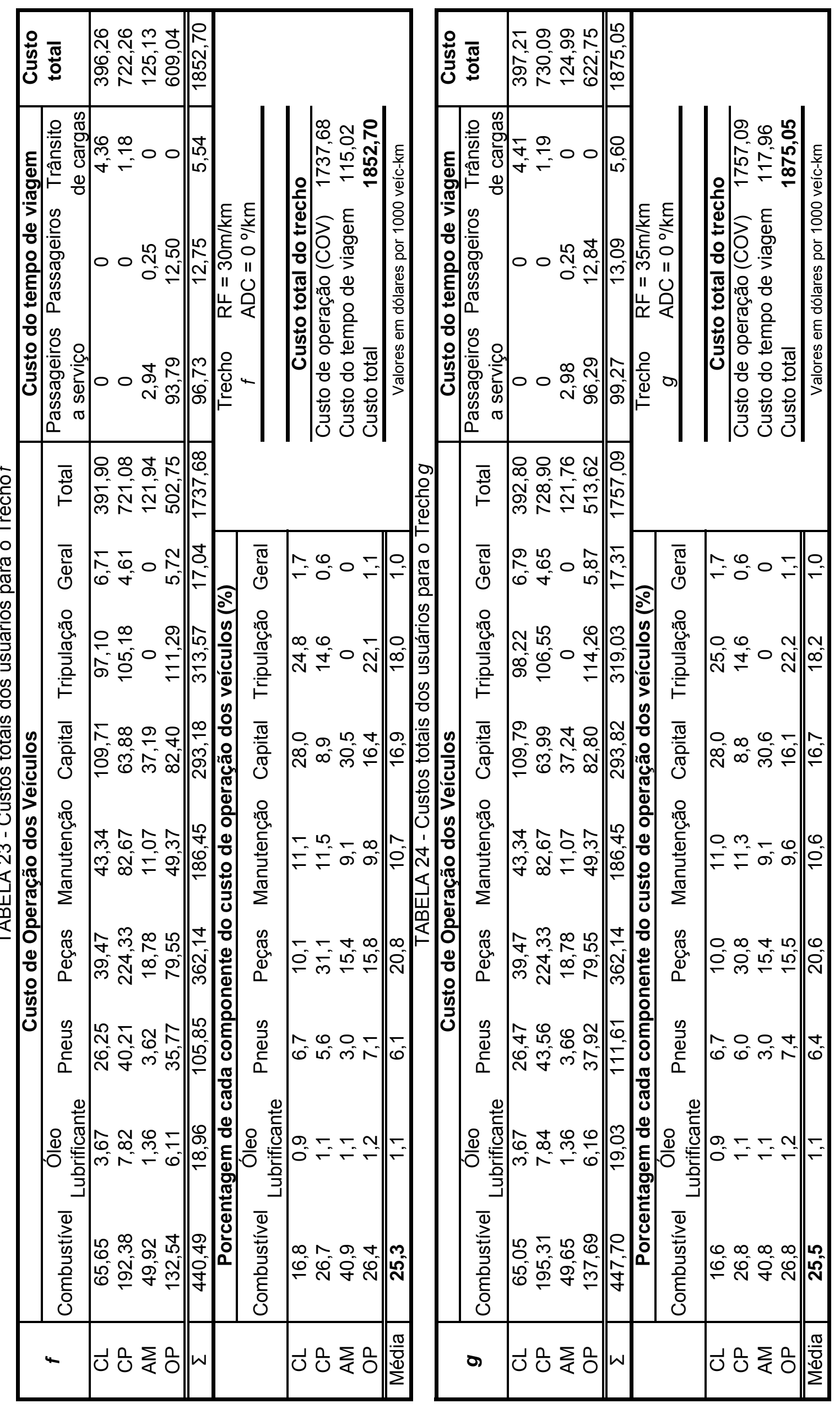




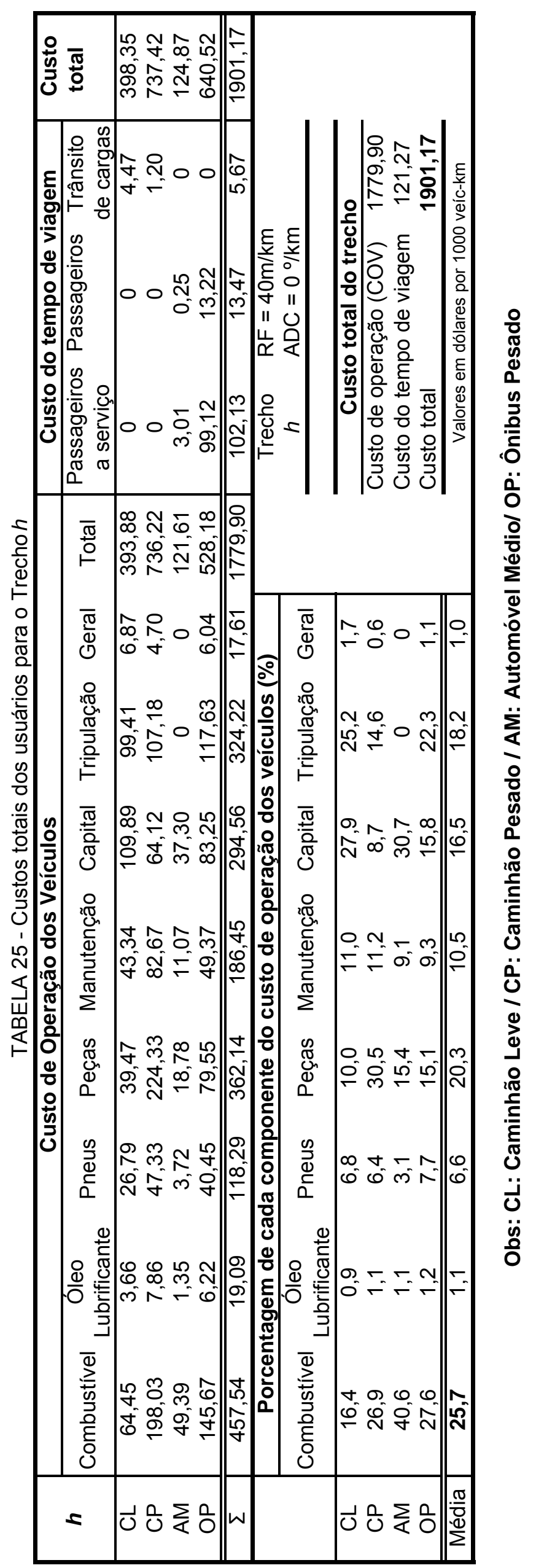




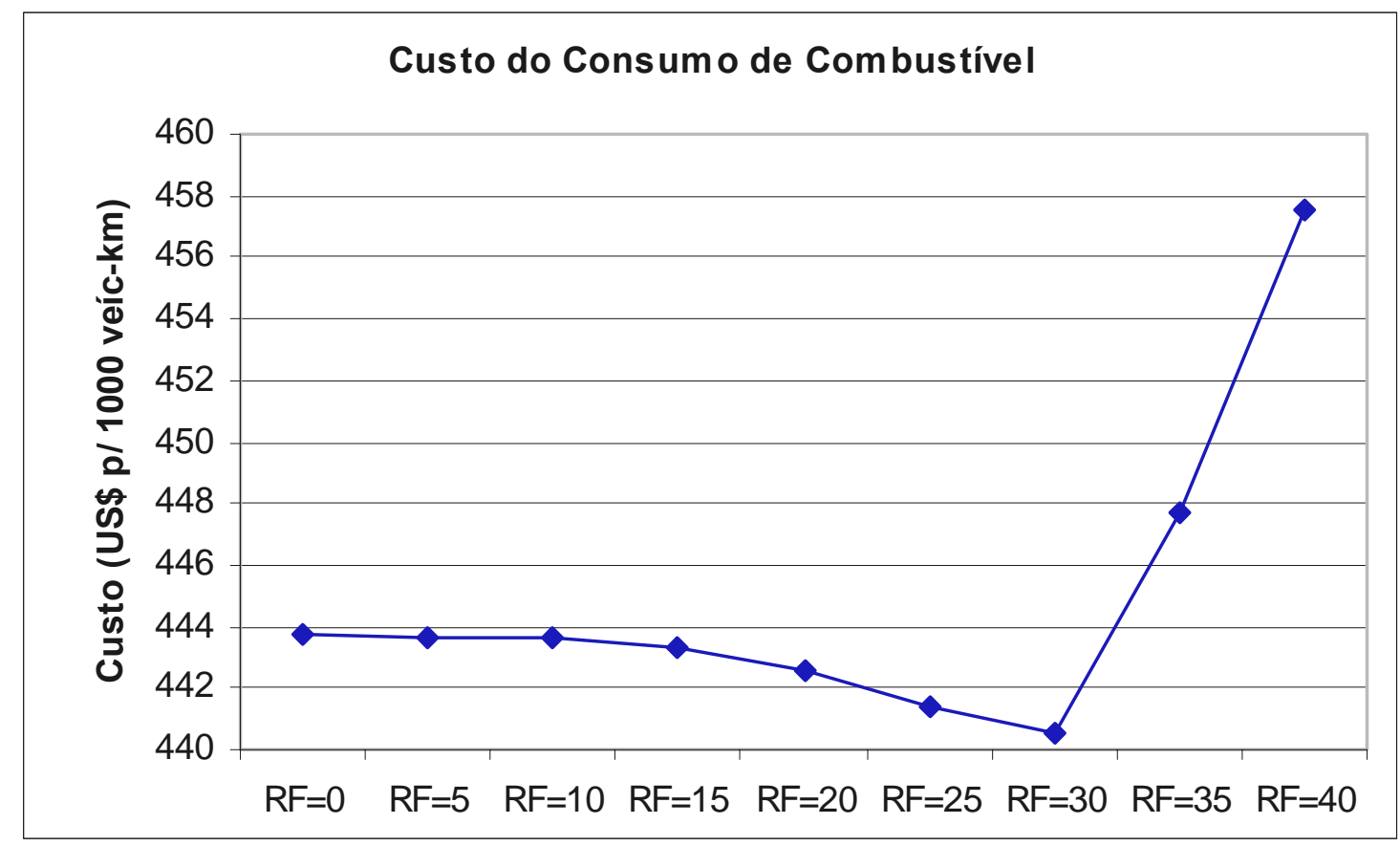

FIGURA 20 - Custo de consumo de combustível em função de RF.

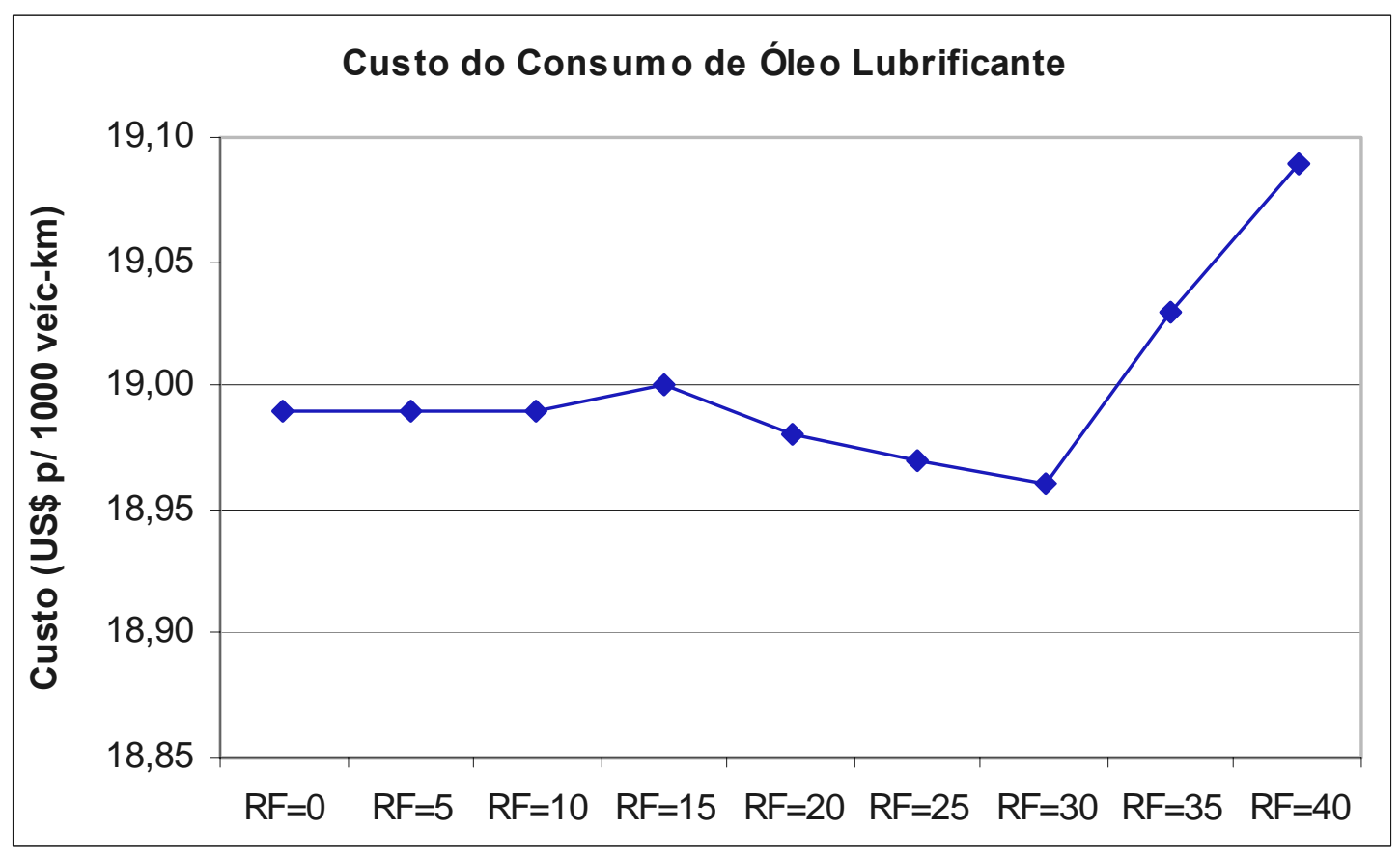

FIGURA 21 - Custo de consumo de óleo lubrificante em função de RF. 


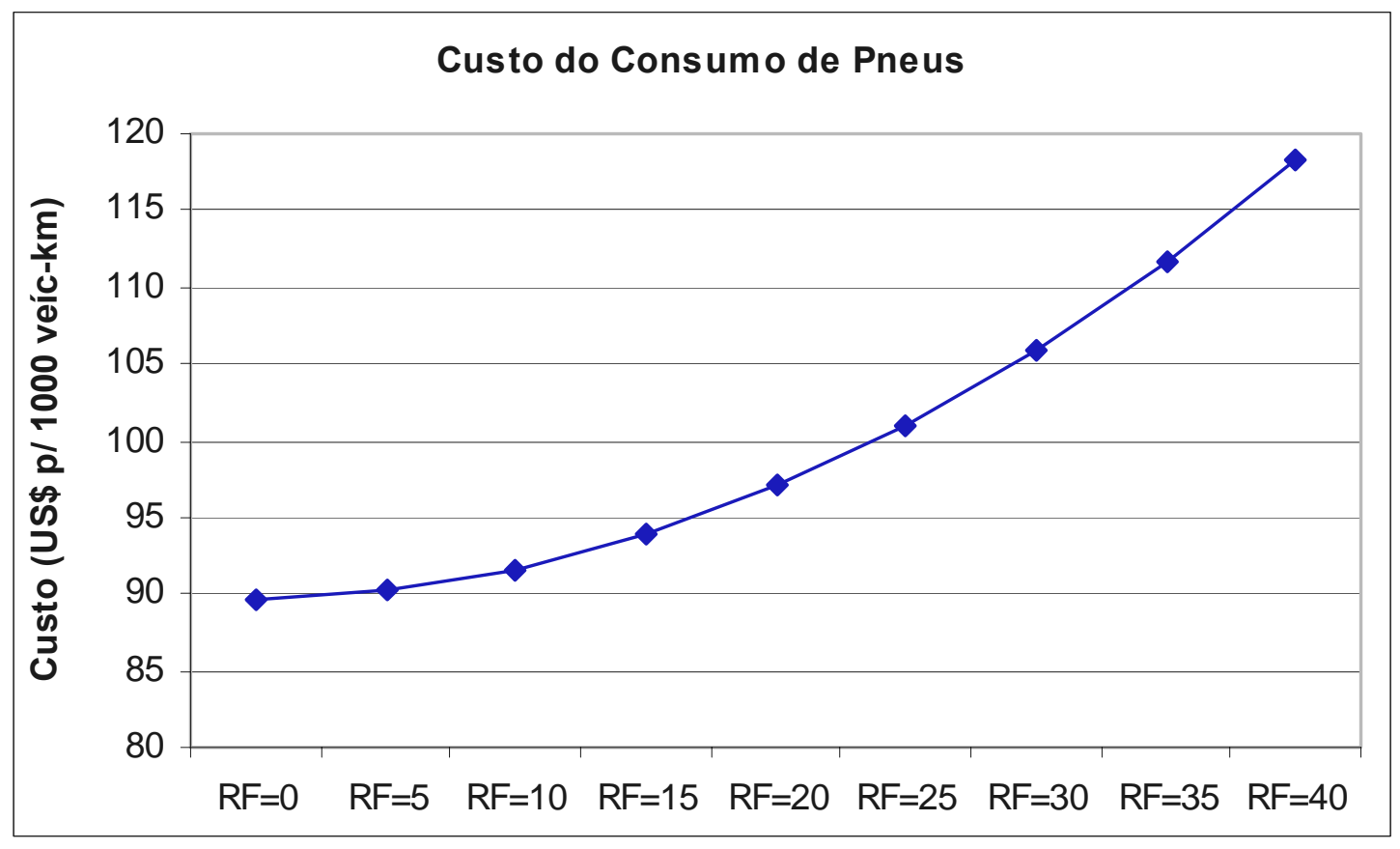

FIGURA 22 - Custo de consumo de pneus em função de RF.

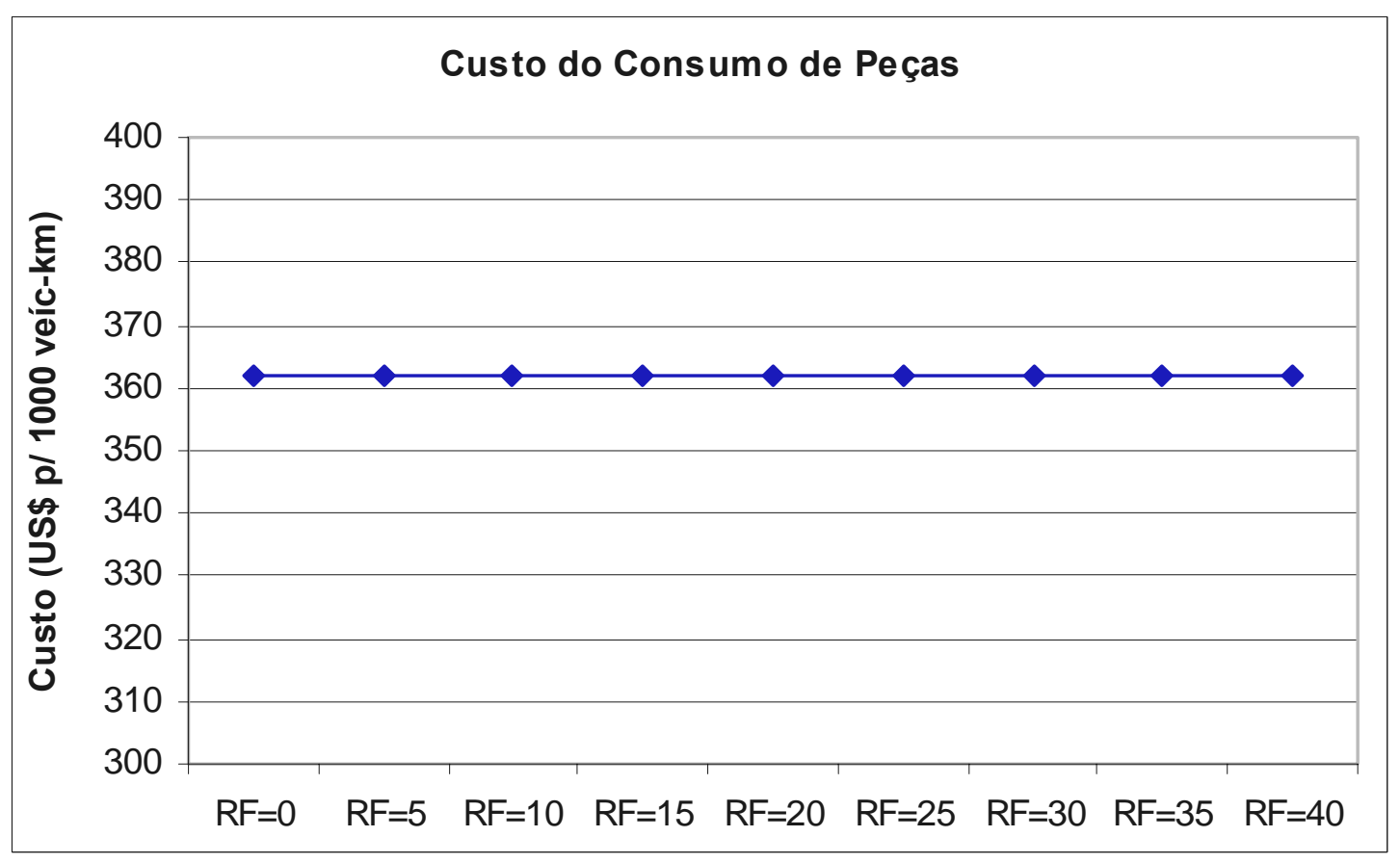

FIGURA 23 - Custo de consumo de peças em função de RF. 


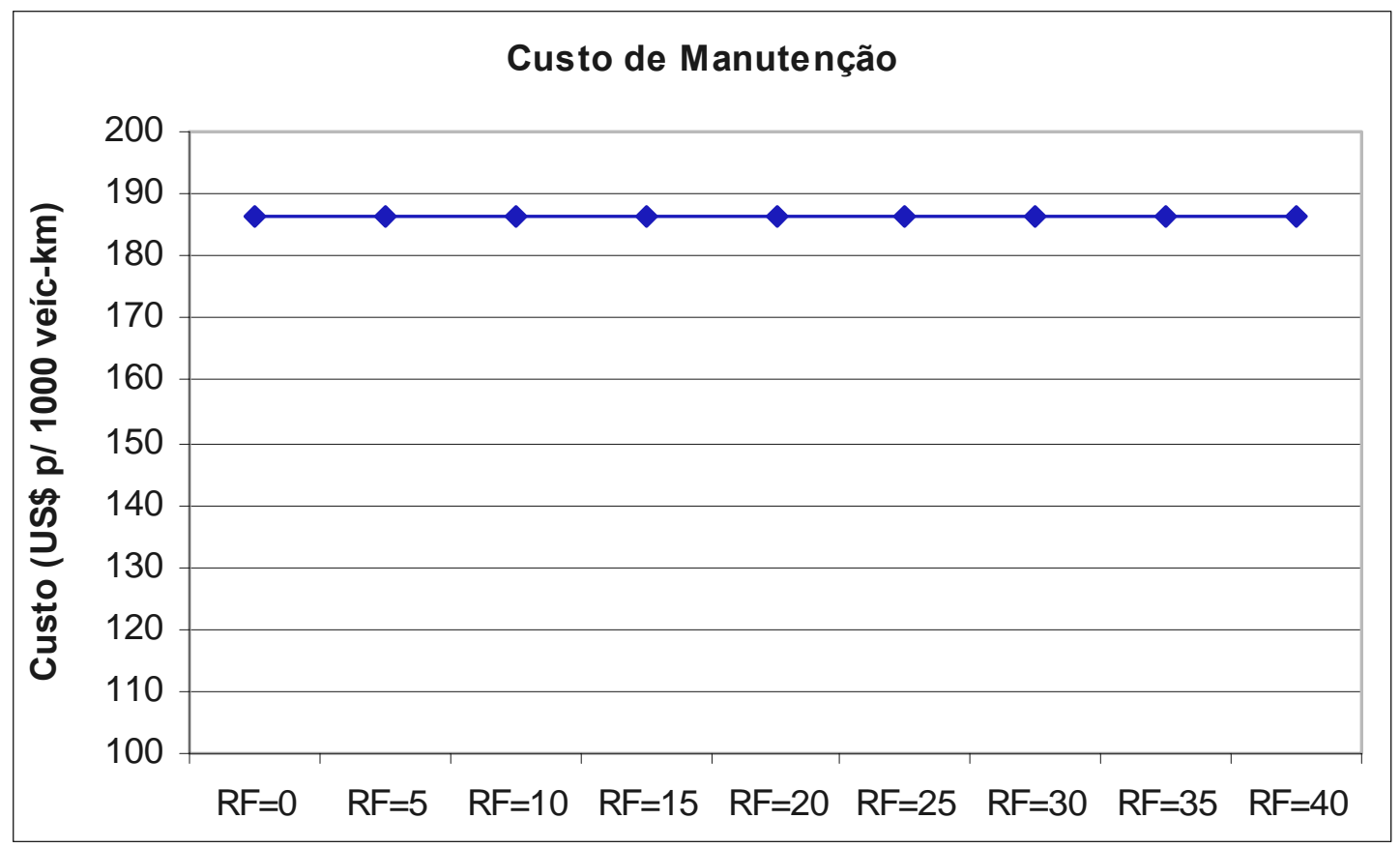

FIGURA 24 - Custo de manutenção dos veículos em função de RF.

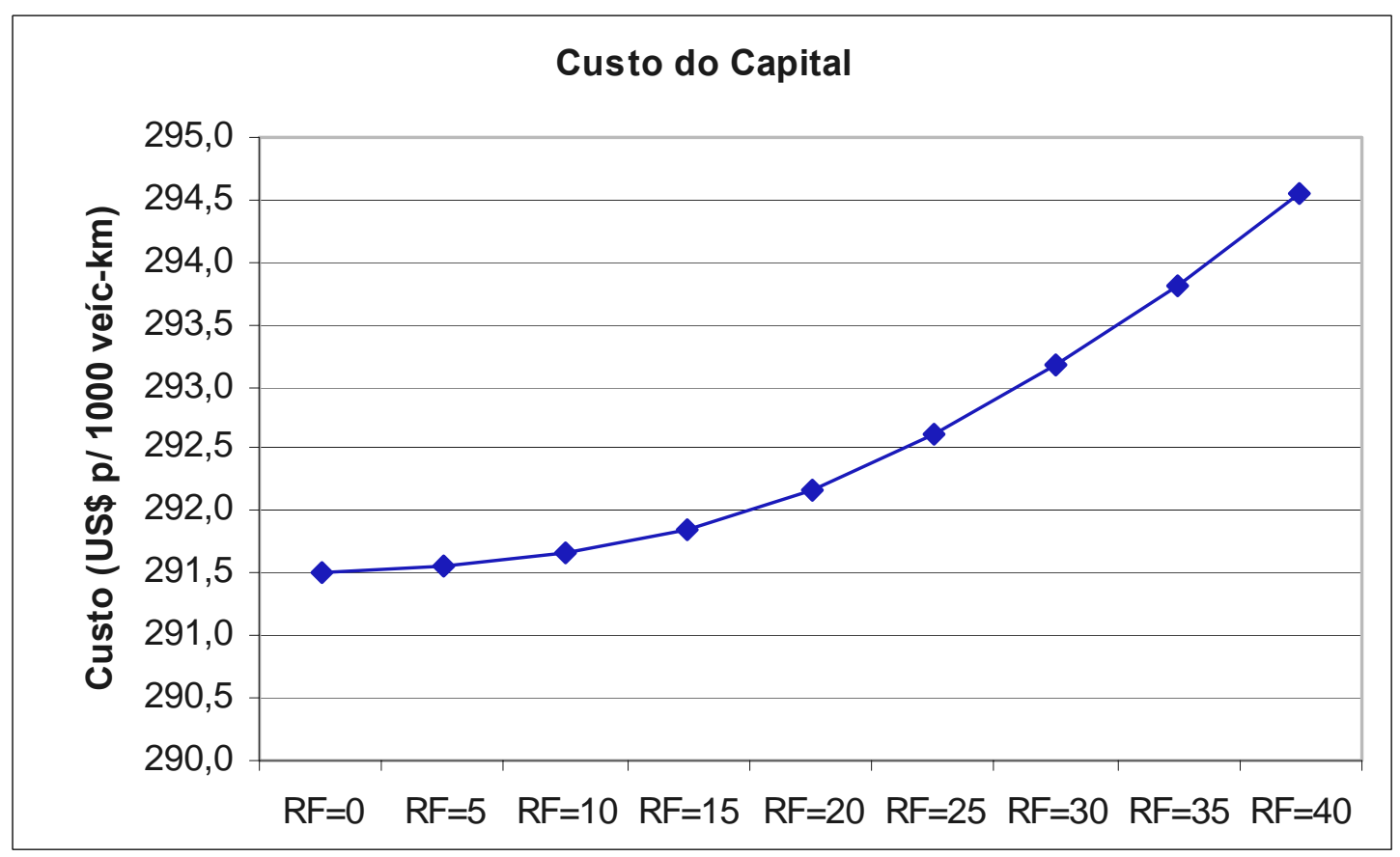

FIGURA 25 - Custo do capital em função de RF. 


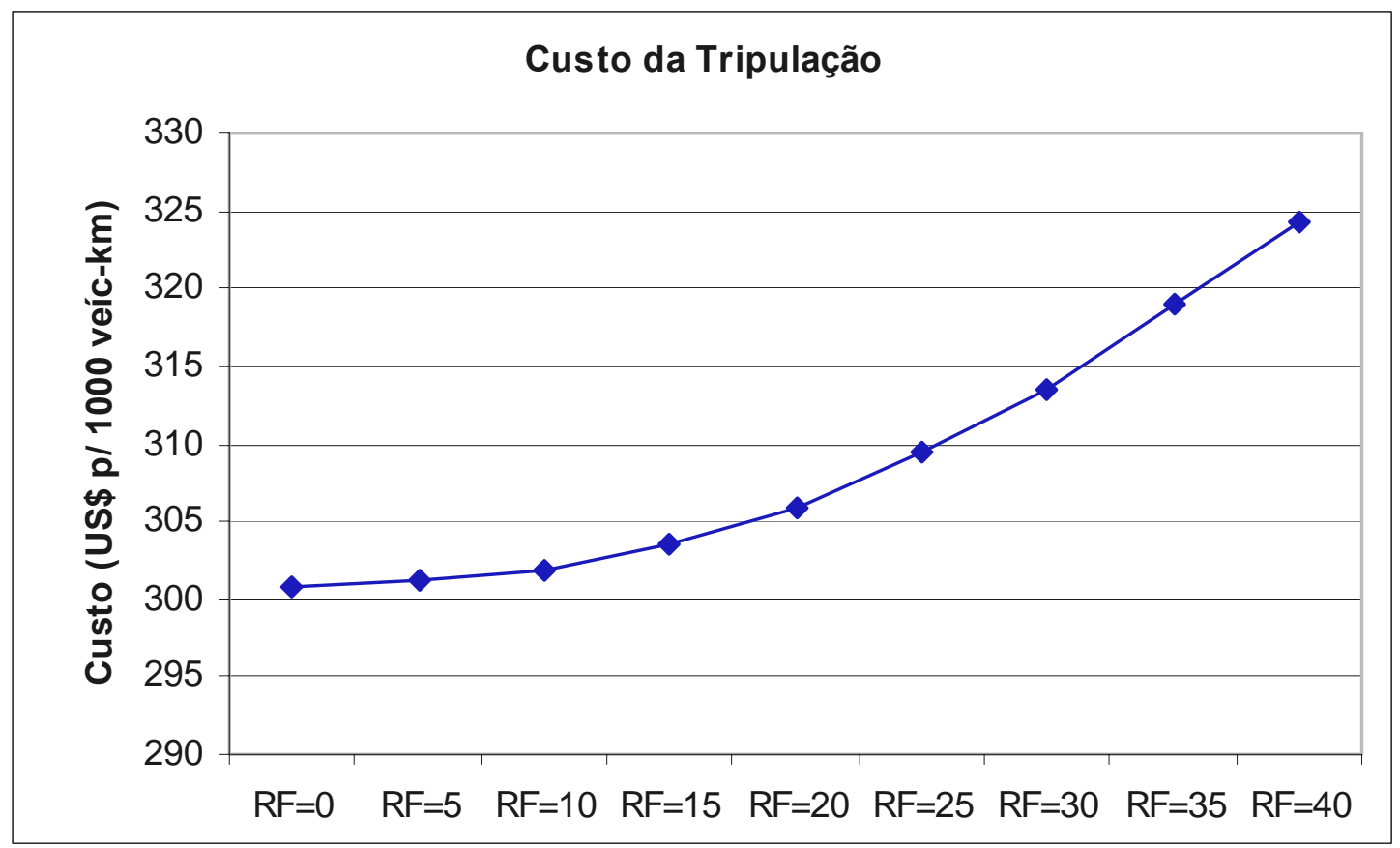

FIGURA 26 - Custo da tripulação em função de RF.

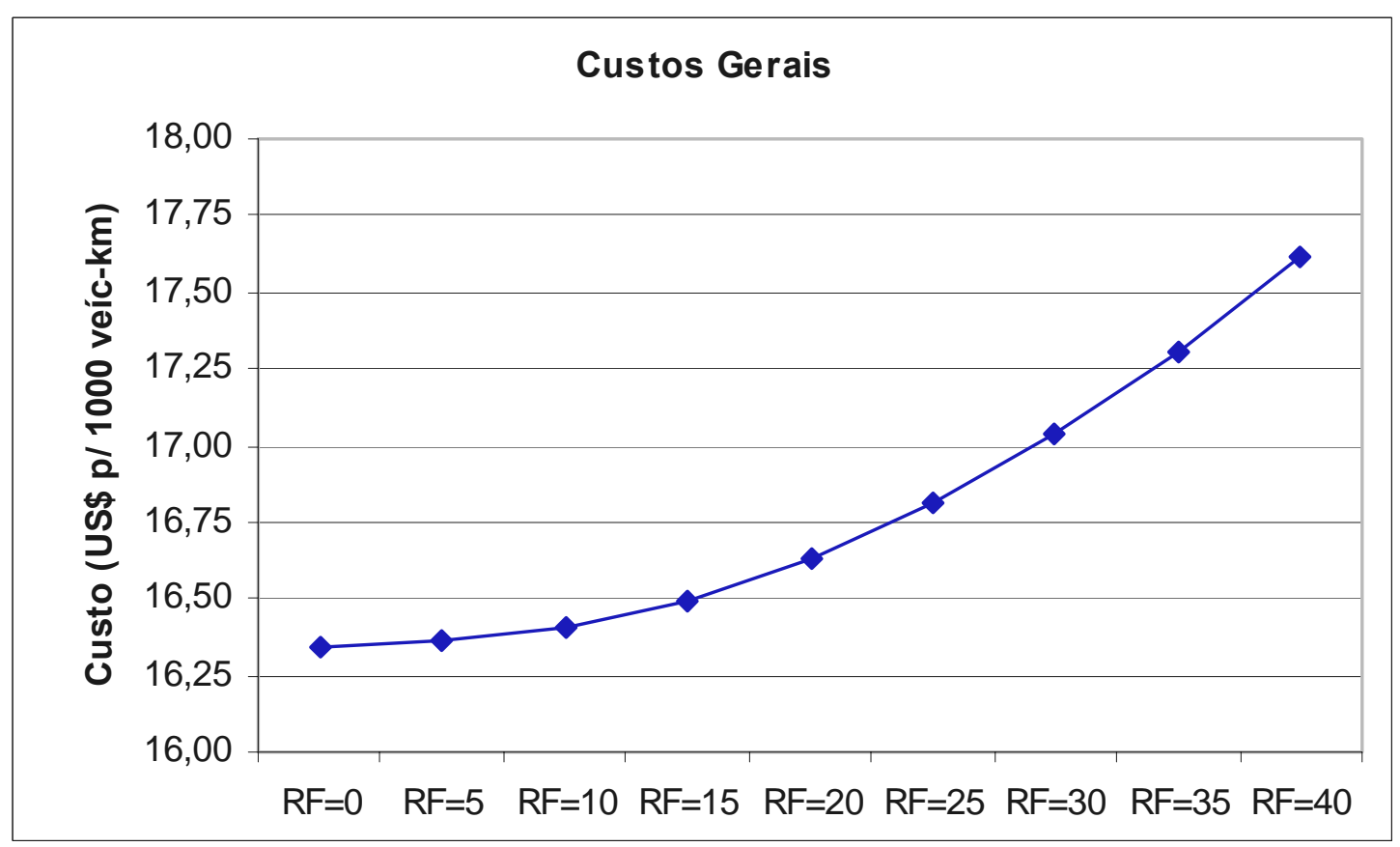

FIGURA 27 - Custos gerais em função de RF. 


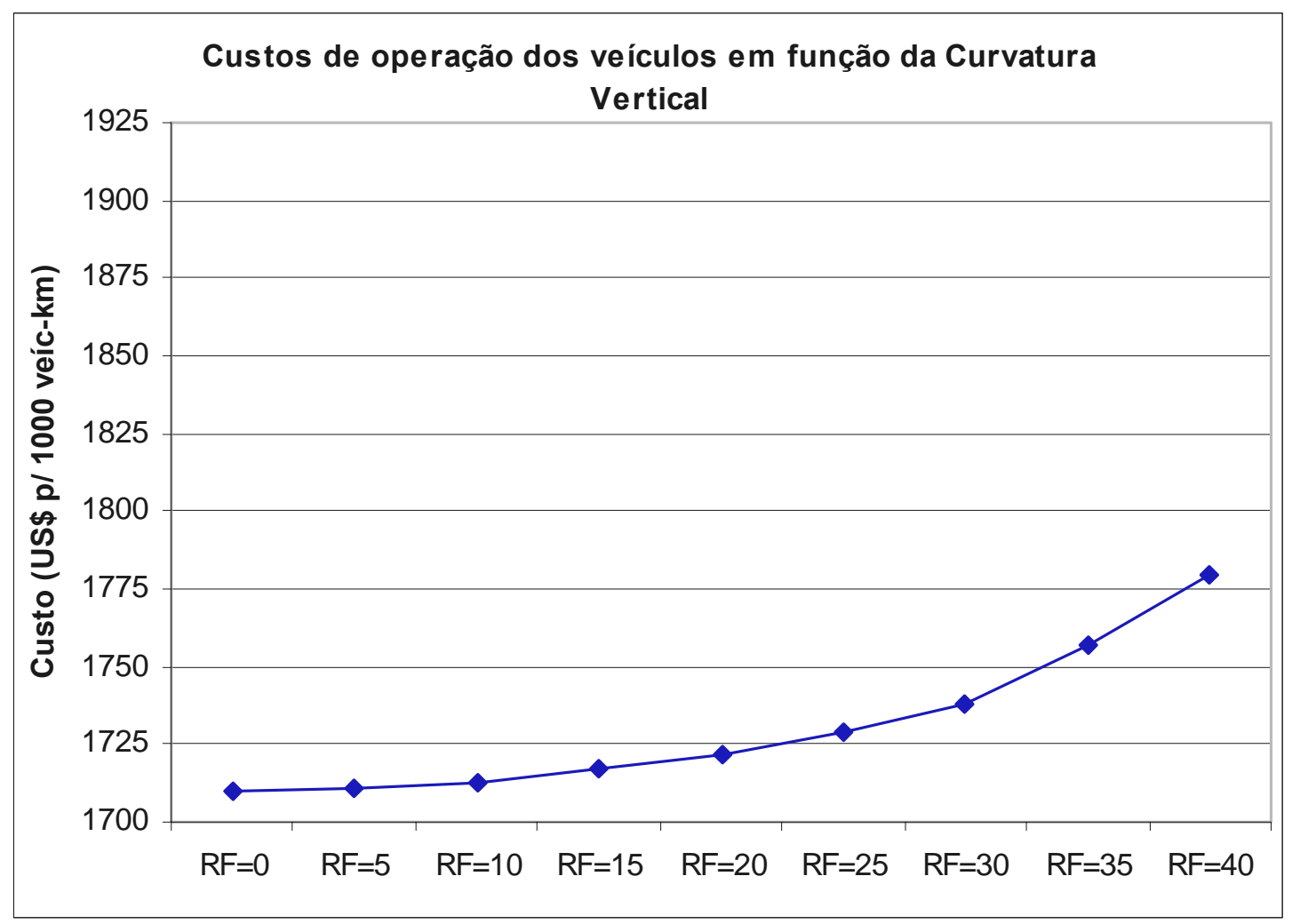

FIGURA 28 - Custo de operação dos veículos em função de RF.

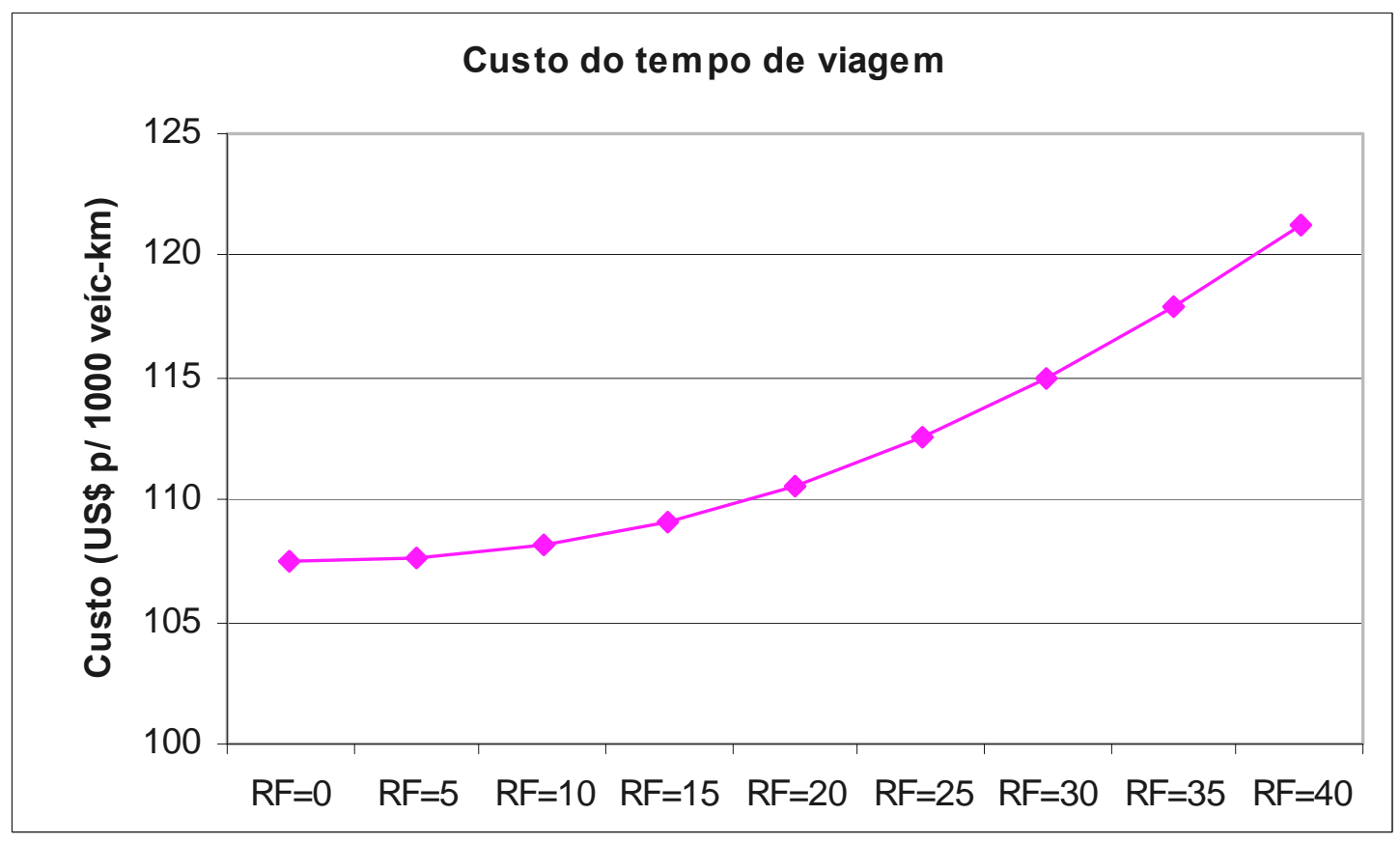

FIGURA 29 - Custo do tempo de viagem em função de RF. 


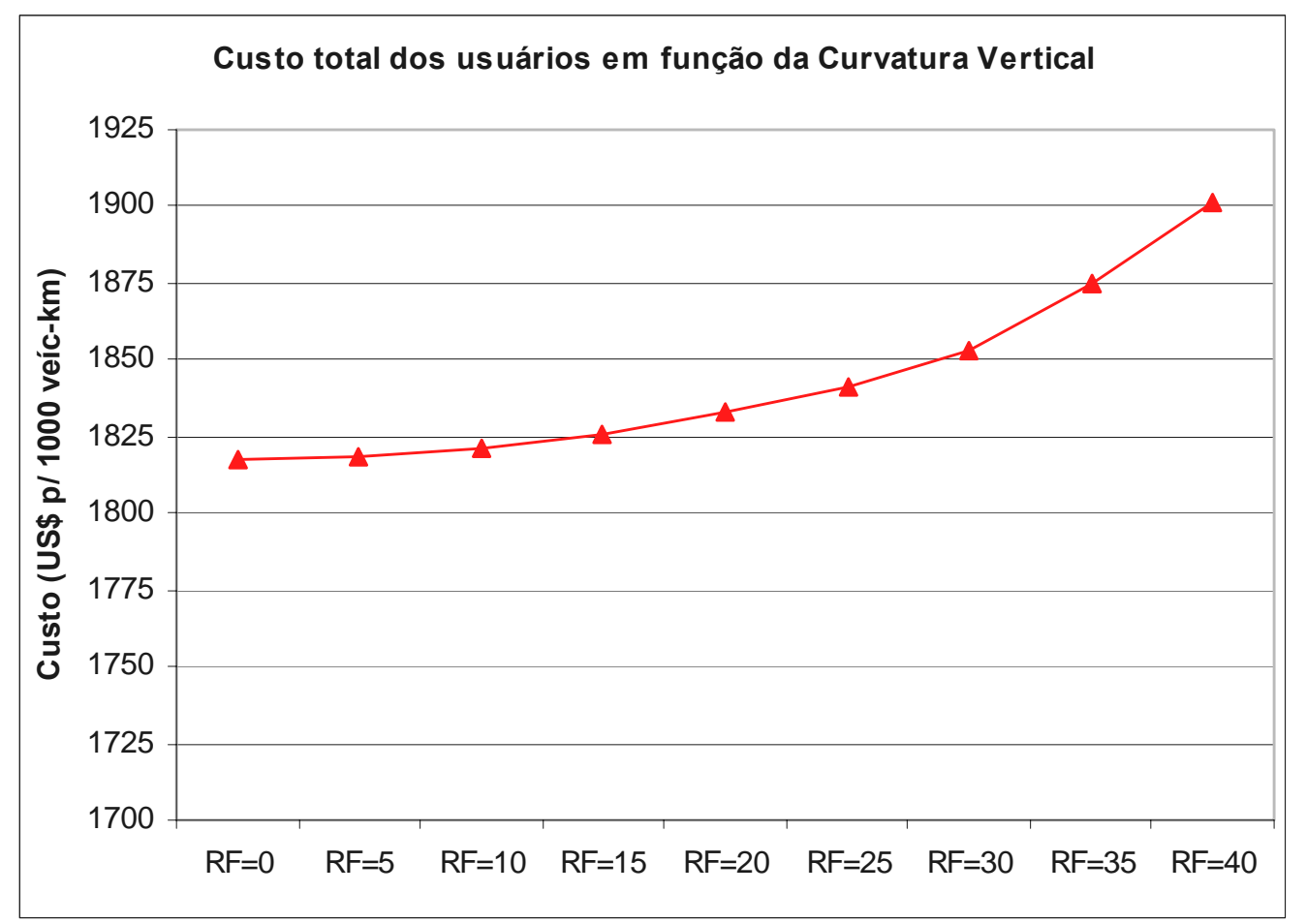

FIGURA 30 - Custo total dos usuários em função de RF.

Para uma melhor compreensão dos resultados, são mostradas, na Tabela 26 e nas Figuras 31 e 32, as variações da velocidade de operação e do consumo de combustível de cada tipo de veículo em função de RF.

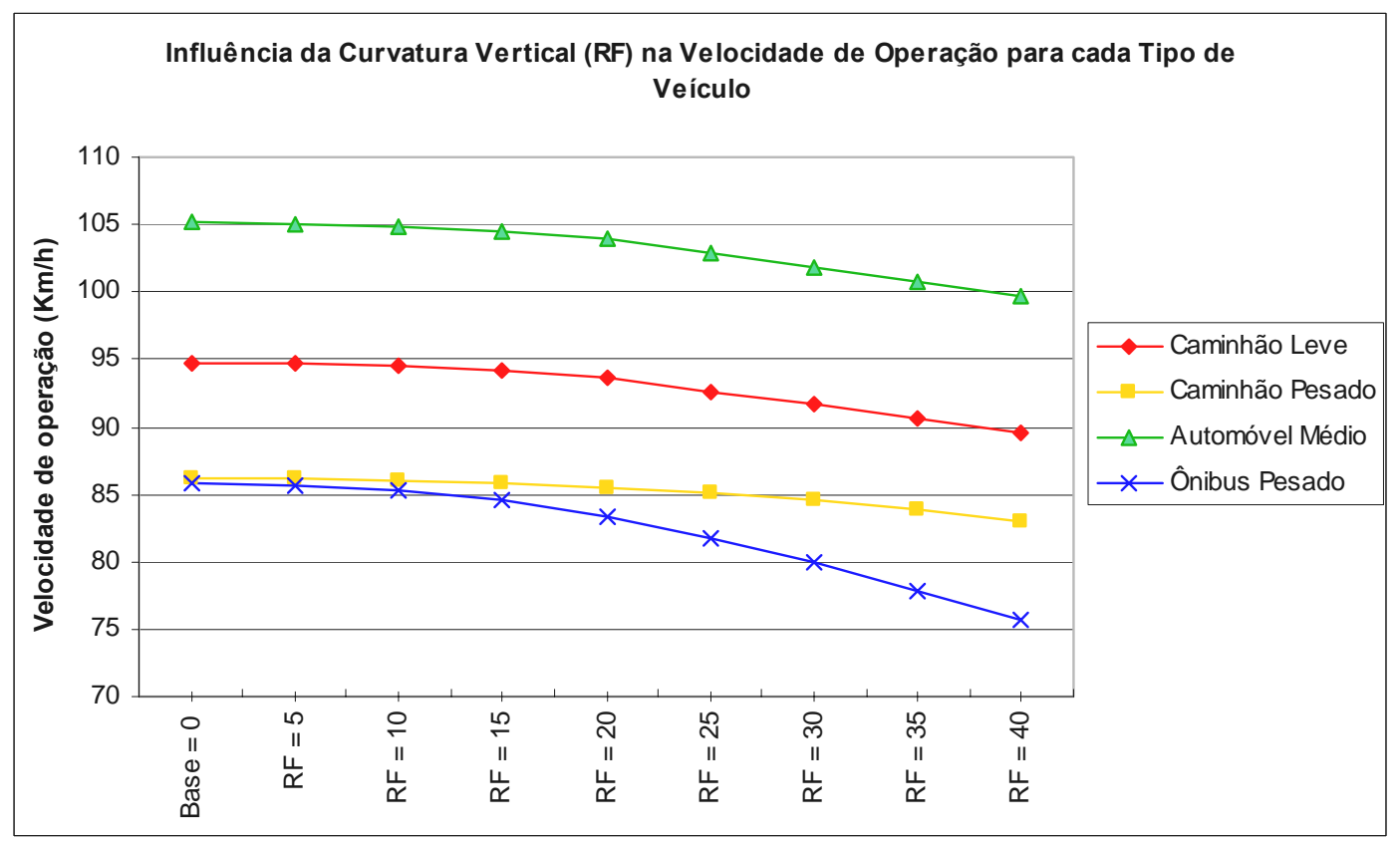

FIGURA 31 - Influência da curvatura vertical (RF) na velocidade de operação de cada tipo de veículo. 


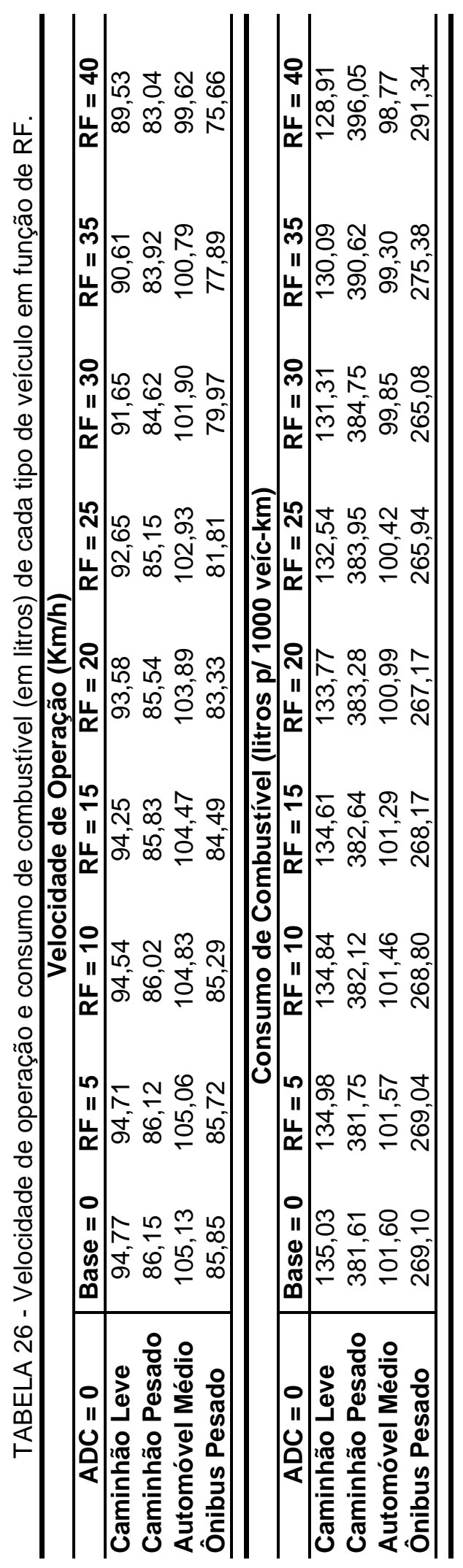




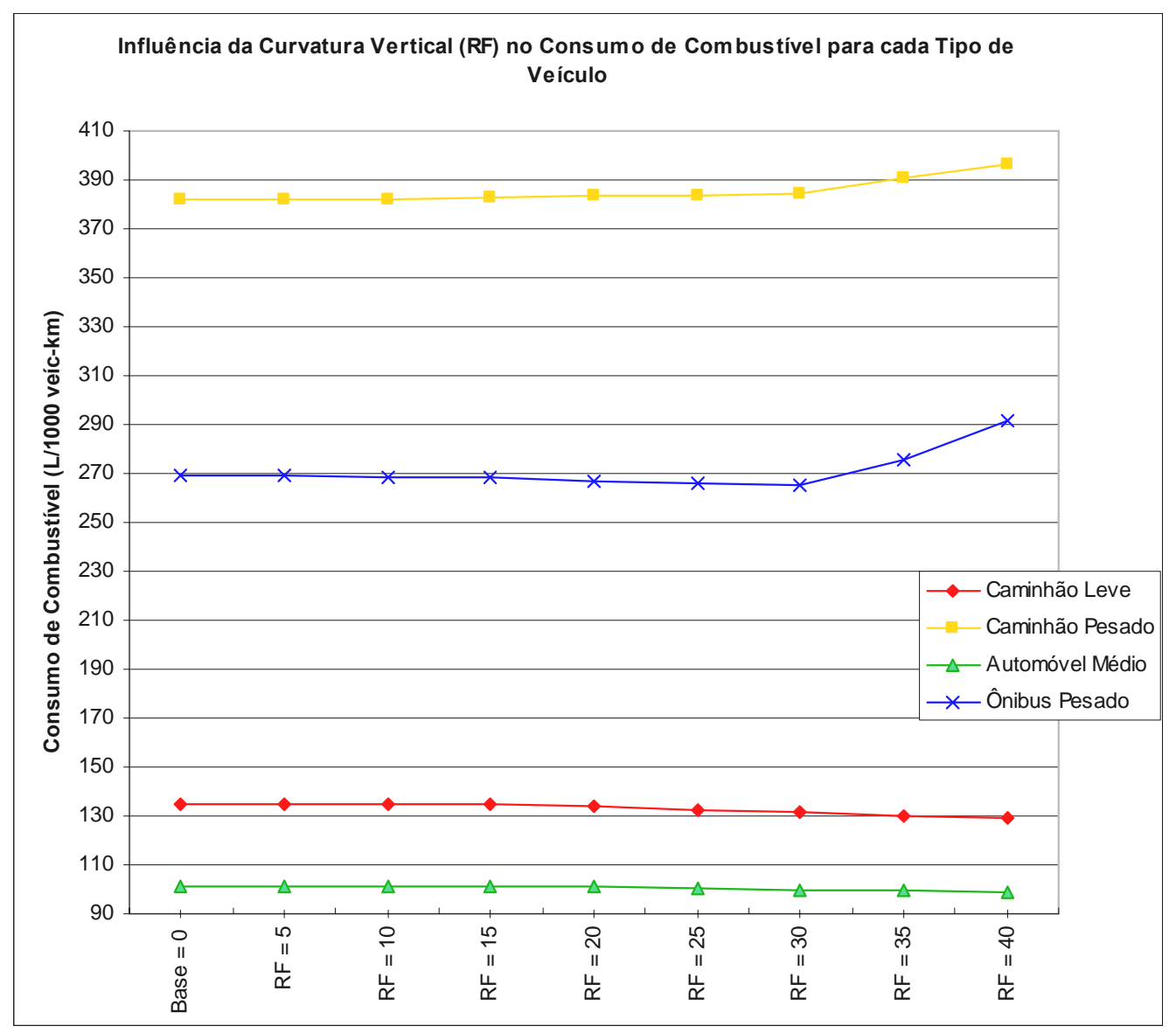

FIGURA 32 - Influência da curvatura vertical (RF) no consumo de combustível de cada tipo de veículo.

A Tabela 27 apresenta os componentes com maior contribuição para o custo de operação dos veículos (COV), em função da geometria vertical, a partir dos resultados apresentados nas Tabelas 17 a 25. O componente que tem maior influência é o consumo de combustível, seguido pelo custo do desgaste das peças e os custos da tripulação.

TABELA 27 - Componentes com maiores porcentagens no COV - Trechos Base e Trechos $a$ a $h$.

\begin{tabular}{cccc}
\hline Trechos & Maior $\%$ & $\mathbf{2}^{\text {a. }}$ maior $\%$ & $\mathbf{3}^{\text {a. }}$ maior $\%$ \\
\hline Base $(\mathbf{R F}=\mathbf{0})$ & Combustível & Peças & Tripulação \\
$\mathbf{a}(\mathbf{R F}=\mathbf{5})$ & Combustível & Peças & Tripulação \\
$\mathbf{b}(\mathbf{R F}=\mathbf{1 0})$ & Combustível & Peças & Tripulação \\
$\mathbf{c}(\mathbf{R F}=\mathbf{1 5 )}$ & Combustível & Peças & Tripulação \\
$\mathbf{d}(\mathbf{R F}=\mathbf{2 0})$ & Combustível & Peças & Tripulação \\
$\mathbf{e}(\mathbf{R F}=\mathbf{2 5})$ & Combustível & Peças & Tripulação \\
$\mathbf{f}(\mathbf{R F}=\mathbf{3 0})$ & Combustível & Peças & Tripulação \\
$\mathbf{g}(\mathbf{R F}=\mathbf{3 5})$ & Combustível & Peças & Tripulação \\
$\mathbf{h}(\mathbf{R F}=\mathbf{4 0})$ & Combustível & Peças & Tripulação \\
\hline
\end{tabular}


A Tabela 28 apresenta os custos de terraplenagem para a melhoria da geometria vertical mediante redução do RF. A geometria vertical de referência tem RF igual a $40 \mathrm{~m} / \mathrm{km}$, tendo sido calculados os custos correspondentes à redução do RF, admitindo-se um trecho com duas rampas ascendentes e duas rampas descendentes, numa extensão de $10 \mathrm{~km}$. Foram considerados os custos de terraplenagem (escavação, transporte e compactação) da Tabela de Preços Unitários do DER-SP (2004).

TABELA 28 - Custos totais de terraplenagem para redução do RF.

\begin{tabular}{|c|c|c|c|c|c|c|}
\hline $\begin{array}{c}\text { RF } \\
(\mathrm{m} / \mathbf{k m})\end{array}$ & $\begin{array}{c}\text { Desnível } \\
\text { do ponto } \\
\text { original (m) }\end{array}$ & $\begin{array}{c}\text { H médio } \\
\text { da seção } \\
\text { (m) }\end{array}$ & $\begin{array}{l}\text { Área média } \\
\text { da seção } \\
\left(\mathrm{m}^{2}\right)\end{array}$ & $\begin{array}{l}\text { Volume de } \\
\text { cada corte/ } \\
\text { aterro }\left(\mathrm{m}^{3}\right) \\
\end{array}$ & $\begin{array}{c}\text { Volume } \\
\text { Total do } \\
\text { Trecho }\left(\mathbf{m}^{3}\right) \\
\end{array}$ & $\begin{array}{c}\text { Volume de } \\
\text { corte/aterro } \\
\text { total }\left(\mathbf{m}^{3}\right) \\
\end{array}$ \\
\hline 35 & 6,25 & 3,13 & 55,39 & 69238,3 & 553906,3 & 276953,1 \\
\hline 30 & 12,50 & 6,25 & 130,31 & 162890,6 & 1303125,0 & 651562,5 \\
\hline 25 & 18,75 & 9,38 & 224,77 & 280957,0 & 2247656,3 & 1123828,1 \\
\hline 20 & 25,00 & 12,50 & 338,75 & 423437,5 & 3387500,0 & 1693750,0 \\
\hline 15 & 31,25 & 15,63 & 472,27 & 590332,0 & 4722656,3 & 2361328,1 \\
\hline 10 & 37,50 & 18,75 & 625,31 & 781640,6 & 6253125,0 & 3126562,5 \\
\hline 5 & 43,75 & 21,88 & 797,89 & 997363,3 & 7978906,3 & 3989453,1 \\
\hline 0 & 50,00 & 25,00 & 990,00 & 1237500,0 & 9900000,0 & 4950000,0 \\
\hline $\begin{array}{c}\mathrm{RF} \\
(\mathrm{m} / \mathbf{k m})\end{array}$ & $\begin{array}{c}\text { Custo de } \\
\text { escavação } \\
\text { (US\$) }\end{array}$ & $\begin{array}{c}\text { Custo de } \\
\text { Transporte } \\
\text { (US\$) }\end{array}$ & \multicolumn{2}{|c|}{$\begin{array}{c}\text { Custo de } \\
\text { Compactação } \\
\text { (US\$) }\end{array}$} & $\begin{array}{l}\text { Custo } \\
\text { Total } \\
\text { (US\$) }\end{array}$ & $\begin{array}{c}\text { Custo } \\
\text { Total por } \\
\text { km }(\mathbf{U S \$} / \mathbf{k m})\end{array}$ \\
\hline 35 & 344652,78 & 160273,80 & \multicolumn{2}{|c|}{179506,66} & 684433,23 & 68443,32 \\
\hline 30 & 810833,33 & 377061,63 & \multicolumn{2}{|c|}{422309,03} & 1610203,99 & 161020,40 \\
\hline 25 & 1398541,67 & 650363,50 & \multicolumn{2}{|c|}{728407,12} & 2777312,28 & 277731,23 \\
\hline 20 & 2107777,78 & 980179,40 & \multicolumn{2}{|c|}{1097800,93} & 4185758,10 & 418575,81 \\
\hline 15 & 2938541,67 & 1366509,33 & \multicolumn{2}{|c|}{1530490,45} & 5835541,45 & 583554,14 \\
\hline 10 & 3890833,33 & 1809353,30 & \multicolumn{2}{|c|}{2026475,69} & 7726662,33 & 772666,23 \\
\hline 5 & 4964652,78 & 2308711,30 & \multicolumn{2}{|c|}{2585756,66} & 9859120,73 & 985912,07 \\
\hline 0 & 6160000,00 & 2864583,33 & \multicolumn{2}{|c|}{3208333,33} & 12232916,67 & 1223291,67 \\
\hline
\end{tabular}

A Tabela 29 mostra os custos de pavimentação por quilômetro, para uma largura de pista e acostamentos igual a $12,60 \mathrm{~m}$.

TABELA 29 - Custos do pavimento.

\begin{tabular}{|c|c|c|c|}
\hline Camadas & Altura da camada (m) & Volume $\left(\mathrm{m}^{3} / \mathrm{km}\right)$ & Custo por km (US\$) \\
\hline CAUQ & 0,10 & 1260 & 174585,60 \\
\hline Base & 0,25 & 3150 & 79159,50 \\
\hline Sub-base & 0,30 & 3780 & 18181,80 \\
\hline Reforço do subleito & 0,20 & 2520 & 2016,00 \\
\hline \multicolumn{3}{|c|}{ Custo total do pavimento por $\mathrm{km}$ (US\$): } & 273942,90 \\
\hline
\end{tabular}


A composição do custo total por quilômetro da intervenção de redução do RF (a partir de $40 \mathrm{~m} / \mathrm{km}$ ) é dada pela soma do custo de pavimentação com os custos da movimentação de terra para atingir cada valor de RF (Tabela 30 e Figura 33).

TABELA 30 - Custo total para cada intervenção de redução do RF dos trechos.

\begin{tabular}{|c|c|c|c|}
\hline $\begin{array}{c}\text { RF } \\
(\mathbf{m} / \mathbf{k m}) \\
\end{array}$ & $\begin{array}{c}\text { Custo de } \\
\text { terraplenagem } \\
\text { por } \mathbf{k m}(\mathrm{US} \$ / \mathbf{k m})\end{array}$ & $\begin{array}{c}\text { Custo } \\
\text { de pavimentação } \\
\text { por } \mathbf{k m}(\mathrm{US} \$ \mathbf{k m})\end{array}$ & $\begin{array}{c}\text { Custo } \\
\text { total por km } \\
\text { (US\$) } \\
\end{array}$ \\
\hline 35 & 68443,32 & 273942,90 & 342390,66 \\
\hline 30 & 161020,40 & 273942,90 & 434967,73 \\
\hline 25 & 277731,23 & 273942,90 & 551678,56 \\
\hline 20 & 418575,81 & 273942,90 & 692523,14 \\
\hline 15 & 583554,14 & 273942,90 & 857501,48 \\
\hline 10 & 772666,23 & 273942,90 & 1046613,57 \\
\hline 5 & 985912,07 & 273942,90 & 1259859,41 \\
\hline 0 & 1223291,67 & 273942,90 & 1497239,00 \\
\hline
\end{tabular}

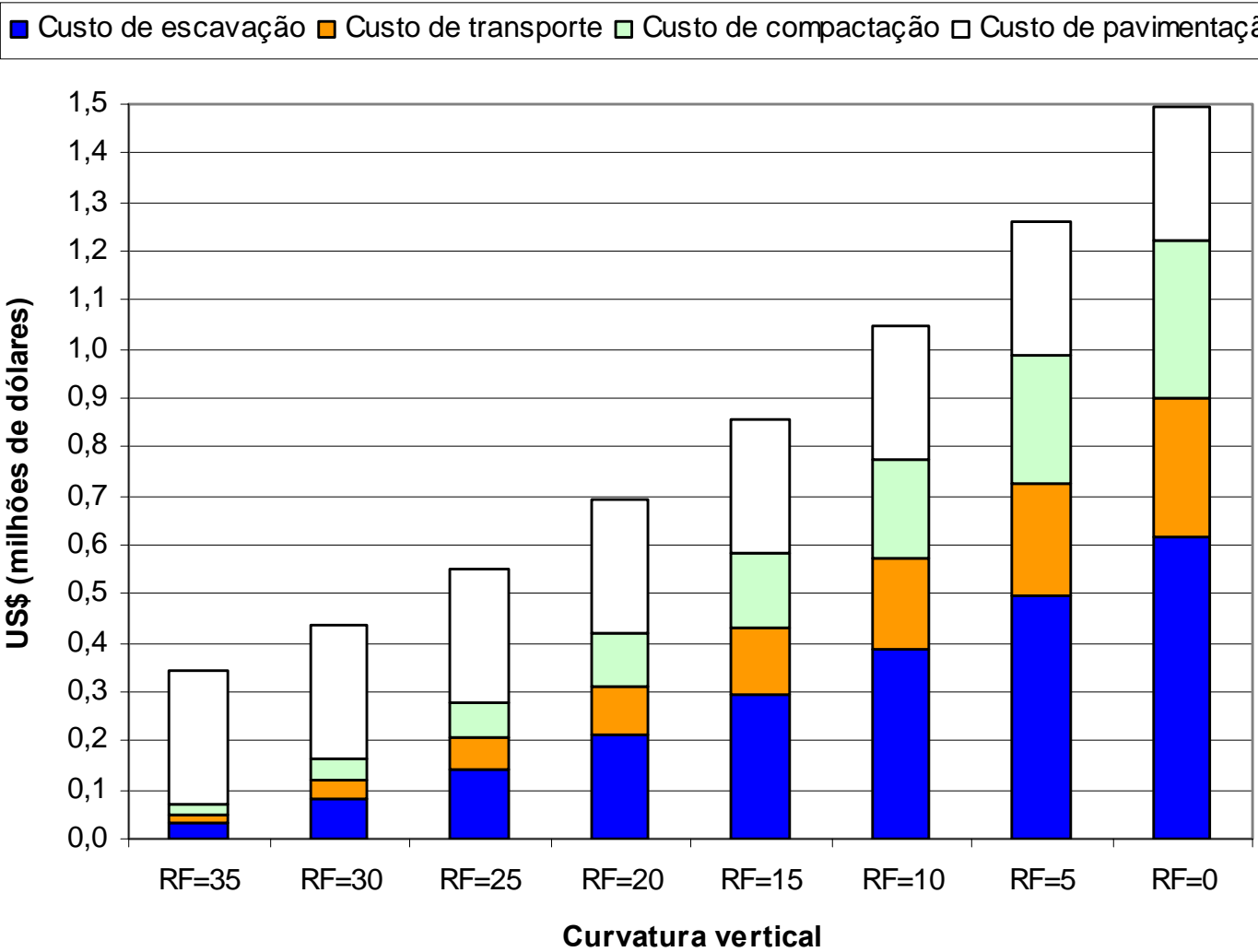

FIGURA 33 - Custos estimados de escavação, transporte, compactação e pavimentação para redução do RF dos trechos.

A Tabela 31 mostra o tempo que levaria para que os benefícios aos usuários se igualassem aos custos das intervenções, para diferentes taxas de desconto $(6,12$ e 18\%). Ela mostra, ainda, o Valor Presente Líquido e a Relação Benefício-Custo das 
intervenções para um período de projeto de 20 anos, para cada taxa de desconto. A Figura 34 mostra as curvas de variação do tempo de retorno de cada alternativa de intervenção para as diferentes taxas de desconto.

TABELA 31 - Avaliação econômica das intervenções para redução do RF dos trechos.

\begin{tabular}{|c|c|c|c|c|c|}
\hline $\begin{array}{c}\text { Taxa } \\
6 \%\end{array}$ & $\begin{array}{c}\text { Tempo de } \\
\text { retorno }\end{array}$ & $\begin{array}{c}\text { Benefícios } \\
\text { descontados * } \\
\text { (US\$ /ano / km) }\end{array}$ & $\begin{array}{c}\text { Custos } \\
\text { descontados * } \\
\text { (US\$ /ano / km) }\end{array}$ & $\begin{array}{l}\text { VPL * } \\
\text { (US\$) }\end{array}$ & $\mathrm{B} / \mathrm{C}$ * \\
\hline $\mathrm{RF}=35$ & 4 anos e 5 meses & 1038843,38 & 196359,69 & 842483,69 & 5,29 \\
\hline $\mathrm{RF}=30$ & 2 anos e 11 meses & 1927746,50 & 249452,28 & 1678294,23 & 7,73 \\
\hline $\mathrm{RF}=25$ & 3 anos & 2377965,00 & 316385,48 & 2061579,52 & 7,52 \\
\hline $\mathrm{RF}=20$ & 3 anos e 4 meses & 2725571,86 & 397159,29 & 2328412,57 & 6,86 \\
\hline $\mathrm{RF}=15$ & 3 anos e 9 meses & 2996021,13 & 491773,72 & 2504247,41 & 6,09 \\
\hline $\mathrm{RF}=10$ & 4 anos e 5 meses & 3209596,51 & 600228,76 & 2609367,75 & 5,35 \\
\hline $\mathrm{RF}=5$ & 5 anos e 3 meses & 3303060,60 & 722524,41 & 2580536,19 & 4,57 \\
\hline $\mathrm{RF}=0$ & 6 anos e 5 meses & 3339253,08 & 858660,67 & 2480592,41 & 3,89 \\
\hline $\begin{array}{l}\text { Taxa } \\
12 \%\end{array}$ & $\begin{array}{c}\text { Tempo de } \\
\text { retorno }\end{array}$ & $\begin{array}{c}\text { Benefícios } \\
\text { descontados * } \\
\text { (US\$ /ano /km) }\end{array}$ & $\begin{array}{c}\text { Custos } \\
\text { descontados * } \\
\text { (US\$ /ano /km) }\end{array}$ & $\begin{array}{l}\text { VPL * } \\
\text { (US\$) }\end{array}$ & $\mathrm{B} / \mathrm{C}$ * \\
\hline $\mathrm{RF}=35$ & 5 anos e 5 meses & 676515,73 & 127873,39 & 548642,34 & 5,29 \\
\hline $\mathrm{RF}=30$ & 3 anos e 4 meses & 1255387,34 & 162448,35 & 1092938,99 & 7,73 \\
\hline $\mathrm{RF}=25$ & 3 anos e 6 meses & 1548578,68 & 206036,60 & 1342542,09 & 7,52 \\
\hline $\mathrm{RF}=20$ & 3 anos e 10 meses & 1774947,27 & 258638,13 & 1516309,14 & 6,86 \\
\hline $\mathrm{RF}=15$ & 4 anos e 6 meses & 1951069,28 & 320252,95 & 1630816,33 & 6,09 \\
\hline $\mathrm{RF}=10$ & 5 anos e 4 meses & 2090153,87 & 390881,05 & 1699272,82 & 5,35 \\
\hline $\mathrm{RF}=5$ & 6 anos e 8 meses & 2151019,56 & 470522,44 & 1680497,12 & 4,57 \\
\hline $\mathrm{RF}=0$ & 8 anos e 5 meses & 2174588,83 & 559177,12 & 1615411,72 & 3,89 \\
\hline $\begin{array}{l}\text { Taxa } \\
18 \%\end{array}$ & $\begin{array}{c}\text { Tempo de } \\
\text { retorno }\end{array}$ & $\begin{array}{c}\text { Benefícios } \\
\text { descontados * } \\
\text { (US\$ /ano /km) }\end{array}$ & $\begin{array}{c}\text { Custos } \\
\text { descontados * } \\
\text { (US\$ /ano / km) }\end{array}$ & $\begin{array}{l}\text { VPL * } \\
\text { (US\$) }\end{array}$ & $\mathbf{B} / \mathbf{C} *$ \\
\hline $\mathrm{RF}=35$ & 6 anos e 11 meses & 484804,14 & 91636,52 & 393167,62 & 5,29 \\
\hline $\mathrm{RF}=30$ & 3 anos e 10 meses & 899634,63 & 116413,60 & 783221,03 & 7,73 \\
\hline $\mathrm{RF}=25$ & 3 anos e 11 meses & 1109741,17 & 147649,77 & 962091,40 & 7,52 \\
\hline $\mathrm{RF}=20$ & 4 anos e 7 meses & 1271961,24 & 185345,04 & 1086616,20 & 6,86 \\
\hline $\mathrm{RF}=15$ & 5 anos e 6 meses & 1398173,65 & 229499,40 & 1168674,25 & 6,09 \\
\hline $\mathrm{RF}=10$ & 6 anos e 10 meses & 1497844,33 & 280112,86 & 1217731,48 & 5,35 \\
\hline $\mathrm{RF}=5$ & 9 anos e 6 meses & 1541461,86 & 337185,40 & 1204276,45 & 4,57 \\
\hline $\mathrm{RF}=0$ & 15 anos e 9 meses & 1558352,05 & 400717,04 & 1157635,01 & 3,89 \\
\hline
\end{tabular}

* Para um período de projeto de 20 anos. 


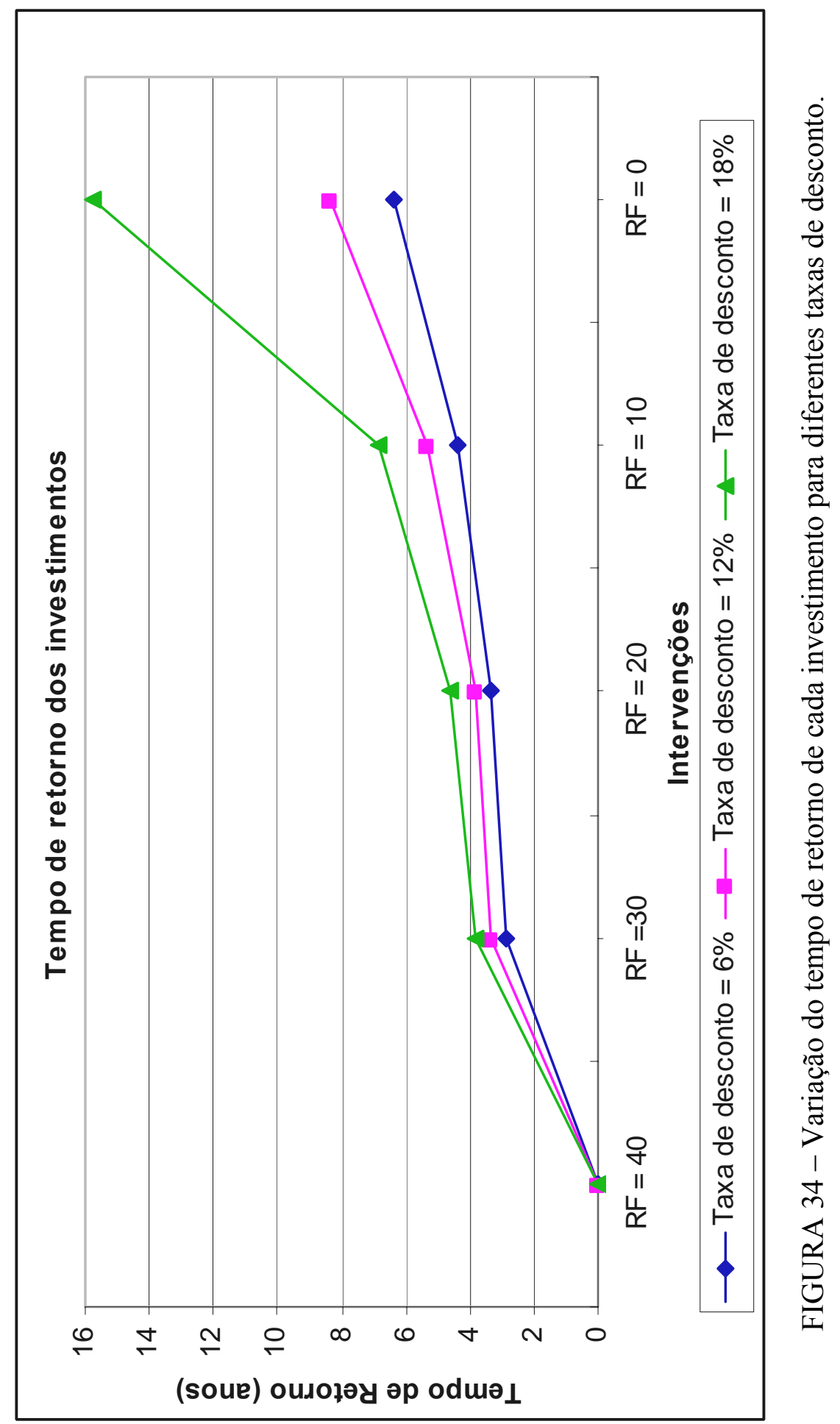




\subsection{RESULTADOS DA INFLUÊNCIA DA GEOMETRIA HORIZONTAL (ADC)}

As Tabelas 32 a 41 apresentam as parcelas dos custos totais dos usuários para os trechos fictícios $i$ a $r$ (que permitem a análise da influência da geometria horizontal - ADC nos custos), bem como as porcentagens de cada componente dos custos de operação dos veículos e do tempo de viagem. Os custos da soma de cada componente do custo de operação dos veículos considerados são mostrados nas Figuras 35 a 42. As Figuras 43 a 45 apresentam os custos de operação, do tempo de viagem e dos custos totais dos usuários de todos os veículos, em função de ADC.

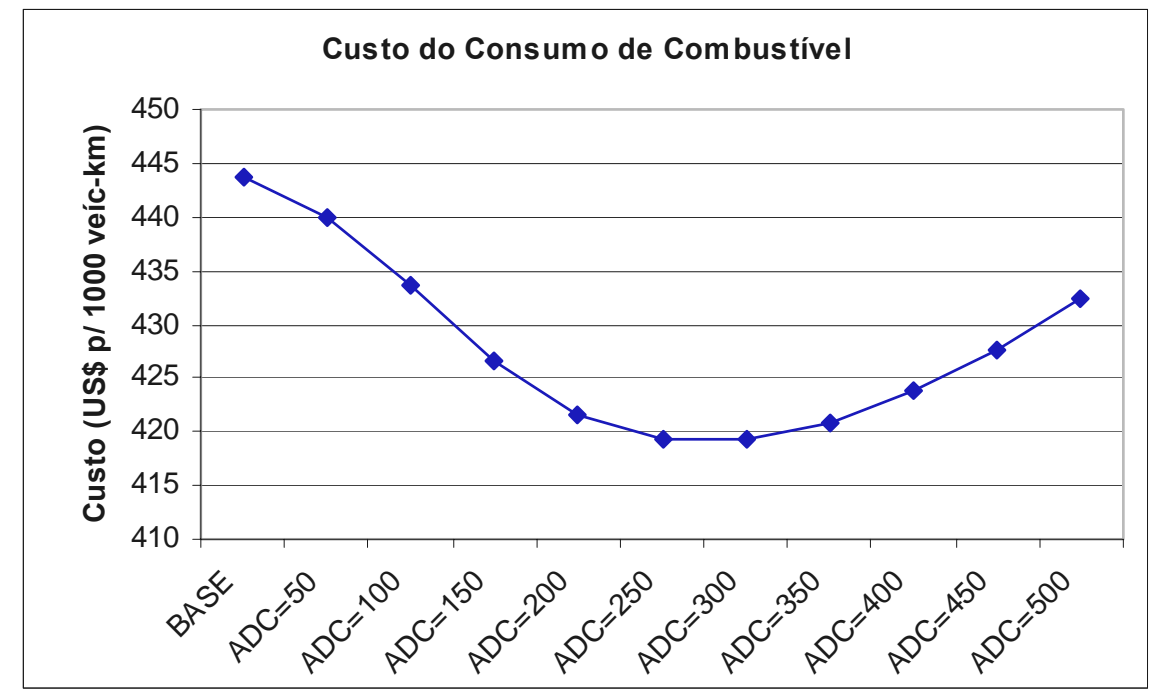

FIGURA 35 - Custo de consumo de combustível em função de ADC.

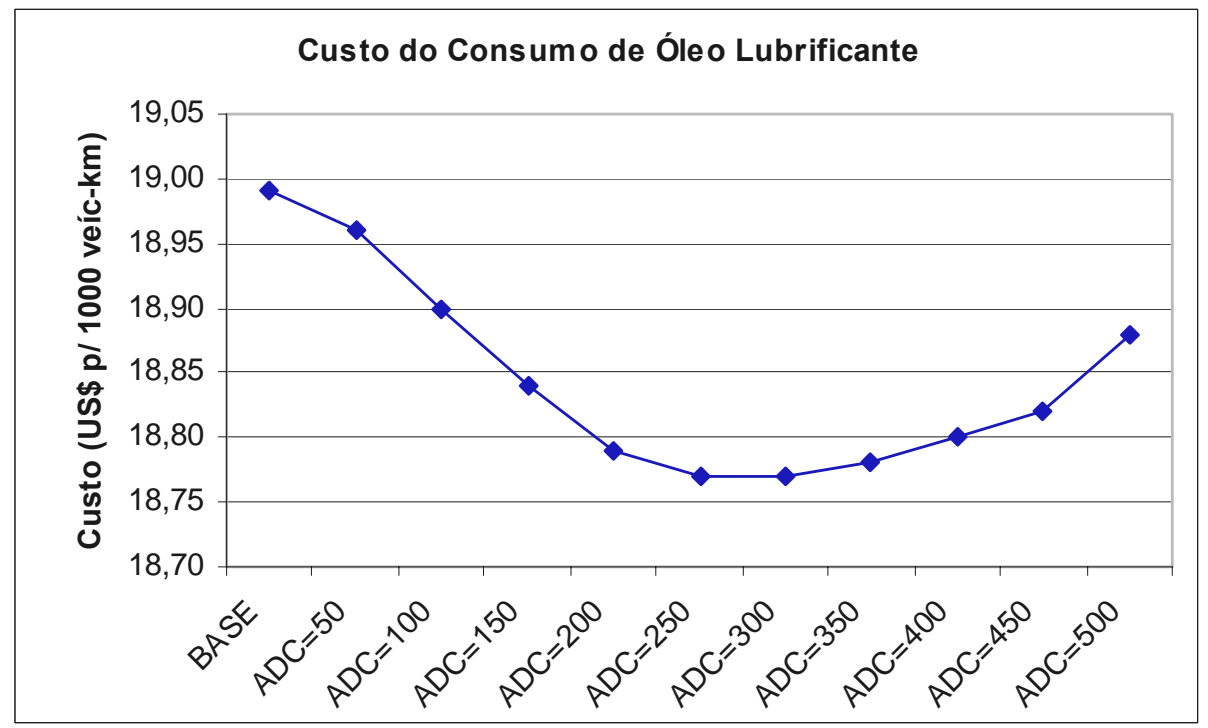

FIGURA 36 - Custo de consumo de óleo lubrificante em função de ADC. 


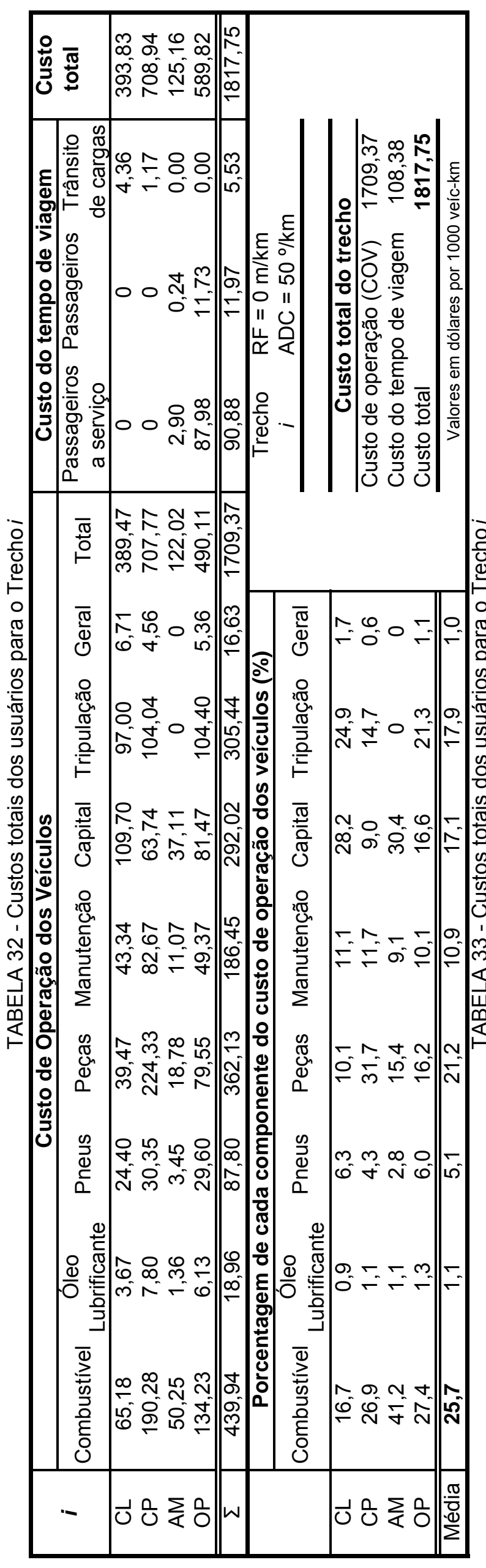

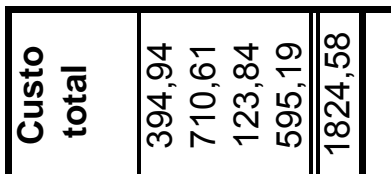

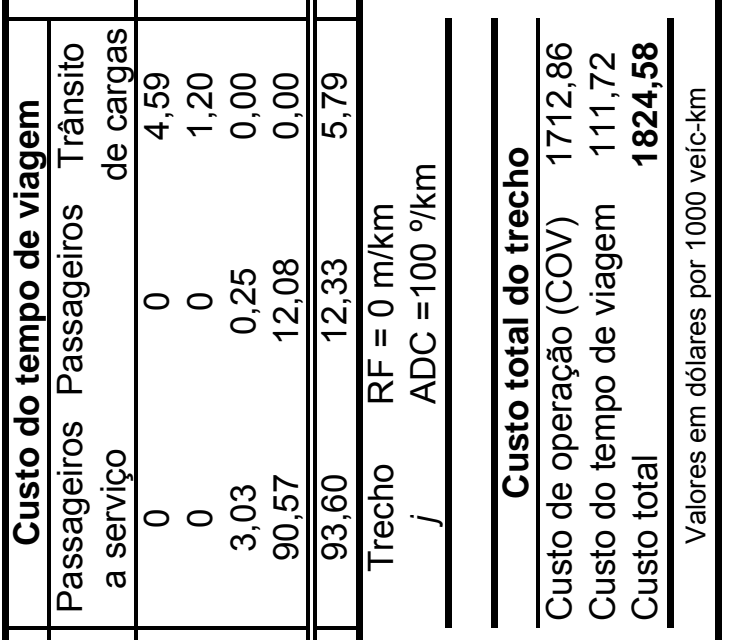

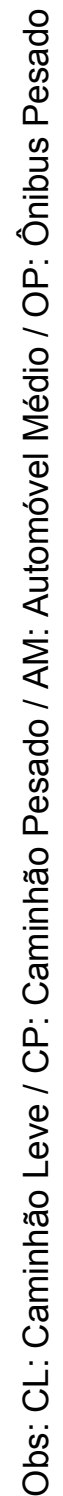

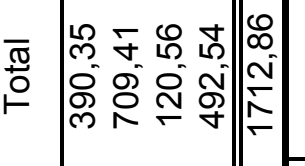

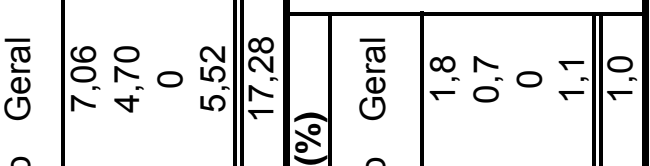

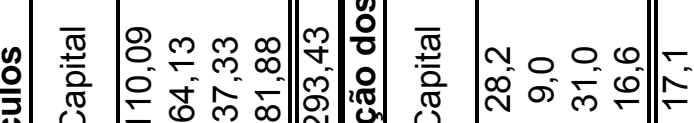

U

i্

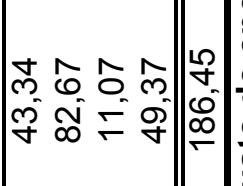

2:

- $r$ r 00

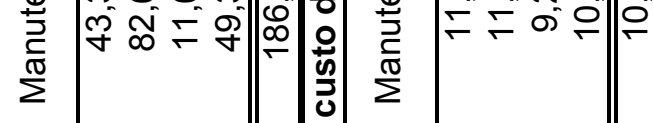

$\left.\begin{array}{l}0 \\ 0\end{array}\right)$ m

Q

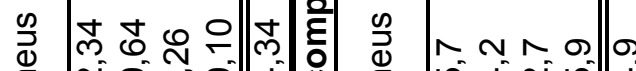

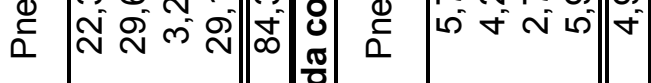

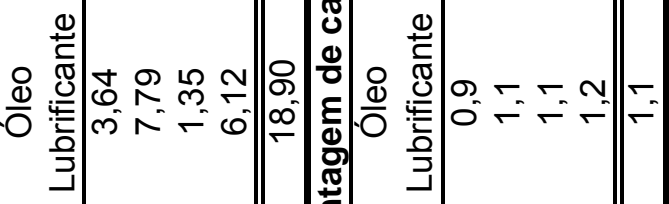




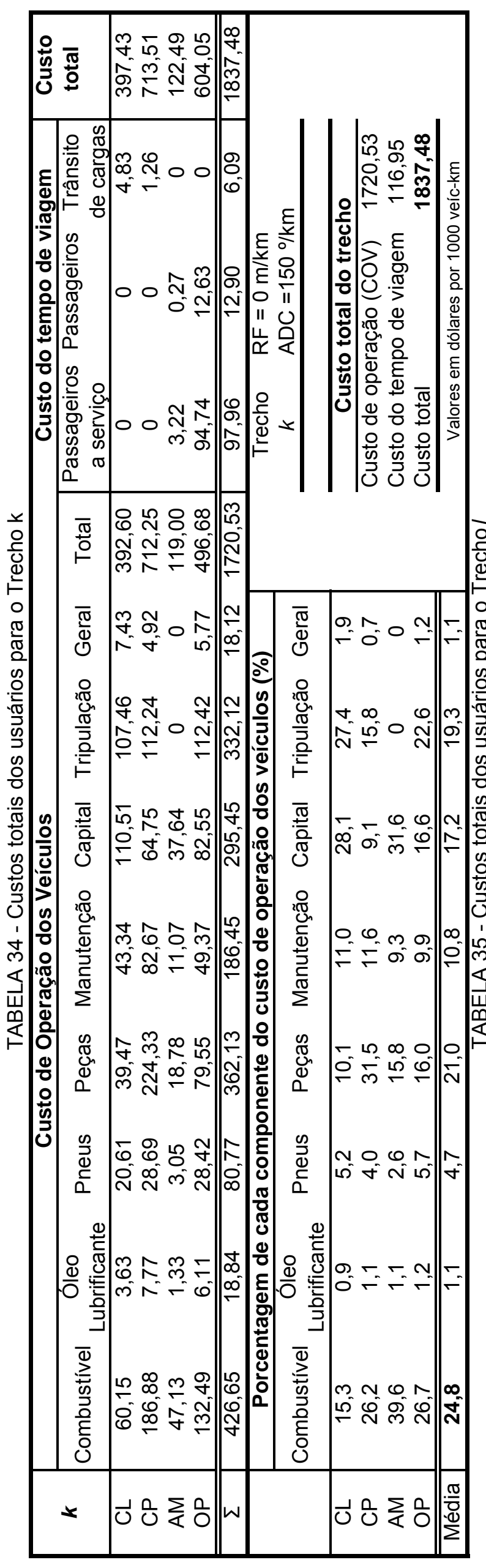

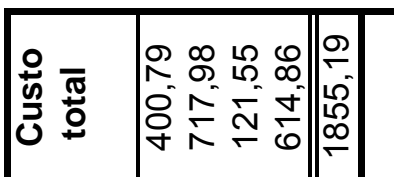

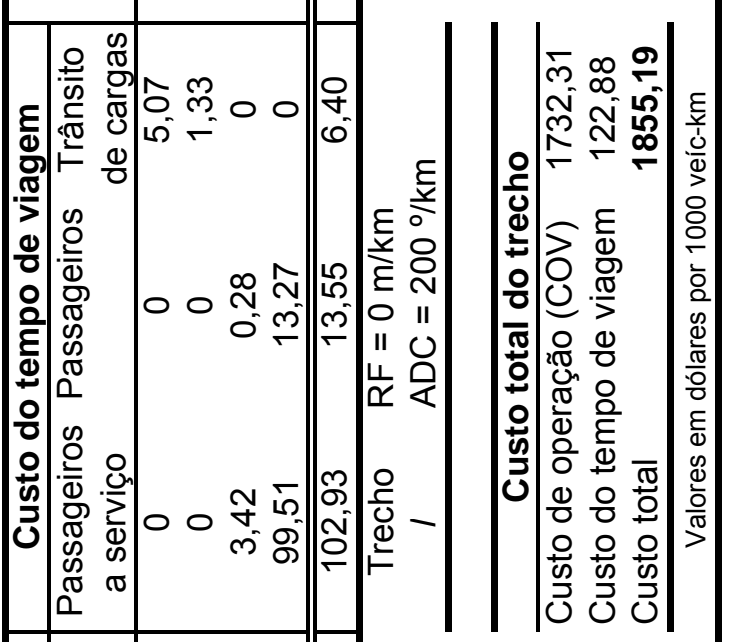

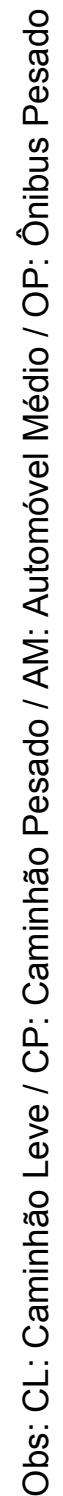

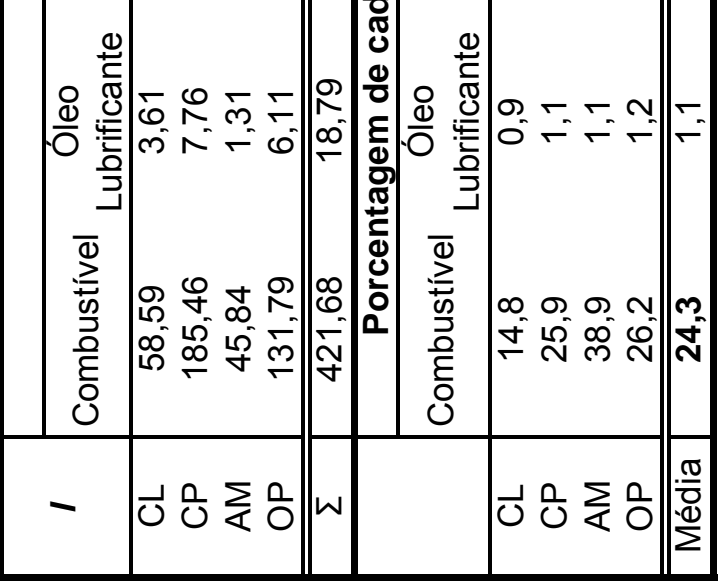




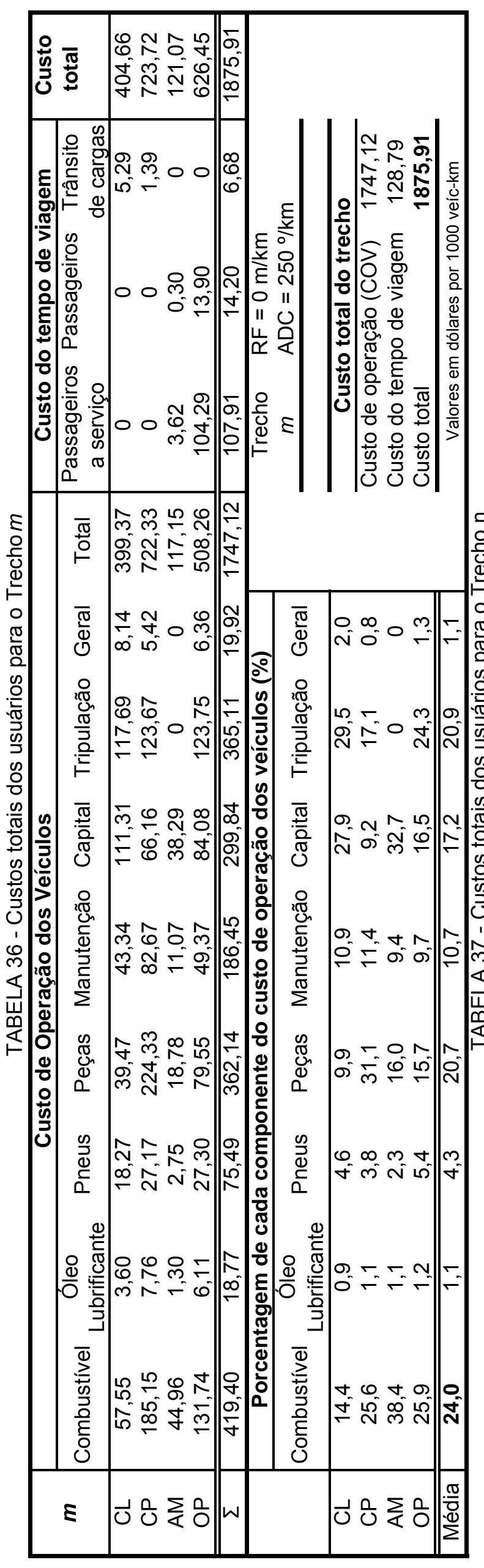

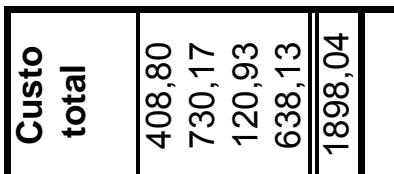

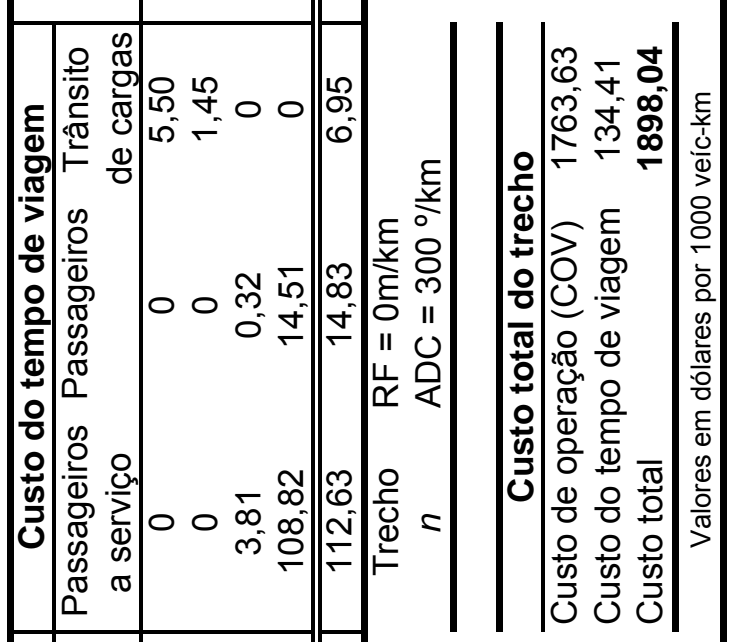

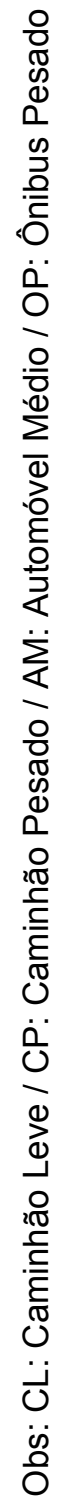

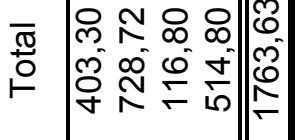

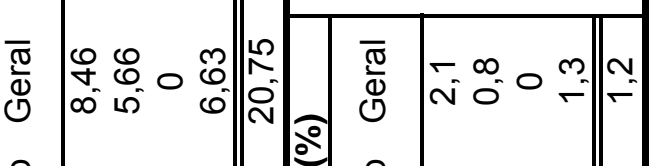

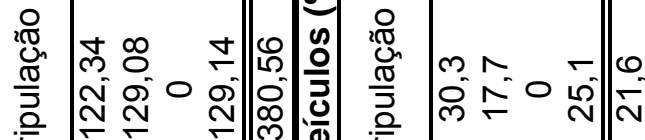

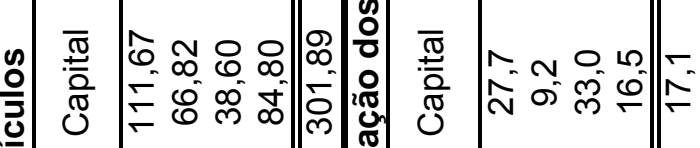

윰

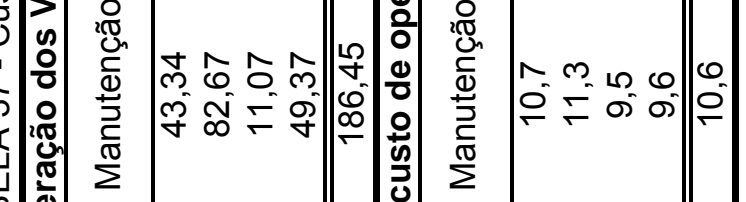

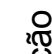

幽

ه

$\stackrel{5}{\mathcal{0}}$

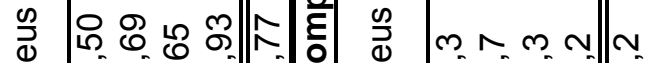

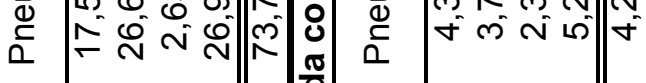

ه

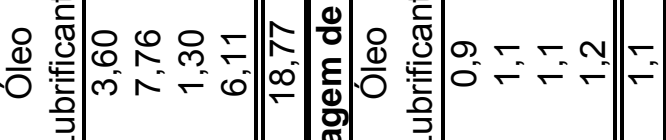

\begin{tabular}{|c|c|c|c|c|c|c|}
\hline 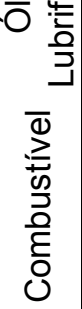 & 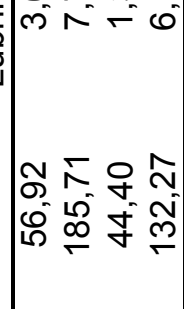 & 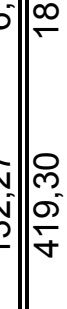 & 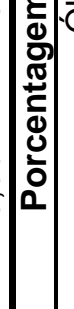 & 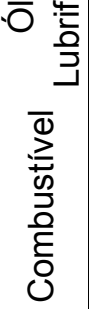 & 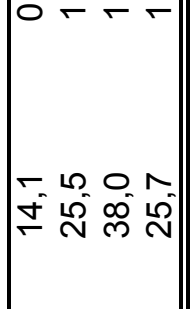 & $\mid \infty$ \\
\hline$=$ & U & 5 & & & U & $\mid \begin{array}{l}\mid \frac{\pi}{2} \\
-\frac{0}{2}\end{array}$ \\
\hline
\end{tabular}




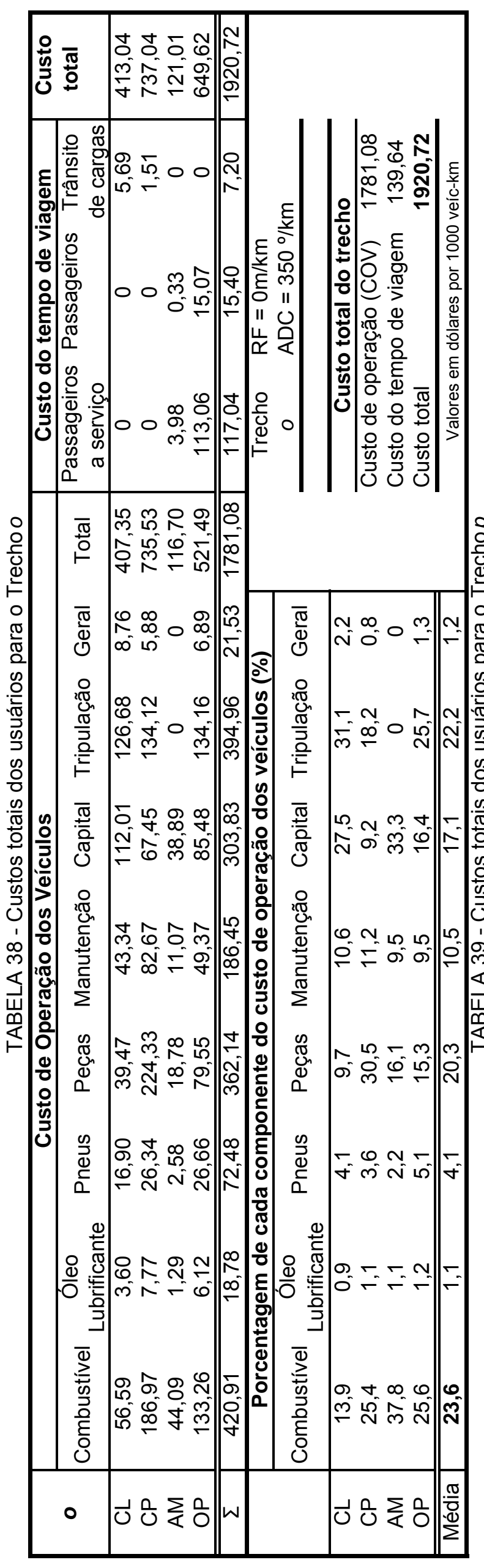

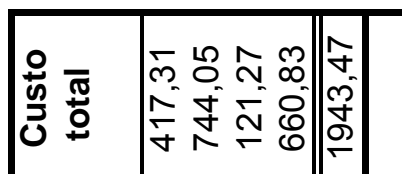

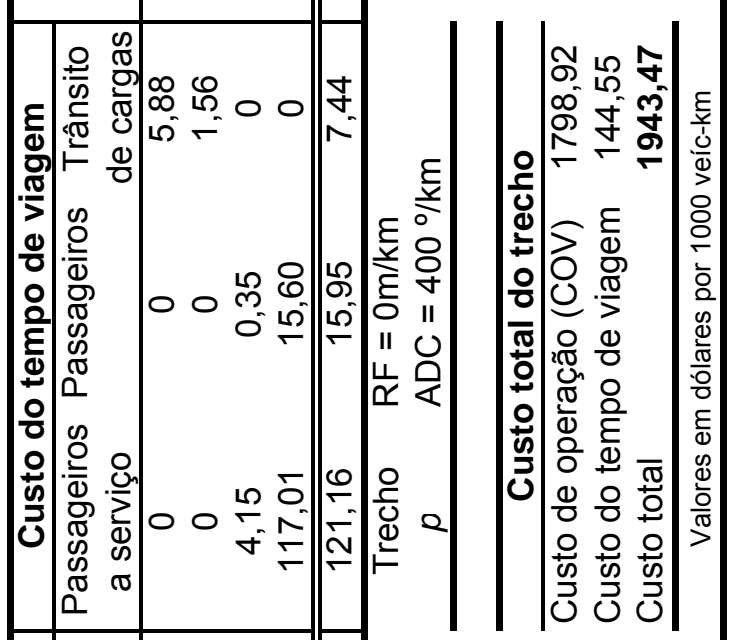

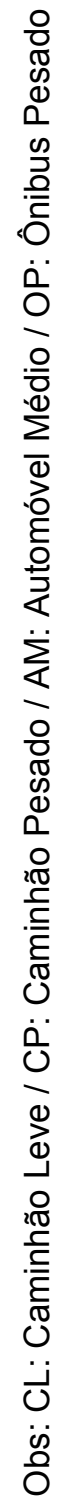

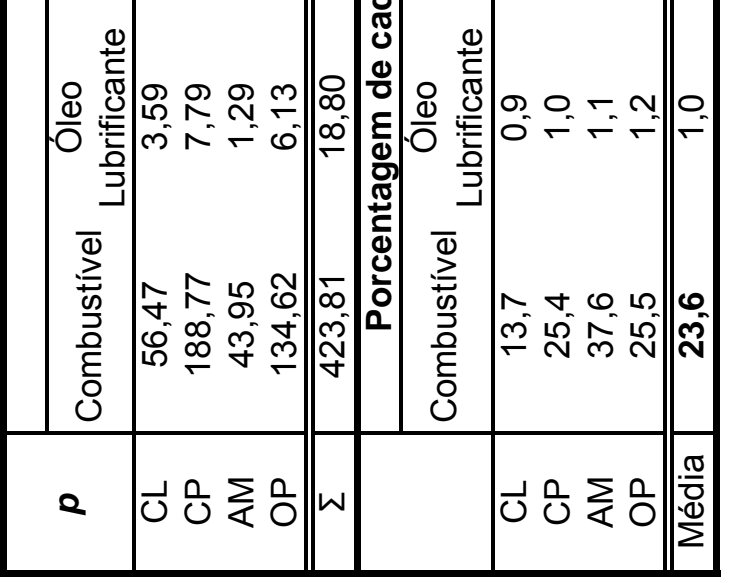




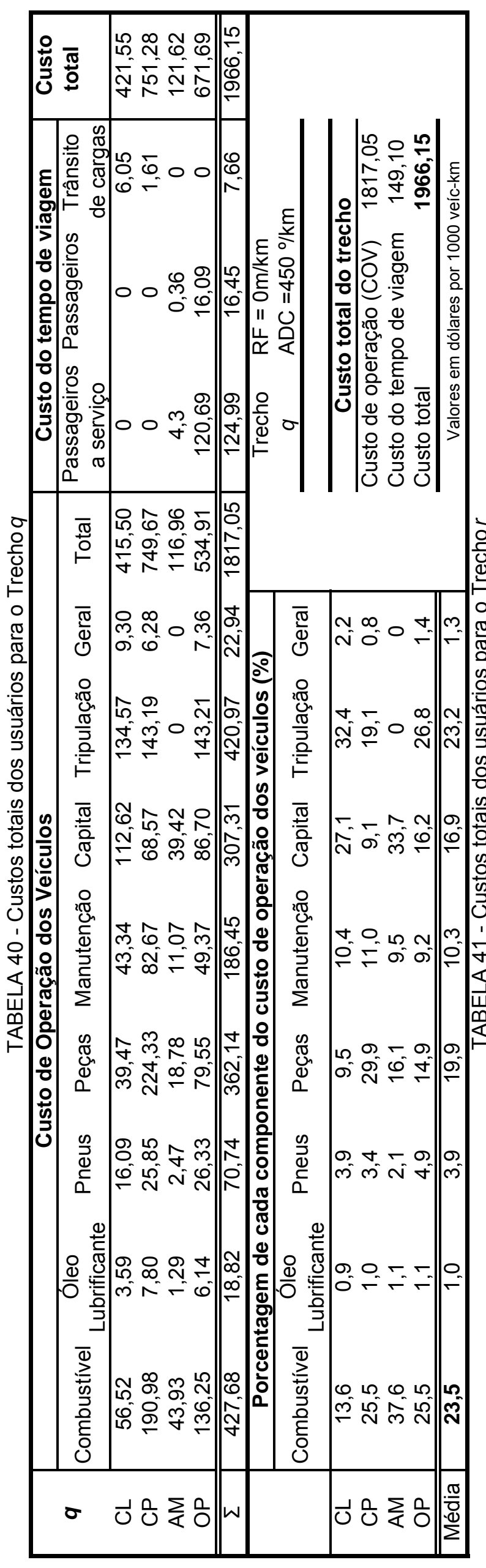

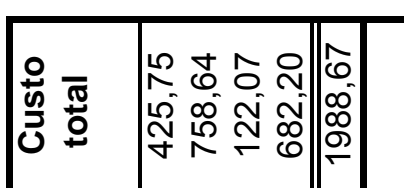

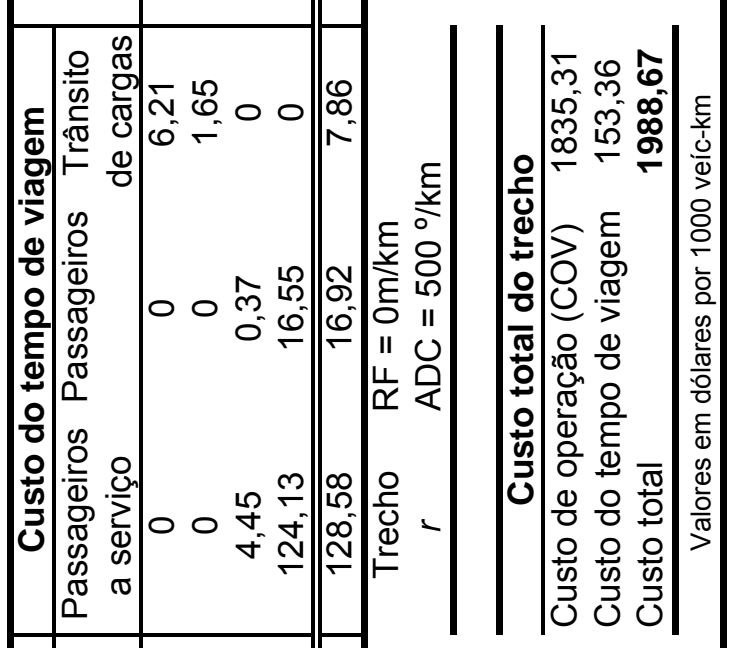

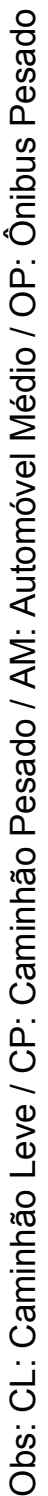

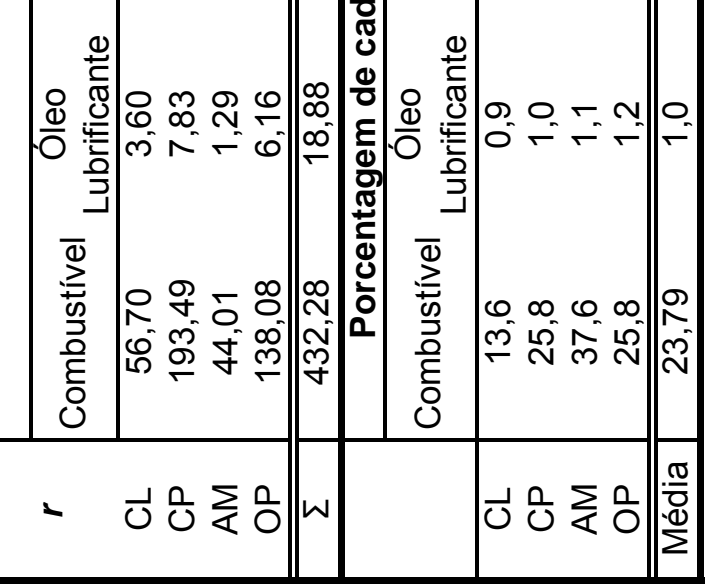




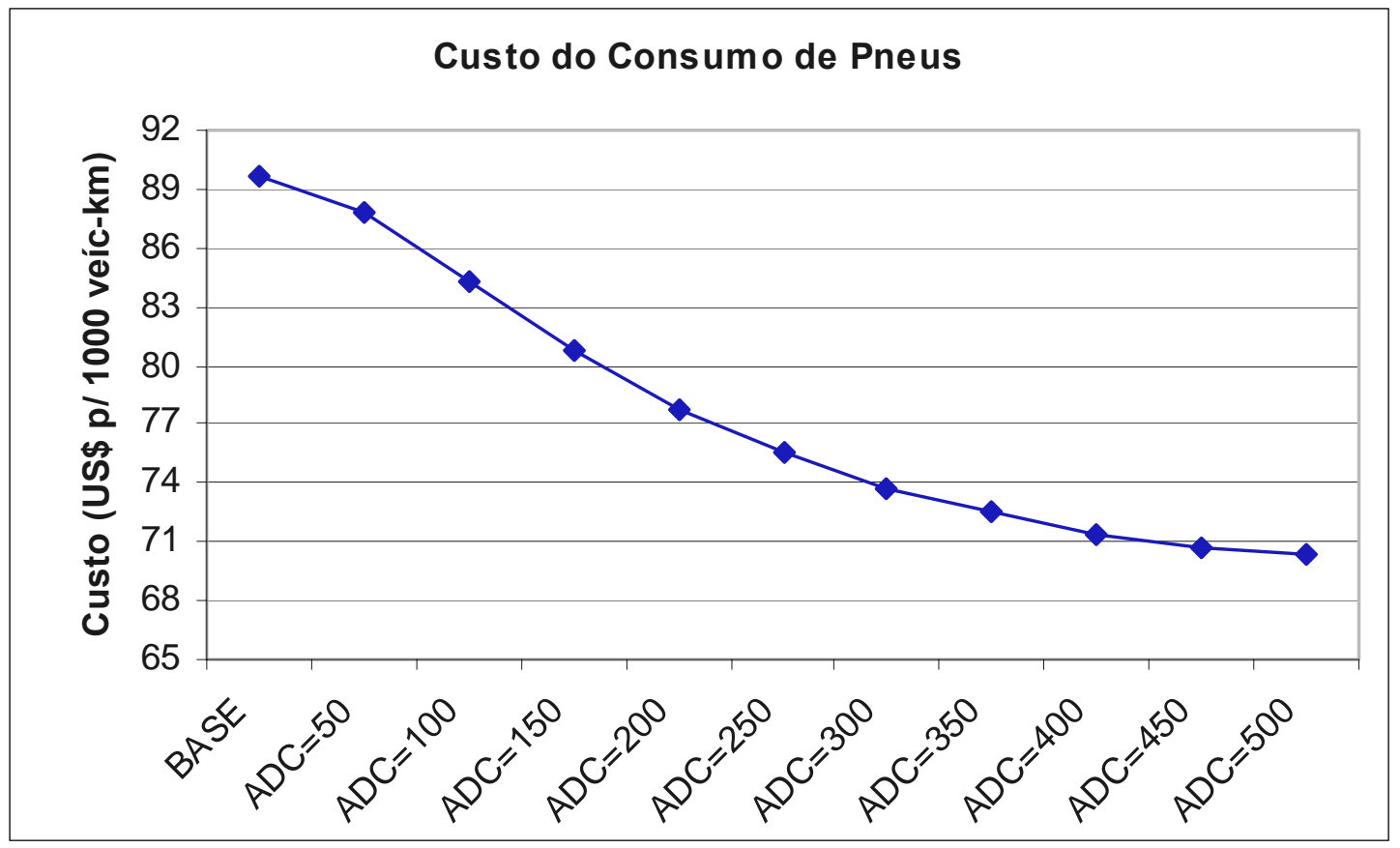

FIGURA 37 - Custo de consumo de pneus em função de ADC.

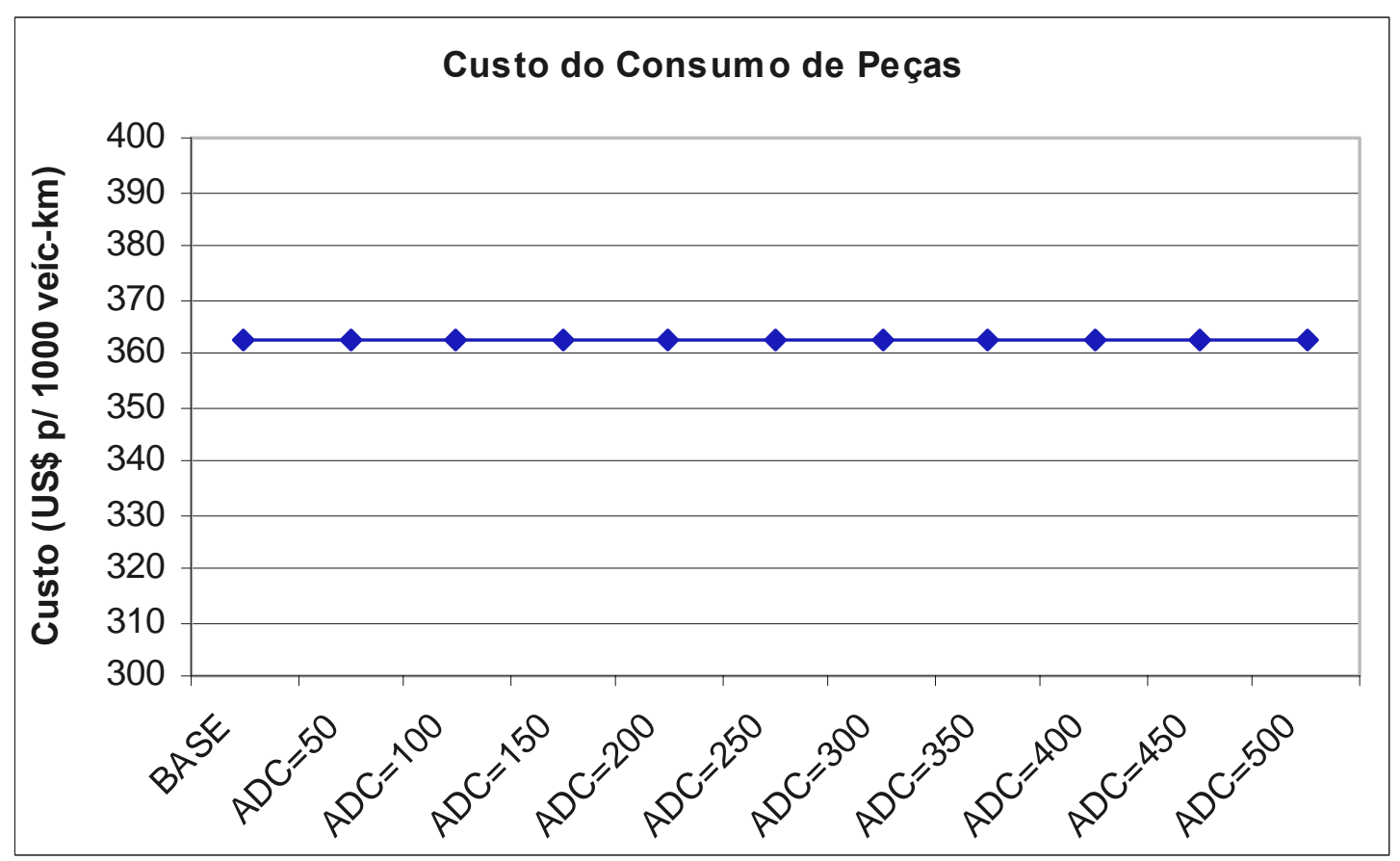

FIGURA 38 - Custo de consumo de peças em função de ADC. 


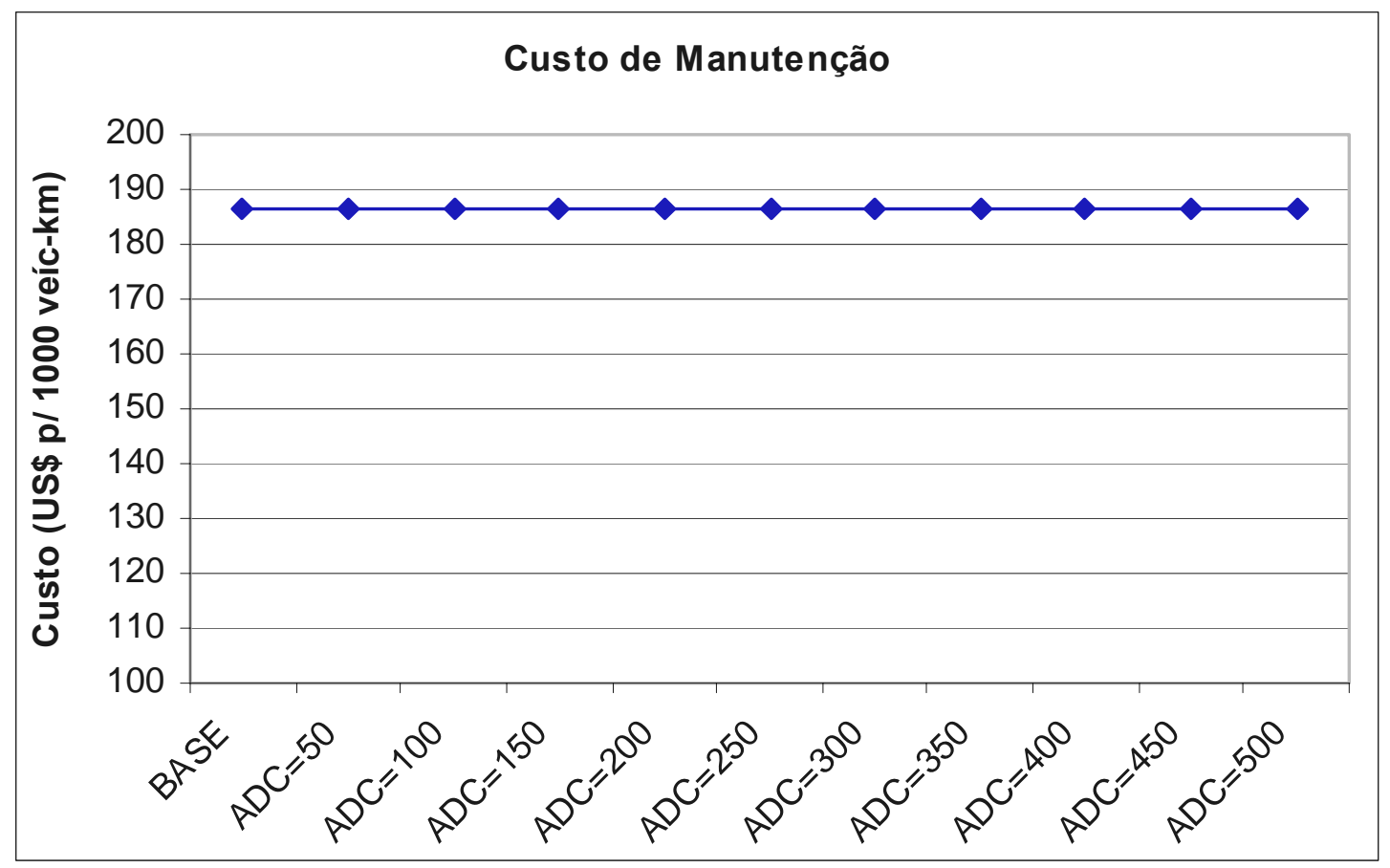

FIGURA 39 - Custo de manutenção dos veículos em função de ADC.

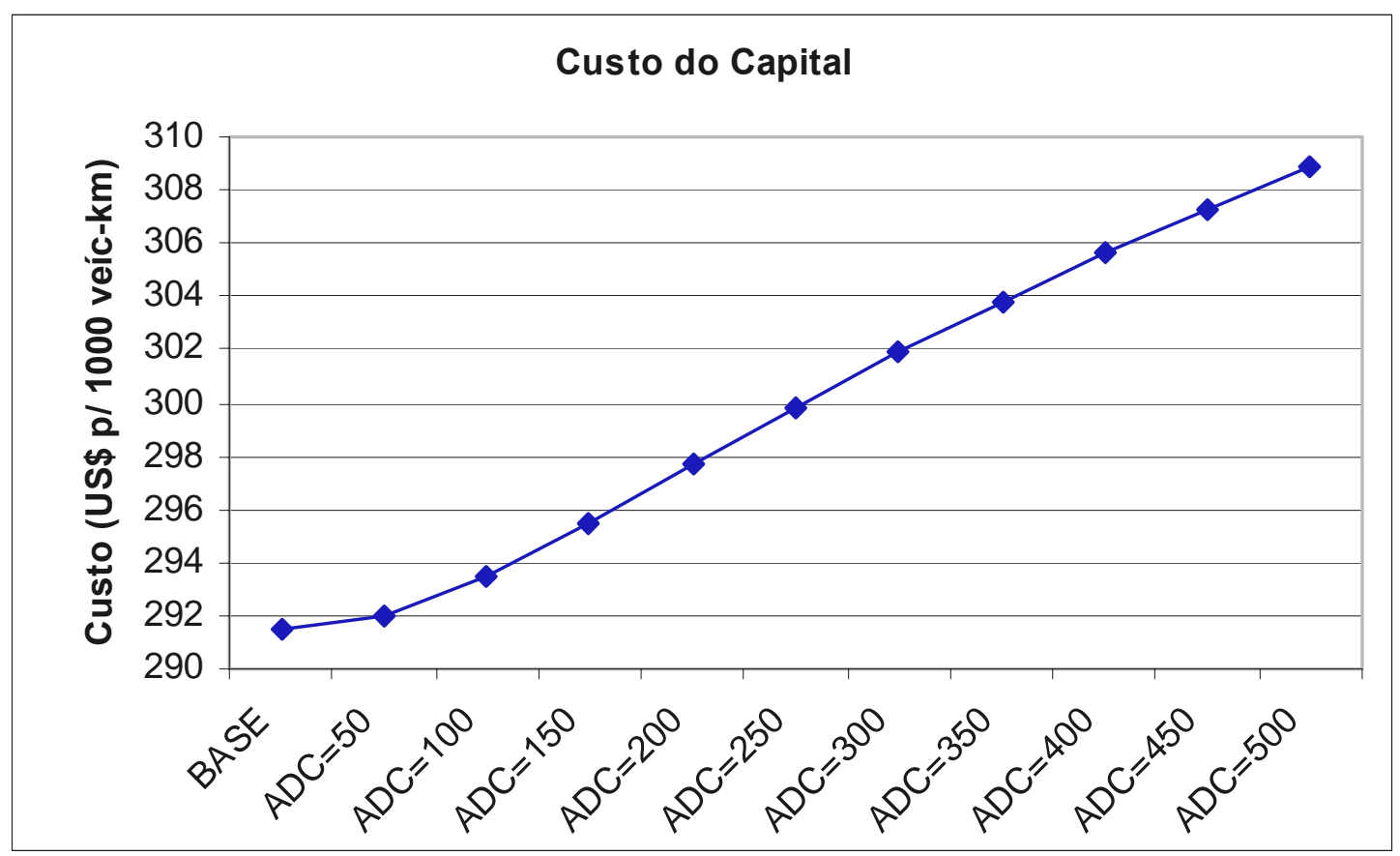

FIGURA 40 - Custo do capital em função de ADC. 


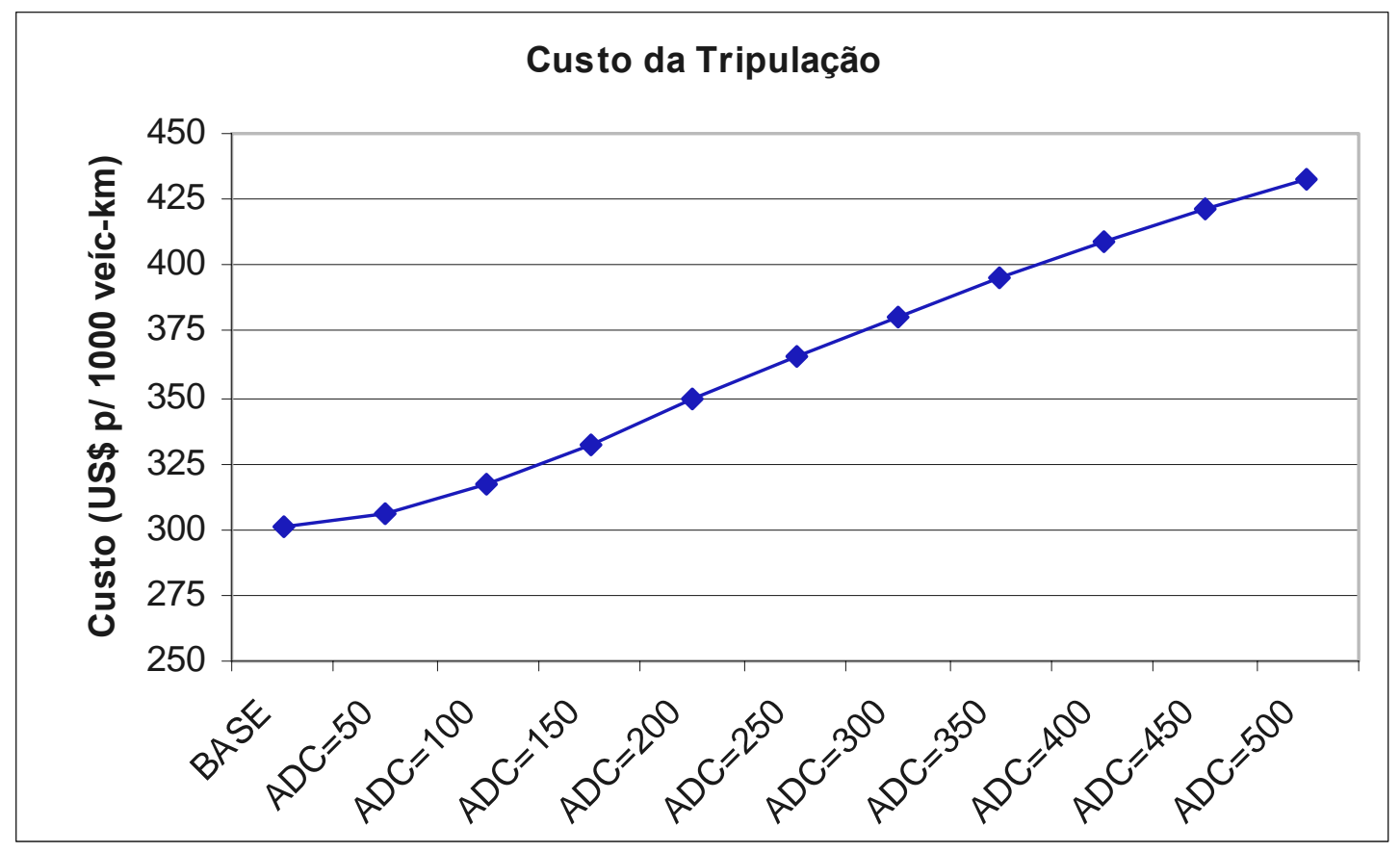

FIGURA 41 - Custo da tripulação em função de ADC.

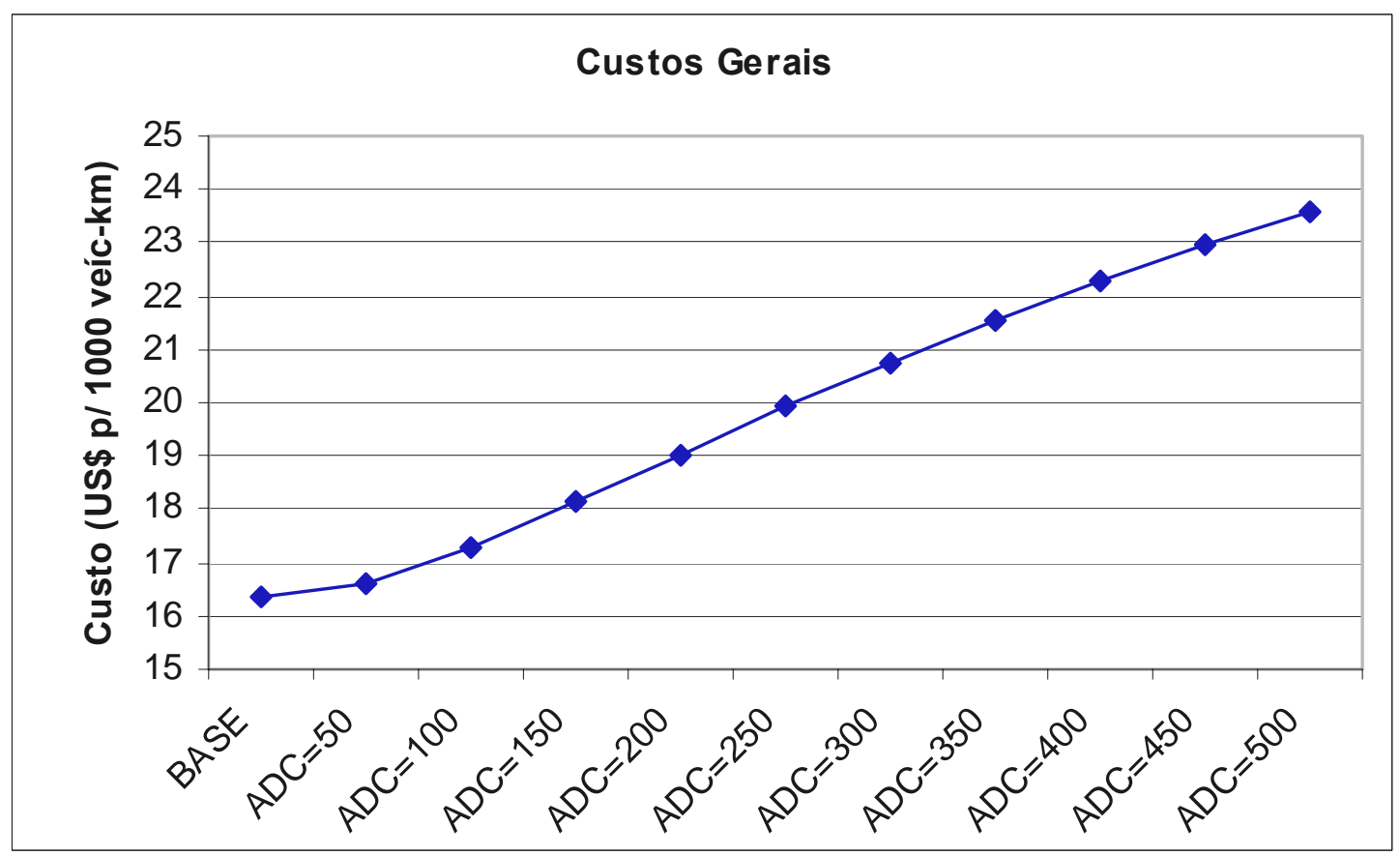

FIGURA 42 - Custos gerais em função de ADC. 


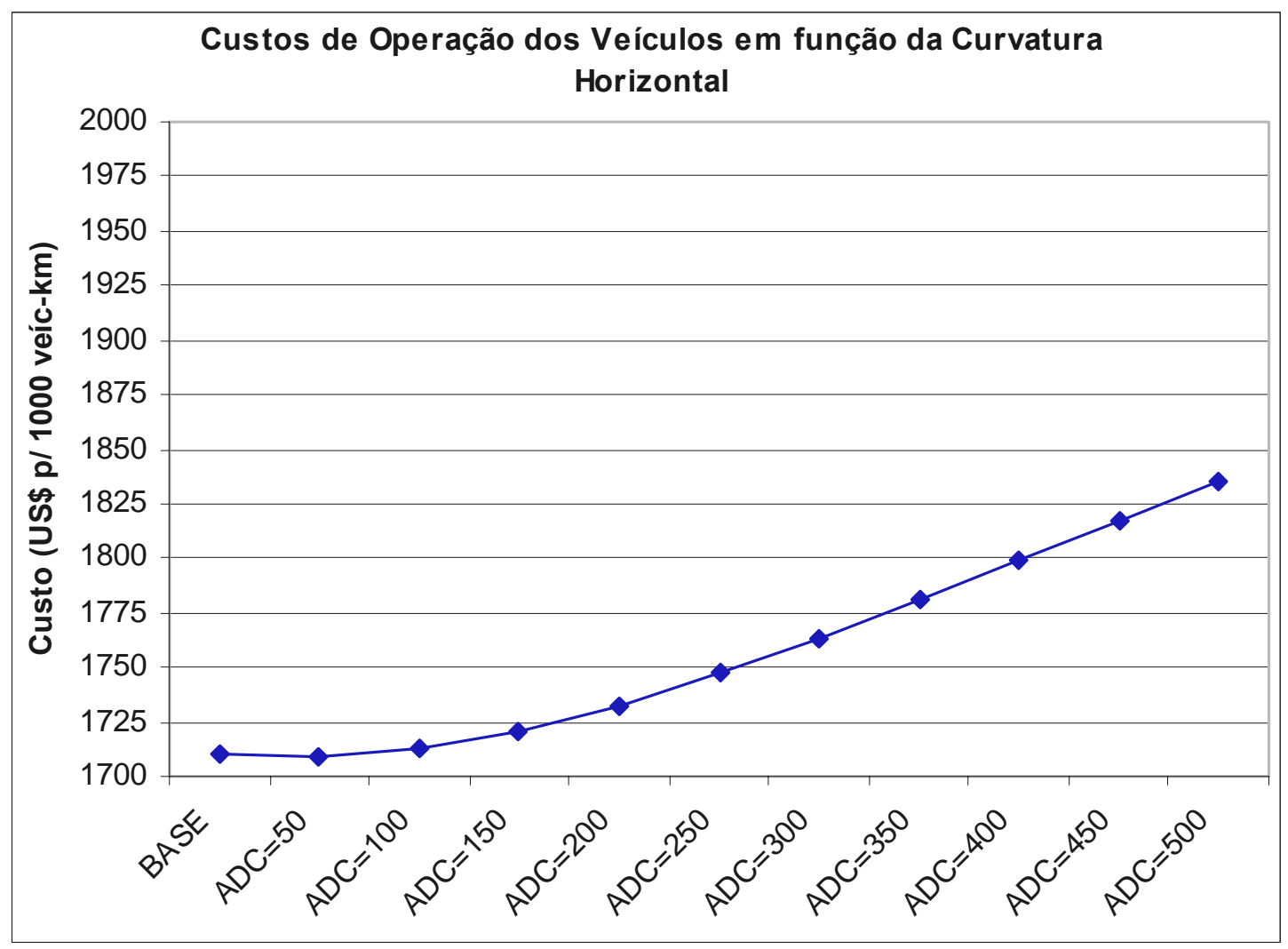

FIGURA 43 - Custo de operação dos veículos em função de ADC.

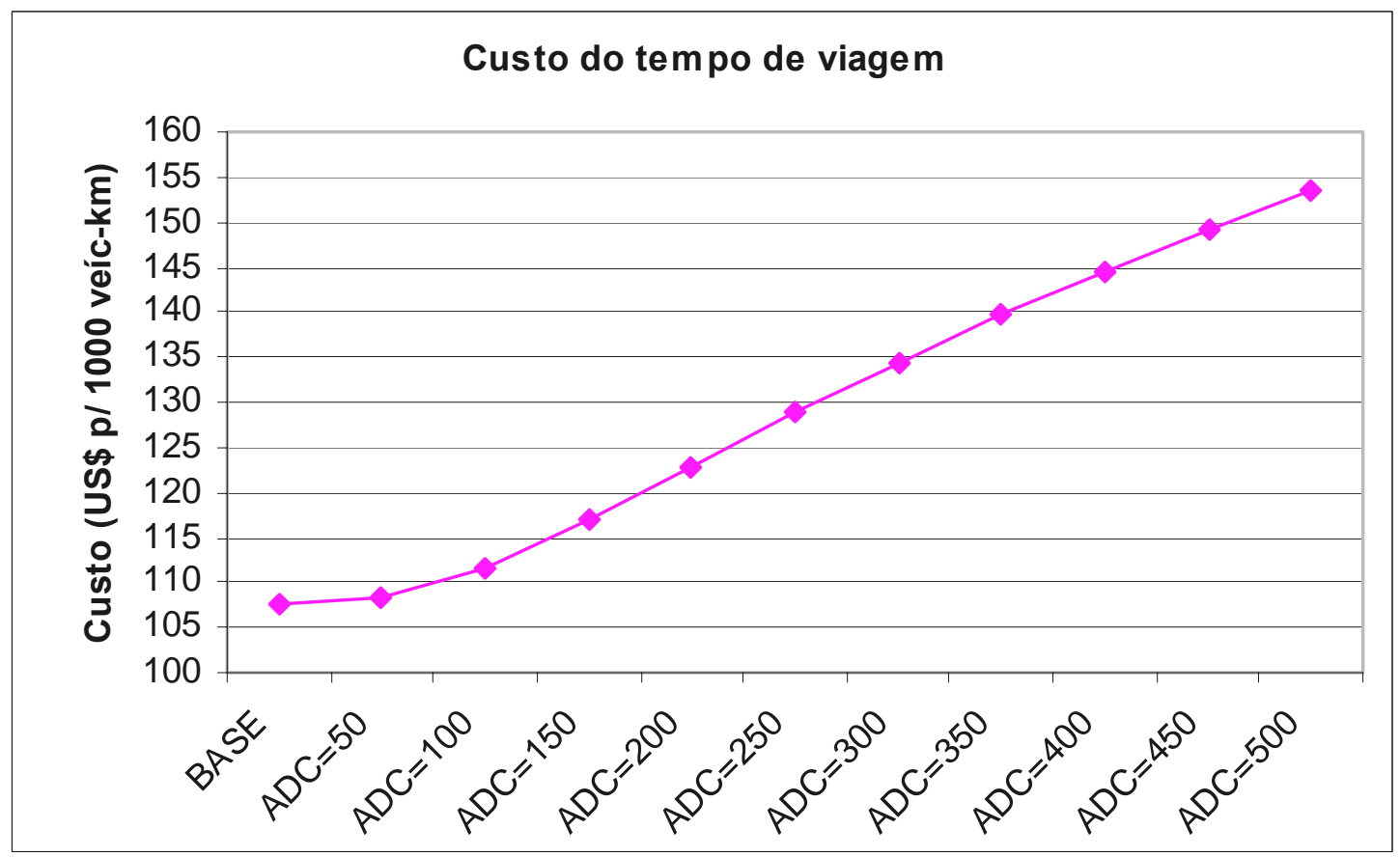

FIGURA 44 - Custo do tempo de viagem em função de ADC. 


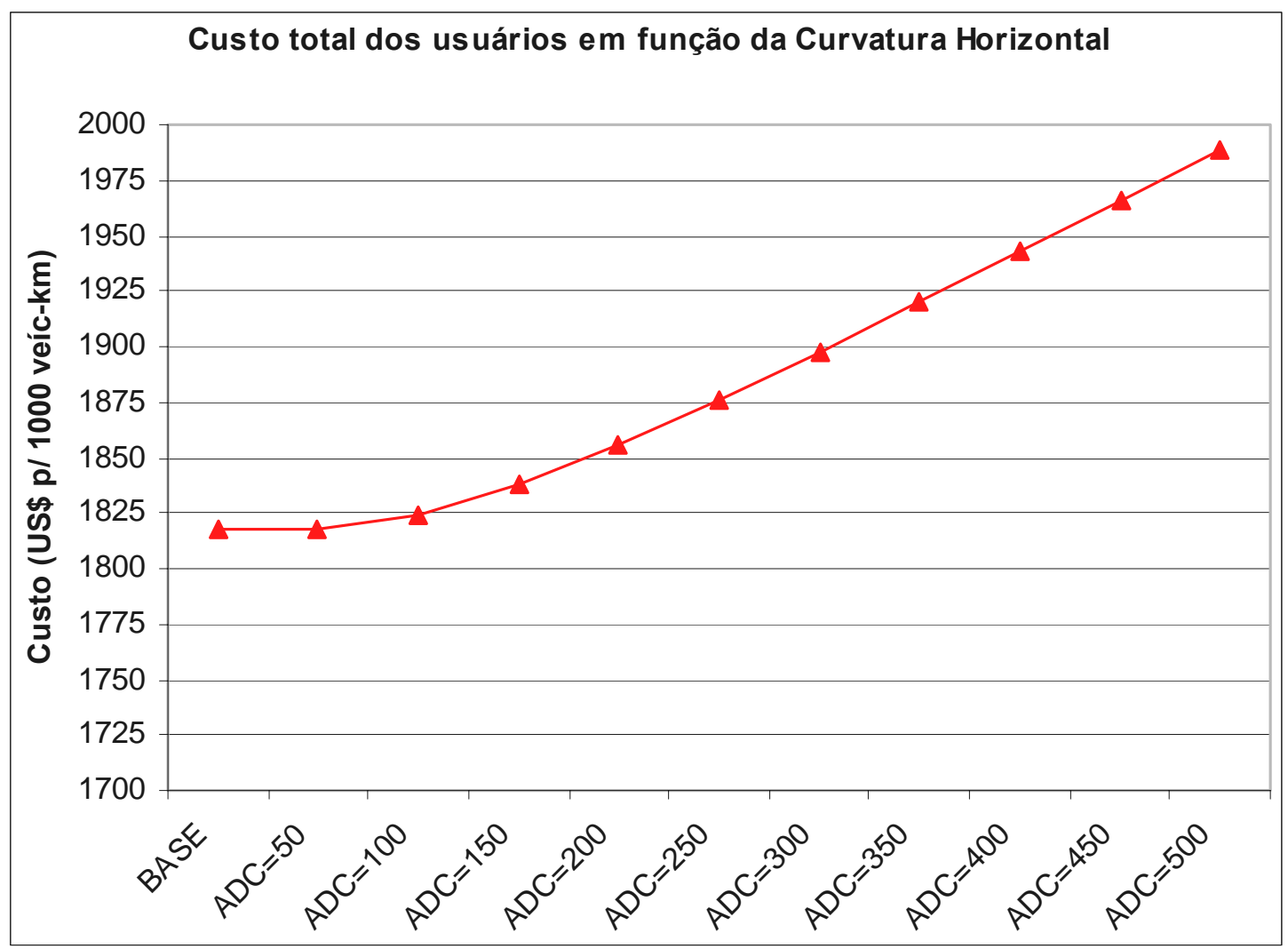

FIGURA 45 - Custo total dos usuários em função de ADC.

A Tabela 42 e as Figuras 46 e 47 apresentam as variações da velocidade de operação e do consumo de combustível de cada tipo de veículo em função de ADC.

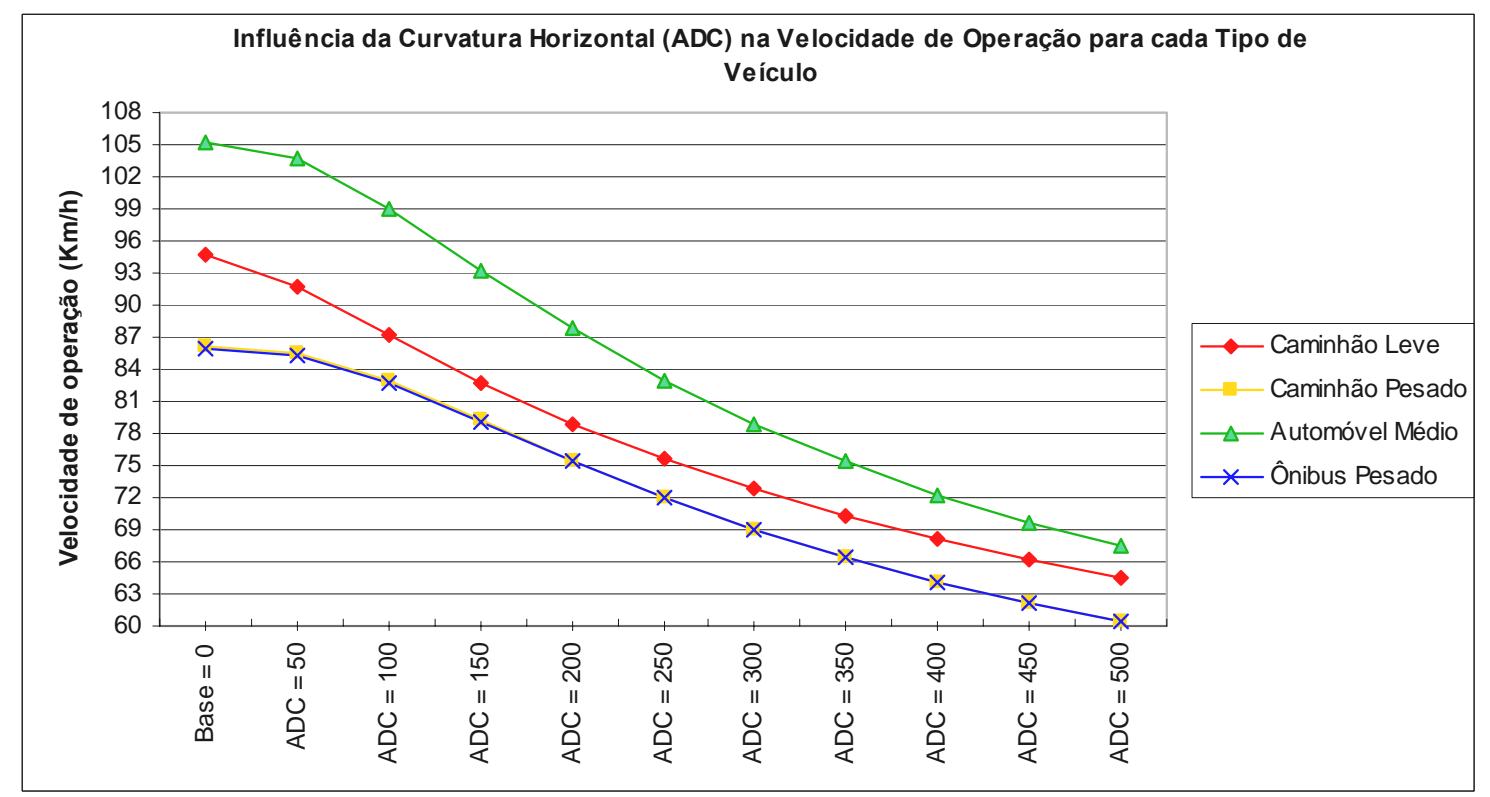

FIGURA 46 - Influência da curvatura horizontal (ADC) na velocidade de operação de cada tipo de veículo. 


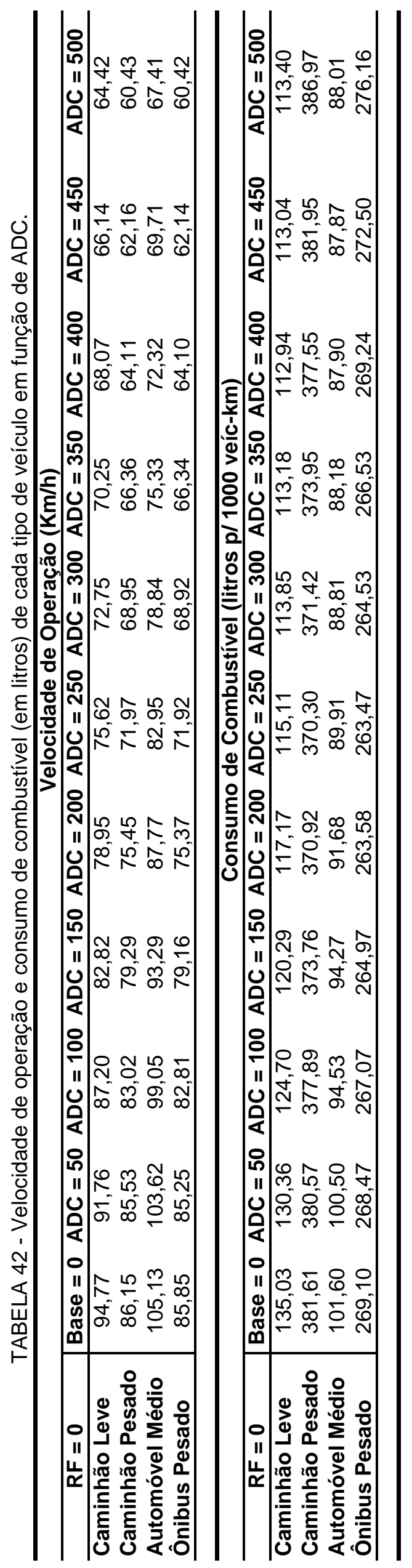




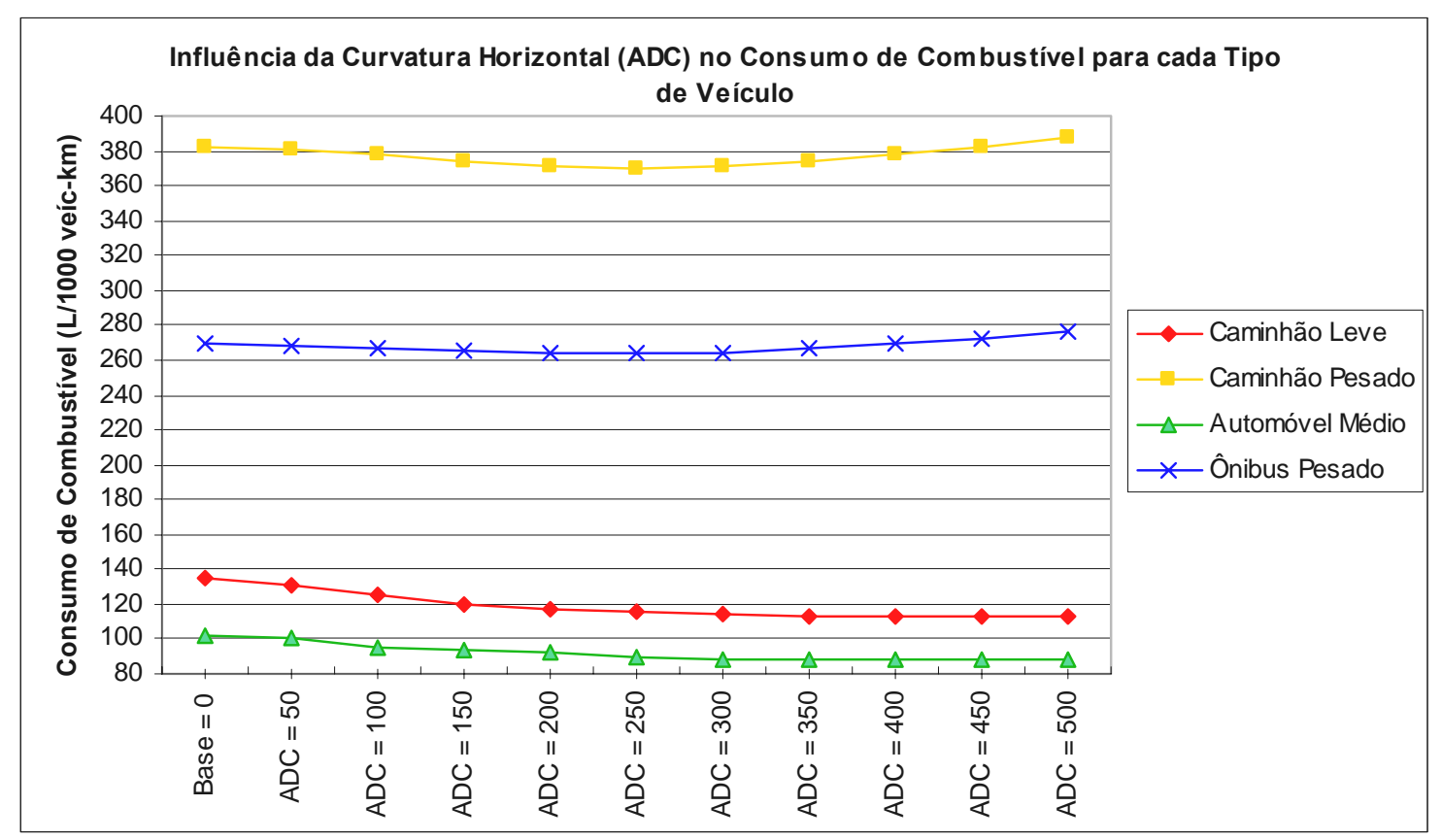

FIGURA 47 - Influência da curvatura horizontal (ADC) no consumo de combustível de cada tipo de veículo.

A Tabela 43 apresenta os componentes com maior contribuição para o custo de operação dos veículos (COV), em função da geometria horizontal, a partir dos resultados apresentados nas Tabelas 32 a 41. Destacam-se o consumo de combustível, que mais contribui em todos os trechos, exceto o trecho com maior ADC, o desgaste das peças e os custos da tripulação.

TABELA 43 - Componentes com maiores porcentagens no COV - Trecho Base e Trechos $i$ a $r$.

\begin{tabular}{|c|c|c|c|}
\hline Trechos & Maior \% & $2^{\text {a. }}$ maior $\%$ & $3^{\text {a. }}$ maior $\%$ \\
\hline Base (ADC $=0)$ & Combustível & Peças & Tripulação \\
\hline$i(A D C=50)$ & Combustível & Peças & Tripulação \\
\hline $\mathrm{j}(\mathrm{ADC}=100)$ & Combustível & Peças & Tripulação \\
\hline$k(A D C=150)$ & Combustível & Peças & Tripulação \\
\hline $\mathrm{I}(\mathrm{ADC}=\mathbf{2 0 0})$ & Combustível & Peças & Tripulação \\
\hline$m(A D C=250)$ & Combustível & Tripulação & Peças \\
\hline$n(A D C=300)$ & Combustível & Tripulação & Peças \\
\hline$\circ(A D C=350)$ & Combustível & Tripulação & Peças \\
\hline$p(A D C=400)$ & Combustível & Tripulação & Peças \\
\hline$q(A D C=450)$ & Combustível & Tripulação & Peças \\
\hline$r(A D C=500)$ & Tripulação & Combustível & Peças \\
\hline
\end{tabular}




\subsection{RESULTADOS DOS TRECHOS DAS CLASSES DE GEOMETRIA DO HDM-4}

As Tabelas 44 a 50 apresentam as parcelas dos custos totais dos usuários para os trechos do HDM-4, bem como as porcentagens de cada componente dos custos de operação dos veículos e os custos do tempo de viagem.

Os gráficos das Figuras 48 a 55 mostram os custos da soma de cada componente do custo de operação dos veículos considerados para cada trecho. As Figuras 56 e 57 apresentam os custos de operação dos veículos e do tempo de viagem.

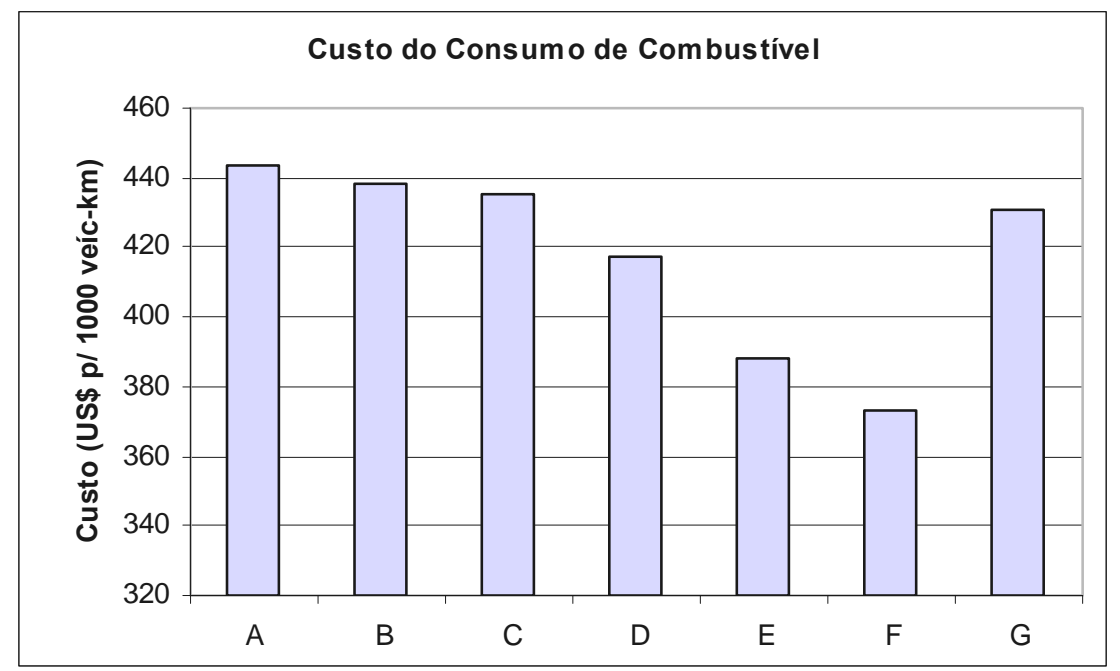

FIGURA 48 - Custo do consumo de combustível para os trechos do HDM-4.

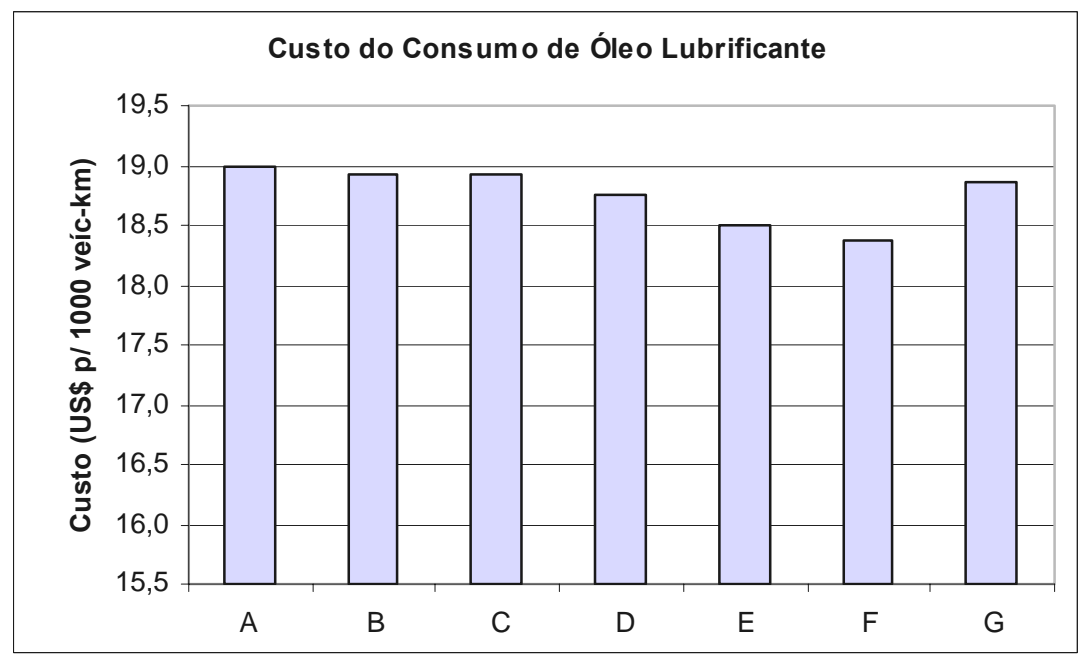

FIGURA 49 - Custo do consumo de óleo lubrificante para os trechos do HDM-4. 


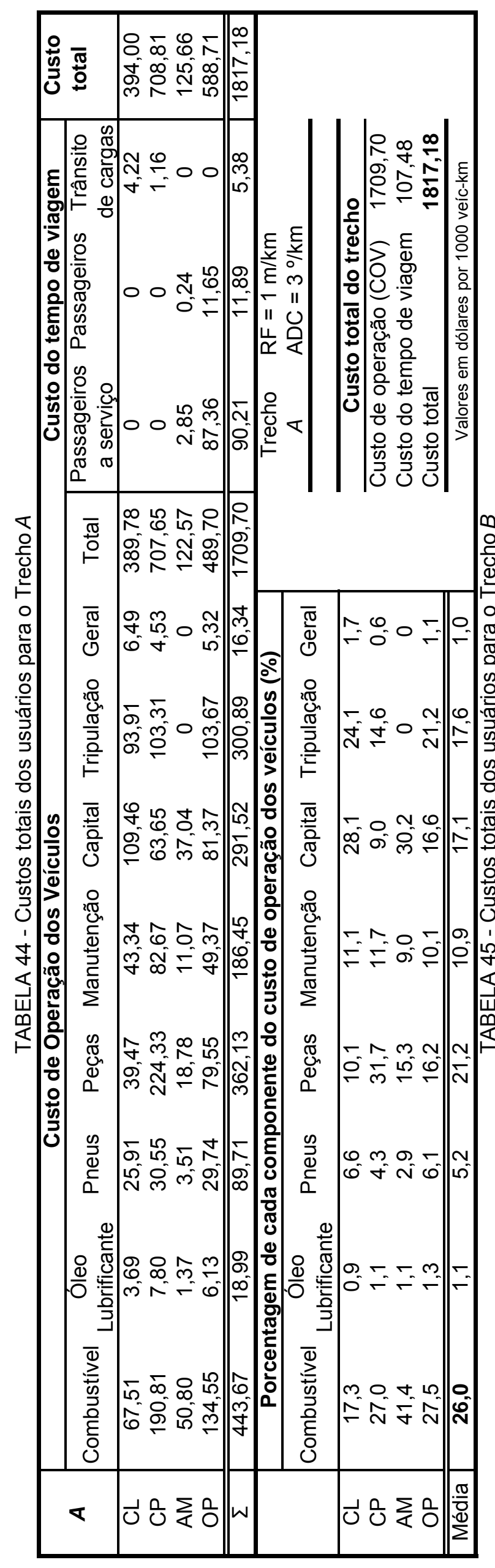

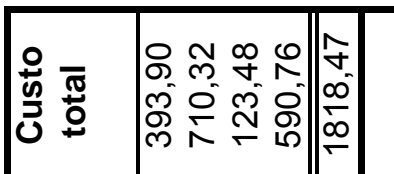

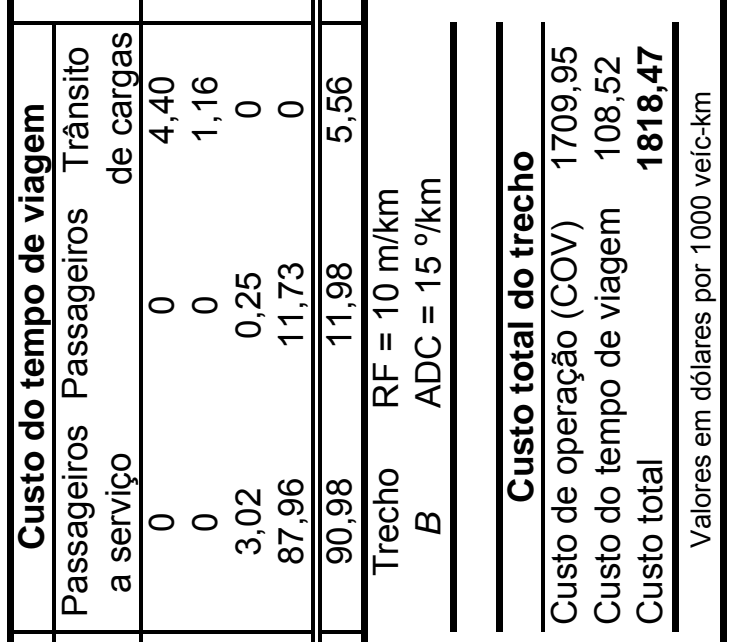

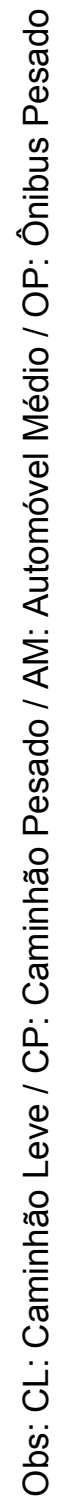

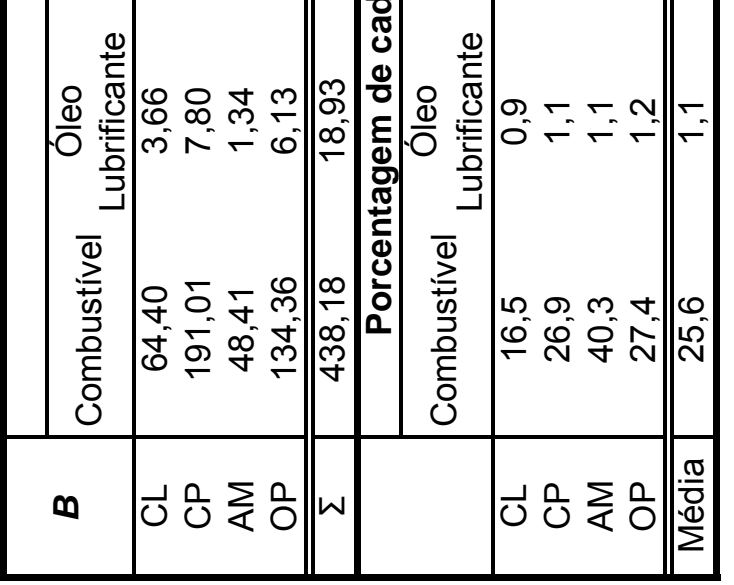




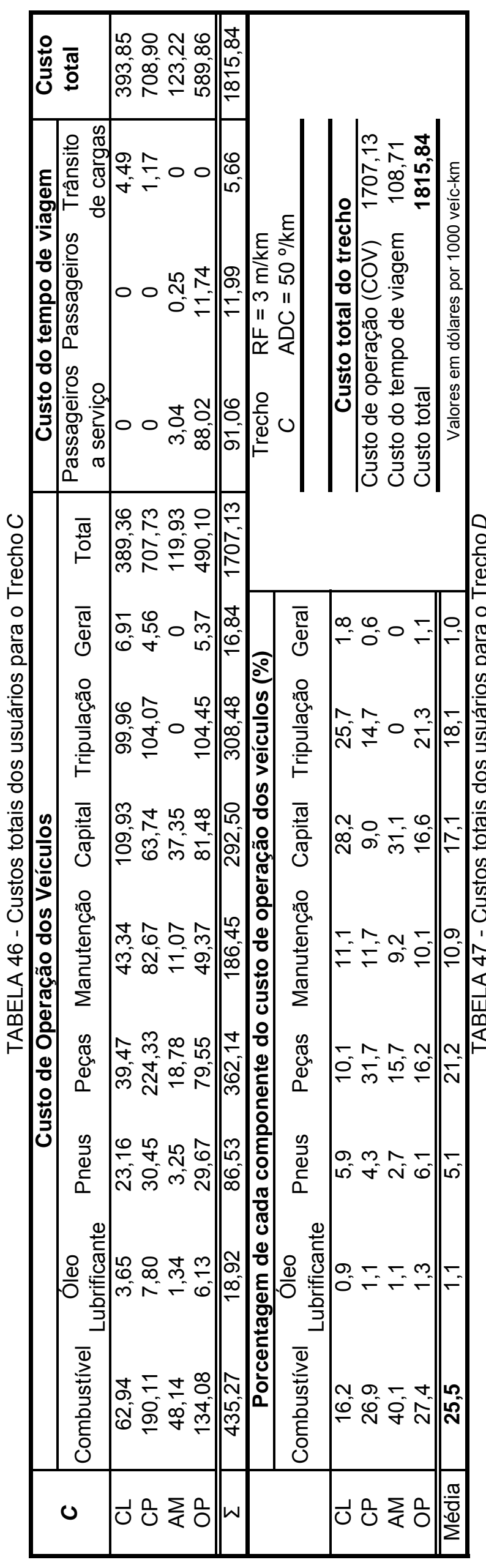

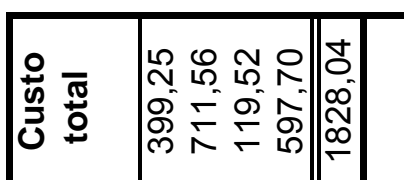

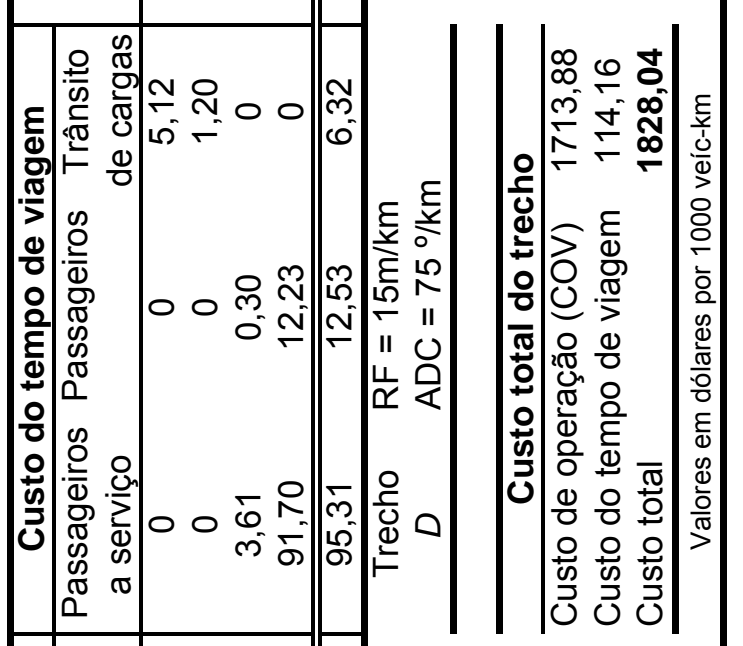

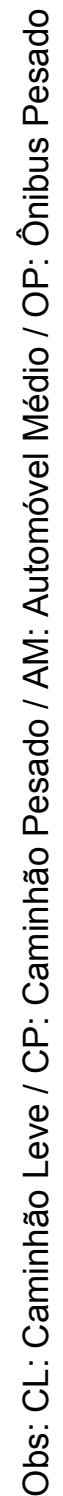

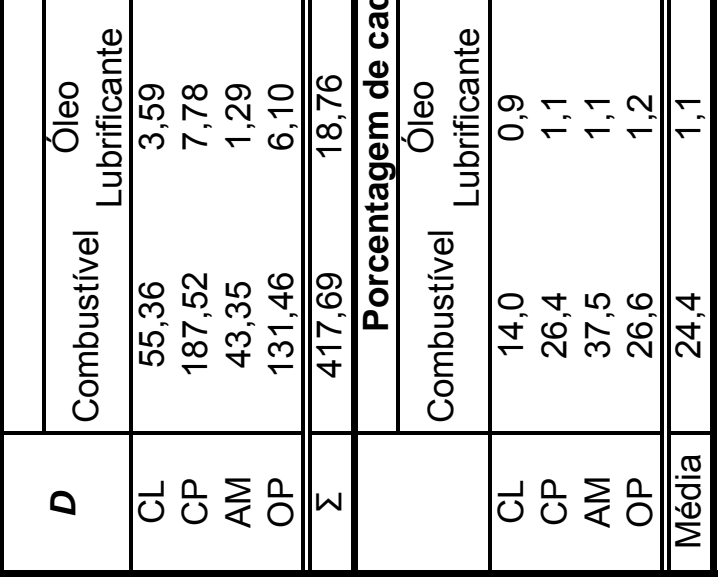




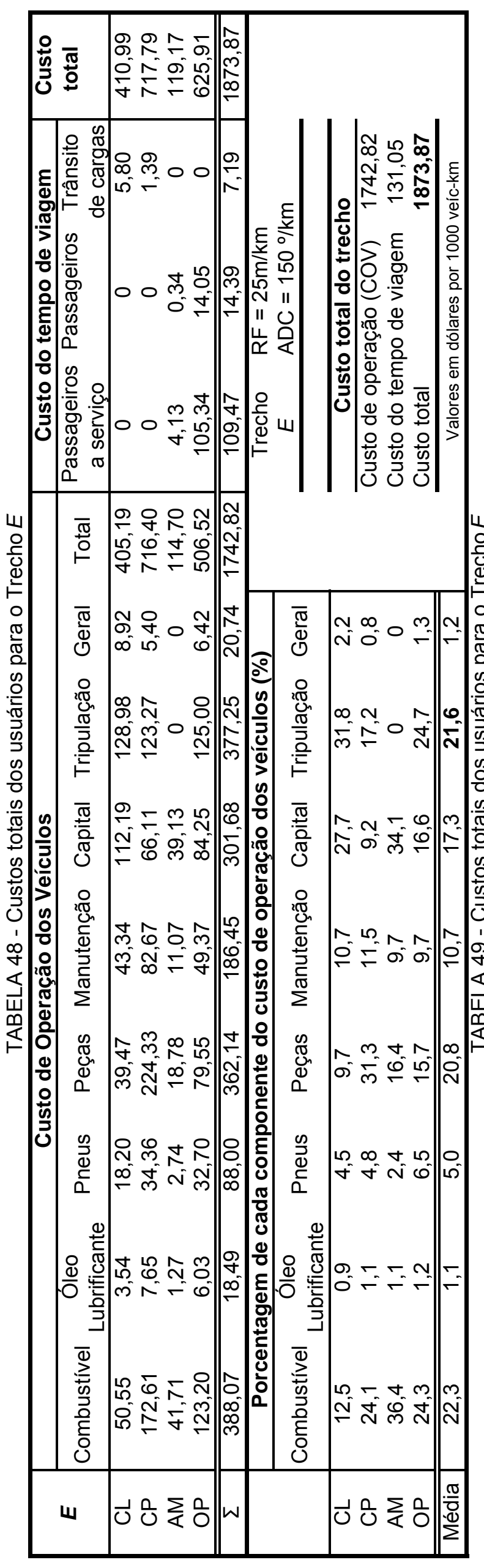

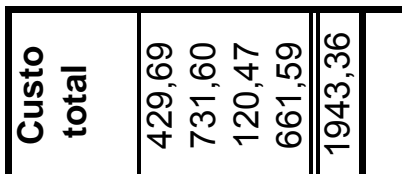

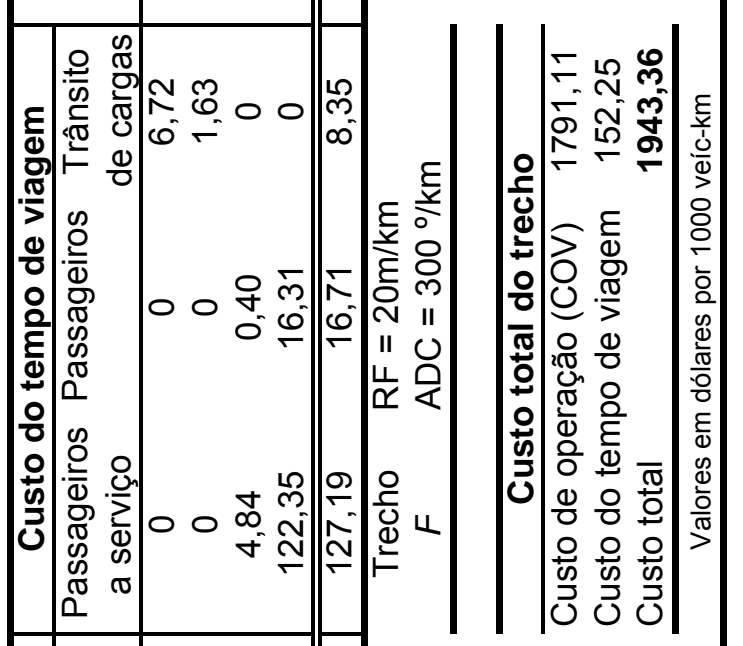

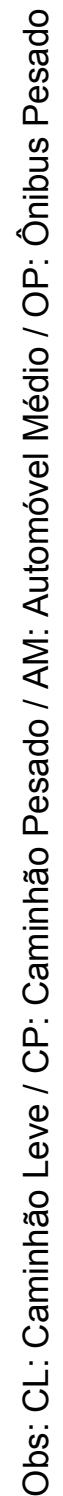

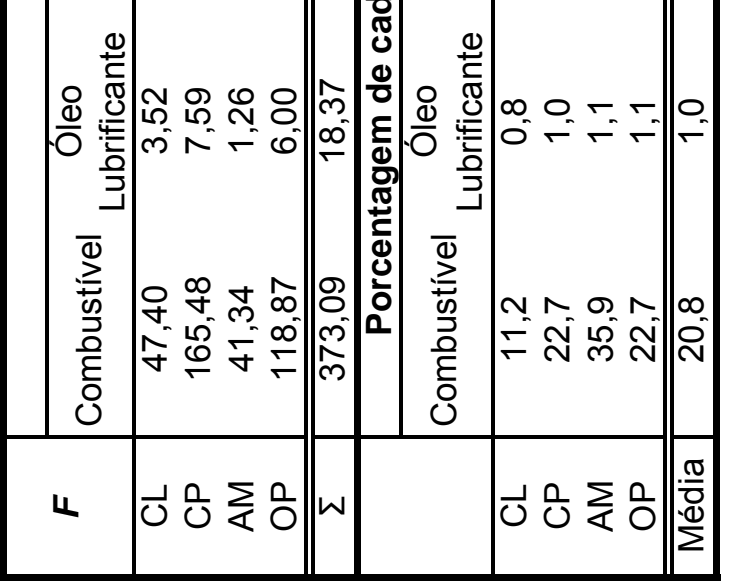




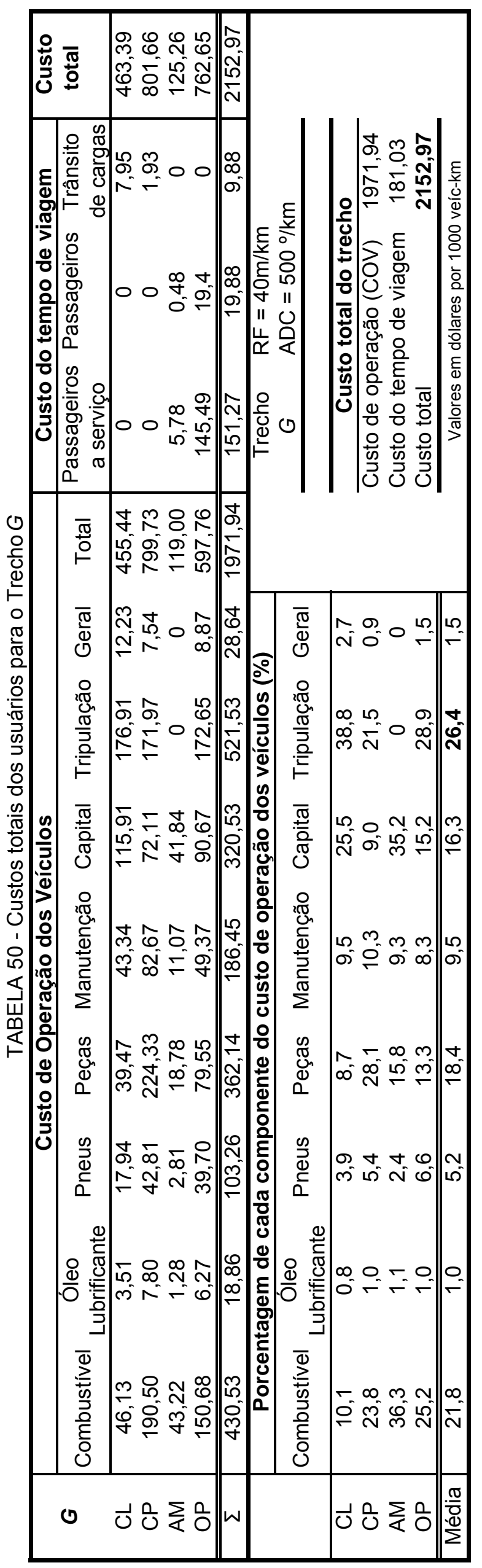

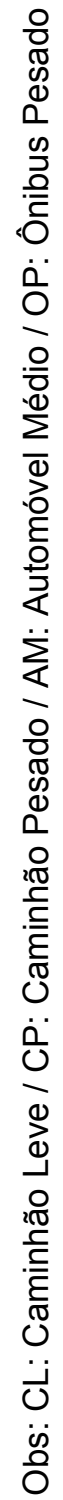




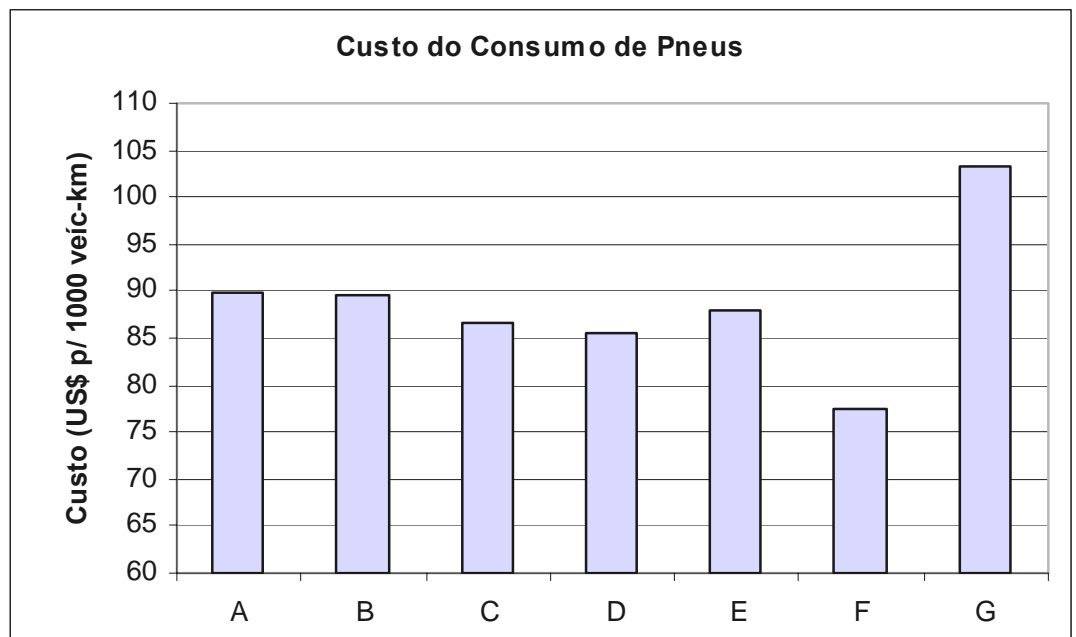

FIGURA 50 - Custo do consumo de pneus para os trechos do HDM-4.

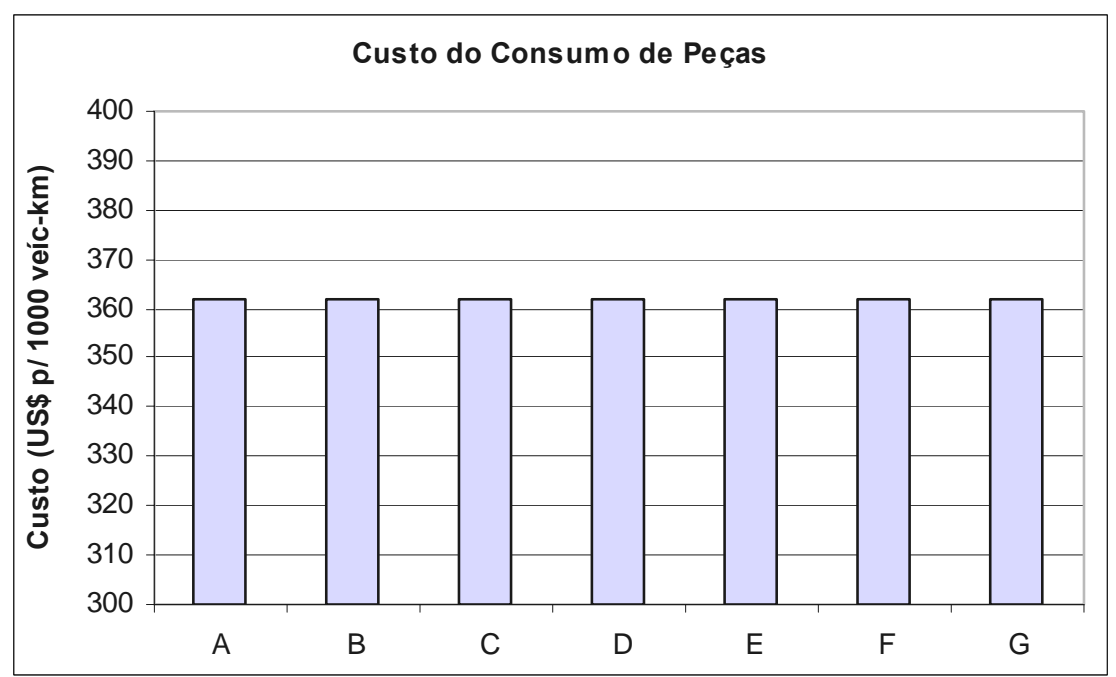

FIGURA 51 - Custo do consumo de peças para os trechos do HDM-4.

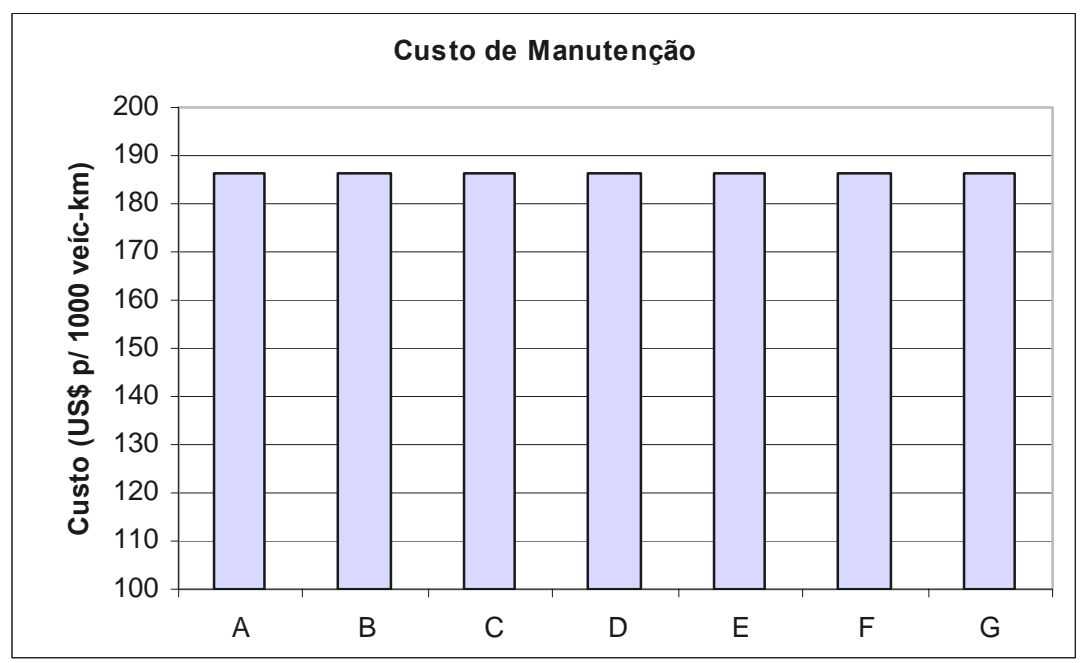

FIGURA 52 - Custo de manutenção dos veículos para os trechos do HDM-4. 


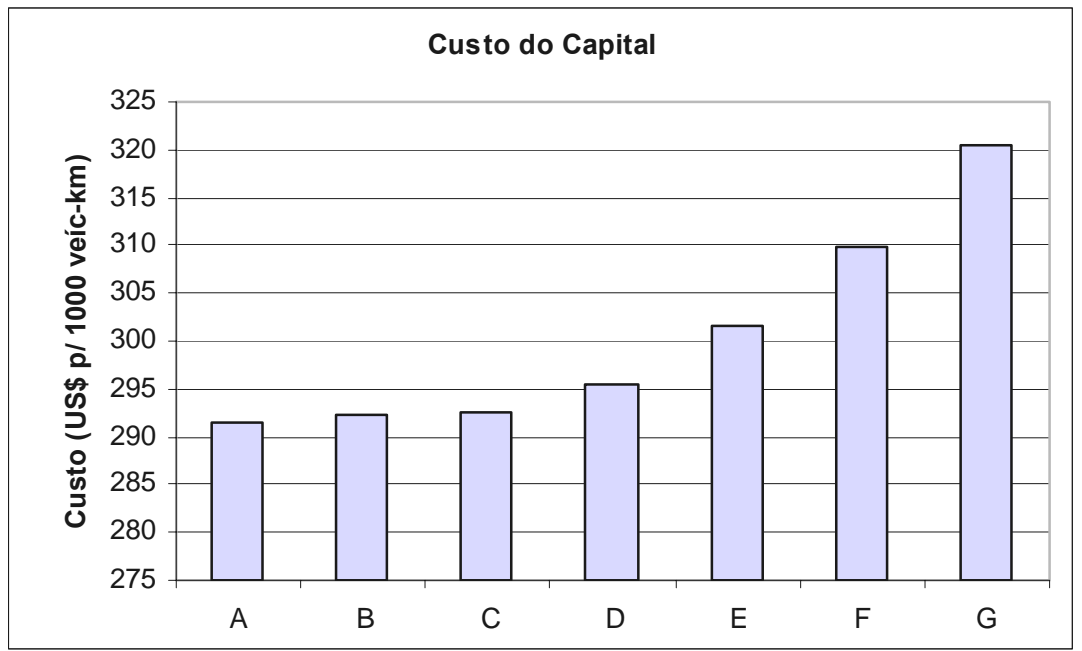

FIGURA 53 - Custo do capital para os trechos do HDM-4.

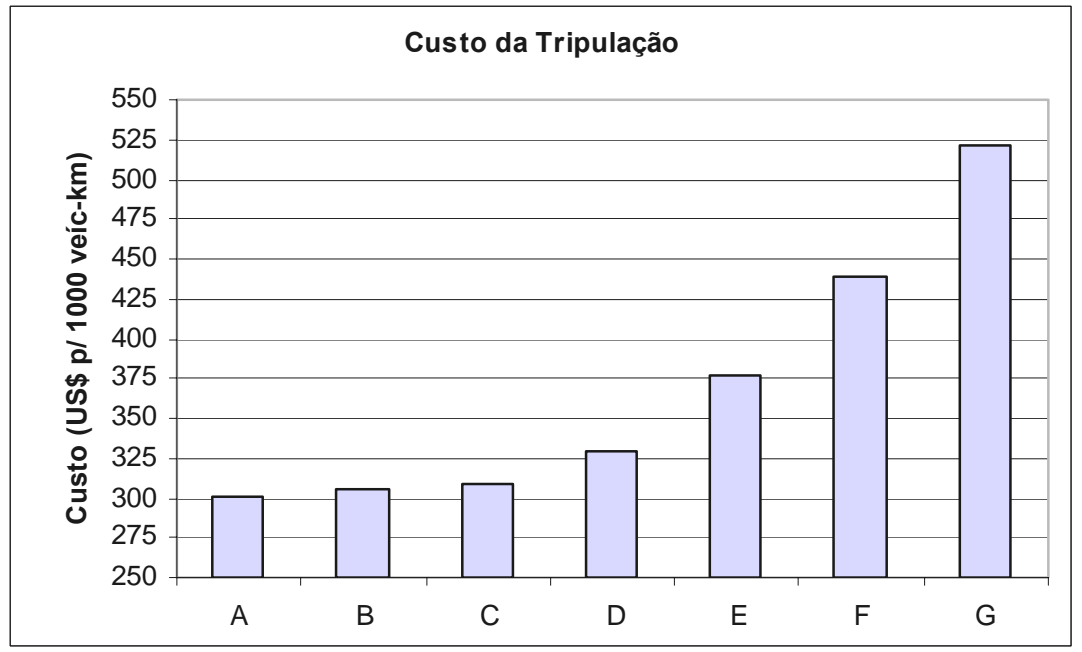

FIGURA 54 - Custo da tripulação para os trechos do HDM-4.

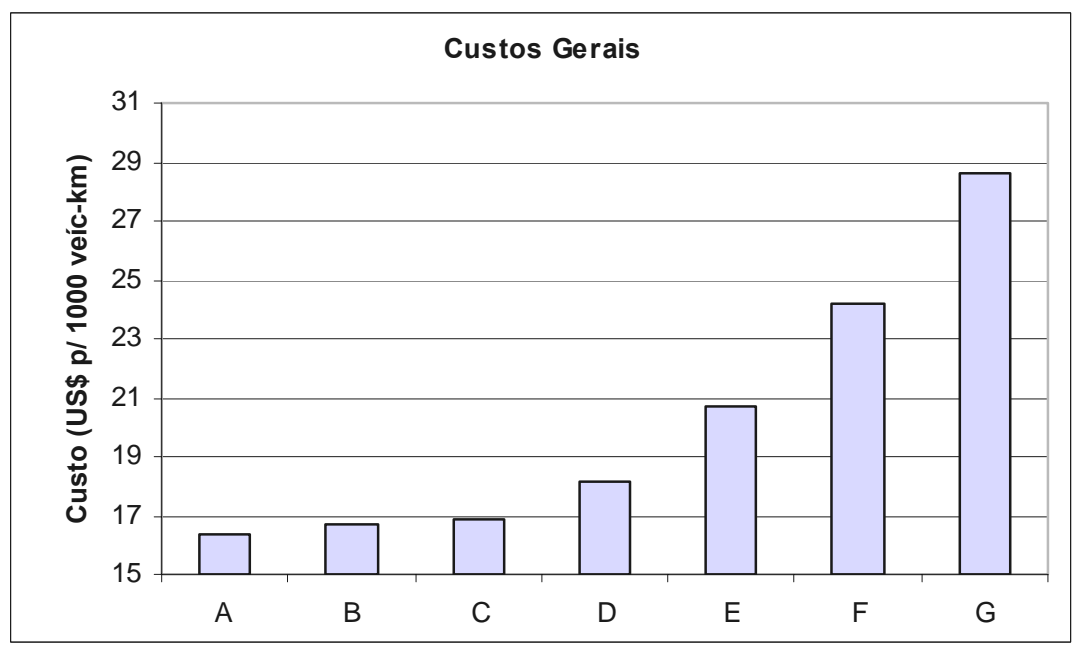

FIGURA 55 - Custos gerais para os trechos do HDM-4. 


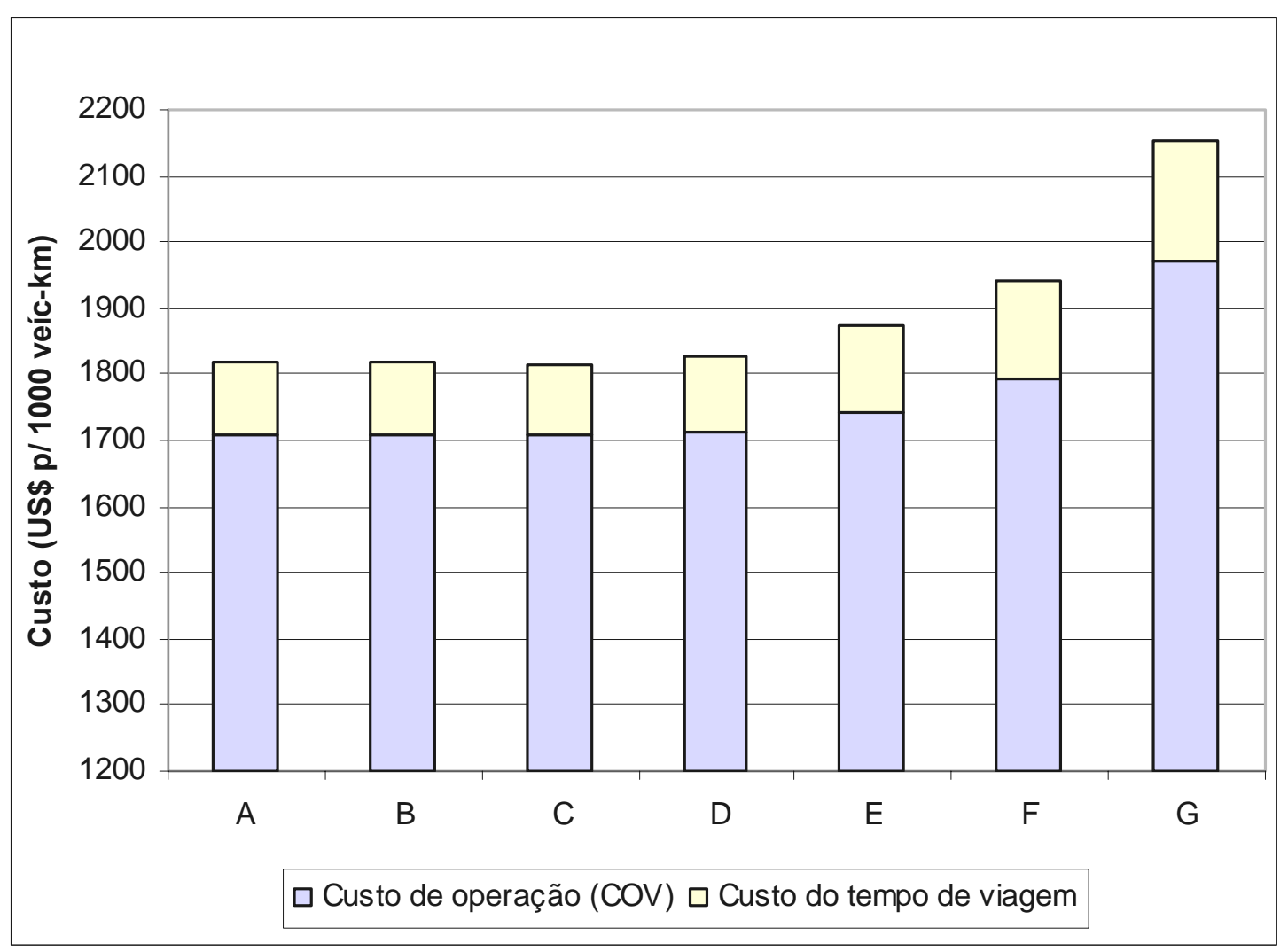

FIGURA 56 - Custos de operação dos veículos e do tempo de viagem na composição do custo total dos trechos do HDM-4.

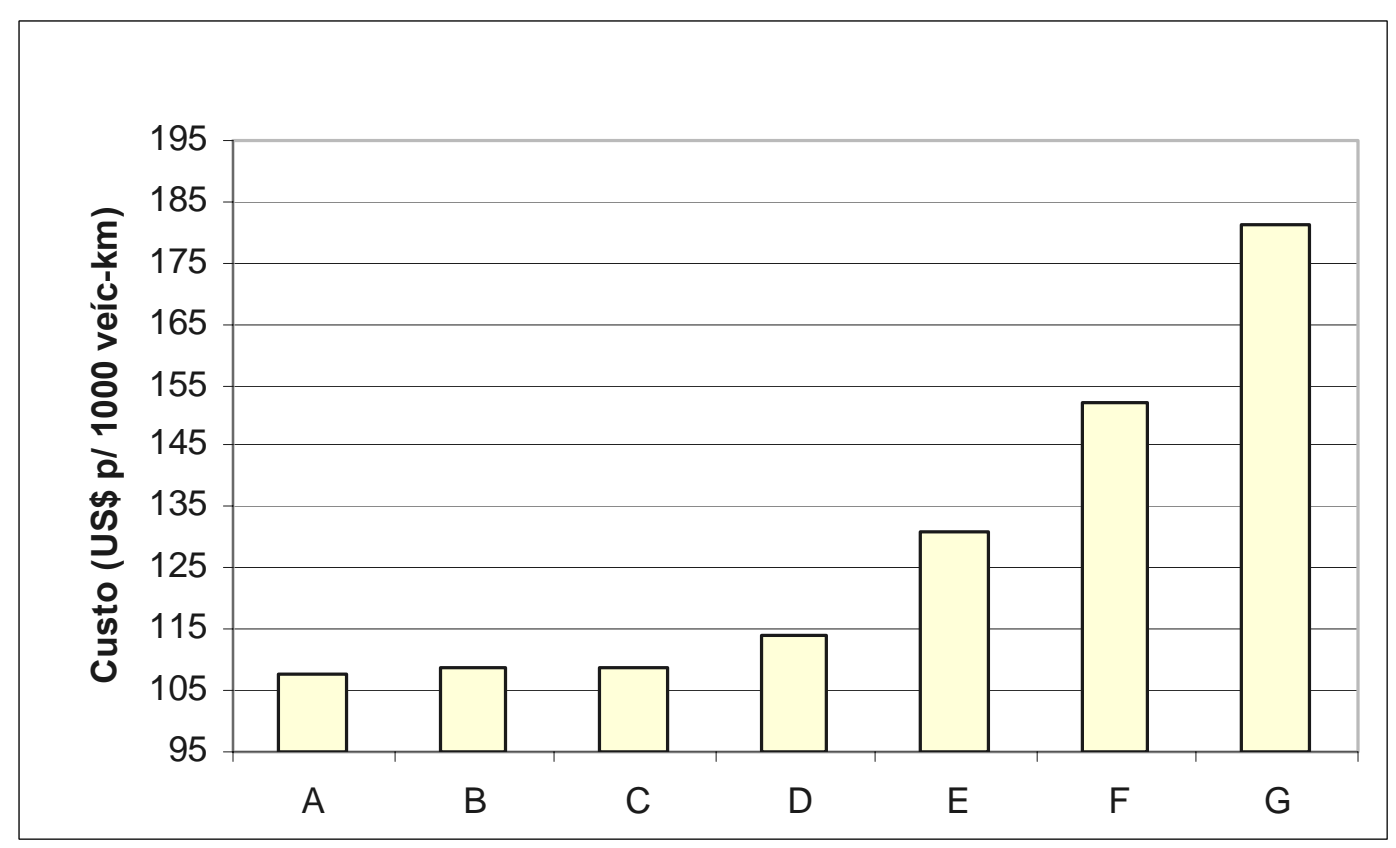

FIGURA 57 - Detalhe do custo do tempo de viagem para os trechos do HDM-4. 
A Tabela 51, assim como as Figuras 58 a 65, apresenta o consumo de combustível e a velocidade de operação de cada tipo de veículo para cada um dos trechos representativos do HDM-4 e para o trecho Base.

TABELA 51 - Consumo de combustível e velocidade de operação dos veículos nos trechos do HDM-4.

\begin{tabular}{lccccccc}
\hline \multicolumn{7}{c}{ Consumo Combustível (litros p/ 1000 veíc-km) } \\
\hline & $\mathbf{A}$ & $\mathbf{B}$ & $\mathbf{C}$ & $\mathbf{D}$ & $\mathbf{E}$ & $\mathbf{F}$ & $\mathbf{G}$ \\
\hline Caminhão Leve & 135,03 & 128,81 & 125,88 & 110,72 & 101,09 & 94,81 & 92,27 \\
Caminhão Pesado & 381,62 & 382,02 & 380,21 & 375,03 & 345,22 & 330,97 & 381,78 \\
Automóvel Médio & 101,60 & 96,81 & 96,29 & 86,69 & 83,43 & 82,68 & 86,44 \\
Ônibus Pesado & 269,10 & 268,73 & 268,16 & 262,92 & 246,40 & 237,73 & 269,09 \\
\hline \multicolumn{10}{c}{} \\
\hline
\end{tabular}

Velocidade de operação $(\mathrm{Km} / \mathrm{h})$

\begin{tabular}{lccccccc}
\hline & A & B & C & D & E & F & G \\
\hline Caminhão Leve & 94,77 & 90,94 & 89,03 & 78,13 & 69,00 & 59,53 & 50,31 \\
Caminhão Pesado & 86,15 & 85,99 & 85,52 & 83,18 & 72,20 & 61,43 & 51,75 \\
Automóvel Médio & 105,13 & 99,36 & 98,62 & 83,01 & 72,69 & 62,03 & 51,86 \\
Ônibus Pesado & 85,85 & 85,27 & 85,20 & 81,79 & 71,20 & 61,30 & 51,55 \\
\hline
\end{tabular}

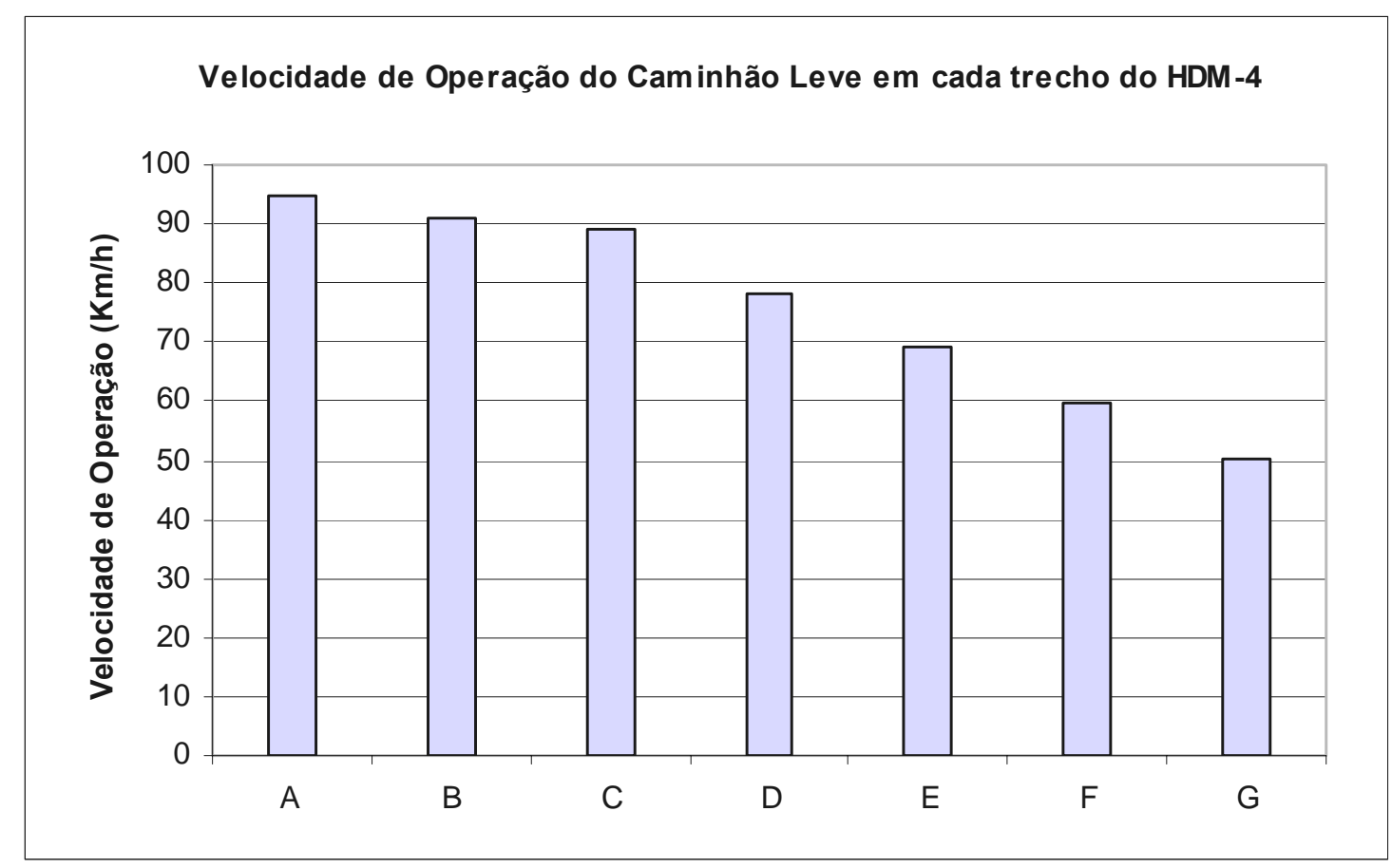

FIGURA 58 - Velocidade de operação do Caminhão Leve - Trechos do HDM-4. 


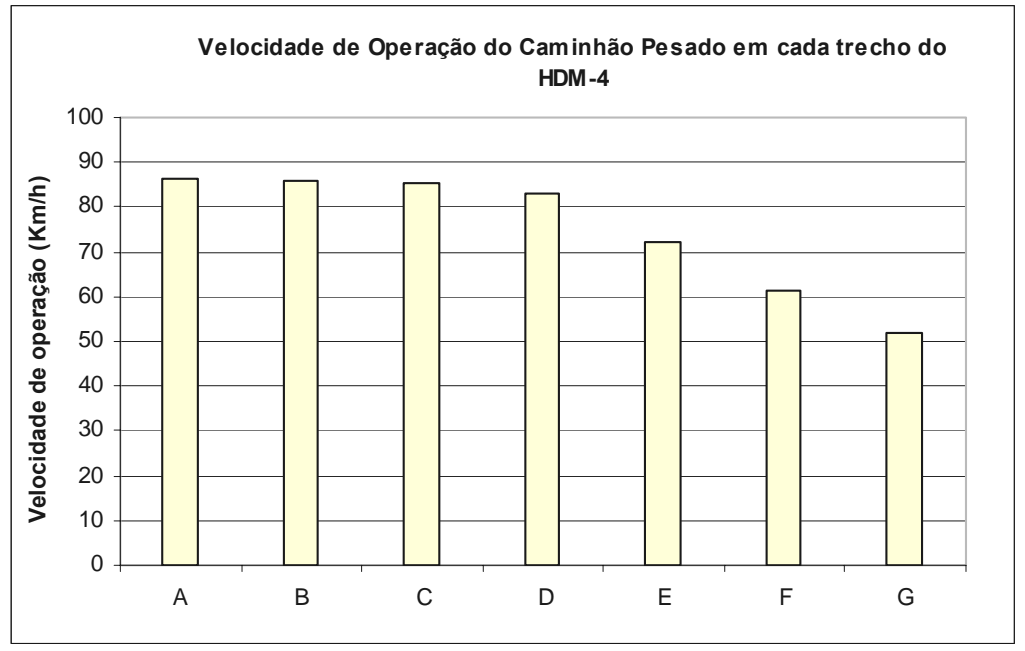

FIGURA 59 - Velocidade de operação do Caminhão Pesado - Trechos do HDM-4.

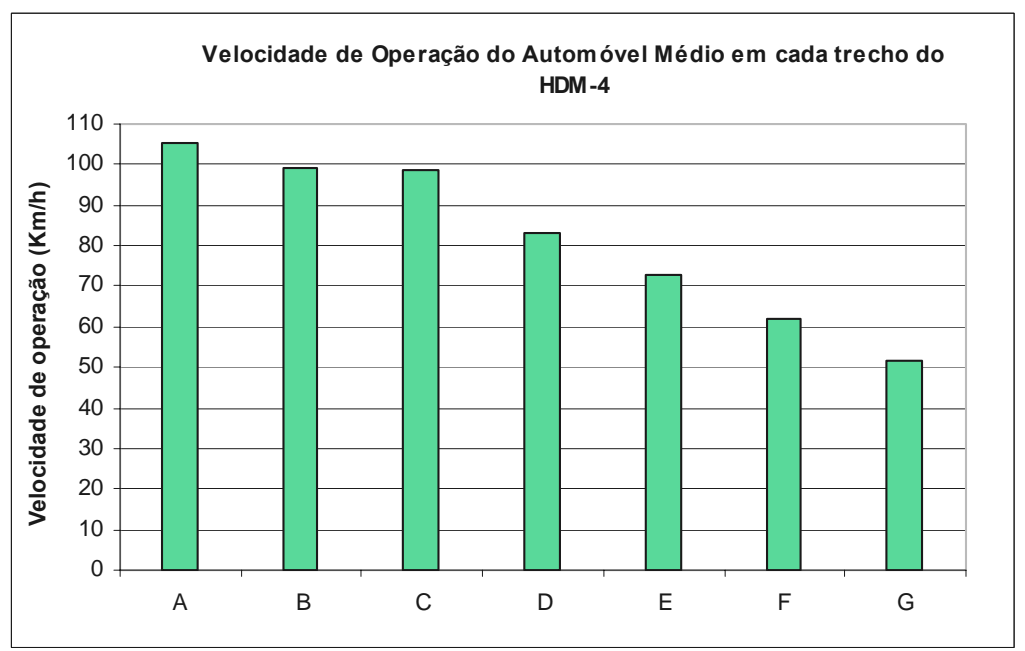

FIGURA 60 - Velocidade de operação do Automóvel Médio - Trechos do HDM-4.

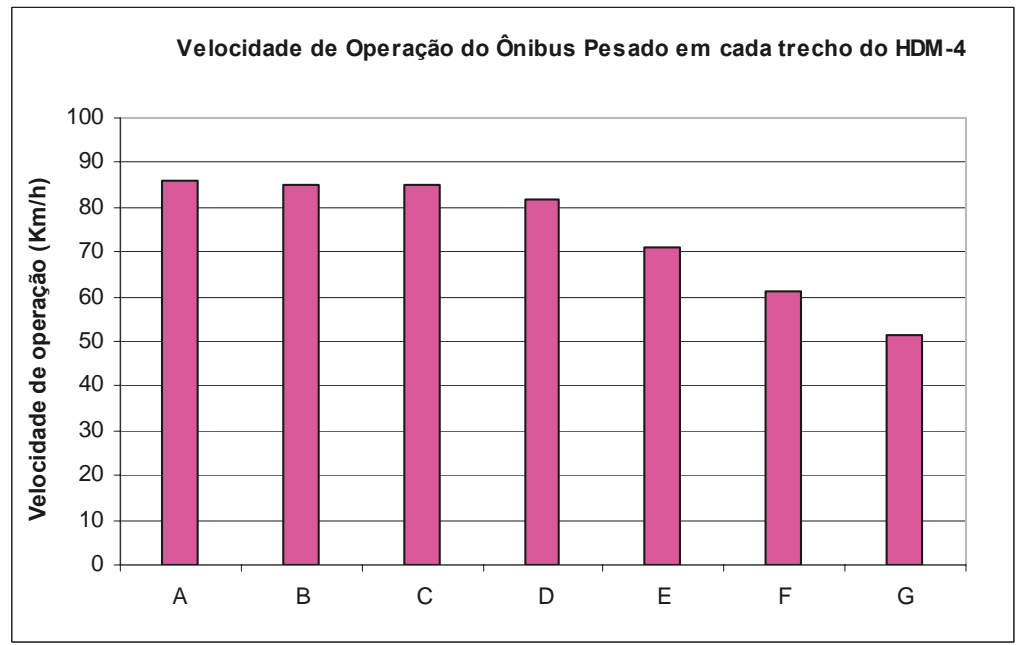

FIGURA 61 - Velocidade de operação do Ônibus Pesado - Trechos do HDM-4. 


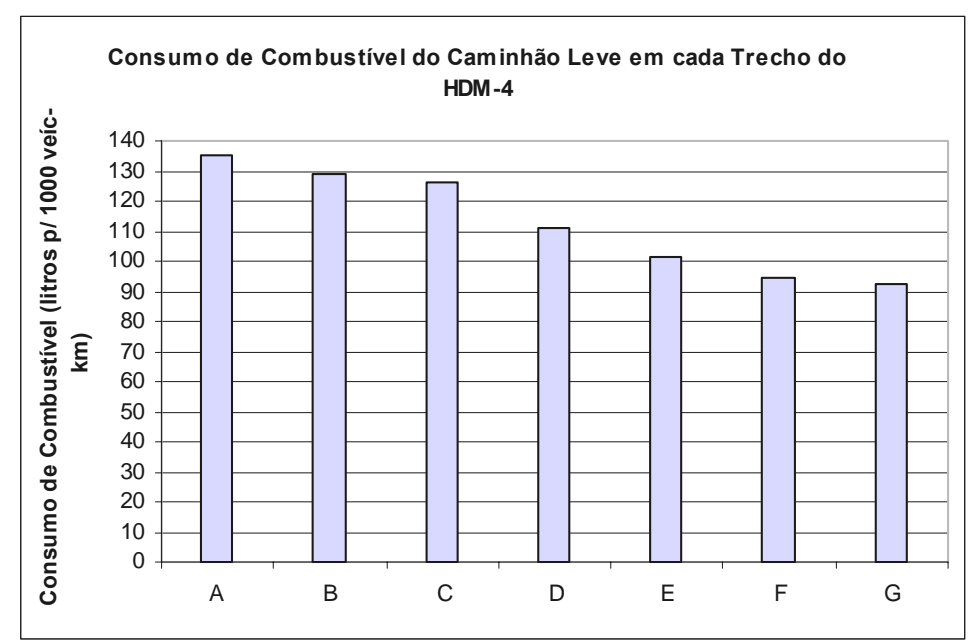

FIGURA 62 - Consumo de combustível do Caminhão Leve - Trechos do HDM-4.

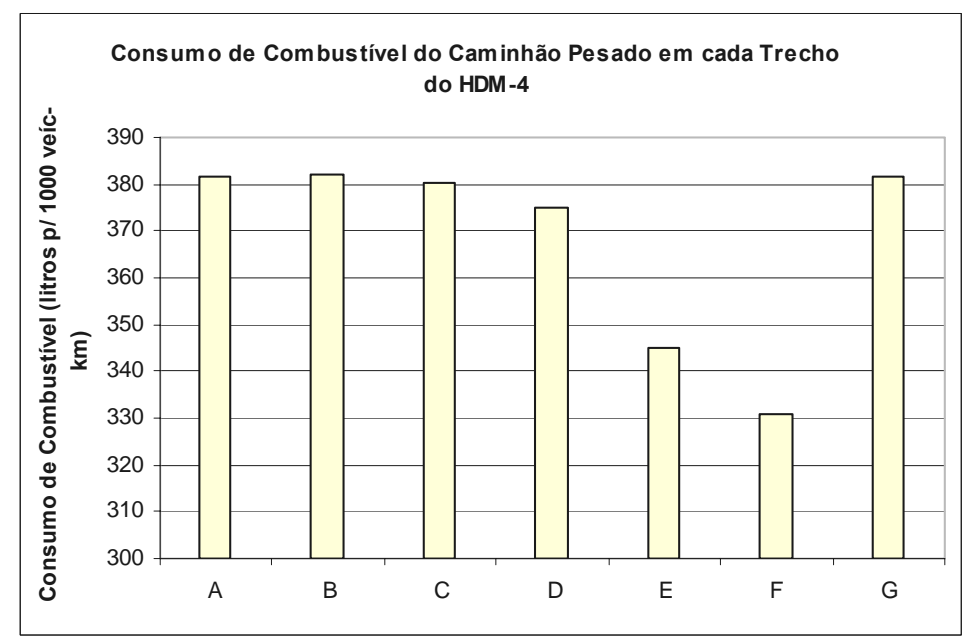

FIGURA 63 - Consumo de combustível do Caminhão Pesado - Trechos do HDM-4.

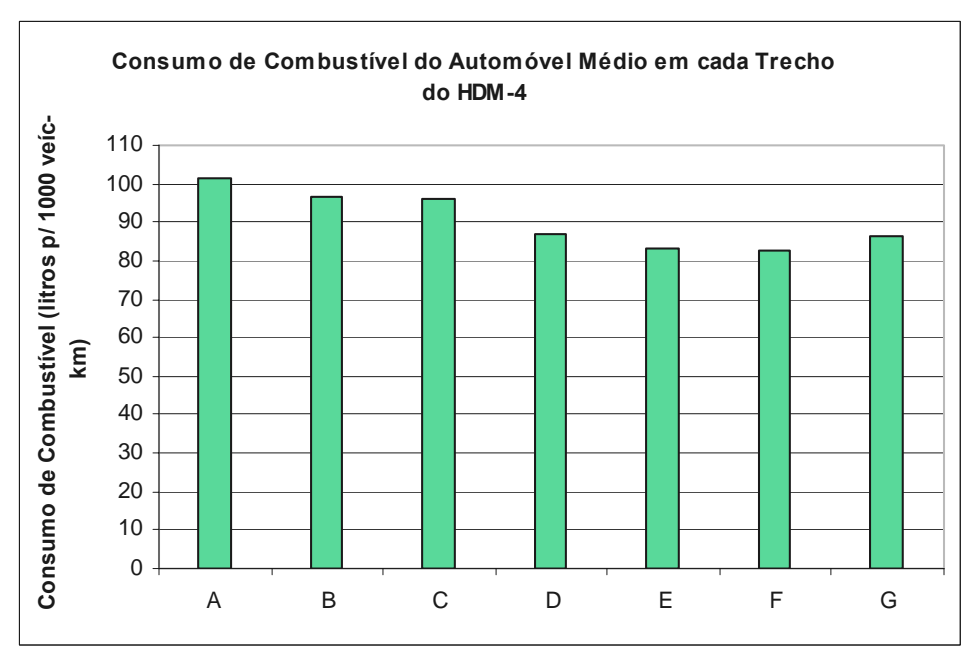

FIGURA 64 - Consumo de combustível do Automóvel Médio - Trechos do HDM-4. 


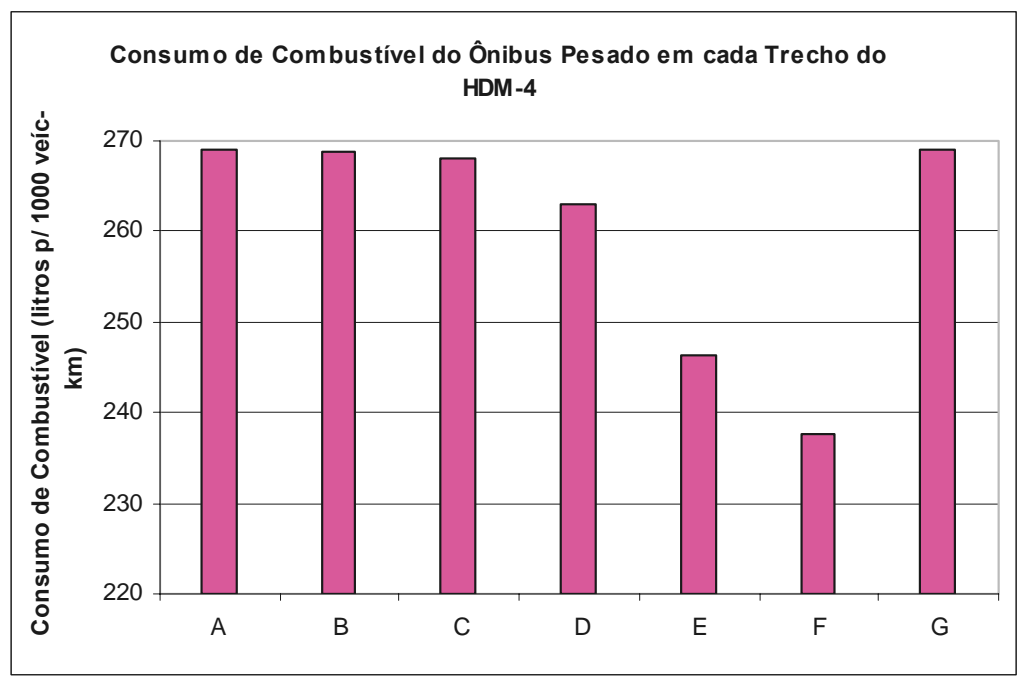

FIGURA 65 - Consumo de combustível do Ônibus Pesado - Trechos do HDM-4.

A Tabela 52 mostra os componentes com as maiores porcentagens no custo de operação dos veículos nos trechos do HDM-4, que são o consumo de combustível, o consumo de peças, os custos com a tripulação e com o capital.

TABELA 52 - Componentes com maiores porcentagens no COV - Trechos do HDM-4.

\begin{tabular}{cccc}
\hline Trechos & Maior $\%$ & $\mathbf{2}^{\text {a. }}$ maior $\%$ & $\mathbf{3}^{\mathbf{a} \cdot}$ maior $\%$ \\
\hline Base & Combustível & Peças & Tripulação \\
A & Combustível & Peças & Tripulação \\
B & Peças & Combustível & Tripulação \\
C & Combustível & Peças & Tripulação \\
D & Peças & Tripulação & Capital \\
E & Tripulação & Peças & Capital \\
F & Tripulação & Peças & Capital \\
G & Tripulação & Peças & Capital \\
\hline
\end{tabular}

\subsection{RESULTADOS DOS TRECHOS DA RODOVIA SP-310}

As Tabelas 53 a 56 apresentam as parcelas dos custos totais dos usuários para os trechos da SP-310, bem como as porcentagens de cada componente dos custos de operação dos veículos e os custos do tempo de viagem. Os custos da soma de cada componente do custo de operação dos veículos considerados para cada trecho são mostrados pelos gráficos das Figuras 66 a 73. As Figuras 74 e 75 apresentam os custos de operação dos veículos e do tempo de viagem. 

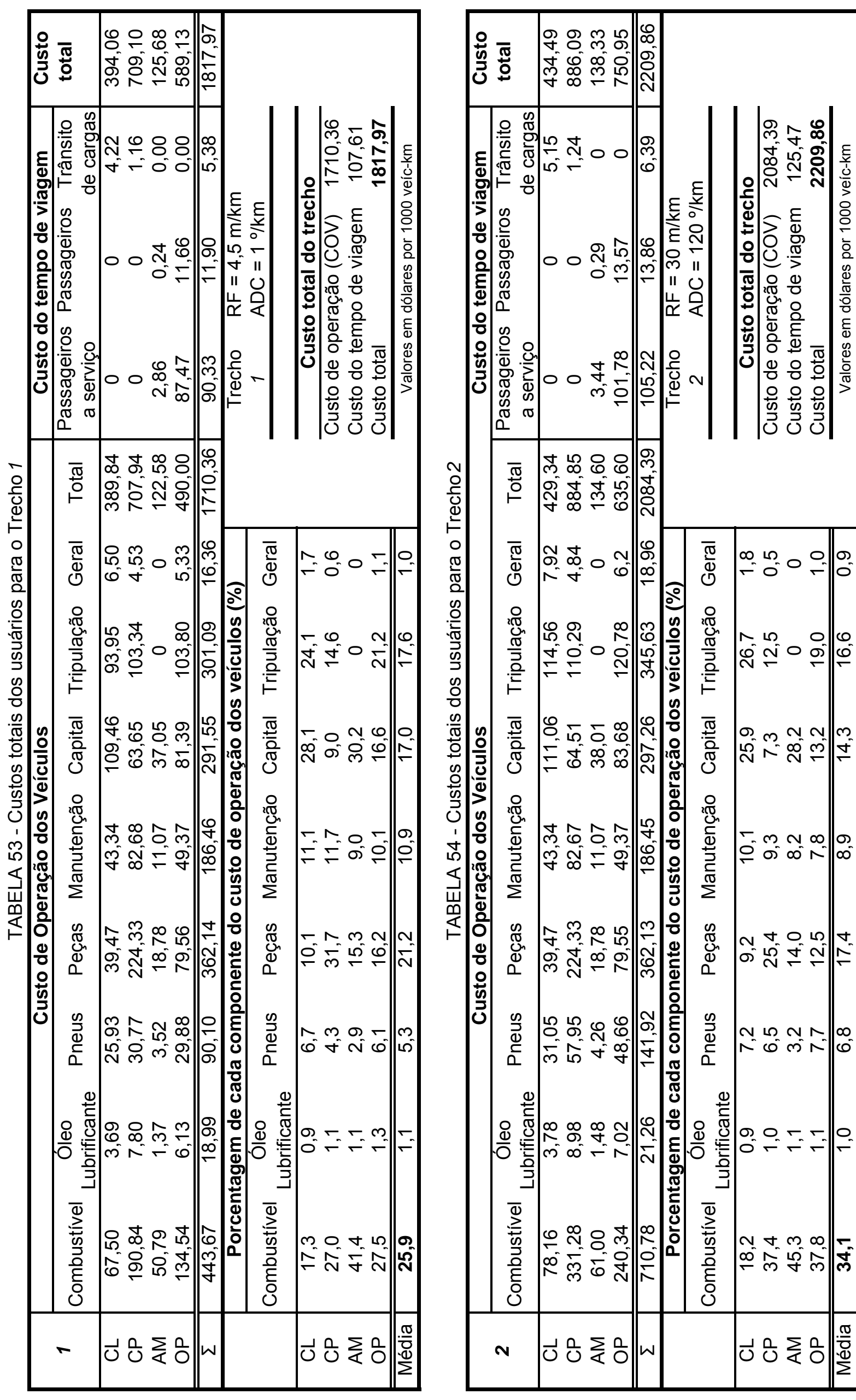

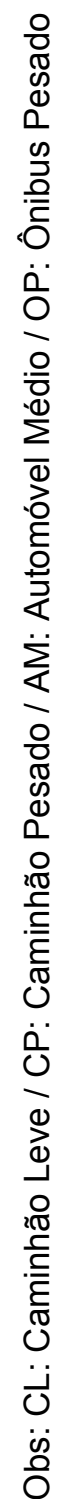

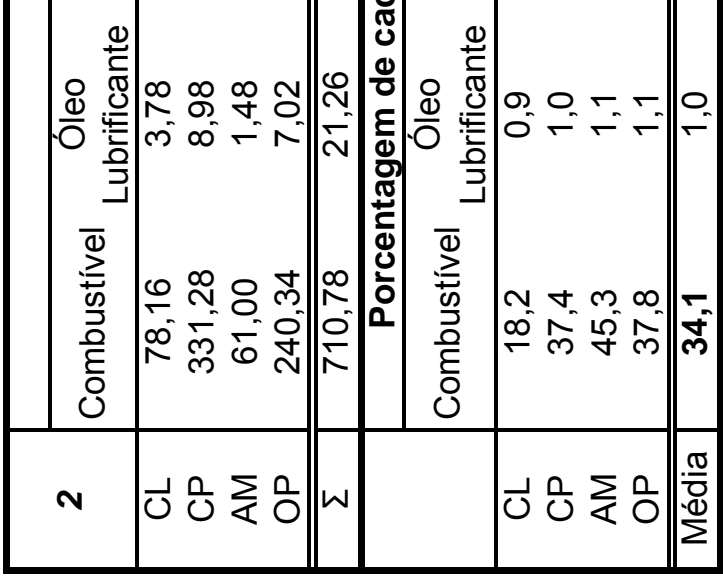




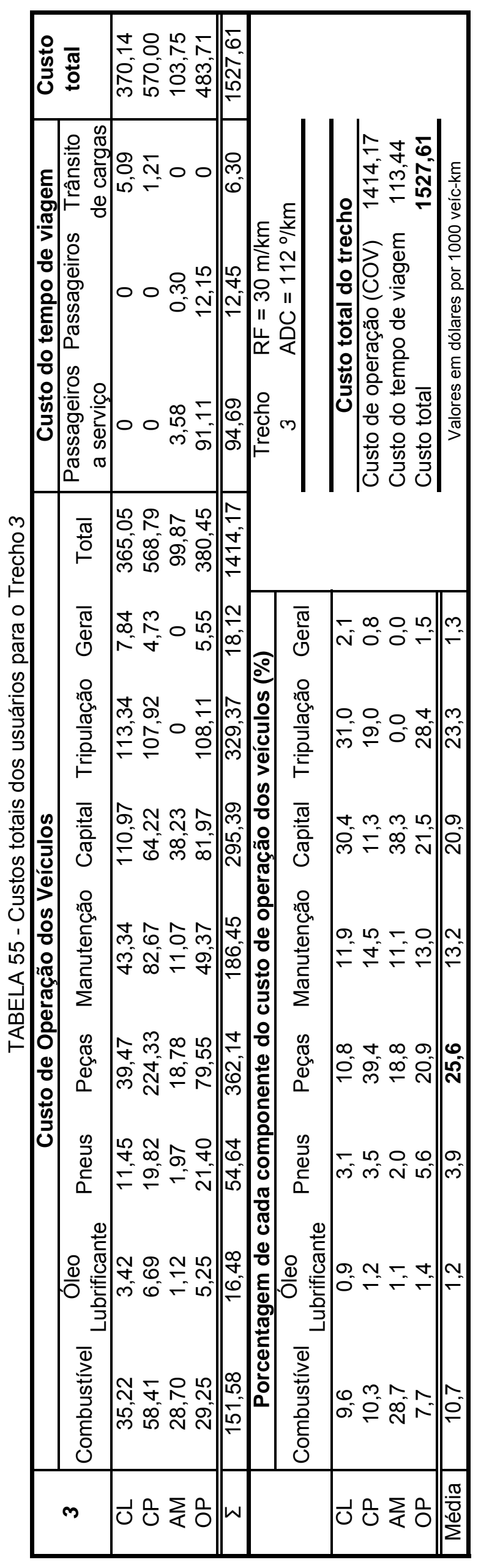

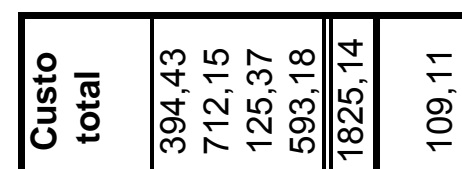

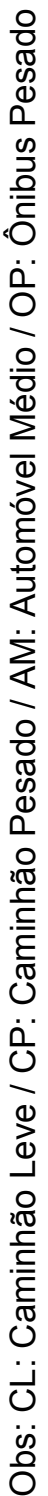

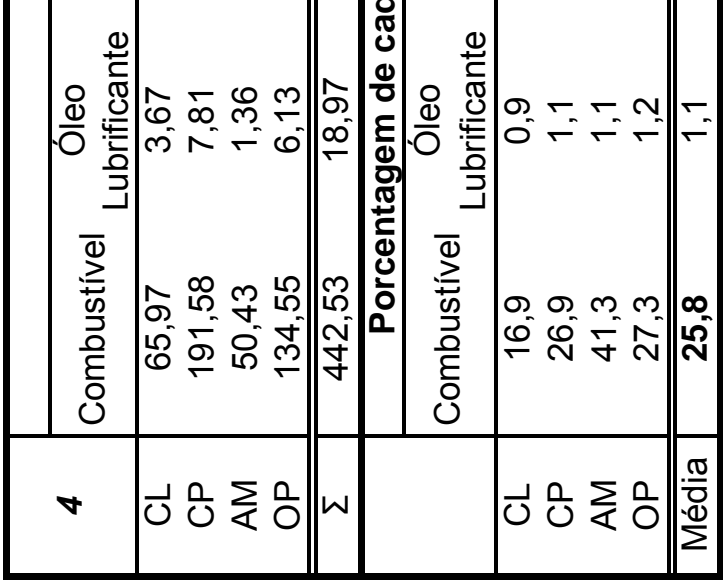




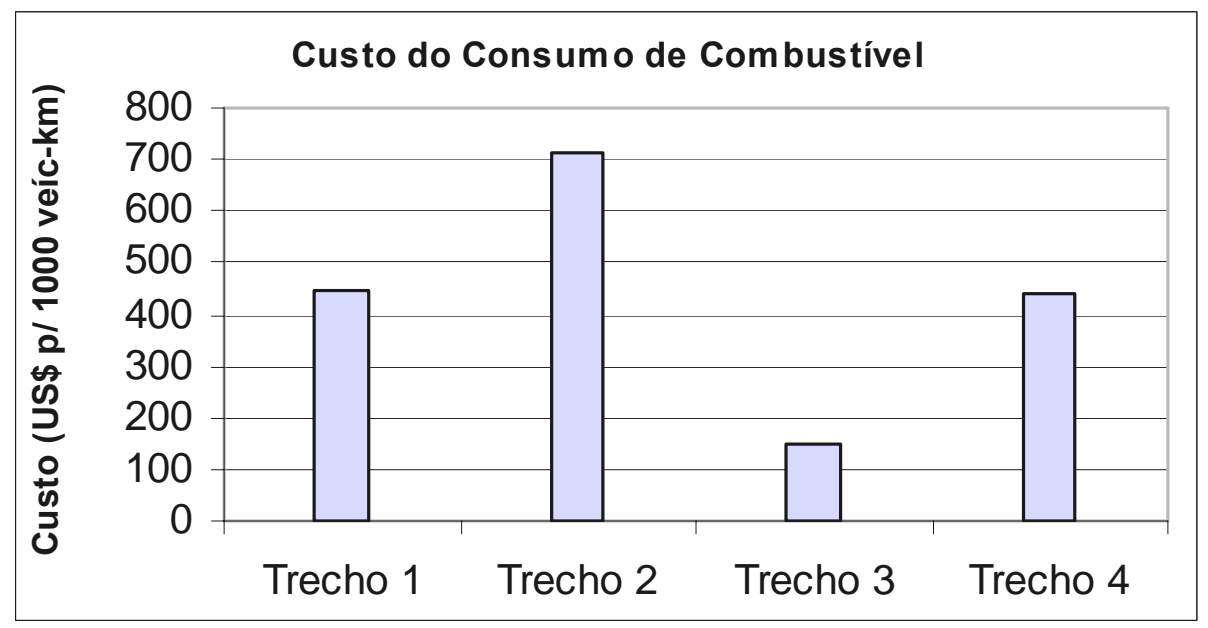

FIGURA 66 - Custo do consumo de combustível para os trechos da SP-310.

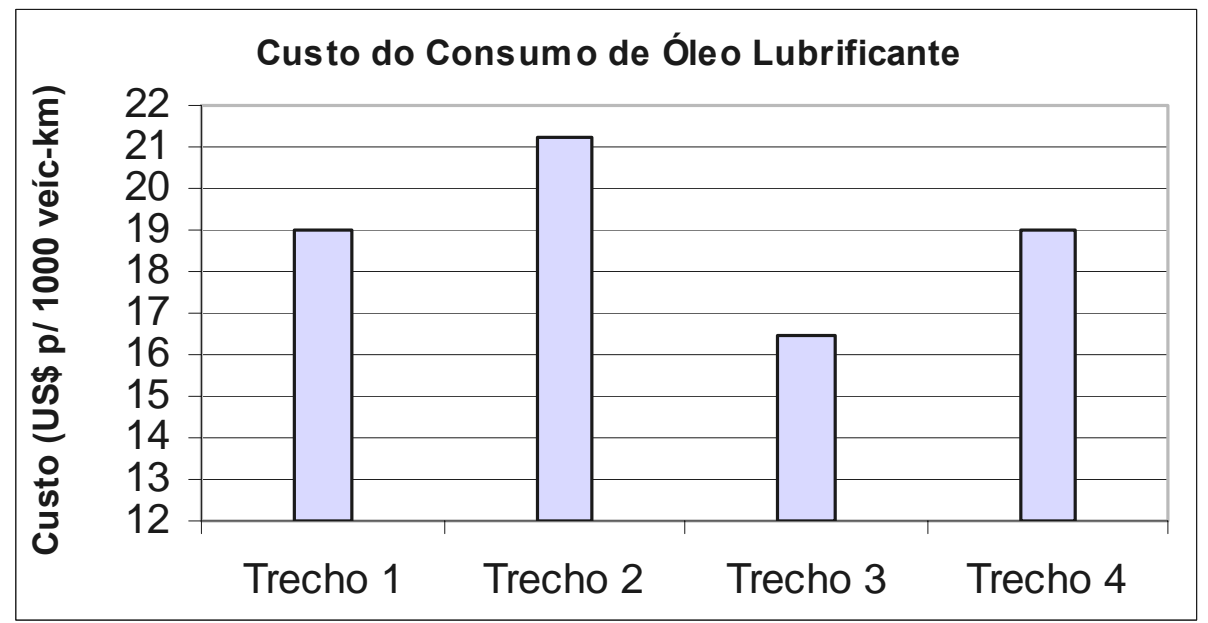

FIGURA 67 - Custo do consumo de óleo lubrificante para os trechos da SP-310.

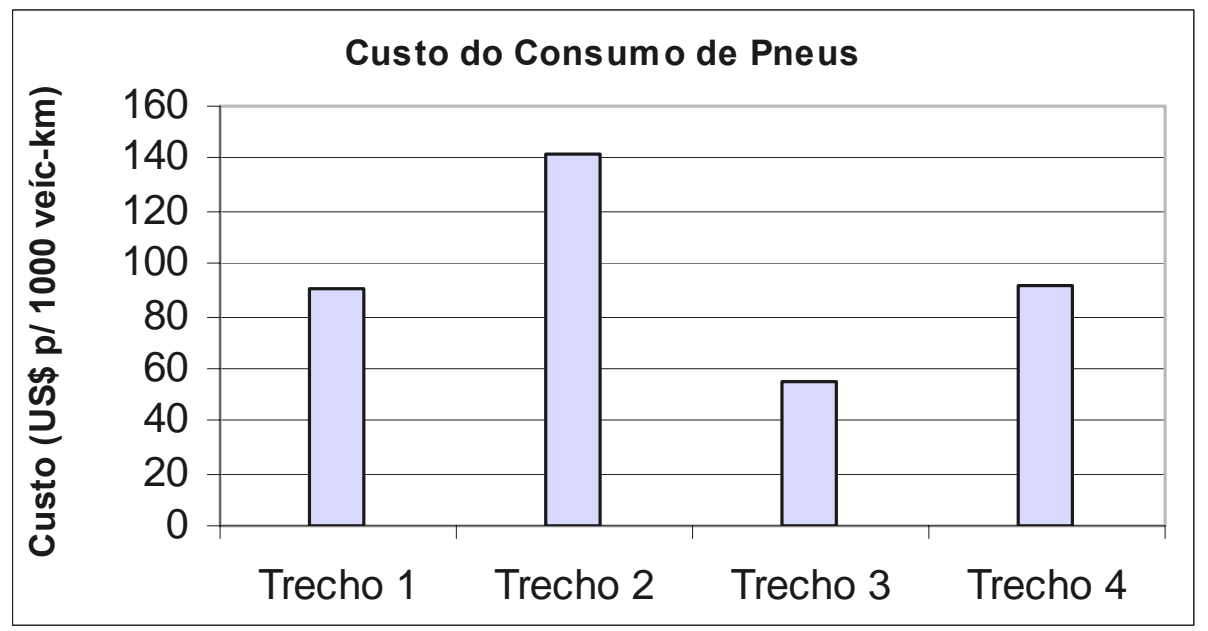

FIGURA 68 - Custo do consumo de pneus para os trechos da SP-310. 


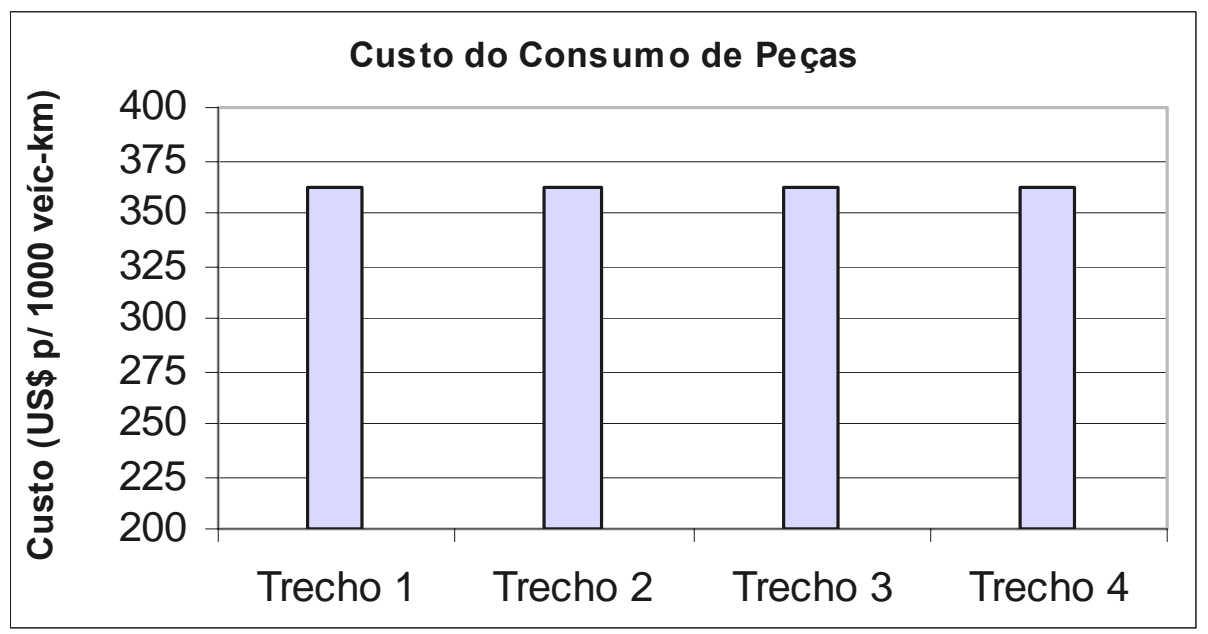

FIGURA 69 - Custo do consumo de peças para os trechos da SP-310.

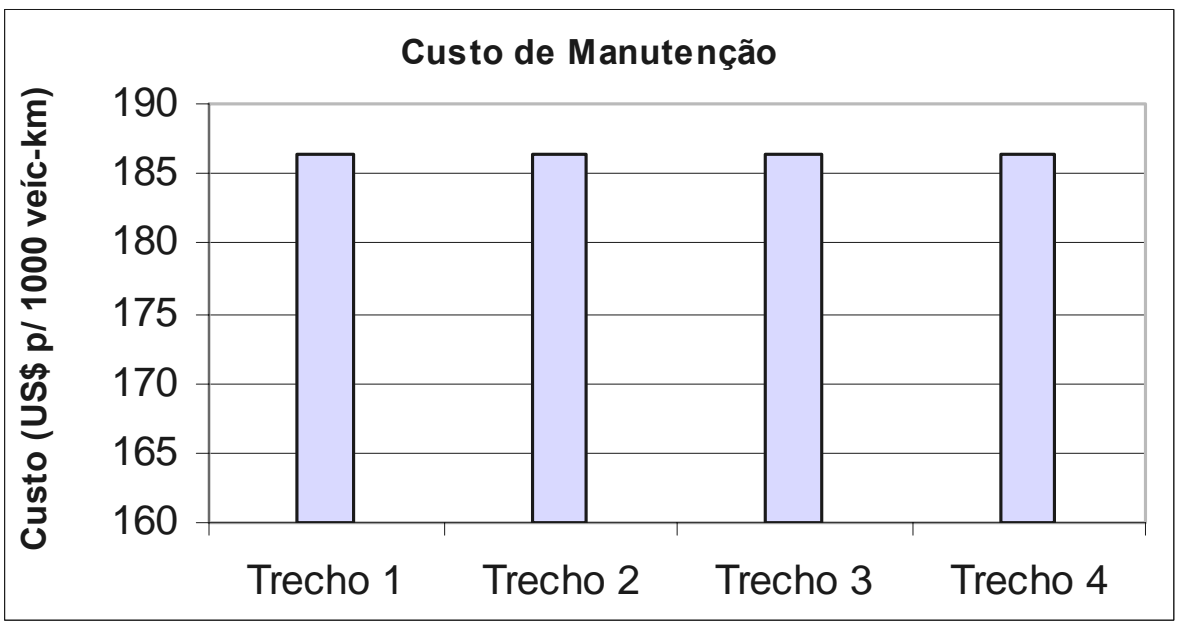

FIGURA 70 - Custo de manutenção dos veículos para os trechos da SP-310.

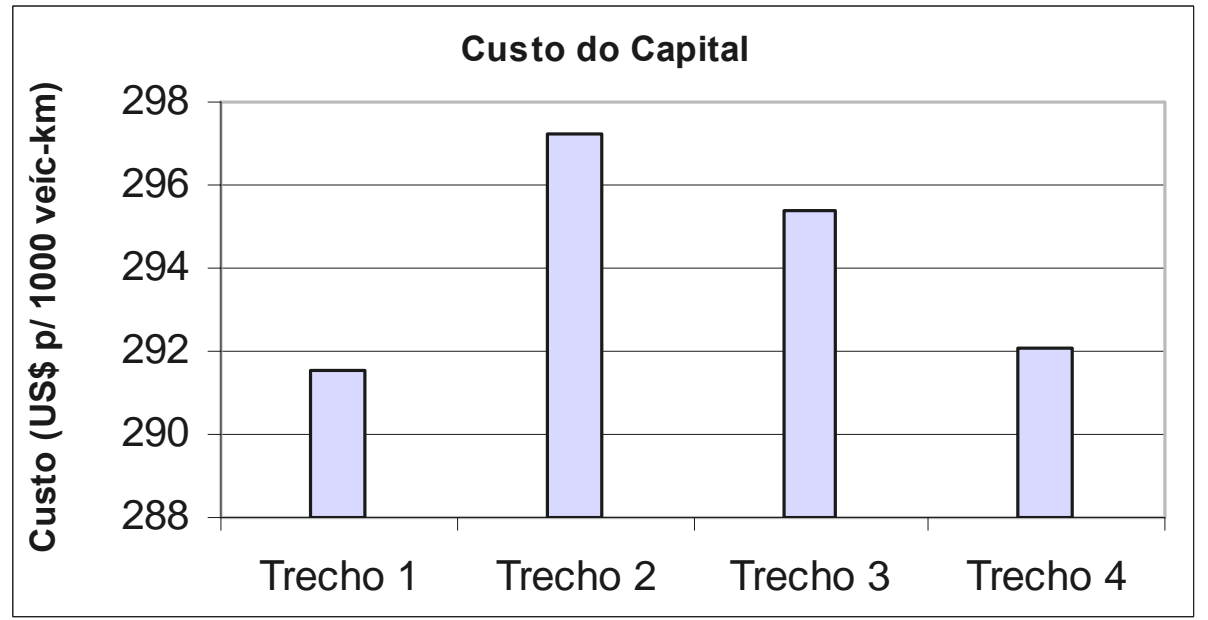

FIGURA 71 - Custo do capital para os trechos da SP-310. 


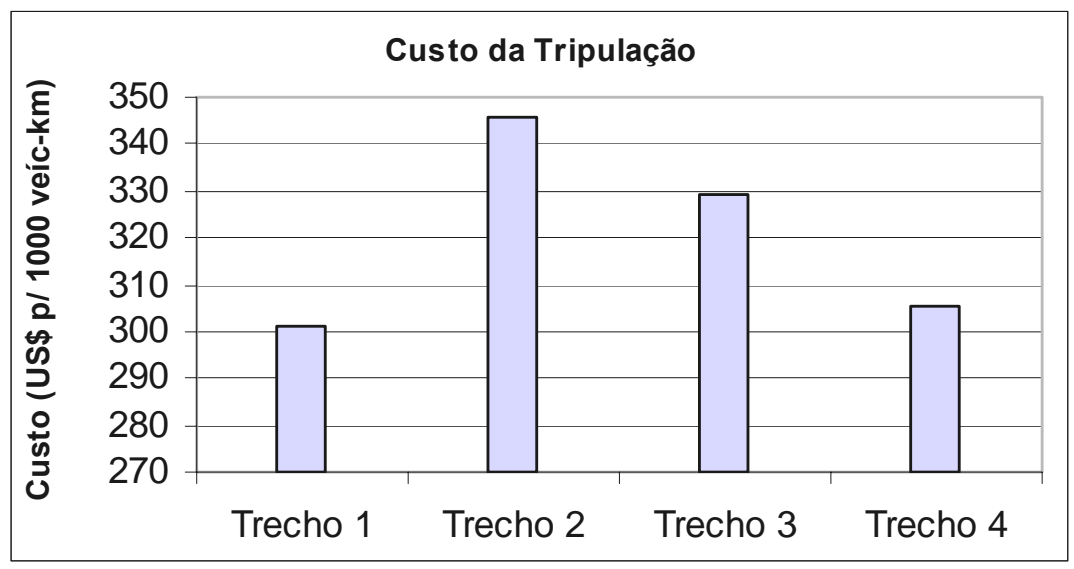

FIGURA 72 - Custo da tripulação para os trechos da SP-310.

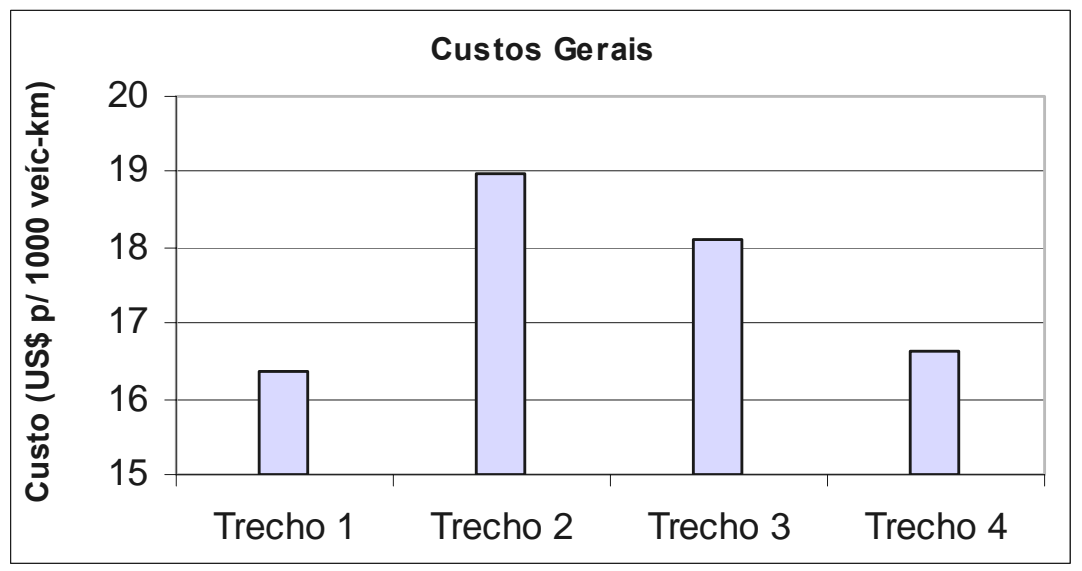

FIGURA 73 - Custos gerais para os trechos da SP-310.

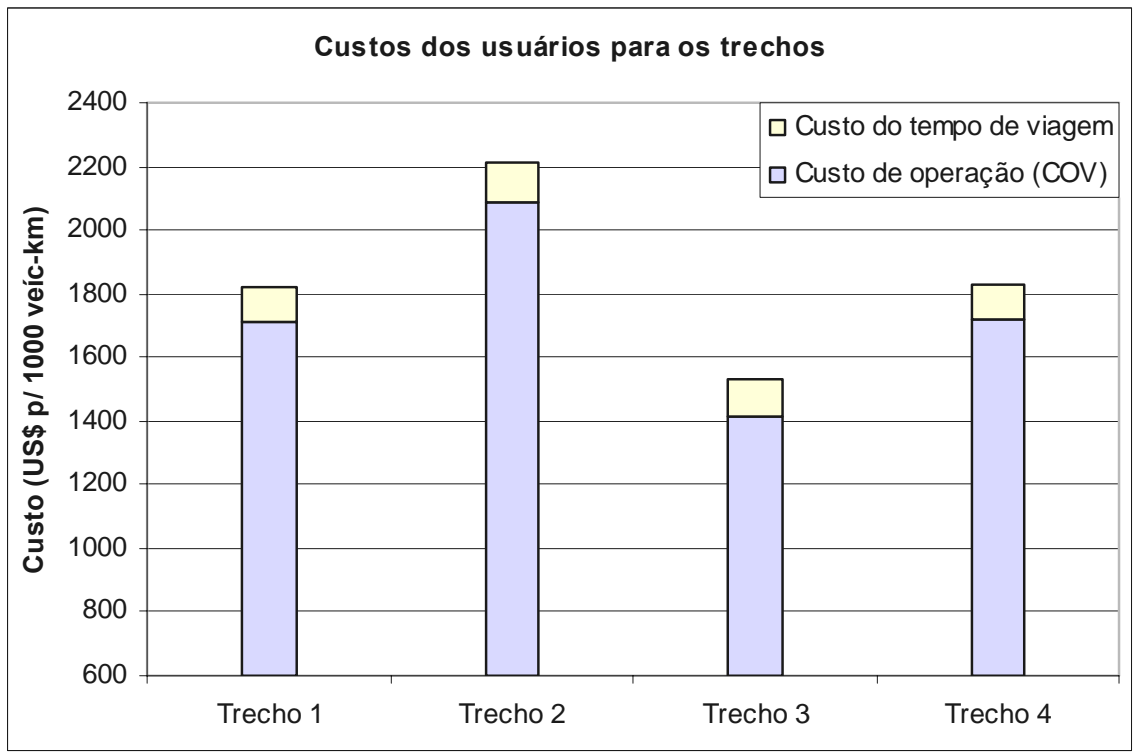

FIGURA 74 - Custos de operação dos veículos e do tempo de viagem na composição do custo total para os trechos da SP-310. 


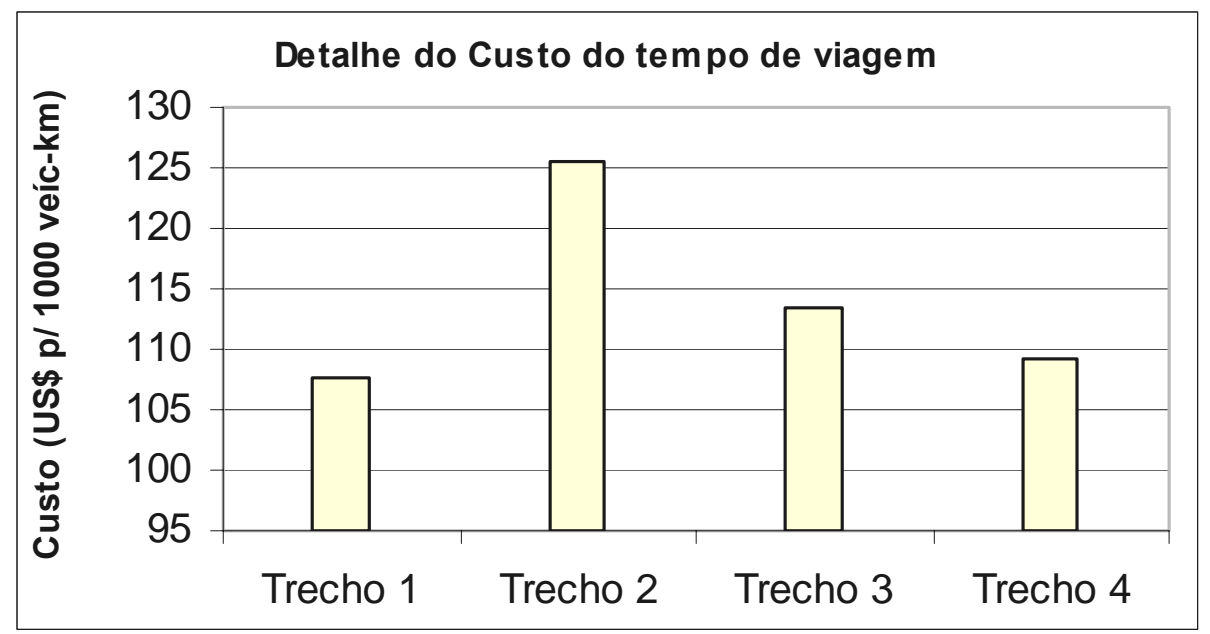

FIGURA 75 - Detalhe do custo do tempo de viagem para os trechos da SP-310.

A Tabela 57, assim como as Figuras 76 e 77, apresenta as velocidades e o consumo de combustível dos veículos em cada trecho da SP-310. Já a Tabela 58 mostra os componentes com maiores porcentagens nos custos de operação dos veículos nos trechos da SP-310.

TABELA 57 - Consumo de combustível e velocidade de operação dos veículos nos trechos da SP-310.

\begin{tabular}{|c|c|c|c|c|}
\hline \multicolumn{5}{|c|}{ Consumo de Combustível (litros p/ 1000 veíc-km) } \\
\hline & Trecho 1 & Trecho 2 & Trecho 3 & Trecho 4 \\
\hline Caminhão Leve & & & & \\
\hline Caminhão Pesado & 3 & 6 & & 16 \\
\hline Automóvel Médio & 10 & 12 & & 37 \\
\hline Pesado & 269,09 & 480,68 & 58,50 & 269,09 \\
\hline \multicolumn{5}{|c|}{ Velocidade de operação $(\mathrm{Km} / \mathrm{h})$} \\
\hline & Trecho 1 & Trecho 2 & Trecho 3 & Trecho 4 \\
\hline Caminhão Leve & 94,73 & 77,69 & 78,53 & 92,48 \\
\hline Caminhão Pesado & 86,13 & 80,69 & 82,47 & 85,61 \\
\hline Automóvel Médio & 105,07 & 87,10 & 83,82 & 103,82 \\
\hline Ônibus Pesado & 85,74 & 73,69 & 82,32 & 84,59 \\
\hline
\end{tabular}

TABELA 58 - Componentes com maiores porcentagens no COV - Trechos da SP-310.

\begin{tabular}{cccc}
\hline Trechos & Maior $\%$ & $\mathbf{2}^{\mathbf{a} \cdot}$ maior $\%$ & $\mathbf{3}^{\mathbf{a} \cdot}$ maior $\%$ \\
\hline $\mathbf{1}$ & Combustível & Peças & Tripulação \\
$\mathbf{2}$ & Combustível & Peças & Tripulação \\
$\mathbf{3}$ & Peças & Tripulação & Capital \\
$\mathbf{4}$ & Combustível & Peças & Tripulação \\
\hline
\end{tabular}




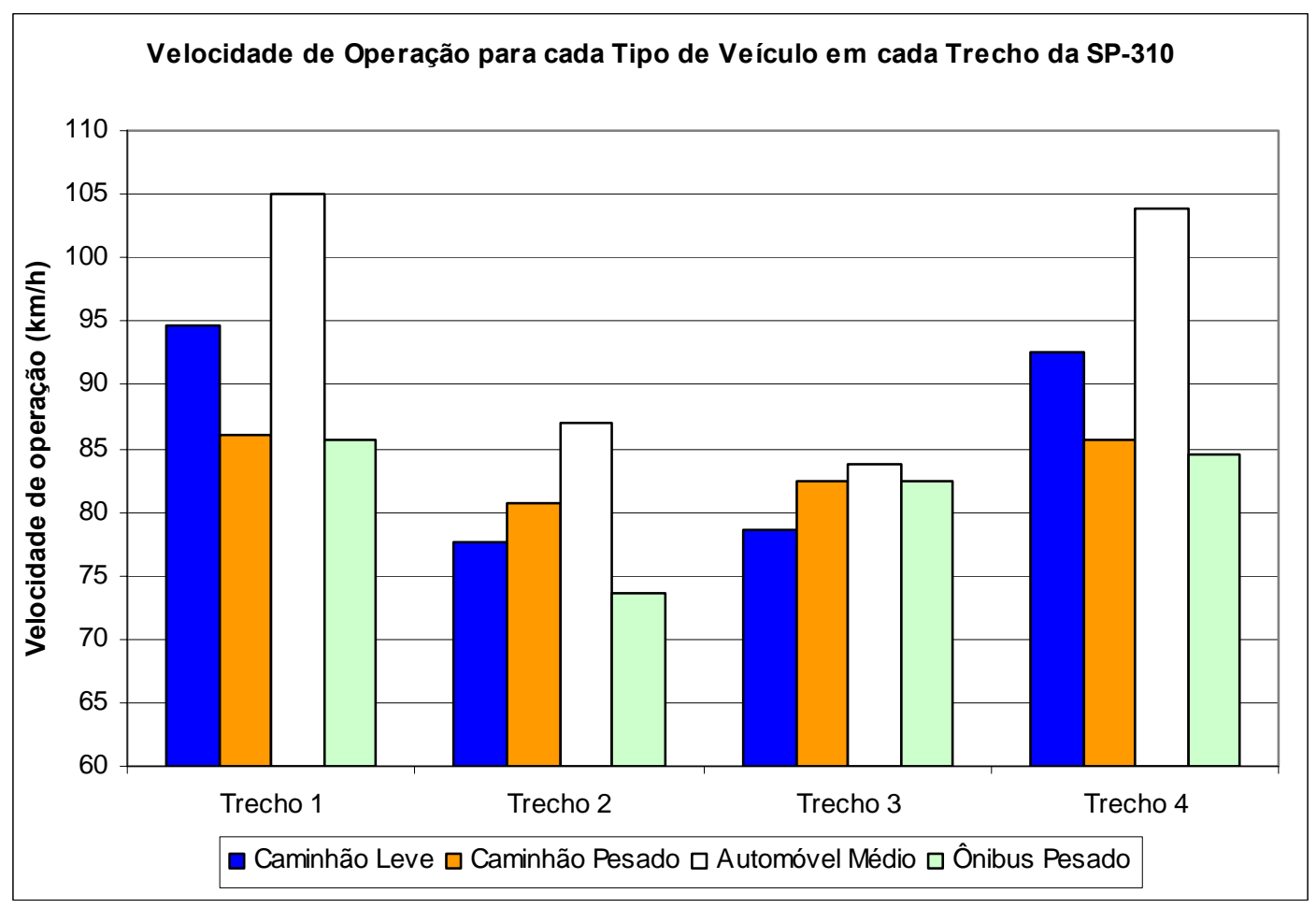

FIGURA 76 - Velocidade de operação de cada tipo de veículo nos trechos da SP-310.

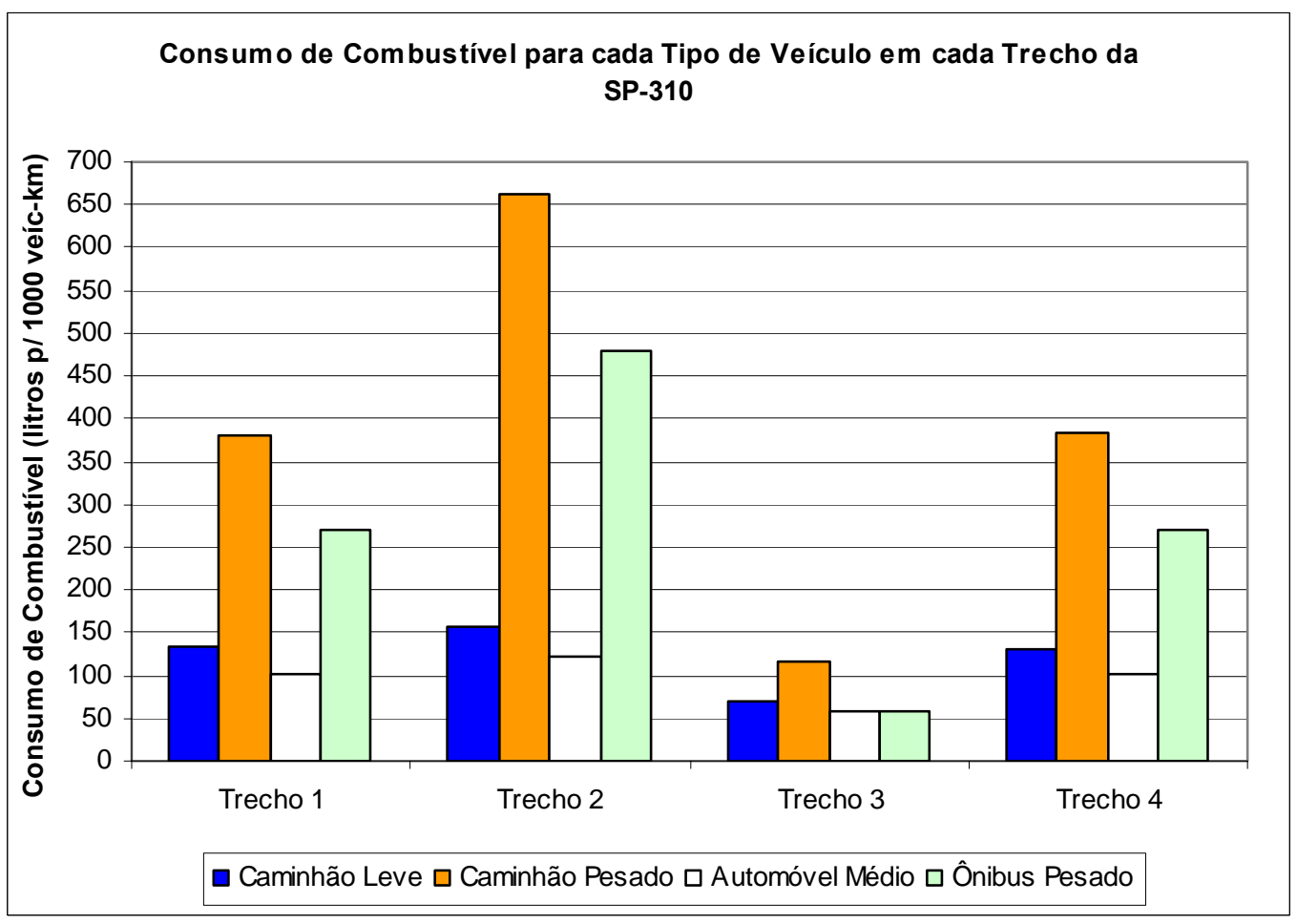

FIGURA 77 - Consumo de combustível de cada tipo de veículo nos trechos da SP-310. 


\subsection{ANÁLISE DOS RESULTADOS}

As situações investigadas com a utilização do programa computacional HDM-4 confirmaram haver influência dos parâmetros geométricos das rodovias nos custos dos usuários, em termos de custo de operação dos veículos e de tempo de viagem.

A geometria vertical, representada pelo parâmetro RF (média de subidas e descidas ao longo do trecho avaliado) é analisada isoladamente em nove segmentos com RF variando de 0 a $40 \mathrm{~m} / \mathrm{km}$ (Trecho Base e trechos $a$ a $h$ ), em intervalos de $5 \mathrm{em} 5 \mathrm{~m} / \mathrm{km}$, mantidas constantes todas as outras variáveis, particularmente o parâmetro representativo da geometria horizontal (ADC - média da curvatura horizontal). Ela influencia a velocidade de operação de todos os veículos analisados, que decresce com o aumento do RF, conforme mostra a Figura 31. No que diz respeito ao consumo de combustível, com o aumento de RF, houve uma pequena redução para o automóvel médio e para o caminhão leve, enquanto que, para o ônibus pesado, essa redução foi pequena até um RF igual a $30 \mathrm{~m} / \mathrm{km}$ e, após este valor, o consumo de combustível começou a aumentar acentuadamente. O caminhão pesado apresentou pequeno aumento no consumo de combustível até RF igual a $30 \mathrm{~m} / \mathrm{km}$ e um aumento acentuado após este valor. Isso fez com que a curva do custo da soma dos consumos de combustível de todos os veículos considerados (Figura 20) apresentasse uma pequena queda até o valor de RF igual a $30 \mathrm{~m} / \mathrm{km}$ e um aumento acentuado após este valor. O mesmo ocorre para o consumo de óleo lubrificante, em função de RF, pois ele é calculado em função do consumo de combustível.

Os custos de consumo de pneu (que é em função da utilização dos veículos) aumentam com o aumento de RF, assim como ocorre com os custos do capital, da tripulação, dos custos gerais e do tempo de viagem (que são funções da velocidade de operação dos veículos). Os custos do consumo de peças (dado em função, principalmente, da idade dos veículos e da irregularidade da via, que são constantes nesse estudo) e de manutenção dos veículos (em função do consumo de peças) permanecem praticamente constantes com o aumento da curvatura vertical. Diante disso, tem-se que o custo de operação dos veículos e do tempo de viagem e, conseqüentemente, os custos totais dos usuários diminuem com a diminuição da curvatura vertical das vias (conforme apresentam as Figuras 28 e 30). Foi verificado, também, que o consumo de combustível 
é o componente com a maior porcentagem na composição do custo de operação dos veículos, seguido pelo consumo de peças e pelos custos com a tripulação (Tabela 27).

Os cálculos dos custos da alteração do traçado de vias, através da redução da curvatura vertical (tomando-se como referência um valor de RF igual a $40 \mathrm{~m} / \mathrm{km}$ ), mostraram que os custos de terraplenagem aumentam quanto mais próximo do plano $(\mathrm{RF}=0)$ apresenta-se o novo traçado da via (Figura 33). Como os benefícios decorrentes dessa melhoria também aumentam, pois o custo total dos usuários diminui (Figura 30), a identificação da alternativa de intervenção de alteração do traçado que é mais vantajosa deve ser realizada através de uma análise econômica utilizando o Valor Presente Liquido, que melhor classifica os investimentos quando não se tem restrição orçamentária, e a Relação Benefício-Custo, quando se tem esta restrição. A Tabela 31 mostra que, para um período de análise de 20 anos e para as taxas de desconto admitidas $(6,12$ e 18\%), a melhor alternativa de intervenção é a redução da curvatura vertical a $10 \mathrm{~m} / \mathrm{km}$ (pelo VPL) e a $30 \mathrm{~m} / \mathrm{km}$ (pela Relação B/C).

A geometria horizontal, representada pelo parâmetro ADC (média da curvatura horizontal do trecho avaliado) é analisada isoladamente em onze segmentos com ADC variando de 0 a 500 graus $/ \mathrm{km}$ (Trecho Base e trechos $i$ a $r$ ), em intervalos de $50 \mathrm{em}$ 50 graus $/ \mathrm{km}$, mantidas constantes todas as outras variáveis, particularmente o parâmetro representativo da geometria vertical (RF). Ela influencia a velocidade de operação de todos os veículos analisados, que decresce com o aumento do ADC, conforme mostra a Figura 46. As curvas de consumo de combustível dos veículos apresentam pontos de mínimo consumo para determinados valores de ADC. No caso do caminhão e do ônibus pesados, tem-se o valor de mínimo consumo para ADC igual a $250 \mathrm{~m} / \mathrm{km}$. O caminhão leve apresenta o menor consumo de combustível para um ADC igual a $400 \mathrm{~m} / \mathrm{km}$, enquanto o valor mínimo para o automóvel médio ocorre para $450 \mathrm{~m} / \mathrm{km}$. Com isso, a curva dos custos da soma dos consumos de combustível de todos os veículos considerados (Figura 35) apresenta uma um ponto de mínimo consumo de combustível para valores de ADC entre 250 e 300 graus $/ \mathrm{km}$, resultado da influência dos valores de consumo para os veículos pesados. O mesmo ocorre para o consumo de óleo lubrificante, em função de $\mathrm{ADC}$, que é calculado em função do consumo de combustível. 
Os custos de consumo de pneu, diferentemente do que era esperado, uma vez que é função da utilização dos veículos, diminuiu com o aumento de ADC (Figura 37), possivelmente porque atinjam um valor de mínimo consumo para curvaturas horizontais acima de 500 graus $/ \mathrm{km}$, que não foram analisadas neste estudo. Os custos do capital, da tripulação e os custos gerais aumentam com o aumento de ADC, assim como os custos do tempo de viagem. Os custos do consumo de peças e de manutenção dos veículos permanecem constantes com o aumento da curvatura horizontal (conforme dito anteriormente, não são afetados diretamente pela geometria da via). Diante disso, tem-se que o custo de operação dos veículos e do tempo de viagem e, conseqüentemente, os custos totais dos usuários ficam menores com a diminuição da curvatura horizontal das vias (conforme apresentam as Figuras 43 e 45). Foi verificado, ainda, que o consumo de combustível é o componente com a maior porcentagem na composição do custo de operação dos veículos, exceto para um ADC de 500 graus $/ \mathrm{km}$, no qual os percentuais dos custos com a tripulação são maiores (Tabela 43).

Os trechos representativos das classes de geometria padronizadas pelo HDM-4 foram criados para permitirem que fossem feitas análises da influência conjunta das geometrias vertical (RF) e horizontal (ADC) nos custos dos usuários. Porém, confirmando o que havia sido apresentado pelos estudos da PICR na década de 80, os efeitos combinados da geometria não são facilmente observados. Diante disso, apresenta-se aqui o que pôde ser analisado sobre os custos de insumos e de tempo de viagem para cada um dos trechos.

Observou-se que a velocidade de operação dos veículos analisados é menor nos trechos do HDM-4 que possuem maiores valores de RF e ADC, como mostram as Figuras 58 a 61. O consumo de combustível de todos os veículos diminui nos trechos com maiores valores de RF e ADC, com exceção do trecho $G$, no qual ocorreu um aumento abrupto do consumo (Figura 48), influenciado pelo aumento dos consumos de combustível do caminhão pesado, do ônibus e do automóvel (Figuras 63 a 65). O mesmo ocorre com os consumos de óleo lubrificante e de pneus. Os custos de consumo de peças e de manutenção são praticamente constantes em todos os trechos do HDM-4 (Figuras 51 e 52) pois, conforme já havia sido explicado, eles dependem principalmente da idade do veículo e da irregularidade do pavimento). Já os custos relacionados à velocidade de operação (custos do tempo de viagem, do capital, da tripulação e custos gerais) seguem 
a tendência já observada nos trechos estudados anteriormente e aumentam com o aumento dos valores de RF e ADC (Figuras 53 a 57). Embora haja a diminuição dos custos dos consumos de combustível, óleo lubrificante e pneus com o aumento de RF e $\mathrm{ADC}$, os custos totais dos usuários aumentam com o aumento desses valores (Figura 56).

A Tabela 52 mostra que o consumo de combustível é o componente com maior porcentagem no custo de operação dos veículos nos trechos com menores valores de RF (Trechos A e C), enquanto que, para trechos com maiores valores de RF (Trechos E, F e G), o componente que corresponde à maior parcela é o custo com a tripulação, pois nesses trechos a velocidade de operação é menor, o que aumenta o tempo de viagem e, conseqüentemente, as horas de trabalho da tripulação. Nos trechos com valores intermediários de RF (Trechos B e D), o consumo de peças apresenta maiores porcentagens no custo de operação dos veículos.

Os trechos da rodovia SP-310 permitiram que fossem exemplificadas as situações de alinhamento vertical e horizontal analisadas pelos demais trechos do estudo de caso, considerando-se suas características quanto ao traçado, à composição do tráfego e outras características geométricas, tais como, número de faixas, velocidades limites etc. Além disso, permitiram que pudessem ser analisadas as diferenças entre segmentos em aclive e em declive que possuem características semelhantes de curvatura vertical e horizontal.

As Figuras 66 a 75 mostram que os custos relacionados ao consumo de insumos é menor para trechos em declive (representados pelo Trecho 3) do que para trechos em aclive (Trecho 2). Isso ocorre, por exemplo, no caso do consumo de combustível, que é calculado através do consumo de energia dos veículos (conforme visto no item 3.6.2.1), pois o consumo de energia dos veículos é menor nas descidas do que nas subidas.

Quanto aos consumos combustível, óleo lubrificante e pneus, tem-se o Trecho 2, o Trecho 4 e o Trecho 1, nesta ordem, apresentam os maiores custos, enquanto que o Trecho 3 apresentou os menores custos desses itens (Figuras 66 a 68). Já os custos relacionados com a velocidade de operação dos veículos (tempo de viagem, custos do capital, da tripulação e custos gerais, apresentados nas Figuras 71 a 73) não seguem a mesma ordem, já que o tempo de viagem no Trecho 3 é maior, devido a limitação da 
velocidade máxima permitida $(80 \mathrm{~km} / \mathrm{h}$ para o automóvel e $60 \mathrm{~km} / \mathrm{h}$ para os demais veículos) em função das condições da geometria do trecho, que se encontra em uma região montanhosa.

Como não é possível classificar diretamente esses trechos (quanto aos parâmetros RF e ADC) de acordo com as classes padronizadas pelo HDM-4, faz-se a comparação dos resultados de velocidade de operação e dos custos totais dos usuários obtidos para os trechos da SP-310 (Tabelas 53 a 57) com aqueles das classes do HDM-4 obtidos para os trechos A a G (Tabelas 44 a 51). Dessa forma, o trecho 1 da SP-310 (com RF igual a $4,5 \mathrm{~m} / \mathrm{km}$ e ADC igual a $1 \mathrm{grau} / \mathrm{km}$ ) poderia ser classificado como tendo geometria Plana e Reta (representada pelo trecho A do HDM-4), pois seus resultados são praticamente os mesmos. O trecho 4 da SP-310, pela classificação quanto à geometria (RF igual a $13 \mathrm{~m} / \mathrm{km}$ e ADC igual a 36 graus $/ \mathrm{km}$ ), estaria situado entre as classes A e D do HDM-4 (vide Tabela 12), o que foi confirmado pela comparação entre os resultados obtidos de velocidade de operação e de custos dos usuários. Quanto aos custos de consumo de combustível, óleo lubrificante e pneus, este trecho identifica-se mais com o Trecho A do HDM-4. Os custos do capital, da tripulação e dos custos gerais deste trecho são mais associados aos do Trecho B, enquanto o custo do tempo de viagem é próximo do Trecho C. Quanto aos custos totais de operação dos veículos e custos totais dos usuários, o Trecho 4 tem resultados próximos aos do Trecho D. Os trechos 2 e 3 não podem ser classificados, pois estão em situações específicas quanto ao sentido do tráfego (somente subida ou somente descida, respectivamente).

\subsection{LIMITAÇÕES DO HDM-4}

Apesar de ser uma evolução de modelos anteriores, no qual procurou-se ampliar a capacidade de abrangência e utilização, o programa HDM-4 ainda apresenta limitações em seus modelos, conforme observado através dos resultados de determinadas situações ou fenômenos explicitados neste trabalho.

Dentre as limitações observadas, pode-se destacar a determinação de alguns parâmetros relacionados aos custos dos usuários em termos do consumo de determinados insumos como, por exemplo, o cálculo do custo do consumo de pneus, especialmente quando há a variação da geometria horizontal (parâmetro $\mathrm{ADC}$ ), em que ocorre a diminuição do 
consumo com o aumento da curvatura (Figura 37), diferentemente do que se era esperado. Além disso, ao analisar, no estudo de caso, o Trecho 3 da SP-310 (trecho em declive), observou-se uma diminuição do consumo de pneus em relação aos demais trechos, o que sugere que o modelo provavelmente não considera o desgaste de pneus devido à frenagem neste trecho descendente.

Deve-se atentar, ainda, para a classificação padrão dos diferentes tipos de veículos dos exemplos apresentados pelo HDM-4, especialmente no que diz respeito aos caminhões, que difere da classificação admitida em estudos de caminhões brasileiros. O HDM-4 permite, entretanto, que esta classificação seja refeita, possibilitando que sejam incluídos novos tipos de veículos com características e especificações próprias. 


\section{Conclusões e sugestões para trabalhos futuros}

\subsection{CONCLUSÕES}

Neste trabalho, foi utilizado o programa HDM-4 para quantificar a influência dos parâmetros geométricos de curvatura vertical (RF) e curvatura horizontal (ADC) sobre as várias parcelas que compõem os custos totais dos usuários de rodovias. Os resultados mostraram, dentro das limitações de representatividade do modelo do programa, que os parâmetros geométricos têm influência significativa tanto sobre os custos de operação dos veículos como sobre os custos relacionados ao tempo de viagem.

Com base nos resultados obtidos, podem ser feitas as seguintes considerações complementares:

- O projeto de construção de uma rodovia deve levar em conta, além dos custos das agências e/ou concessionárias (custos de construção e de manutenção e reabilitação), os custos de operação dos veículos e os custos relacionados ao tempo de viagem, que compõem os custos totais dos usuários. Sendo assim, o investimento na construção da rodovia irá proporcionar maiores benefícios à sociedade. 
- Os investimentos das agências e/ou concessionárias durante a vida útil da rodovia devem ser direcionados não somente para as atividades de manutenção e reabilitação dos pavimentos, mas também para possíveis alterações no traçado das rodovias existentes como, por exemplo, para a redução da quantidade de subidas e descidas (RF) de um trecho. Estas alterações representam investimentos que dão retorno à sociedade, em termos de redução dos custos dos usuários e dos números e da gravidade de acidentes, em um período de tempo relativamente curto.

- Os modelos utilizados pelos programas computacionais, tal como os modelos do HDM-4, podem apresentar limitações em sua utilização para a representação de determinadas situações ou fenômenos, o que pode comprometer os resultados obtidos, caso estas limitações não sejam consideradas nas análises realizadas.

\subsection{SUGESTÕES PARA TRABALHOS FUTUROS}

Sugere-se, inicialmente, diante das limitações apresentadas pelo modelo do programa HDM-4 na determinação de alguns parâmetros relacionados aos custos dos usuários em termos do consumo de determinados insumos, que sejam realizados estudos específicos e detalhados sobre essas limitações.

Sugere-se a análise de sensibilidade das equações do HDM-4 para o cálculo dos componentes dos custos totais dos usuários, atentando-se não somente para os parâmetros relacionados à geometria, mas também àqueles relacionados à condição do pavimento, à condição do tráfego etc.

Complementarmente aos estudos realizados neste trabalho, sugere-se a avaliação dos efeitos da geometria de rodovias sobre o consumo de energia, sobre a emissão de poluentes e sobre os acidentes, que também compõem os custos dos usuários, através das ferramentas disponíveis no HDM-4 e de outros modelos.

Outra sugestão decorrente dos estudos realizados consiste na consideração de rodovias de pista simples, visando à investigação do efeito da geometria sobre a capacidade de 
tráfego e sobre os congestionamentos, que podem ter influência significativa nos custos totais dos usuários.

Permanece atual a recomendação feita pela a Pesquisa sobre o Inter-relacionamento de Custos Rodoviários (PICR), na década de 80, para a continuidade da coleta de dados sobre os custos de operação dos veículos, com atualização das informações sobre os seus principais componentes, analisados neste trabalho, tais como o consumo de combustível, óleos lubrificantes, pneus e peças e o tempo de viagem. Além disso, sugere-se a observação do comportamento dos usuários das rodovias diante das características geométricas da via, com simulação de seu comportamento em experimentos controlados que possibilitem a quantificação, por exemplo, do consumo de combustível. 


\section{Referências Bibliográficas}

ABAYNAYAKA, S.W.; MOROSIUK, G. e HIDE, H. (1977) Prediction of road construction and vehicle operating costs in developing countries. Proceedings of the Institution of Civil Engineers. 62 (Part 1), 419-446.

ARCHONDO-CALLAO, R. e PUROHIT, R. (1989) HDM-PC: user's guide. The Highway Design and Maintenance Standards Series. Washington DC. World Bank.

ARCHONDO-CALLAO, R. (1994) HDM Manager Version 3.0. Transportation, Water and Urban Development Department. Washington DC. World Bank.

BENNETT, C.R. e PATERSON, W.D.O. (2000) The Highway Design and Maintenance Standards Model, Volume 5: A Guide to Calibration and Adaptation. World Bank. Washington, D.C.

BENNETT, C.R. e GREENWOOD, I.D. (1996) Specifications for the HDM-4 Road User Effects Model in HDM-4. $3^{\text {rd }}$ and $4^{\text {th }}$ Draft ISOHDM. University of Birmingham, UK.

. (2001) The Highway Design and Maintenance Standards Model, Volume 7: Modelling Road User and Environmental Effects in HDM-4. World Bank. Washington, D.C.

BIGGS, D.C. (1988) ARFCOM - Models for Estimating Light to Heavy Vehicles Fuel Consumption. Research Report ARR 152. Australian Road Research Board. Nunawading, Australia.

CNT - Confederação Nacional do Transporte (2004). Pesquisa Rodoviária 2004 Relatório Gerencial. Brasília, CNT.

CRRI (1982) Road user cost study in India. Final Report. Central Road Research Institute. New Delhi, India.

CUNDILL, M.A. e WITHNALL, S.J. (1995) Road transport investment model RTIM3. Sixth International Conference on Low-Volume Roads, Conference Proceedings 6, Volume 1. National Academy Press. Washington, DC.

DER-SP - Departamento de Estradas de Rodagem - SP. Tabelas de Preços Unitários de Serviços e Obras na Área de Transportes - Página da Internet: www.der.sp.gov.br Dezembro, 2004.

GEIPOT (1982) Pesquisa sobre o Inter-relacionamento dos Custos de Construção, Conservação e Utilização de Rodovias. Relatório Final - 1981. Volumes 1, 5 e 9. Ministério dos Transportes. Empresa Brasileira de Planejamento de Transportes. Brasília, DF.

HARRAL, C.G. e OUTROS (1979) The Highway Design and Maintenance Standards Model (HDM): model structure, empirical foundations and applications. PTRC 
Summer Annual Meeting. University of Warwick. PTRC Education and Research Services. London.

KERALI, H.G.R. (2000) The Highway Design and Maintenance Standards Model, Volume 1: Overview of HDM-4. World Bank. Washington, D.C.

KERALI, H.G.R.; McMULLEN, D. e ODOKI, J.B. (2000) The Highway Design and Maintenance Standards Model, Volume 2: Applications Guide. World Bank. Washington, D.C.

KLAUBERT, E. C. (2001) Highway Effects on Vehicle Performance. FHWA Report $\mathrm{n}^{\circ}$ RD-00-164. Federal Highway Administration. Washington, DC.

LELEUR, S. (1995) Road Infrastructure Planning: A Decision-Oriented Approach. Polyteknisk Forlag. Denmark.

MOAVENZADEH, F.; STAFFORD, J.H.; SUHBRIER, J. e ALEXANDER, J. (1971) Highway Design study phase I: the model. IBRD Economics Department of Civil Engineering Working Paper No. 96. International Bank for Reconstruction and Development. Washington, DC.

MOAVENZADEH, F.; BERGER, F.; BRADEMEYER, B. e WYATT, R. (1975) The Highway Cost Model: General Framework. MIT Department of Civil Engineering Research Report No. 75-4. Massachusetts Institute of Technology. Cambridge, Massachusetts.

MOROSIUK, G e ABAYNAYAKA, S.W. (1982) Vehicle operating costs in the Caribbean: an experimental study of vehicle performance. TRRL Laboratory Report 1056. Transport and Road Research Laboratory. Crowthorne.

NDLI (1995) Modeling Road User Effects in HDM-4, Final Report to the Asian Development Bank, N.D. Lea International Ltd., Vancouver, Canada.

ODOKI, J.B. e KERALI, H.G.R. (2000) The Highway Design and Maintenance Standards Model, Volume 4: Analytical Framework and Model Description. World Bank. Washington, D.C.

PARSLEY, L.L. e ROBINSON, R. (1982) The TRRL road investment model for developing countries (RTIM2). TRRL Laboratory Report 1057. Transport and Road Research Laboratory. Crowthorne.

WATANATADA, T.; HARRAL, C.G.; PATERSON, W.D.O.; DHARESHWAR, A.M.; BHANDARI, A.; TSUNOKAWA, K. (1987) The Highway Design and Maintenance Standards Model. Volume 1: Description of the HDM - III Model. World Bank. The John Hopkins University Press. Baltimore, MD.

WIGHTMAN, D.C.; Stannard, E.E.; Dakin, J.M. (2000) The Highway Design and Maintenance Standards Model, Volume 3: Software User Guide. World Bank. Washington, D.C. 


\section{Bibliografia Consultada}

CNT - Confederação Nacional do Transporte (2003). Pesquisa Rodoviária 2003 Relatório Gerencial. Brasília, CNT.

FERNANDES JR., J.L. (1994) Investigação dos Efeitos das Solicitações do Tráfego sobre o Desempenho de Pavimentos. Tese (Doutorado) - Escola de Engenharia de São Carlos, Universidade de São Paulo.

GEIPOT (2000) Anuário Estatístico do GEIPOT - Transportes Rodoviários, GEIPOT, Ministério dos Transportes, Brasília, DF.

GILLESPIE, T. D. (1992) Fundamentals of Vehicle Dynamics. Society of Automotive Engineers. Warrendale, PA, USA.

HAAS, R.; HUDSON, W. R. e ZANIEWSKI, J. (1994) Modern Pavement Management. Krieger Publishing Co. Malabar, Florida.

KHISTY, C.J. e LALL, B.K. (1998) Transportation Engineering: An Introduction. $2^{\text {a }}$. Edição. Prentice Hall. Upper Saddle River, N.J.

KLEIN, F.C.; NASCIMENTO, D.M. e FERNANDES JR., J.L. (2004) Análise Econômica de Estratégias de Intervenções em Pavimentos Rodoviários Através do Programa HDM-4. 35 . Reunião Anual de Pavimentação - ABPv. Rio de Janeiro,RJ.

KOPITTKE, B. H. e CASAROTTO FILHO, N. (2000) Análise de Investimentos. Atlas. São Paulo.

LAY, M.G. (1998) Handbook of Road Technology. $3^{\text {a }}$ Edição. Gordon and Breach Science. Australia.

NASCIMENTO, D.M.; KLEIN, F.C.; YSHIBA, J.K. e FERNANDES JR., J.L. (2004) Análise Comparativa de Modelos para Previsão da Irregularidade Longitudinal de Pavimentos. 35ª Reunião Anual de Pavimentação - ABPv. Rio de Janeiro,RJ.

OGLESBY, C.H. e HICKS, R.G. (1982) Highway Engineering. Quarta edição. Estados Unidos.

PIARC (1999) Highway Development and Management Series. Volumes 1, 2 and 3. The World Road Association.

PIMENTA, C. R. T. e OLIVEIRA, M. P. (2001) Projeto Geométrico de Rodovias. Editora RiMa. São Carlos, SP.

RICO, A., MENDOZA, A. e DURAN, G. (1995) Algunos elementos de uma estratégia óptima de conservación de carreteras pavimentadas. Boletin Notas $\mathrm{N}^{\mathrm{o}} 25$ de Instituto Mexicano Del Transporte. Sanfandila, México.

TRANSPORTATION RESEARCH BOARD (1987) Designing Safer Roads. Special Report 214. National Research Council. Washington, DC. 
. (1987) Relationship Between Safety and Key Highway Features. State of the Art Report 6. National Research Council. Washington, DC.

- (2001) Recent Geometric Design Research for Improved Safety and Operations. National Cooperative Highway Research Program Synthesis 299. National Research Council. Washington, DC. 


\section{Apêndice}

\section{Tabelas utilizadas nos cálculos da velocidade e do consumo de combustível dos veículos}

A velocidade e o consumo de combustível dos quatro tipos de veículos adotados na composição da frota para os trechos estudados podem ser calculados utilizando-se tabelas com valores padronizados dos parâmetros para cada tipo de veículo, apresentadas a seguir (Tabelas A1 a A9):

a) Tabelas para os cálculos das resistências:

TABELA A1 - Classes de veículos e suas características básicas.

\begin{tabular}{cccccccc}
\hline Tipo & $\begin{array}{c}\text { Tipo de } \\
\text { Combustível }\end{array}$ & $\begin{array}{c}\mathbf{N}^{\mathbf{0}} \mathbf{d e} \\
\text { eixos }\end{array}$ & $\begin{array}{c}\mathbf{N}^{\mathbf{0}} \mathbf{d e} \\
\text { rodas }\end{array}$ & $\begin{array}{c}\text { Coef. Aerodi- } \\
\text { nâmico }\end{array}$ & $\mathbf{A F}\left(\mathbf{m}^{2}\right)$ & $\begin{array}{c}\text { Peso } \\
(\mathbf{t})\end{array}$ & $\begin{array}{c}\text { Peso de } \\
\text { operação (t) }\end{array}$ \\
\hline $\begin{array}{c}\text { Automóvel } \\
\text { médio }\end{array}$ & Gasolina & 2 & 4 & 0,42 & 1,9 & 1,0 & 1,2 \\
$\begin{array}{c}\text { Caminhão } \\
\text { leve }\end{array}$ & Diesel & 2 & 4 & 0,55 & 4,0 & 1,8 & 2,0 \\
$\begin{array}{c}\text { Caminhão } \\
\text { pesado }\end{array}$ & Diesel & 3 & 10 & 0,70 & 8,5 & 9,0 & 13,0 \\
$\begin{array}{c}\text { Onibus } \\
\text { Pesado }\end{array}$ & Diesel & 3 & 10 & 0,65 & 6,5 & 8,0 & 10,0 \\
\hline
\end{tabular}

Fonte: Modificada de NDLI (1995).

TABELA A2 - Parâmetros para o cálculo da resistência à inércia.

\begin{tabular}{cccc}
\hline \multirow{2}{*}{ Veículos } & \multicolumn{3}{c}{ Parâmetros de resistência à inércia } \\
\cline { 2 - 4 } & EMRATa0 & EMRATa1 & EMRATa2 \\
\hline Automóvel médio & 1,05 & 0,213 & 1260,7 \\
Caminhão leve & 1,04 & 0,830 & 12,4 \\
Caminhão pesado & 1,07 & 1,910 & 10,1 \\
Ônibus pesado & 1,04 & 0,830 & 12,4 \\
\hline
\end{tabular}

Fonte: Modificada de Bennett e Greenwood (1996). 
TABELA A3 - Parâmetros para o cálculo das resistências aerodinâmica e de rolamento.

\begin{tabular}{|c|c|c|c|c|c|c|c|c|c|}
\hline \multirow{3}{*}{ Veículo } & \multirow{2}{*}{\multicolumn{3}{|c|}{$\begin{array}{l}\text { Parâmetros de } \\
\text { resistência } \\
\text { aerodinâmica }\end{array}$}} & \multicolumn{6}{|c|}{ Parâmetros de resistência ao rolamento } \\
\hline & & & & \multirow{2}{*}{$\begin{array}{c}\mathrm{N}^{\circ} \text { de } \\
\text { rodas } \\
\mathrm{NW}\end{array}$} & \multirow{2}{*}{$\begin{array}{c}\begin{array}{c}\text { Diâmetro } \\
\text { das rodas } \\
(\mathrm{m})\end{array} \\
\text { WD }\end{array}$} & \multirow{2}{*}{$\begin{array}{c}\text { Tipo de } \\
\text { pneu }\end{array}$} & \multicolumn{3}{|c|}{ Parâmetros do pneu } \\
\hline & $\mathbf{C D}_{\text {mult }}$ & CD & $\begin{array}{c}\text { AF } \\
\left(\mathrm{m}^{2}\right)\end{array}$ & & & & $\begin{array}{c}\text { CRB } \\
\text { a0 }\end{array}$ & $\begin{array}{c}\text { CRB } \\
\text { a1 }\end{array}$ & $\begin{array}{c}\text { CRB } \\
\text { a2 }\end{array}$ \\
\hline $\begin{array}{c}\text { Automóvel } \\
\text { médio }\end{array}$ & 1,10 & 0,42 & 1,9 & 4 & 0,60 & Radial & 37 & 0,064 & 0,012 \\
\hline $\begin{array}{c}\text { Caminhão } \\
\text { leve }\end{array}$ & 1,13 & 0,55 & 4,0 & 4 & 0,80 & Diagonal & 37 & 0,064 & 0,012 \\
\hline $\begin{array}{c}\text { Caminhão } \\
\text { pesado }\end{array}$ & 1,14 & 0,70 & 8,5 & 10 & 1,05 & Diagonal & 37 & 0,064 & 0,012 \\
\hline $\begin{array}{l}\text { Ônibus } \\
\text { pesado }\end{array}$ & 1,14 & 0,65 & 6,5 & 10 & 1,05 & Diagonal & 37 & 0,064 & 0,012 \\
\hline
\end{tabular}

Fonte: Modificada de Bennett e Greenwood (1996).

TABELA A4 - Parâmetros do modelo de resistência ao rolamento.

\begin{tabular}{ccccccccccc}
\hline & & \multicolumn{4}{c}{ W $_{\text {OP }} \leq 2500 \mathbf{k g}$} & \multicolumn{5}{c}{ W $_{\text {OP }}>2500$ kg } \\
\cline { 3 - 10 } Classe da & Tipo de & a0 & a1 & A2 & Kcr2 & a0 & a1 & a2 & Kcr2 \\
superfície & superfície & & & & & & & & \\
\hline Betuminoso & MA ou TS & 0,90 & 0,022 & 0,022 & 1 & 0,84 & 0,03 & 0,03 & 1 \\
\hline
\end{tabular}

Fonte: Modificada de NDLI (1995).

$\underline{\text { Tipo de superfície }}$

MA: Mistura asfáltica

TS: Tratamento Superficial 
b) Tabelas para o cálculo das velocidades:

TABELA A5 - Parâmetros do modelo de velocidade de equilíbrio.

\begin{tabular}{cccccccc}
\hline & \multicolumn{2}{c}{ Parâmetros } & \multicolumn{5}{c}{ VDR } \\
\cline { 2 - 7 } Veículo & $\boldsymbol{\alpha}$ & $\mathbf{B}$ & $\begin{array}{c}\text { PDR } \\
(\mathbf{k W})\end{array}$ & $\begin{array}{c}\text { PBR } \\
(\mathbf{k W})\end{array}$ & $\mathbf{C G R a 0}$ & CGRa1 & CGRa2 \\
\hline Automóvel médio & 0 & 0,151 & 33 & 20 & 94,9 & 0,85 & 2,80 \\
Caminhão leve & 0 & 0,191 & 50 & 45 & 94,9 & 0,85 & 2,80 \\
Caminhão pesado & 0 & 0,110 & 227 & 255 & 94,9 & 0,85 & 2,80 \\
Ônibus pesado & 0 & 0,110 & 120 & 120 & 94,9 & 0,85 & 2,80 \\
\hline
\end{tabular}

Fonte: Modificada de Bennett e Greenwood (1996).

TABELA A6 - Parâmetros do modelo para o cálculo das velocidades de curvatura e de irregularidade longitudinal.

\begin{tabular}{ccccc}
\hline \multirow{2}{*}{ Veículos } & \multicolumn{3}{c}{ VCU } & \multicolumn{2}{c}{ VRO } \\
\cline { 2 - 5 } & VCUa0 & VCUa1 & ARV $_{\text {MAX }}(\mathbf{m m} / \mathbf{s})$ & VROa0 \\
\hline Automóvel médio & 3,9 & 0,34 & 203 & 1,15 \\
Caminhão leve & 4,8 & 0,29 & 200 & 1,15 \\
Caminhão pesado & 4,6 & 0,28 & 180 & 1,15 \\
Ônibus pesado & 4,6 & 0,28 & 180 & 1,15 \\
\hline
\end{tabular}

Fonte: Modificada de Bennett e Greenwood (1996).

TABELA A7 - Parâmetros para o cálculo da velocidade desejada.

\begin{tabular}{ccccccc}
\hline \multirow{2}{*}{ Veículos } & \multicolumn{7}{c}{$\begin{array}{c}\text { Velocidade Desejada } \\
\text { (vias de superfície betuminosa) }\end{array}$} \\
\cline { 2 - 7 } & VDES2 & VDESa0 & VDESa1 & VDESa2 & CW1 & CW2 \\
\hline Automóvel médio & 34,8 & 0,0020 & 2,9 & 0,75 & 4 & 6,8 \\
Caminhão leve & 35,6 & 0,0028 & 0,7 & 0,75 & 4 & 6,8 \\
Caminhão pesado & 24,6 & 0,0033 & 0,7 & 0,75 & 4 & 6,8 \\
Ônibus pesado & 24,8 & 0,0033 & 0,6 & 0,75 & 4 & 6,8 \\
\hline
\end{tabular}

Fonte: Modificada de Bennett e Greenwood (1996). 
TABELA A8 - Parâmetros do modelo de dureza do pneu.

\begin{tabular}{ccccc}
\hline \multirow{2}{*}{ Coeficiente } & \multicolumn{2}{c}{$\mathbf{W}_{\text {op }} \leq \mathbf{2 5 0 0} \mathbf{~ k g}$} & \multicolumn{2}{c}{$\mathbf{W}_{\text {op }}>\mathbf{2 5 0 0} \mathbf{~ k g}$} \\
\cline { 2 - 5 } & Diagonal (Bias) & Radial & Diagonal (Bias) & Radial \\
\hline $\mathrm{CSa} 0$ & 30 & 43 & 8,8 & 0 \\
$\mathrm{CSa} 1$ & 0 & 0 & 0,088 & 0,0913 \\
$\mathrm{CSa} 2$ & 0 & 0 & $-0,0000225$ & $-0,0000114$ \\
$\mathrm{~K}_{\mathrm{cs}}$ & 1 & 1 & 1 & 1 \\
\hline
\end{tabular}

Fonte: NDLI (1995).

c) Tabela para o cálculo do consumo de combustível:

TABELA A9 - Parâmetros do modelo para o cálculo do consumo de combustível.

\begin{tabular}{|c|c|c|c|c|c|c|}
\hline \multirow{2}{*}{ Veículo } & \multicolumn{4}{|c|}{ Parâmetros do modelo de velocidade do motor } & \multirow{2}{*}{$\begin{array}{c}\text { Velocidade } \\
\text { inerente } \\
\text { do motor } \\
\text { RPMid }_{\text {id }} \\
(\mathrm{rpm})\end{array}$} & \multirow{2}{*}{$\begin{array}{c}\text { Taxa de } \\
\text { consumo } \\
\text { inerente } \\
\text { IF } \\
(\mathrm{ml} / \mathrm{s})\end{array}$} \\
\hline & $\begin{array}{c}\text { RPMa0 } \\
\text { (rpm) }\end{array}$ & $\begin{array}{l}\text { RPMa1 } \\
(\mathbf{r p m} / \mathbf{m} / \mathbf{s})\end{array}$ & $\begin{array}{c}\text { RPMa2 } \\
\text { RPM/(m/s)2 }\end{array}$ & $\begin{array}{c}\text { RPMa3 } \\
(\mathrm{m} / \mathrm{s})\end{array}$ & & \\
\hline Automóvel médio & 2280 & 17 & 0,83 & 42 & 800 & 0,36 \\
\hline Caminhão leve & 1214 & 17,6 & 2,32 & 22 & 500 & 0,37 \\
\hline Caminhão pesado & 1167 & $-24,0$ & 1,76 & 22 & 500 & 1,12 \\
\hline Ônibus pesado & 1167 & $-24,0$ & 1,76 & 22 & 500 & 1,12 \\
\hline \multirow[t]{2}{*}{ Veículo } & $\begin{array}{c}\text { Eficiência } \\
\text { do } \\
\text { combustível }\end{array}$ & $\begin{array}{l}\text { Decresci- } \\
\text { mo na } \\
\text { eficiência }\end{array}$ & $\begin{array}{l}\text { Potência } \\
\text { do motor }\end{array}$ & $\begin{array}{c}\text { Eficiência } \\
\text { da } \\
\text { transmissão }\end{array}$ & \multicolumn{2}{|c|}{$\begin{array}{l}\text { Potência do motor } \\
\text { e acessórios }\end{array}$} \\
\hline & $\begin{array}{c}\mathbf{Z}_{\mathrm{b}} \\
(\mathrm{ml} / \mathrm{kW} / \mathrm{s})\end{array}$ & EHP & $\begin{array}{l}\text { PRAT } \\
(\mathbf{k W})\end{array}$ & EDT & $\mathbf{P A}_{\mathrm{cs}} \mathbf{a 0}$ & $\mathbf{P T P}_{\mathrm{e}}$ \\
\hline Automóvel médio & 0,067 & 0,25 & 70 & 0,90 & 0,20 & 80 \\
\hline Caminhão leve & 0,057 & 0,10 & 75 & 0,86 & 0,20 & 80 \\
\hline Caminhão pesado & 0,056 & 0,10 & 280 & 0,86 & 0,20 & 80 \\
\hline Ônibus pesado & 0,057 & 0,10 & 130 & 0,86 & 0,20 & 80 \\
\hline
\end{tabular}

Fonte: Modificada de Bennett e Greenwood (1996). 